\title{
Mind the heart : epidemiology, risk factors and treatment of depression following first myocardial infarction
}

Citation for published version (APA):

Strik, J. J. M. H. (2003). Mind the heart : epidemiology, risk factors and treatment of depression following first myocardial infarction. [Doctoral Thesis, Maastricht University]. Universiteit Maastricht. https://doi.org/10.26481/dis.20031107js

Document status and date:

Published: 01/01/2003

DOI:

$10.26481 /$ dis.20031107js

Document Version:

Publisher's PDF, also known as Version of record

Please check the document version of this publication:

- A submitted manuscript is the version of the article upon submission and before peer-review. There can be important differences between the submitted version and the official published version of record.

People interested in the research are advised to contact the author for the final version of the publication, or visit the DOI to the publisher's website.

- The final author version and the galley proof are versions of the publication after peer review.

- The final published version features the final layout of the paper including the volume, issue and page numbers.

Link to publication

\footnotetext{
General rights rights.

- You may freely distribute the URL identifying the publication in the public portal. please follow below link for the End User Agreement:

www.umlib.nl/taverne-license

Take down policy

If you believe that this document breaches copyright please contact us at:

repository@maastrichtuniversity.nl

providing details and we will investigate your claim.
}

Copyright and moral rights for the publications made accessible in the public portal are retained by the authors and/or other copyright owners and it is a condition of accessing publications that users recognise and abide by the legal requirements associated with these

- Users may download and print one copy of any publication from the public portal for the purpose of private study or research.

- You may not further distribute the material or use it for any profit-making activity or commercial gain

If the publication is distributed under the terms of Article $25 \mathrm{fa}$ of the Dutch Copyright Act, indicated by the "Taverne" license above, 


\section{MIND THE HEART}

Epidemiology, risk factors and treatment of depression following first myocardial infarction 
The studies presented in this thesis were conducted at the Department of Psychiatry and Neuropsychology of Maastricht University Hospital, which participates in the Maastricht Brain \& Behaviour Institute of Maastricht University.

All studies were sponsored by Eli Lilly BV, the Dutch Prevention Fund (ZON), and the Maastricht University Hospital Research Fund.

Financial support for this thesis has kindly been provided by Eli Lilly BV, Janssen Cilag BV and GlaxoSmithKline BV.

ISBN 90-9017384-6

Production: Datawyse

Lay-out: OWP Research

(C) 2003, JJMH Strik

No part of this book may be reproduced or transmitted in any form or by any means, without written permission of the author, or when appropriate, the publisher of the article. 


\section{MIND THE HEART}

Epidemiology, risk factors and treatment of depression following first myocardial infarction

\section{PROEFSCHRIFT}

ter verkrijging van de graad van doctor aan de Universiteit Maastricht op gezag van de Rector Magnificus

Prof. Dr. A.C. Nieuwenhuijzen Kruseman volgens het besluit van het College van Decanen in het openbaar te verdedigen op vrijdag 7 november 2003 om 12.00 uur

door

Jacqueline Julienne Marie Huberthe Strik 
Promotor:

Prof. Dr. J. van Os

\section{Co-promotores:}

Dr. A. Honig

Prof. Dr. H.M. van Praag

\section{Beoordelingscommissie:}

Prof. Dr. F.R.J. Verhey (voorzitter)

Prof. Dr. H.J.G.M. Crijns

Prof. Dr. E.J.L. Griez

Prof. Dr. H. Ormel (Rijksuniversiteit Groningen)

Prof. Dr. A. Schene (Universiteit van Amsterdam) 
Voor mijn moeder

Voor mijn broer 



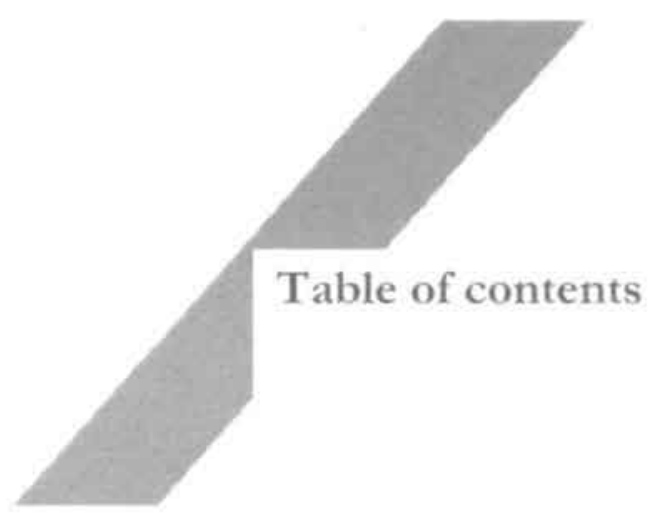

Introduction

\section{A. EPIDEMIOLOGY}

1. Depression and myocardial infarction: relationship between heart and mind

2. One year cumulative incidence of depression following myocardial infarction and impact on cardiac outcome

3. Comparing symptoms of depression and anxiety as predictors of cardiac events and increased health care consumption following myocardial infarction

\section{B. DIAGNOSTIC ISSUES}

4. Sensitivity and specificity of observer and self-report questionnaires in major and minor depression following myocardial infarction

5. Psychological characteristics of post-myocardial infarction depression: looking for symptoms of mixed anxiety-depression

6. The relationship between depressive and vital exhaustion symptomatology post-myocardial infarction 


\section{RISK FACTORS}

7. Relation of levels of serum lipoproteins to depression after acute myocardial infarction

8. Clinical correlates of depression following myocardial infarction

9. Atypical cognitive profile in patients with depression after myocardial infarction

10. Personality and vulnerability to depression following myocardial infarction: a prospective follow-up study

D. TREATMENT

11. Efficacy and safety of fluoxetine in the treatment of patients with major depression after first myocardial infarction: findings from a double-blind, placebocontrolled trial

12. Cardiac side effects of two SSRIs in middle aged and elderly depressed patients

13. Fluoxetine and effect on cognitive performance in depressed patients post myocardial infarction

General discussion

Summary

Samenvatting

Dankwoord

Curriculum vitae

Bibliography 


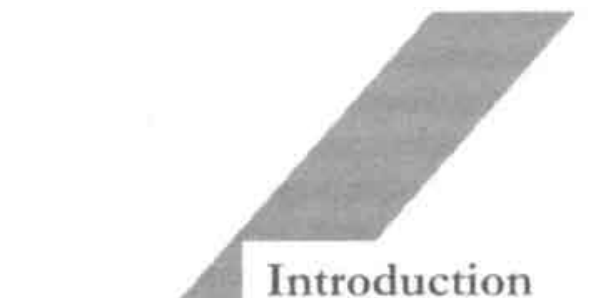

Introduction 
This thesis has been launched following an influential paper by Frasure-Smith in 1993 I. In this paper Frasure-Smith and co-workers reported depression to be a major risk factor for increased cardiac mortality and morbidity in the first 6 months post myocardial infarction (MI) independent of cardiac functioning after MI. An editorial by Williams and Chesney, accompanying this influential publication by Frasure-Smith in 1993 ', stressed the importance to undertake clinical trials evaluating pharmacological interventions in men and women with ischemic heart disease ${ }^{2}$. These new findings formed the start of an intensive clinical and research relationship between departments of Psychiatry and Cardiology of the Academic Hospital Maastricht (azM) on affective disorders in cardiology.

Cardio-psychiatry has developed into a major line of research, called affective disorders and somatic co-morbidity, within the department of Psychiatry of the azM and the Institute of Brain \& Behaviour of the Maastricht University (UM). The first research effort on the topic of depression post-MI is focussed on a double-blind placebo-controlled study of a selective serotonergic reuptake inhibitor (SSRI), an antidepressive agent. Concurrently a study based on grants from the Dutch Prevention Fund and of the Maastricht University Hospital Research Fund is developed, focussing on the epidemiology of post-MI depression in the Netherlands, and on risk factors that could identify patients at risk for depression post-MI.

These activities led to this thesis on epidemiology, risk factors and treatment of depression in patients following first MI. Two consecutive cohorts of first MI patients are selected for this thesis. The first cohort on pharmacological intervention is selected between May 1994 and May $1997(\mathrm{n}=206)$, and the second, on epidemiology and risk factors for depression post-MI, between May 1997 and September $1999(\mathrm{n}=206)$. Data of papers in this thesis are derived either from the first (chapters 6,8, and 11-13), the second (chapters 2, 4, 5, 7, and 10) or from both cohorts (chapters 1,3, and 9). This thesis is divided in four parts, each addressing a different research topic. The title of this thesis refers to the firm but complex relationship between the heart and the brain, which will be addressed in the general discussion.

\section{Part A addresses the question: Is then a relationship between Heart and Mind?}

Studies reported that prevalence of depression in patients with MI is higher than prevalence of $5-10 \%$ in the general population. Recent studies found that prevalence of major depression ranges from 15 to $30 \%$ in cohorts with both first and multiple MI, and of minor depression and depressive symptoms in another $25 \%$ 1.3.- Also a relationship between diagnosis of depression or even depressive symptoms as negative prognostic factor in the post-MI period has been reported $1,3,5,8.10$. This negative impact on cardiac prognosis is as strong as for example smoking or high levels of serum cholesterol ${ }^{1,11}$.

Chapter 1 provides a review of literature on possible relationships, specific and a-specific, between depression and MI ${ }^{12}$. Chapter 2 focuses on incidence and 
course of major and minor depression in post-first-MI patients ${ }^{13}$. Chapter 3 describes the impact of depressive symptoms, and other negative emotions such as anxiety and hostility, on cardiac prognosis in the post-MI period. Psychological symptoms, measured one month post-MI, are studied in relation to recovery, being death, re-infarction, re-hospitalization and visits at the cardiac out-patient clinic, of first MI patients up to 6 years post-MI ${ }^{14}$.

Part B of this thesis focuses on the question: How valid are depression rating scales for screening in this specific population?

As depressive symptoms may be a predictor of cardiac outcome, it is important to screen MI patients for depressive disorder with an instrument validated in this specific population. Rating scales for depression, such as the 90 -item Symptom Check list (SCL-90) ${ }^{15}$, the Beck Depression Inventory (BDI) ${ }^{16}$ and the Hospital Anxiety and Depression Scale (HADS) ${ }^{17}$, frequently used in MIpopulations, are not validated for MI-populations. For screening purposes such an instrument should have high sensitivity, i.e. few patients falsely diagnosed as not being depressed. Simultaneously, such an instrument should have a high negative predictive value, i.e. a high proportion of non-depressed patients testing negative in the screening instrument. In chapter $\mathbf{4}$, the sensitivity and specificity of three self rating scales, i.e. the SCL-90 ${ }^{15}$, the BDI ${ }^{16}$ and the HADS 17, and one observer rating scale, the 17-item Hamilton Depression Rating Scale (HAMD-17) ${ }^{18}$, are evaluated ${ }^{19}$. The Structured Clinical Interview for DSM-IV axis-1 disorders (SCID-I-R) is used as the gold standard 20 . In chapter $\mathbf{5}$ the question is addressed how the clinician can easily identify patients at risk for depression post-MI. In order to identify depression more efficiently, a 4-item screening questionnaire for mixed Anxiety-Depression is developed with the same psychometric abilities as the questionnaires (total 125 items) investigated in chapter $4{ }^{21}$. Finally, in chapter 6 the question is addressed whether 'vital exhaustion', with as core symptom fatigue, is a syndrome independent from depression ${ }^{22}$. In this paper correlations of two self-rating scales for depression (depression subscale of the SCL- $90{ }^{15}$ and the Zung Depression Rating Scale ${ }^{23}$ ) are compared with the correlation of each of these depression scales with a self rating scale for vital exhaustion, the Maastricht Questionnaire ${ }^{24}$.

Part $\mathrm{C}$ is dedicated to the question: Which clinical variables can identify patients at risk for post-MI depression?

How can we identify patients at risk for depression? There have been few studies investigating biological, psychological and social risk factors for depression post-MI. One study by Ladwig showed that complications during hospitalization increased the risk of depression post-MI ${ }^{25}$. Frasure-Smith and co-workers found that patients with a history of depression are more at risk for depression post-MI while in-hospital '. Not being able to stop smoking and lifetime prescription of benzodiazepines have also been reported to be 
associated with depression and development of MI ${ }^{26-29}$. Most studies reporting data on markers for post-MI depression deal with methodological difficulties 1.25-29. One methodological flaw consists of the comparison of depressed patients with non-matched controls. Secondly, if depression is diagnosed within 2 weeks of the MI, it is difficult to differentiate depression from short-lived depressive symptoms directly related to an acute and potentially life-threatening disease. Thirdly, it is difficult to differentiate a so-called risk factor as trigger for depression post-MI, or as an early sign of a depressive episode that already exist before the MI. So, the question on biological and psychological risk factors, such as size of infarction and previous depressive episode, is as yet unequivocally answered.

In chapter 7, biological risk factors for depression post-MI are evaluated. In this chapter, serum lipids, being total cholesterol, high density cholesterol, low density cholesterol and triglycerides, are investigated as a risk factor for depressive symptoms in the first 6 months post-MI ${ }^{30}$.

Clinical correlates than easily can be obtained by the clinician, such as complications post-MI, prescription of benzodiazepines, not being able to stop smoking and history of depressive episode, are investigated in relation to development of depression post-MI in chapter $8^{31}$. Chapter 9 focuses on cognitive functioning, such as memory, speed and concentration, as risk factor for depression post-MI ${ }^{32}$. Cognitive profile of depressed MI patients is compared with that of non-depressed MI patients and controls in this chapter. Psychological factors as possible risk factors for post-MI depression are evaluated in chapter 10. In this chapter personality traits are related to the development of depression post-MI ${ }^{33}$.

Finally, Part D focuses on the question: What is the effect of pharmacological treatment on depressive symptomatology and cardiac functions in depressed patients with ischemic beart disease?

As depression frequently co-occurs with $\mathrm{MI}$ and is simultaneously a potent risk factor for mortality post-MI, it is important to determine whether depression can be treated in MI-patients. As yet, only open and comparative studies with antidepressive agents have been performed to evaluate pharmacological treatment in post-MI depression. However, in order to investigate whether pharmacological treatment has a true beneficial effect, one has to discriminate between placebo effects and therapeutic actions, directly related to antidepressant drugs. The first double-blind placebo-controlled trial evaluating efficacy and safety of an antidepressive agent, fluoxetine, has been evaluated in 54 depressed post-MI patients in chapter $11{ }^{34}$. Chapter 12 focuses on cardiac side effects of two SSRIs, fluoxetine or fluvoxamine, which are evaluated in middle-aged and elderly patients with ischemic heart disease ${ }^{35}$. These patients are selected from a different population than the 2 cohorts mentioned previously, namely from a cohort of the outpatients, referred to the specialty mood-disorder clinic of the azM between May 1994 and May 1997. Finally, in 
chapter 13, cognitive side effects of fluoxetine in the same 54 depressed MI patients of chapter 11 are evaluated ${ }^{36}$.

\section{References}

1. Frasure-Smith N, Lespérance F, Talajic M. Depression following myocardial infarction: impact on 6-months survival. JAMA 1993; 270:999-1005.

2. Williams RB, Chesney MA. Psychosocial factors and prognosis in established coronary artery disease. The need for research on interventions. JAMA 1993; 270:1860-1.

3. Schleifer SJ, Macari-Hinson MM, Coyle DA, et al. The nature and course of depression following myocardial infarction. Arch Intern Med 1989; 149;1785-9.

4. Carney RM, Rich MW, Freedland KE, et al. Major depressive disorder predicts cardiac events in patients with coronary artery disease. Psychosom Med 1988; 50:627-33.

5. Ladwig KH, Roll G, Breithardt G, Budde T, Borggrefe M. Post infarct depression and incomplete recovery 6 months after acute myocardial infarction. The Lancet $1994 ; 343: 20-3$.

6. Honig A, Lousberg R, Wojchiechowski F, Cheriex EC, Wellens H, Van Praag HM. Depression following a first heart infarct; similarities with and difference from 'ordinary' depression. Ned Tijdschr Geneeskunde 1997; 141:196-9.

7. Ladwig KH, Kieser M, Konig J, Breithardt G, Borggrefe M. Affective disorders and survival after acute myocardial infarction (results from the post-infarction late potential study). Eur Heart J 1991; 12:959-64.

8. Frasure-Smith N, Lesperance F, Talajic M. Depression and 18 months prognosis after myocardial infarction. Circulation. 1995; 91:999-1005.

9. Barefoot JC, Schroll M. Symtomps of depression, acute myocardial infarction, and total mortality in a community sample. Circulation 1996; 93:1976-80.

10. Ahern DH, Gorkin L, Anderson JL, et al. Biobehavioral variables and mortality on cardiac arrest in the Cardiac Arrhythmia pilot study (CAPS). Am J Cardiology 1990; 66:59-62.

11. Glassman $\mathrm{AH}$, Shapiro PA. Depression and the course of coronary artery disease. Am J Psychiatr 1998; 155:4-11.

12. Strik JJMH, Honig A, Maes M. Depression and myocardial infarction: Relationship between heart and mind. Progr Neuropsychopharmacol \& Biol Psychiatry 2001; 25:879-92.

13. Strik JJMH, Lousberg R, Cheriex EC, Honig A. One year cumulative incidence of depression after first myocardial infarction and impact on cardiac outcome. J Psychosom Res 2003; In Press:

14. Strik JJMH, Denollet J, Lousberg R, Honig A. Comparing symptoms of depression and anxiety as predictors of cardiac events and increased health care consumption following myocardial infarction. JACC 2003; In Press.

15. Arrindell WA, Ettema JHM. Dimensional structure, reliability and validity of the Dutch version of the Symptom Checklist (SCL-90). Ned Tijdschr Psychologie 1981; 43:381-7.

16. Beck AT, Ward CH, Mendelson M, Mock J, Erbaugh J. An inventory for measuring depression. Arch Gen Psychiatry 1961; 4:561-71. 
17. Herrmann C. International experiences with the hospital anxiety and depression rating scale: a review of validation data and clinical results. J Psychosom Res 1997; $1: 17-41$.

18. Hamilton M. A rating scale for depression. J Neurol Neurosurg Psychiatry. 1960; 23:56-62.

19. Strik JJMH, Honig A, Lousberg R, Denollet J. Sensitivity and specificity of observer and self rating questionnaires in depression following myocardial infarction. Psychosomatics 2001; 42:423-8.

20. First MB, Spitzer RL, Gibbon M, Williams JB. Structured Clinical Interview for DSM-IV Axis I disorders-Patient Edition (SCID-1/P, Version 2.0). New York: Biometrics Research Department, New York State Psychiatric Institute, 1995.

21. Denollet J, Strik JJMH, Lousberg R and Honig A. Psychological characteristics of post-myocardial infarction depression: looking for Symptoms of mixed AnxietyDepression. Psychosomatics 2003; Submitted.

22. Woijiechowski F, Strik JJMH, Falger P, Lousberg R, Honig A. Depression and vital exhaustion: two concepts for one phenomenon? Act Psych Scandinavica 2000; 102:359-65.

23. Zung WW, Richards CB, Short MJ. A selfrating depression scale. Arch Gen Psychiatry 1965; 12:63-70.

24. Appels A, Mulder P. Fatigue and heart disease. The association between 'vital exhaustion' and past, present and future coronary heart disease. J Psychosom Res $1989 ; 33: 727-38$.

25. Iaduig KH. Factors which provoke post-infarction depression. Results from the post-infarction late potcritial study. I Psychosom Res 1992; 34:723-9.

26. Glassman AH, Stetner F, Walsh BT, et al. Heavy smokers, smoking cessation, and clondinct results of a double-blind, randomised trial JAMA 1988; 259:2863-6.

27. Wikland I. Oden A, Sanne H, et al. Prognostic importance of somatic and psychosocial variables after a first myocardial infarction. Am ] Epidemiology 1988; 128:786:95.

28. Denollet 1, Sys SU, Stroobant N, Rombouts H, Gillebert TC, Brutsaert DI. Personaliry as independent predictor of long-term mortality in patients with coronary heart disease. Lancet 1996, 347:417-21.

29. Denollet ], Vaes ]. Adverse effects of type D personality and younger age on 5-year prognosis and quality of life. Circulation $2000,102630-5$.

30. Strik ]JMH, Honig A, Lousberg R, Maes M. Relation of levels of serum lipoproteins to depression after acute myocardial infarction. Am ] Cardiol 2002; 90:1368-70.

31. Strik JJMH, Hong A, Lousberg R, Van Os ], Van den Berg E, Van Praag HM. Clinical correlates of depression following first MI. Int ] Psych Med 2001; 31:27180.

32. Dijkstra JB, Strik J]MH, Homig A, ct al. Arypical cognituve profile in patients with depression after myocardial infarcticn. J. Aff Dis 2002; 70:181-90.

33. Strik IIMH, Dencllet J, Lousberg R, Woijiechowski F and Honig A. Personaliry and valnerabaliny to depression following myocardal infarcaon: A prospective follow-up study. Am ] Psychatry 2003, Subrritted.

34. Stnk IJMH, Homig A, Lousberg R, et al. Efficacy and safety of fluoxerine in the treatment of patients with major depression following first myocardial infanction: findings from a double-blind placebo-controlled trial. Psychosem Med 2000; 62:783.9. 
35. Strik JJMH, Honig A, Lousberg R, Cheriex EC, Van Praag HM. Cardiac side-effects of two selective serotonin reuptake inhibitors in middle-aged and elderly depressed patients. Int Clin Psychopharm 1998; 13:263-7.

36. Strik JJMH, Honig A, Klinkenberg E, Dijkstra J, Jolles J. Fluoxetine and effect on cognitive performance in depressed patients post myocardial infarction. Psychosomatics 2003; Submitted. 


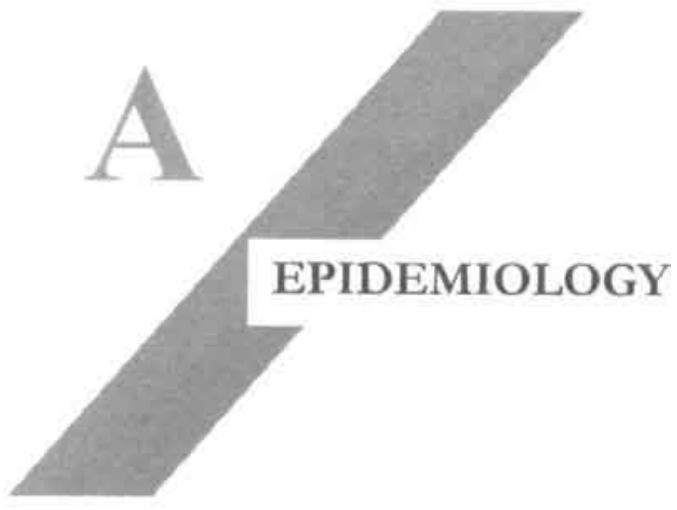





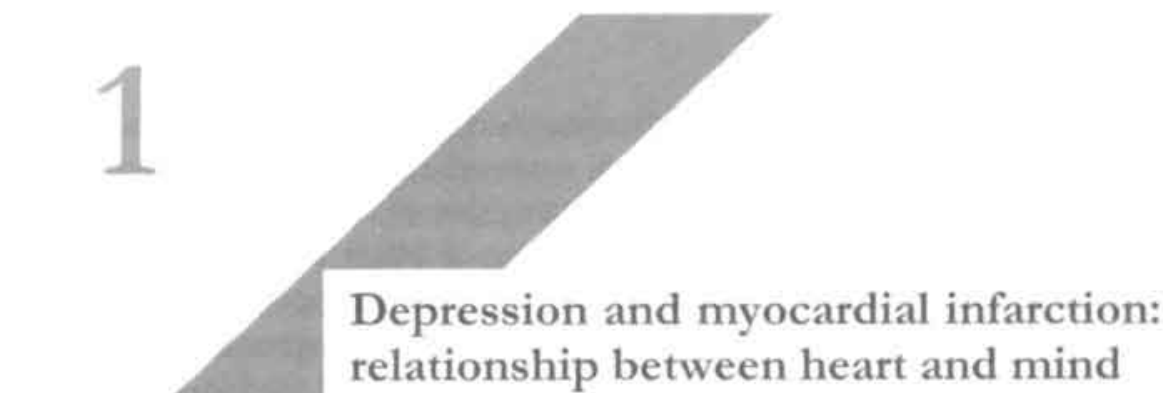




\begin{abstract}
There is a relationship between depression and myocardial infarction (MI) as higher levels of depression and severe depression (major versus minor) are associated with higher morbidity and mortality due to cardiac events, which are mainly caused by arrhythmia. Second, severity of MI is not or even inversely related to development of depression. Depression post-MI goes often unrecognised as only $10 \%$ of depressed MI patients are diagnosed as such. This underestimation of depression is attributed to its atypical profile, tendency of physicians to interpret depressive symptoms as a transient and 'natural' reaction to a life-threatening event, and the scarce knowledge of risk factors associated with development of post-MI depression. During the first 18 months following MI major depression occurs in $15-30 \%$ of patients. Depression should be assessed in an early stage as depression has the highest prevalence in hospital and in the first 6 months post-MI. Risk factors for developing post-MI depression include complications during hospitalization, prescription of benzodiazepines during hospitalization, previous history of depression, and not being able to stop smoking. Selective serotonin reuptake inhibitors (SSRIs) appear to be first choice treatment in post-MI depression. As yet there is no information on the efficacy and safety of serotonin and noradrenalin reuptake inhibitors.
\end{abstract}

\title{
Reference
}

Strik JJMH, Honig A, Maes M. Depression and myocardial infarction: relationship between heart and mind. Progr Neuropsychopharmacol Biol Psychiatry 2001; 25: 879-92. 


\section{Introduction}

Depression co-occurring with ischemic heart disease has a major negative impact on cardiovascular prognosis; it increases cardiac morbidity and mortality four to fivefold in the first 18 months post myocardial infarction (MI) ${ }^{1.3}$. Depression is a risk factor for worse prognosis of $\mathrm{MI}$ as strong as for example smoking or previous MI 1,4. Furthermore, depressed post-MI patients are more frequently re-hospitalized and recover more difficult. Also new cardiac events, like angina pectoris and re-infarction, are reported to be more frequent in depressed than in non-depressed MI patients ${ }^{2}$. This increased risk can last until 5 years after the MI ${ }^{5}$. Prevalence of depression in $\mathrm{MI}$ is higher than in the general population, but comparable to that in patients with other somatic diseases, such as rheumatoid arthritis and diabetes mellitus. There are arguments for a specific relationship between depression and MI, which will be discussed in this paper. The possible biological mechanisms underlying the relationship between depression and MI are well discussed in other recent reviews and will not be addressed in the present paper ${ }^{6-10}$.

Depression post-MI goes often unrecognised as only $10 \%$ of depressed MI patients are diagnosed as such 1,11. This underestimation of depression is attributed to its atypical profile ${ }^{12}$, tendency of physicians to interpret depressive symptoms as a transient and 'natural' reaction to a life-threatening event ?, and the scarce knowledge of risk factors associated with development of post-MI depression. It is unclear whether the aetiology of post-MI depression is similar to that in non-somatic compromised depressed patients. Furthermore it is as yet questionable whether treatment of post-MI depression is similar to that of non-somatic compromised depression and whether psychiatric treatment decreases cardiac morbidity and mortality.

In the present paper the possible relationships between depression and MI will be discussed as well as epidemiology, clinical profile, risk factors, and treatment of post-MI depression.

\section{Possible relationships between depression and MI}

Two types of relationships between depression and MI can be postulated. One argument for an aspecific relationship is that higher depression scores and severe depression (major versus minor) are associated with increased morbidity and mortality, especially in patients with prior ischemic heart disease $3,13,14$. Second, negative mood driven behaviour, associated with depression, facilitates the occurrence of cardiac events. Examples of negative mood driven behaviour are smoking, unhealthy diet, physical inactivity, which are known risk factors for MI and for an unfavourable cardiac course. Also during the course of MI, depression may have a negative effect as depressed MI patients tend to drop out in rehabilitation programs, are often socially isolated, have a lower 
compliance with cardiac medication, fail to stop smoking, fail to use a diet and to comply with exercise advises ${ }^{15-17}$.

The first argument for a specific relationship between depression and $\mathrm{MI}$ is that depression is a risk factor for increased morbidity and mortality post-MI ', mainly due to arrhythmic events. Depression increases morbidity and mortality three to fourfold despite other risk factors for MI, associated with the above stated negative mood driven behaviour ${ }^{3,18}$. This effect lasted up to 18 months ${ }^{3}$. Second, severity of physical illness is one of the most important variables associated with depression in patients with somatic illnesses ${ }^{7}$. This relationship between severity of somatic illness and development of depression exists not in MI. Depression is not related to degree of cardiac dysfunction, measured by left ventricular function, Holter registration or angiography 13,18,19. Also studies using enzymes as a measure of severity of MI found that depression was unrelated with severity of $\mathrm{MI} 2,20,21$. One study linked the enzyme aspartate aminotransferase (ASAT) to emotional coping after MI ${ }^{22}$. A tendency was found towards a significant negative correlation between emotional upset after the MI and ASAT 22 . We found in a consecutive cohort of 173 first MI patients

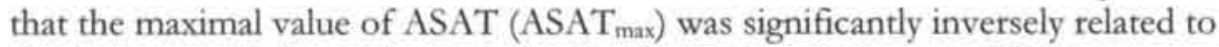
development of depression within the first 12 months post-MI ${ }^{23}$, as were $\mathrm{ASAT}_{\max }$ concentrations ${ }^{24}$.

\section{Clinical profile and prevalence}

Listlessness rather than depressed mood is the core symptom patients frequently report ${ }^{12}$. The depressed mood is often regarded as a "normal reaction" following the MI, not only by patients but also by cardiologists ${ }^{25}$. Because of this, patients do not report the depressed mood spontaneously and depression is often not recognised; only $10 \%$ of the depressed patients are diagnosed as depressed ${ }^{13}$. Also somatic symptoms of depression, such as sleep disturbances and fatigue, which are reported by more than half of the MI patients ${ }^{26}$, are believed by patients and doctors to be cardiac related 11 . Furthermore, depressed MI patients are more hostile than depressed noncardiac compromised patients ${ }^{12}$. Hostility is associated with thoughts, feelings and behaviour typical for negative state of anger, and inability to express these feelings adequately. Hostility is thereby expressed as aggression, irritation, anger and resentment ${ }^{12,27}$. Like depression, hostility seems to be a risk factor for increased mortality post-MI. Denollet reported that type D (distress) personality increases mortality four fold in patients with CAD ${ }^{28}$. Type D personality is, as is hostility, associated with not being able to express negative feelings. As the clinical profile of post-MI depression is atypical, it is questionable whether questionnaires used in general and hospitalized populations are valid in this patient population. For diagnosing depression two 
aspects are important, i.e. the screening of depressive symptoms and diagnosing major depression.

Concerning screening, validity of self-rating scales, assessed within one week post-MI, are as yet not available. For screening purposes it is important to have few false negatives (depressed patients falsely diagnosed as not being depressed) and a high negative predictive value (NPV) of a questionnaire, i.e. the chance of not having a major depression when scoring beneath the cut-off. In one of our studies validity of three self rating scales often used for screening in CAD patients, i.e. 90 item Symptom Check List (SCL-90) ${ }^{27}$, Beck Depression Inventory (BDI) ${ }^{29}$ and Hospital Anxiety and Depression Scale (HADS) ${ }^{30}$, were evaluated in a consecutive cohort of 206 first-MI patients one month post-MI 31. We found that all three questionnaires are valid screenings instruments for post-MI major and minor depression as NPV was between $93.3 \%$ and $99.3 \%$ (positive predictive value, PPV, was between 25.3-45.2\%).

If self-rating scales are used for diagnostic purposes it is important to have a low number of false positive results (non-depressed patients falsely diagnosed as being depressed) and a high PPV. We found that the self-rating questionnaires SCL-90, BDI and HADS had a PPV of only $25.3-45.2 \%{ }^{31}$. The HADS was the best self-rating questionnaire for diagnostic dichotomization. Thus, if self-rating scales are used for dichotomization one has to interpret results with caution. In clinical studies the diagnosis of major depression is often assessed by diagnostic interviews. Diagnostic interviews are sometimes modified if they are used during hospitalization. In the study by Frasure-Smith the DIS (Diagnostic Interview Schedule) was modified as the duration criterion for major depression in the hospital was shorter than specified in the DSMIIIR'. The criteria "seeking treatment for depressive symptoms" or "experiencing impairment in daily activities" were also not included, because patients were in a health care setting ${ }^{1}$. Besides different or modified diagnostic instruments, other differences may be present in studies diagnosing post-MI depression such as dissimilar patient populations, different hospitalization status and non-specific heart disease ${ }^{1,7,13}$.

Taking the above into account, prevalence rates of post-MI depression differ between studies. Recent studies report prevalence rates of major depression in MI patients of $15-30 \%$ within the first 18 months $1,12,17,32$, with another $20 \%$ of MI patients showing minor depression or depressive symptoms $3,18,19,33$. Thus, depression is a frequent co-morbid condition in patients with CAD and more prevalent than in the general population. Because of the risk of increased morbidity and mortality, it is important to determine when depression develops after MI. Unfortunately, literature addressing the peak incidence of depression is scarce. One study using the DIS evaluated the incidence rate of depression in the first 12 months post-MI ${ }^{14}$. In this study 222 MI patients were followed up during one year. The incidence rate was highest during hospitalization $(15.8 \%)$ with a second peak at 6 months post-MI $(16.8 \%)$, tailing off at one year $(3.6 \%)$. We found that in 173 first MI patients followed up for 12 months post-MI the 
peak incidence rate occurred at one month post-MI ${ }^{23}$. However, the second peak of major depression at 6 months as reported by Lespérance ${ }^{14}$ could not be replicated in our study ${ }^{23}$. This may be explained by the fact that we only selected first MI patients whereas Lespérance investigated patient with first and recurrent $\mathrm{MI}$, one of the study differences mentioned above.

\section{Risk factors of post-MI depression}

Risk factors could help the cardiologists and consultant-liaison psychiatrists to recognise depressed MI patients and identify patients at risk. However, it is difficult to evaluate whether risk factors are triggers or early signs of a depressive episode that already exist before or at the time of the MI, are associated phenomena or even consequences of the disease. For example, arrhythmia, which complicates recovery after MI, has been linked to depression, already present before MI 7 . On the other hand, it could also be a clinical marker for depression developing after $\mathrm{MI}^{3+}$. Design for identifying risk factors for post-MI depression should therefore be prospective with incident cases of post-MI depression. Unfortunately such studies have not been performed yet. Any definite conclusions of risk factors for post-MI depression are therefore not permitted. Studies, which have focused on risk factors for post-MI depression, proposed some biological, psychological and psychosocial variables as risk factors.

\section{Biological risk factors}

Ladwig and co-workers found complications during hospitalization to increase risk of depression after MI ${ }^{34}$. Also in our case-control study, in which 35 depressed first-MI patients were compared with 35 non-depressed counterparts, matched for gender, age and $\mathrm{ASAT}_{\max }$, complications during hospitalization were associated with depression ${ }^{35}$. Smoking and hypertension are other factors associated with post-MI depression ${ }^{36,37}$. Glassman reported that patients became depressed upon quitting smoking and that depressed MI patients failed to quit smoking after the MI ${ }^{38}$. Medication may also be related to development of post-MI depression; first-time prescription of benzodiazepines during the acute hospitalization has been related to development of depression $28,39,40$. There is ample evidence that beta-blockers do not cause depression 8; no differences between depressed and nondepressed first-MI patients in use of beta-blockers were found in our casecontrol study ${ }^{35}$. In one study warfarine was reported to be associated with post-MI depression '. In this same study ', it was reported that women had higher rates of moderate to severe depression than men, both in-hospital and within the first 12 months post-MI. Gender was the strongest predictor of level of depression at one year post-MI ${ }^{41}$. 


\section{Psychological risk factors}

Complications during hospitalization may not only be regarded as a biological but also as a psychological risk factor; they may be considered to be a life event, triggering depression. Patients with history of depression were more likely to develop post-MI depression in the hospital than after discharge 1. Negative mood states such as exhaustion ${ }^{42-4}$, hostility and fear ${ }^{45}$ frequently co-occur with or precede depression. In hospitalized post-MI patients, fatigue was three times more common among depressed than among non-depressed patients ${ }^{14}$. Therefore, it was concluded that feelings of tiredness and lack of energy might be particularly important indicators of post-MI depression. Furthermore it may be suggested that vital exhaustion may well reflect depression in some patients 14. Negative mood states, such as type D personality, hostility and social inhibition, are like depression reported to have a negative effect on morbidity and mortality post-MI $28,42,43,45,46$.

\section{Social risk factors}

There are few studies, which relate social risk factors, such as living alone to the development of post-MI depression. Frasure-Smith found that patients without close friends were more likely to become depressed after an acute MI '. Most studies address to cardiac prognosis in stead of development of depression post-MI. Cardiac prognosis has been shown to be related to several social variables, such as living alone ${ }^{47}$, social isolation ${ }^{48}$, and lack of emotional support ${ }^{49}$. It is, however, unclear whether these variables are direct risk factors for post-MI mortality or indirect via development of depression.

\section{Treatment of post-MI depression}

\section{Pharmacological treatment}

There are some important aspects concerning pharmacological treatment of depression post-MI: 1) efficacy, 2) safety and 3) effect on cardiac prognosis. As depression in somatic compromised patients like MI may have a different pathogenesis, placebo controlled trials should be performed to evaluate whether antidepressive agents, such as selective serotonergic reuptake inhibitors (SSRIs) are efficacious in this patient population. To the best of our knowledge, only one double-blind placebo-controlled SSRI trial has been performed in MI patients ${ }^{50}$. We found that the overall difference between fluoxetine and placebo was not significant, but that there was a trend favouring fluoxetine in a relatively small number of patients ( $n=54)$. The response rate $\geq 50 \%$ decrease on Hamilton Depression Rating Scale, 17 items) of fluoxetine was comparable to other studies in which depressed patients with cardiovascular disease were treated with SSRIs 51,52 . In addition, fluoxetine seemed to be particularly effective in patients with mild depression and was associated with a statistically significant reduction in hostility. Besides this double-blind placebo-controlled 
trial an open study in MI patients has been performed. In this study Shapiro found a responder rate of $62.5 \%$ in MI patients treated during 16 weeks with sertraline. Comparative studies performed in patients with CAD showed that SSRIs are as effective as tricyclics, but have less cardiac side effects 52,53 .

Tricyclics are reported to have intrinsic harmful effects to cardiac functioning, whereas SSRIs are safer in this respect ${ }^{54}$. The Cardiac Arrhythmia Suppression Trials report an increase in mortality among patients treated with antiarrhythmic agents as compared with those treated with placebo 55,56 . Tricyclics have this same type of anti-arrhythmic properties as the agents used in the CAST studies and may not be safe for patients known to have ischemic heart tissue. Furthermore, tricyclics are reported to increase heart rate, induce orthostatic hypotension, slow intraventricular cardiac conduction and suppress ventricular premature depolarisations (VPD) in depressed patients with and without heart disease ${ }^{57-60}$. SSRIs have no cardiotoxic effects in healthy volunteers or in the elderly with CAD 52,61-65. SSRIs are probably safe to treat depressed MI patients. In an open study sertraline did not have negative effects on the myocardium in the 26 MI-patients treated ${ }^{5}$. Fluoxetine, evaluated in a double-blind placebo controlled study, had no negative effect on cardiac function in first-MI patients 3-12 months post-MI 50 .

Third, because co-morbid depression is a common and potent risk factor for mortality after acute MI, it is important to determine whether the prognosis of those patients can be improved. Data from randomised controlled trials relating the treatment of depression to the risk of cardiac morbidity and mortality are scarce. One study reported that cardiac death was more prevalent in depressed patients who had not received adequate medical treatment compared to those with adequate antidepressive treatment ${ }^{66}$. However, the results were based on a small number of end points and the patients had no ischemic heart disease. One of our papers reported that fluoxetine tended to reduce re-hospitalizations due to cardiac events in post-MI depression ${ }^{50}$. Furthermore, there are several ongoing studies that examine whether antidepressive treatment may increase prognosis of MI patients. The SADHART ${ }^{51}$ and MIND-IT ${ }^{67}$ studies focus on sertraline and mirtazepine respectively. The ENRICHD study evaluates the efficacy of cognitive therapy ${ }^{68}$. Whether any treatment for depression can decrease cardiac morbidity and mortality may depend on whether it alters the underlying mechanisms through which depression worsens cardiac prognosis.

\section{Rehabilitation, psychological intervention, and psychotherapy}

The purpose of cardiac rehabilitation is to offer the patients medical treatment, education, counselling, exercise training, risk factor modification and secondary prevention to limit the harmful physical and psychological effects of heart disease. In general, intervention studies have shown better outcome in terms of exercise tolerance, plasma lipid levels, smoking, psychosocial well being and stress reduction ${ }^{69}$. However, cardiac rehabilitation is often offered to young patients only, who are likely to benefit or patients who had had their first MI 70 . 
For example, little is known of the rehabilitation effect in women and elderly people ${ }^{71}$. The above mentioned underlines the need for further research and the inclusion of adequate numbers of women and elderly in future post-MI trials.

Psychosocial treatment consists of programs targeting at reducing Type A behaviours, at smoking cessation, at increasing exercise, or at stress management. Some small studies reported that these programmes improved cardiac outcome in MI patients and may be effective in reducing psychological distress and increasing effective coping, although frequently only in the shortterm. There is little evidence that such changes afford benefits in terms of coronary heart disease mortality or morbidity. A recent psychological intervention trial by Jones et al. showed no benefit in reducing depression, anxiety, morbidity or mortality in patients with MI ${ }^{72}$. Frasure-Smith and coworkers reported that home-based psychological intervention for MI patients had small impact on depression. In contrast, cardiac and all cause mortality were higher in women in the intervention group, but not in men ${ }^{73}$. However, a prior study of the same investigators showed that men in the intervention trial, i.e. monthly telephone monitoring of psychological distress and home nursing visits, were half likely to die of cardiac causes during the year and less likely experience long term recurrence of $\mathrm{MI}{ }^{74}$.

To date, there have not been any studies evaluating the efficacy of psychotherapy for depression in MI patients ${ }^{8}$. Recently a large-scale clinical trial of cognitive behavioural therapy for post-MI patients has started ${ }^{68}$. Goals are to determine whether cognitive behavioural therapy reduces the risk of death or subsequent MI in patients who suffer from depression or have low social support, and to enrol large number of women.

\section{Conclusions}

There may be an aspecific relationship between depression and MI as higher levels of depression score and severe depression (major versus minor) are associated with higher risk of increases morbidity and mortality, especially in patients with prior ischemic heart disease 3.13 .14 . Second, negative mood driven behaviour, associated with depression such as smoking, unhealthy diet and dropping out rehabilitation programmes, facilitates the occurrence of cardiac events 15.17 . However, an argument for a specific relationship between depression and MI is that depression increases morbidity and mortality mainly due to arrhythmic events. This increase in morbidity and mortality remains despite other risk factors for MI, associated with the above stated negative mood driven behaviour 3,18. Second, severity of MI is not 1,3,18,19 or even inversely ${ }^{22,23}$ related to development of depression.

Depression post-MI has a different clinical profile than general depression, with listlessness as core symptom and hostility as specific symptom. This aspecific 
profile leads often to underdiagnosis and to the question whether screenings instruments for depression are valid in MI patients. As yet there are no data of validity of screening and diagnostic instruments in the first week after MI. However, SCL-90, BDI and HADS are valid screening instrument for post-MI depression one month post-MI. For diagnostic purposes the HADS is the best instrument ${ }^{31}$. Structured interviews may not recognise depression as most patients do not report depressed mood spontaneously; semi structured interviews performed by experienced psychiatrists are to be preferred. Furthermore, it may be important to focus not only on diagnosis of major depression, but also on depressive symptoms, as they may worsen post-MI prognosis.

Taken the method of assessment into account, major depression occurs in 15$30 \%$ of patients, at least during the first 18 months following MI. Depression has to be recognised in an early stage as depression has the highest prevalence in hospital and in the first 6 months post-MI. Unfortunately literature of risk factors for post-MI depression, evaluated in prospective studies are scarce. Risk factors that are identified and can easily be obtained by practical clinicians, i.e. consultant cardiologists, include complications during hospitalization, prescription of benzodiazepines during hospitalization, previous history of depression and female gender. Especially those who had a combination of risk factors were at risk for post-MI depression. Furthermore it is difficult to determine whether variables are risk factors for or early signs of a depression that already existed before the MI.

As yet it is not clear how depression as risk factor for increased cardiac morbidity and mortality can be treated, or whether treatment decreases this risk. On treatment of post-MI depression SSRIs are as efficacious as tricyclics, but without cardiovascular side effects. SSRIs therefore seems to be first choice treatment in post-MI depression. As yet there is no information on efficacy and safety of serotonin and noradrenalin reuptake inhibitors (SNRIs) as venlafaxine and mirtazapine evaluated in double-blind placebo-controlled trials; these studies are needed and ongoing.

\section{References}

1. Frasure-Smith N, Lespérance F, Talajic M. Depression following myocardial infarction: impact on 6-months survival. JAMA 1993;270:999-1005.

2. Ladwig KH, Roll G, Breithardt $G$, Budde $T$, Borggrefe M. Post infaret depression and incomplete recovery 6 months after acute myocardial infarction. The Lancet 1994;343:20-3.

3. Frasure-Smith N, Lespérance F, Talajic M. Depression and 18 months prognosis after myocardial infarction. Circulation. 1995;91:999-1005.

4. Glassman AH, Shapiro PA. Depression and the course of coronary artery disease. Am J Psychiatr 1998;155:4-11. 
5. Barefoot JC, Helms MJ, Mark DB, et al. Depression and long-term mortality risk in parients with coronary heart disease. Am J Cardiology 1996;78:613-7.

6. Honig A, Maes M. Psycho-immunology as a common pathway in myocardial infarction, depression and cardiac death. Curr Opin Psychiatry 2000;13:661-4.

7. Musselman DL, Evans DL, Nemeroff CB. The relationship of depression to cardiovascular disease. Arch Gen Psychiatry 1998;55:580-92.

8. Carney RM, Freedland KE, Veith RC, Jaffe AS. Can treating depression reduce mortality after an acute myocardial infarction? Psychosom Med 1999;61:666-75.

9. Albert CM, Hennekens $\mathrm{CH}$, O'Donnel CJ, et al. Fish consumption and risk of cardiac death. JAMA 1998;279:23-8.

10. Maes M, Smith R, Cristophe A, Cosyns P, Desnyder R, Meltzer H. Fatty acids and composition in major depression: decreased omega-3-fractions in cholestryl esters and increased C20:4 omega-6/C20:5 omega-3 ratio in cholesteryl esters and phospholipids. J Aff Disorders 1996;38:35-46.

11. Freedland KE, Lustman PJ, Carney RM, Hong BA. Underdiagnosis of depression in patients with coronary arterie disease: the role of nonspecific symptoms. Int J Psychiatry Med 1992;22:221-9.

12. Honig A, Lousberg R, Wojchiechowski F, Cheriex EC, Wellens H, Van Praag HM. Depression following a first heart infarct; similarities with and difference from 'ordinary' depression. Ned Tijdschr Geneeskunde 1997;141:196-9.

13. Penninx BWJH, Beekman ATF, Honig A, et al. Depression and cardiac mortality: results from a community-based longitudinal study. Arch Gen Psychiatry 2001;58:221-7.

14. Lespérance F, Frasure-Smith N, Talajic M. Major depression before and after myocardial infarction: its nature and consequences. Psychosom Med 1996;58:99110.

15. Maeland JG, Havik OE. Psychological predictions of return to work after a myocardial infarction. J Psychosom Res 1987;31:471-81.

16. Trelawny Ross C, Russell O. Social and psychological responses to myocardial infarction: multiple determinants of outcome at six months. J Psychosom Res 1987;31:125-30.

17. Schleifer SJ, Macari-Hinson MM, Coyle DA, et al. The nature and course of depression following myocardial infarction. Arch Intern Med 1989;149:1785-9.

18. Ladwig KH, Kieser M, Konig J, Breithardt G, Borggrefe M. Affective disorders and survival after acute myocardial infarction (results from the post-infarction late potential study). Eur Heart J 1991;12:959-64.

19. Ahern DK, Gorkin L, Anderson JL, et al. Biobehavioral variables and mortality on cardiac arrest in the Cardiac Arrhythmia pilot study (CAPS). Am J Cardiology 1990;66:59-62.

20. Forrester AW, Lipsey JR, Teitelbaum ML, DePaulo JR, Andrzejeweski PL. Depression following myocardial infarction. Int J Psychiatry Med 1992;22:33-46.

21. Stern MJ, Pascale L, Ackerman A. Life adjustment postmyocardial infarction: determining predictive variables. Arch Int Med 1977;137:1680-5.

22. Havik OE, Maeland JG. Patterns of emotional reactions after a myocardial infarction. J Psychosom Res 1990;34:271-85.

23. Strik JJMH, Honig A, Lousberg $\mathrm{R}$, et al. Depression following first myocardial infarction: a prospective study of incidence and relationship with size of infarction. J Psychosom Res; In Press. 
24. Kuijpers PMJC, Strik JJMH, Honig A, et al. Depression after a first myocardial infarction has no influence on mortality. Am J Cardiol; Submitted.

25. Taylor CB, Miller NH, Smith PM. Prevention of depression and anxiety in patients with cardiovascular disease. J Prev Interv Com 1996;13:53-69.

26. Denollet J. Health complaints and outcome assessment in coronary heart disease. Psychosom Med 1994;56:463-74.

27. Arrindell WA, Ettema JHM. Dimensional structure, reliability and validity of the Dutch version of the Symptom Checklist (SCL-90). Ned Tijdschr Psychologie 1981;43:381-7.

28. Denollet J, Sys SU, Stroobant N, Rombouts H, Gillebert TC, Brutsaert DL. Personality as independent predictor of long-term mortality in patients with coronary heart disease. Lancet 1996;347:417-21.

29. Beck AT, Steer RA. Beck Depression Inventory Manual. San Antonio: HarcourtBrace-Jovanovich, 1987:1-25.

30. Herrmann C. International experiences with the hospital anxiety and depression rating scale: a review of validation data and clinical results. J Psychosom Res $1997 ; 1: 17-41$.

31. Strik JJMH, Honig A, Lousberg R, Denollet J. Sensitivity and specificity of observer and self rating questionnaires in depression following myocardial infarction. Psychosomatics 2001;42:423-8.

32. Carney RM, Freedland KE, Jaffe AS. Insomnia and depression prior to myocardial infarction. Psychosom Med 1990;52:603-9.

33. Frasure Smith N, Lespérance F, Talajic M. The impact of negative emotions on prognosis following myocardial infarction: is it more than depression? Health Psychol 1995;14:388-98.

34. Ladwig KH. Factors which provoke post-infarction depression. Results from the post-infarction late potential study. J Psychosom Res 1992;34:723-9.

35. Strik JJMH, Honig A, Lousberg R, Van Os J, Van den Berg E, Van Praag HM. Clinical correlates of depression following first MI. Int J Psych Med 2001;31:27180.

36. Pfohl B, Rederer M, Coryell W, Stangl D. Association between post dexamethasone cortisol levels and blood pressure in depressed inpatients. J Nerv Ment Dis 1991;179:44-7.

37. Wells KB, Golding JM, Burnam MA. Affective, substance abuse, and anxiety disorders in persons with arthritis, diabetes, heart disease, high blood pressure or chronic lung conditions. Gen Hosp Psychiatry 1989;1:320-7.

38. Glassman AH, Stetner F, Walsh BT, et al. Heavy smokers, smoking cessation, and clonidine: results of a double-blind, randomised trial. JAMA 1988;259:2863-6.

39. Wiklund I, Oden A, Sanne H, et al. Prognostic importance of somatic and psychosocial variables after a first myocardial infarction. Am J Epidemiol 1988;128:786-95.

40. Denollet J, Vaes J. Adverse effects of type D personality and younger age on 5year prognosis and quality of life. Circulation 2000;102:630-5.

41. Frasure-Smith N, Lespérance F, Juneau M, Talajic M, Bourassa MG. Gender, depression, and one-year prognosis after myocardial infarction. Psychosom Med 1999;61:26-37.

42. Appels A. Psychological prodromata of myocardial infarction and sudden death. Psychoth Psychosom 1987;34:187-95. 
43. Appels A, Mulder P. Fatigue and heart disease. The association between 'vital exhaustion' and past, present and future coronary heart disease. J Psychosom Res 1989;33:727-38.

44. Appels A. Mental Precursors of myocardial infarction. Br J Psychiatry 1990;156:465-71.

45. Denollet J, Brutsaert DL. Personality, disease severity and the risk of long term cardiac events in patients with a decreased ejection fraction after myocardial infarction. Circulation 1998;97:176-3.

46. Denollet J. Personality and mortality after myocardial infarction. Psychosom Med 1995;57:582-91.

47. Case RB. Living alone after myocardial infarction: Impact on prognosis. JAMA 1992;267:515-9.

48. Ruberman, Weinblatt, Goldberg. Psychosocial influences on mortality after MI. N Eng J Med 1984;311:553-9.

49. Berkman LF. Emotional support and survival after myocardial infarction. A prospective, population based study of the elderly. Ann Intern Med 1992;117:1003-9.

50. Strik JJMH, Honig A, Lousberg R, et al. Efficacy and safety of fluoxetine in the treatment of patients with major depression following first myocardial infarction: findings from a double-blind placebo-controlled trial. Psychosom Med 2000;62:783-9.

51. Shapiro PA, Lespérance F, Frasure-Smith N, et al. An open-label prelimanary trial of sertraline for treatment of major depression after acute myocardial infarction (the SADHAT trial). Am Heart J 1999;137:1100-6.

52. Roose SP, Laghrissi-Thode F, Kennedy JS, et al. Comparison of paroxetine and nortriptyline in depressed patients with ischemic heart disease. JAMA 1998;279:287-91.

53. Roose SP, Glassman AH, Attia E, Woodring S. Comparative efficacy of selective serotonin reuptake inhibitors and tricyclics in the treatment of melancholia. Am J Psychiatry 1994;151:1735-9.

54. Menting JEA, Honig A, Verhey FRJ, et al. Selective serotonin reuptake inhibitors (SSRIs) in the treatment of elderly depressed patients: a qualitative analysis of the literature on their efficacy and side-effects. Int Clin Psychopharm 1996;11:165-75.

55. The Cardiac Arrhythmia Suppression Trial (CAST) Investigators. Prelimanary report: effect of encainide and flecainide on mortality in a randomised trial of arrhythmia suppression after myocardial infarction. N Eng J Med 1989;321:40612.

56. The Cardiac Arrhythmia Suppression Trial (CAST) Investigators. Effect of the antiarrhythmic agent morizine on survival after myocardial infarction. $\mathrm{N}$ Eng J of Med 1992;327:227-33.

57. Glassman AH, Roose SP. Risk of antidepressants in the elderiy: Trycyclic antidepressants and Arrhythmia-Revising risks. Gerontology 1994;40:15-20.

58. Glassman AH, Stage KB. Depressed patients with cardiovascular disease: treatment considerations. CNS. Drugs 1994;1:435-40.

59. Roose SP, Glassman AH. Cardiovascular effects of tricyclic antidepressants in depressed patients with and without heart disease. J Clin Psychiatry 1989;50:1-18.

60. Kantor SJ, Glassman AH, Bigger JT, Perel JM, Giardina EV. The cardiac effects of therapeutic plasma concentrations of imipramine. Am J Psychiatry $1978 ; 135: 534-8$. 
61. Feighner JP. cardiovascular safety in depressed patients: focus on venlafaxine. J Clin Psychiatry 1995;56:574-9.

62. Brymer $\mathrm{C}$, Winograd $\mathrm{CH}$. Fluoxetine in elderly patients: is there a cause of concern? J Am Geriatr Soc 1992;40:902-5.

63. Kellet JM. Fluvoxamine: an antidepressant for the elderly? J Psychiatr Neurosc 1991;42:410-21.

64. Roose SP, Glassman AH, Attia E, Woodring S, Giardina E-GV, Bigger T. Cardiovascular Effects of Fluoxetine in Depressed Patients with Heart Disease. Am J Psychiatry 1998;155:660-5.

65. Strik JJMH, Honig A, Lousberg R, Cheriex EC, Van Praag HM. Cardiac sideeffects of two selective setonine reuptake inhibitors in middle-aged and elderly depressed patients. Int Clin Psychopharm 1998;13:263-7.

66. Avery D, Winokur G. Mortality in depressed patients treated with electroconvulsive therapy and antidepressants. Arch Gen Psychiatry 1976;33:1029-37.

67. Van Melle JP, Van den Brink RHS, Winter JB, et al. Treatment of depression after myocardial infarction and the effects on cardiac prognosis: the Myocardial Infarction and Depression-Intervention Trial (MIND-IT). Spring meeting of the Dutch Association of Cardiology. The Hague, The Netherlands, 2000.

68. The ENRICHD Investigators. Enhancing recovery in coronary heart disease patients (ENRICHD): study design and methods. Am Heart J 2000;139:1-9.

69. Heller RF, Knapp JC, Valenti LA, Dobson AJ. Secondary prevention after acute myocardial infarction. Am J Cardiology 1993;72:759-62.

70. Melville MR, Packham C, Brown N, Weston C, Gray D. Cardiac rehabilitation: socially deprived patients are less likely to attend but patients ineligable for thrombolysis are less likely to be invited. Heart 1999;82:373-7.

71. Cooper A, Lloyd G, Weinman J, Jackson G. Why patients do not attend cardiac rehabilitation: role of intentions and illness beliefs. Heart 1999;82:234-6.

72. Jones DA, West RR. Psychological rehabilitation after myocardial infarction: multicentre randomised controlled trial. BMJ 1996;313:1517-21.

73. Frasure-Smith N, Lespérance F, Prince RH, et al. Randomised trial of homebased psychosocial nursing intervention for patients recovering from myocardial infarction. Lancet 1997;350:473-9.

74. Frasure-Smith N. The Montreal heart attack readjustment trial. J Cardiopulm Rehab 1995;15:103-6. 


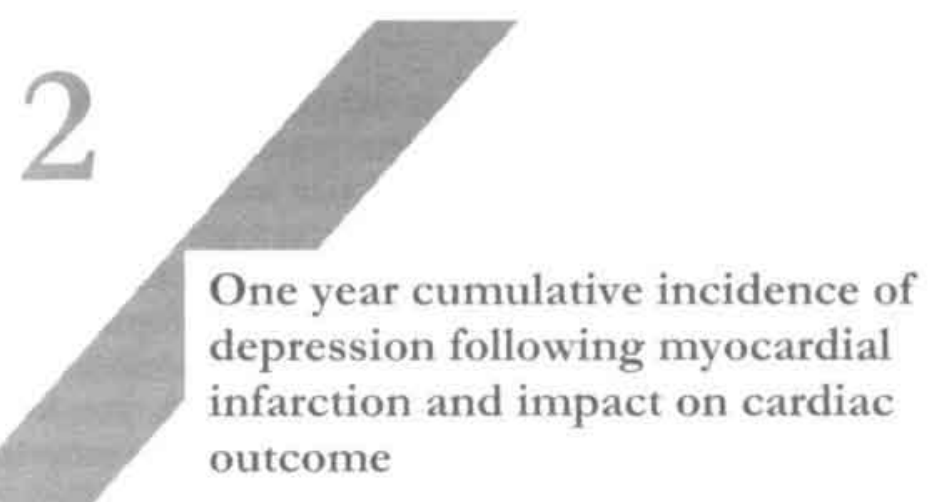




\section{Abstract}

Major depression has been identified as an independent risk factor for increased morbidity and mortality in mixed patients populations with first and recurrent myocardial infarction (MI). The aim of this study was to evaluate whether incidence of major and minor depression is as high in a population with merely first-MI patients as in recurrent MI populations. Furthermore it was evaluated whether in first-MI patients major and minor depression, and depressive symptoms, had an impact on cardiac mortality and morbidity up to 3 years post-MI. A consecutive cohort of 206 patients with a first-MI was included in this study. One month following MI, all patients were interviewed using the Structured Clinical Interview for DSM-IV (SCID-I-R). Three, six, nine and twelve months following MI, patients filled out three psychiatric selfrating scales for depression, the Beck Depression Inventory (BDI), the Hospital Anxiety and Depression Scale (HADS), and the 90-item Symptom Check List (SCL-90). Patients, exceeding a previously defined cut-off value on at least one of these scales, were re-interviewed using the SCID-I-R. The BDI was applied to assess depressive symptoms in relation to cardiac outcome as the SCL-90 and HADS showed similar results. Cardiac outcome was defined as major cardiac event, i.e. death or recurrent MI, and health care consumption, i.e. cardiac re-hospitalization and/or frequent visits at the cardiac outpatient clinic. Depression outcome was assessed from 1 month post-MI up to 1 year post-MI whereas cardiac outcome was assessed between 1 month and 3 years post-MI. A one-year incidence of $26.7 \%$ of major and minor depression was found in first-MI patients. The highest incidence rate for both major and minor depression was found in the first month after MI. Compared with nondepressed patients, depressed patients were younger $(p=0.001)$, female $(p=$ $0.04)$ and were known with a previous depressive episode $(p=0.002)$. Neither major/minor depression nor depressive symptoms significantly predicted major cardiac events, but did predict health care consumption $(p=0.04$ and $p<$ 0.001 respectively). Incidence of major and minor depression is similar in this first-MI patient population as in recurrent MI populations. Major/minor depressive disorder and depressive symptoms predicted neither mortality nor re-infarction.

\section{Reference}

Strik JJMH, Lousberg R, Cheriex EC, Honig A. One year cumulative incidence of depression following myocardial infarction and impact on cardiac outcome. J Psychosom Res 2003; In Press. 


\section{Introduction}

The incidence of depression increases after myocardial infarction (MI). Incidence estimates have varied largely from 15 to $30 \%$ for major depression and another $20 \%$ for minor depression or depressive symptoms '. This wide range can, at least in part, be explained by differences in patient populations, i.e. first versus recurrent MI patients, study design, and diagnostic criteria ${ }^{2,3}$.

Major depression, but also minor depression and depressive symptoms have been identified as independent risk factors for cardiac mortality in hospitalized patients with MI in most ${ }^{47}$, but not all, studies 8.9 . In one study with MI patients, major depression and depressive symptoms predicted cardiac mortality until 12 months post-MI; only the depressive symptoms predicted mortality also until 18 months ${ }^{10}$. In a community-based longitudinal study, the excess cardiac mortality risk was more than twice as high for major depression as for minor depression in subjects with and without cardiac disease at baseline 11 . Studies reporting an increased risk for cardiac mortality found also an increased risk for morbidity, an important indicator for quality of life and health care consumption 47,12 .

In the above mentioned studies, depression rates were assessed in patient populations with both first and recurrent MI. The aim of this study was to evaluate prospectively the cumulative one-year incidence of major and minor depression in a consecutive cohort of patients following a first-MI. Secondly, we evaluated whether in this patient population major and minor depression, and depressive symptoms, predicted cardiac mortality and morbidity up to 3 years post-MI.

\section{Methods}

\section{Patients}

Patients with a diagnosis of first-MI were eligible for the present study. The patients were recruited from the Emergency Aid of the department of cardiology of the Maastricht University Hospital, the Netherlands. This hospital serves both as a local catchement area and a university hospital, as it is the only hospital in the vicinity of Maastricht, serving approximately 180.000 habitants.

MI diagnoses were made by a cardiologist according to the following criteria: clinical picture and electrocardiographic signs typical for an acute $\mathrm{MI}$, and a maximum value of the enzyme aspartate aminotransferase (ASAT max $_{\text {) }}$ of at least $80 \mathrm{U} / \mathrm{L}$ (twice above the upper limit) ${ }^{13}$. Patients were excluded who had a major psychiatric disorder other than affective disorders (e.g. schizophrenia, dementia, or a present psychotic episode). Additionally, patients who were unable to communicate reliably (e.g. because of cognitive dysfunction or not speaking Dutch), lived more than 50 kilometres from the study centre (due to 
problems with follow-up) or with a co-morbid life-threatening illnesses were excluded.

All participants gave written informed consent. The local medical ethics committee approved the study.

\section{Psychiatric assessments}

All patients were followed-up during the first year after MI. One month following MI, all patients were interviewed using the Structured Clinical Interview for DSM-IV (SCID-I-R) ${ }^{14}$. The SCID-I-R is a structured psychiatric diagnostic interview allowing for a diagnosis of present and previous episode of major or minor depression according to DSM-IV 15. Patients were diagnosed with major depression if fulfilling at least one core criterion (depressed mood or loss of interest) and at least four additional criteria (total of 5) with duration of at least two weeks. A diagnosis of minor depression was made in case of one to three instead of four additional criteria. A trained physician (JS) administered all interviews. Demographic data, level of education, living situation, family history of psychiatric disorders, and medication were collected on interview as was history of depression, measured using the SCID-I-R.

At the other 4 time points during the first year of follow up, i.e. three, six, nine and twelve months following MI, patients were asked to fill out three psychiatric self-rating scales for depression. These were the Beck Depression Inventory (BDI) ${ }^{16.17}$, the Hospital Anxiety and Depression Scale (HADS) ${ }^{18}$, and the 90-item Symptom Check List (SCL-90) 19,20. Patients scoring above the general accepted cut-off values of at least one of these scales were reinterviewed using the SCID-I-R. Cut-off values applied for the SCL-90 were $22 / 23$ for men and $27 / 28$ for women, for the BDI $9 / 10$ and for the HADS $7 / 8$ for both the depression and anxiety subscale. Sensitivity of the general accepted cut-offs and predictive validity of the instruments have been reported elsewhere ${ }^{1}$.

The BDI was applied to assess depressive symptoms in relation to cardiac outcome, as the BDI is a well accepted instrument to assess depressive symptoms in MI patients and the other two questionnaires, SCL-90 and HADS, showed similar results.

\section{Cardiac assessments}

Data concerning intervention at the time of the MI, such as thrombolytic therapy or invasive intervention like PTCA (percutaneous transluminal coronary angioplasty), medication (beta-blockers, platelet aggregation inhibitors), and cardiovascular risk factors (smoking, hypercholesterolemia) were taken from patient's records.

Of all patients cardiac outcome was recorded from 1 month up to a 3 years post-MI. Data of cardiac outcome including deaths were collected from patient's records and/or a systematic hospital assessment computer program of the University Hospital. Cardiac outcome was defined as major cardiac events, 
i.e. death or recurrent MI; increased health care consumption as cardiac rehospitalization, and/or $>6$ visits at the cardiac outpatient clinic during followup. Survival and medical data were evaluated over 36 months; psychiatric data only during the first year post-MI.

\section{Analysis}

Cumulative incidence rates were analysed using survival analysis techniques. Missing values concerning depressive status during follow up were filled up as follows. A score "not depressed" was given, if the patient was not depressed at the time of the former assessment and the depressive status at the next screening was validly measured. In all other situations, the case was excluded from further analysis from the time point of the missing value onwards.

To rule out that depressed patients may be at greater risk because of more severe cardiac disease or cardiac risk factors, we evaluated differences in baseline characteristics between depressed and non-depressed patients. Independent t-tests were used to compare continuous variables. Chi-square test was used for all dichotomous variables. Fisher's exact probabilities were calculated if applicable.

For analyses of depression as predictor of a major cardiac event in the followup period, Cox model hazard ratio was used. To select appropriate covariates for statistical control, all baseline variables were dichotomised (at predetermined points). All baseline variables were furthermore tested in univariate Cox regression analysis whether they were significantly related to major cardiac events. Covariates which were expected to predict cardiac outcome (LVEF, thrombolysis and PTCA) were included in the multivariate Cox regression model. In addition, those variables significantly related to death and re-infarction in the univariate Cox regression models were also entered into the multiple Cox regression analysis, followed by the addition of the depression variable. The depression variable was defined as diagnosis of major/minor depression and depressive symptoms (above cut-off BDI of at least one of the screening moments).

For analysis of depression as predictor for increased health care consumption, univariate logistic regressions were firstly performed to determine which baseline variables were significantly related to increased health care consumption. Those variables significantly related to health care consumption, together with LVEF, thrombolysis and PTCA, were entered in multivariate logistic regression analysis, followed by the addition of the depression variable.

For all analyses, the level of statistical significance was set at $\mathrm{p}<0.05$ (twotailed). 


\section{Results}

\section{Patients}

Two-hundred-six MI patients were included into the study, out of a total of 422 consecutive patients. Ninety-six MI patients were excluded $(22.7 \%)$, while 99 eligible patients refused participation $(23.5 \%)$ and an additional $21(5 \%)$ only filled in the questionnaires but refused to attend the interview. Reasons for exclusion of the 96 patients were logistic problems (living to far, moving to another city, foreign language, $n=45$ ), death within the first month post-MI ( $\mathrm{n}$ $=28)$, severe co-morbidity $(\mathrm{n}=20)$, and other major psychiatric disorder $(\mathrm{n}=$ 3)(see Figure 1).

Patients who refused to participate were older $(65.6 \pm 12.2$ versus $59.0 \pm 10.6, \mathrm{p}$ $<0.001)$; also women refused more frequently than men $(47.4 \%(45 / 95)$ versus $21.2 \%(54 / 255) ; \mathrm{p}<0.001)$. In order to test the assumption that depressive feelings and symptoms are predictive of participation refusal, refusers were asked to fill out the SCL-90, BDI, and HADS. One third of the refusing MI patients $(33.3 \% ; \mathrm{n}=33)$ filled out the questionnaires. Mean depression scores of the SCL-90, BDI and the HADS did not significantly differ between refusers and participators. Non-response was $7.5 \%(\mathrm{n}=15)$ at 3 months post-MI increasing to $11.5 \%(\mathrm{n}=24)$ at 12 months post-MI. The reasons for nonresponse are withdrawn consent $(9.5 \%, \mathrm{n}=20)$, death within the first 12 months post-MI $(1 \%, n=2)$, incidental non-response $(1 \%, n=2)$.

One-hundred-fifty-six male and 50 female patients participated. Demographic and cardiovascular characteristics of the total study sample are summarised in Table 1. Mean age was 59 years $(\mathrm{SD}=10.6)$. Of the 206 participants, $18 \%(\mathrm{n}=$ 37) had a history of depression, $11.2 \%(\mathrm{n}=23)$ family history of depression and $18 \%(n=37)$ lived alone. Depressed patients differed from non-depressed patients with regard to age, gender, previous depression and prescription of platelet aggregation inhibitors. Mean LVEF was $53.3 \%(S D=9.93)$. Of the 206 included patients, $14.4 \%(\mathrm{n}=30)$ smoked after the MI, 30.6\% $(\mathrm{n}=63)$ had hypercholesterolemia, $90.8 \%(\mathrm{n}=187)$ were prescribed platelet aggregation inhibitors and $39.8 \%(n=82)$ beta-blockers. 


\section{Table 1}

Demographic and cardiovascular characteristics of the 206 first-MI patients included in the present study.

\begin{tabular}{|c|c|c|c|c|}
\hline & & $\begin{array}{c}\text { Depressed } \\
\text { MI-patients } \\
n=63\end{array}$ & $\begin{array}{c}\text { Non-depressed } \\
\text { MI-patients } \\
n=143\end{array}$ & p-value \\
\hline Gender (female) & & $33.3 \%$ & $20.3 \%$ & 0.040 \\
\hline Age, yrs (mean \pm SD) & $\begin{array}{l}\leq 58 \\
>58\end{array}$ & $\begin{array}{l}49.2 \% \\
50.8 \%\end{array}$ & $\begin{array}{l}26.3 \% \\
72.7 \%\end{array}$ & 0.002 \\
\hline $\begin{array}{l}\text { Level of education } \\
\text { Primary school } \\
\text { Junior secondary vocational education } \\
\text { Senior secondary vocational education } \\
\text { (Pre-)university education }\end{array}$ & & $\begin{array}{l}25.4 \% \\
20.6 \% \\
31.7 \% \\
20.6 \%\end{array}$ & $\begin{array}{l}24.5 \% \\
19.6 \% \\
30.8 \% \\
23.8 \%\end{array}$ & NS \\
\hline Living alone & & $18.0 \%$ & $17.9 \%$ & NS \\
\hline Personal history of depression & & $31.7 \%$ & $13.3 \%$ & 0.002 \\
\hline Family history of depression & & $17.5 \%$ & $8.4 \%$ & 0.060 \\
\hline Post-MI LVEF, \% & $\begin{array}{l}\leq 48 \% \\
>48 \%\end{array}$ & $\begin{array}{l}44.4 \% \\
55.6 \%\end{array}$ & $\begin{array}{l}30.9 \% \\
69.1 \%\end{array}$ & NS \\
\hline PTCA & & $35.5 \%$ & $35.6 \%$ & NS \\
\hline Current smoking & & $9.5 \%$ & $12.6 \%$ & NS \\
\hline Hypercholesterolemia & & $34.9 \%$ & $28.7 \%$ & NS \\
\hline PAI & & $81.0 \%$ & $95.1 \%$ & 0.001 \\
\hline Beta blockers & & $39.7 \%$ & $39.9 \%$ & NS \\
\hline
\end{tabular}

p-value $=2$-tailed level of significance; NS: not statistically significant; LVEF: left ventricular ejection fraction; MI: myocardial infarction; PAI: platelet aggregation inhibitor; PTCA: percutaneous transluminal coronary angioplasty.

\section{Incidence of depression and depressive symptoms}

Between 1 and 12 months post-MI, 30 patients (14.6\%) were diagnosed with major depression and $33(16 \%)$ with minor depression. Of the 63 patients with depression, $9(14.3 \%)$ were known to have major depression within 6 months pre-MI and $2(3.2 \%)$ to have minor depression, assessed by the SCID-I-R section for previous episode of major and minor depression. For analyses of the incidence rates, these 11 patients who were already depressed before the MI were additionally excluded. The one-year cumulative incidence of major and minor depression is then $26.7 \%$. Figure 1 shows the cumulative incidence rates of both major and minor depression during the first year after MI. From Figure 1 the incidence of both major and minor depression can be observed to be highest after the first month $(14.4 \%, \mathrm{n}=28)$. This indicates that depression has an early onset in most cases. Furthermore, the incidence of minor depression was higher from 3 to 12 months than that of major depression. 


\section{Figure 1}

Cumulative incidence of major and minor depression from 1 month to 12 months post-first-MI.

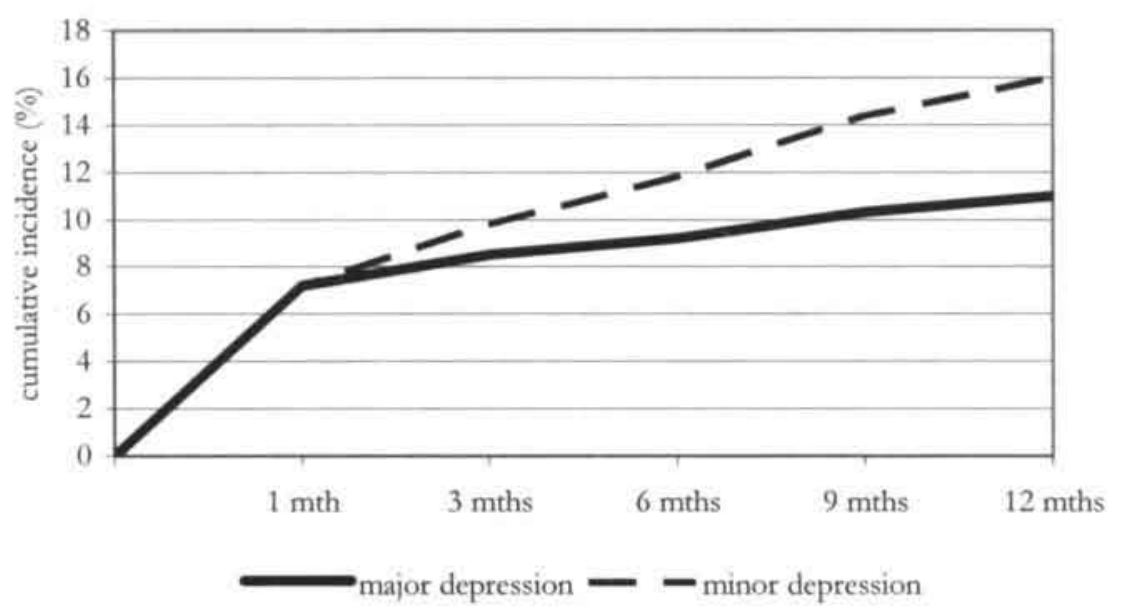

Of the included patients, $52.7 \%(\mathrm{n}=109)$ developed depressive symptoms (scored at least once above the cut-off of the BDI). Incidence rate of depressive symptoms was, as diagnosis of major/minor depression, the highest in the first month post-MI.

\section{Cardiac outcome}

Of the 206 MI patients, 5 patients died and 5 patients had recurrent MI between 1 and 6 months post-MI. Between 6 months and 3 years post-MI, 2 patients died and another 4 underwent a recurrent MI. So, in total, $5.6 \%(n=7)$ of the first-MI patients died between 1 month and 3 years post-MI, and $7.3 \%$ $(n=9)$ developed a recurrent MI. All further analyses were carried out for the total numbers of death and re-infarction between 1 month and 3 years post-MI (Figure 2). 


\section{Figure 2}

Flow-chart showing course of the first-MI patient in relation to major cardiac events.

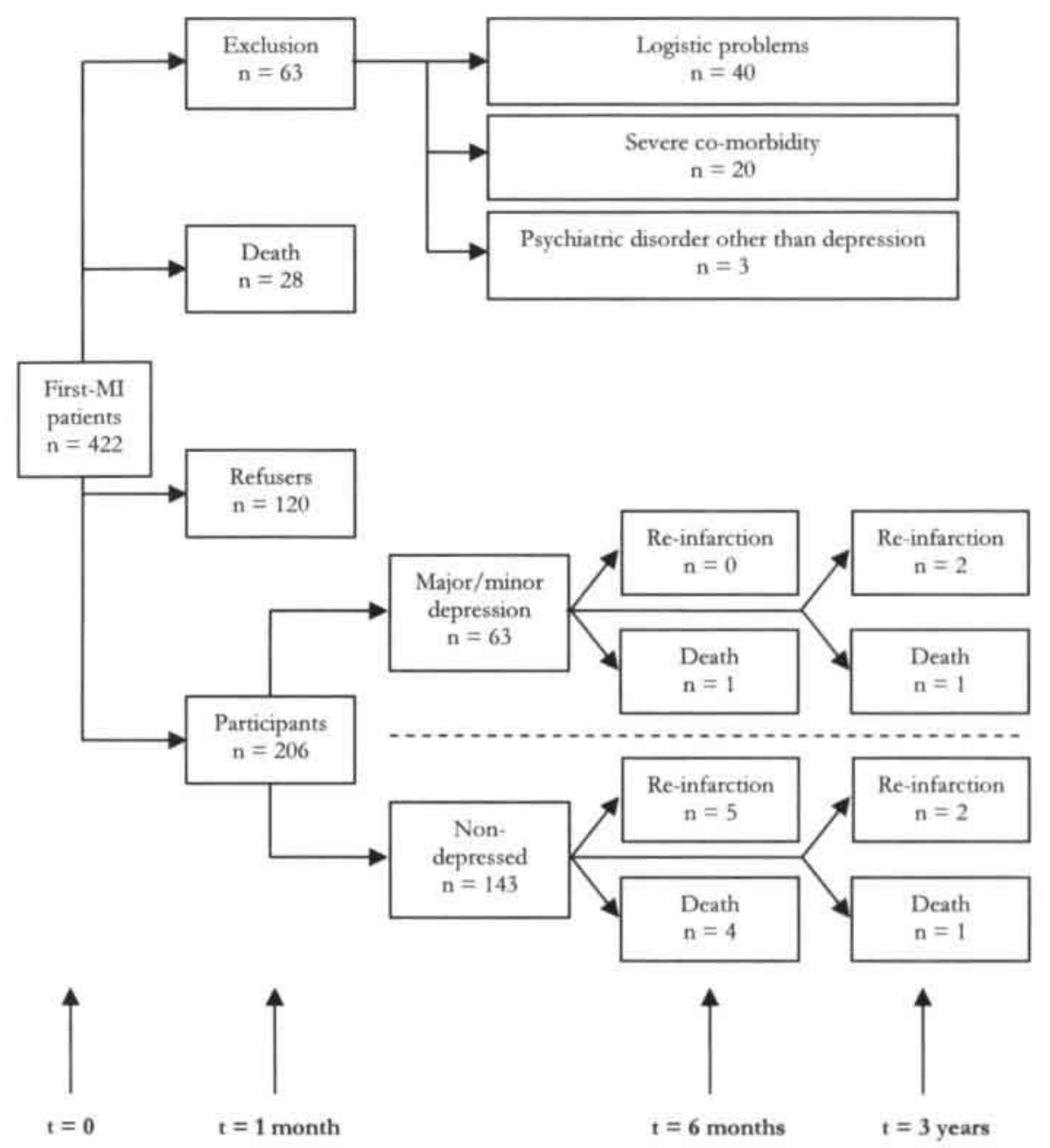

There were no variables predicting major cardiac events in univariate analyses (Table 2). As there was a trend that female gender predicted major cardiac events in the univariate analysis, this variable was included in the multivariate Cox regression model, together with LVEF, PTCA and thrombolysis. In this multivariate model, neither diagnoses of major and minor depression, nor 
depressive symptoms, predicted major cardiac events after correction for gender, LVEF, PTCA and thrombolysis. However, there was a trend for PTCA and female gender to predict major cardiac events up to 3 years post-MI in the Cox regression models with depressive symptoms $(P=0.091$ and 0.146 respectively, Table 3 ).

\section{Table 2}

Relation between demographic/cardiovascular risk factors, and major cardiac events in univariate Cox-regression analyses.

\begin{tabular}{|c|c|c|c|c|}
\hline \multirow[t]{2}{*}{ Univariate models } & & \multicolumn{3}{|c|}{ Major cardiac events (MCE) } \\
\hline & & $\%$ (No) & $\begin{array}{c}\text { Hazard ratio } \\
(95 \% \mathrm{CI})\end{array}$ & p-value \\
\hline Gender & $\begin{array}{r}F \\
M\end{array}$ & $\begin{array}{l}19.4(7 / 36) \\
10.2(9 / 88)\end{array}$ & $2.47(0.92-6.63)$ & 0.073 \\
\hline Age & $\begin{array}{l}\leq 58 \\
>58\end{array}$ & $\begin{array}{c}12.8(11 / 86) \\
13.2(5 / 38)\end{array}$ & $1.12(0.39-3.24)$ & 0.827 \\
\hline LVEF & $\begin{array}{l}\leq 48 \\
>48\end{array}$ & $\begin{array}{l}14.0(7 / 50) \\
12.1(9 / 74)\end{array}$ & $1.36(0.51-3.65)$ & 0.542 \\
\hline Beta blockers & $\begin{array}{l}\text { Yes } \\
\text { No }\end{array}$ & $\begin{array}{l}14.0(7 / 50) \\
12.1(9 / 74)\end{array}$ & $0.81(0.30-2.18)$ & 0.675 \\
\hline PAI & $\begin{array}{l}\text { Yes } \\
\text { No }\end{array}$ & $\begin{array}{c}13.6(15 / 110) \\
7.10(1 / 14)\end{array}$ & $0.48(0.06-3.64)$ & 0.480 \\
\hline Thrombolysis & $\begin{array}{l}\text { Yes } \\
\text { No }\end{array}$ & $\begin{array}{c}7.99(4 / 50) \\
16.4(12 / 73)\end{array}$ & $2.03(0.65-6.29)$ & 0.221 \\
\hline PTCA & $\begin{array}{l}\text { Yes } \\
\text { No }\end{array}$ & $\begin{array}{c}6.50(3 / 46) \\
16.9(13 / 77)\end{array}$ & $2.35(0.67-8.26)$ & 0.183 \\
\hline Current Smoking & $\begin{array}{l}\text { Yes } \\
\text { No }\end{array}$ & $\begin{array}{c}10.5(2 / 19) \\
13.3(14 / 105)\end{array}$ & $1.01(0.23-4.46)$ & 0.985 \\
\hline Hypercholesterolemia & $\begin{array}{l}\text { Yes } \\
\text { No }\end{array}$ & $\begin{array}{c}15.8(6 / 38) \\
11.6(10 / 86)\end{array}$ & $1.34(0.49-3.70)$ & 0.565 \\
\hline Previous depression & $\begin{array}{l}\text { Yes } \\
\text { No }\end{array}$ & $\begin{array}{c}5.9(1 / 17) \\
14.0(15 / 107)\end{array}$ & $0.61(0.14-2.67)$ & 0.507 \\
\hline Family history of depression & $\begin{array}{l}\text { Yes } \\
\text { No }\end{array}$ & $\begin{array}{c}9.50(2 / 21) \\
13.6(14 / 103)\end{array}$ & $0.95(0.35-2.52)$ & 0.910 \\
\hline Major/minor depression & $\begin{array}{l}\text { Yes } \\
\text { No }\end{array}$ & $\begin{array}{c}12.5(4 / 32) \\
13.0(12 / 92)\end{array}$ & $1.10(0.36-3.42)$ & 0.867 \\
\hline$\geq$ Cut-off BDI & $\begin{array}{l}\text { Yes } \\
\text { No }\end{array}$ & $\begin{array}{l}11.1(9 / 81) \\
12.1(4 / 33)\end{array}$ & $1.02(0.32-3.32)$ & 0.970 \\
\hline
\end{tabular}

$95 \%$ CI $=95 \%$ confidence interval; $\mathrm{p}$-value $=2$-tailed level of significance; BDI: Beck Depression Inventory; LVEF: left ventricular ejection fraction; PAI: platelet aggregation inhibitor; PTCA: percutaneous transluminal coronary angioplasty. 
Table 3

Impact of major and minor depression, corrected for gender and LVEF, on major cardiac events in multivariate Cox-regression analysis.

\begin{tabular}{l|c|c}
\hline & \multicolumn{2}{|c}{ Major cardiac events (MCE) } \\
\cline { 2 - 3 } & Exp (95\%CI) & p-value \\
\hline Major/Minor depression & $0.88(0.26-2.93)$ & 0.832 \\
Female Gender & $1.93(0.68-7.26)$ & 0.219 \\
Age $>58$ years & $0.75(0.24-2.35)$ & 0.624 \\
LVEF $\leq 48 \%$ & $0.90(0.32-2.52)$ & 0.836 \\
PTCA & $2.82(0.79-10.1)$ & 0.110 \\
Thrombolysis & $2.22(0.68-7.26)$ & 0.188 \\
Current smoking & $1.37(0.29-6.41)$ & 0.693 \\
\hline$\geq$ cut-off BDI & $0.56(0.16-2.03)$ & 0.381 \\
Female gender & $2.97(0.70-10.6)$ & 0.146 \\
Age $>58$ years & $0.53(0.15-1.82)$ & 0.313 \\
LVEF $\leq 48 \%$ & $1.04(0.31-3.52)$ & 0.951 \\
PTCA & $3.76(0.81-17.5)$ & 0.091 \\
Thrombolysis & $2.73(0.70-10.6)$ & 0.146 \\
Currost ssmobing & $3.09(0.37-363)$ & 0.299 \\
\hline
\end{tabular}

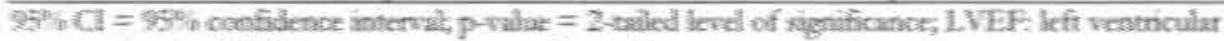

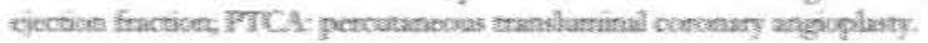

Forty-three percent $(\mathrm{s}=\mathrm{32})$ of whe included MI patients had a higher than sverage health cate consumption, ife. visits at the outpatient cardiac clinic and ex-bospitalizations due to candiac events. None of the demographic or candiorascular sariables predicted bealth care consamption (Table 4). However, is there was a trend that current smoking and gownger age were related to increased beslth care consurreption, they were included in the multivariate lagitac regression model. In the multivaniate analyses (Table 5), diagnosis of both major and minos depression ( $(\mathrm{p}=0.05$ ) as well as depressive symptoms (p $<$ a.0i1) predicted bealth cart consumption. Men had a bigher health care consumption than women $(p=0$ ( 013$)$. 


\section{Table 4}

Relation between demographic/cardiovascular risk factors and health care consumption in univariate logistic regression analyses.

\begin{tabular}{|c|c|c|c|c|}
\hline \multirow[t]{2}{*}{ Univariate models } & & \multicolumn{3}{|c|}{ Health care consumption (HCC) } \\
\hline & & $\%($ No) & $\begin{array}{c}\text { Hazard ratio } \\
(95 \% \mathrm{CI})\end{array}$ & p-value \\
\hline Gender & $\begin{array}{c}\mathrm{F} \\
\mathrm{M}\end{array}$ & $\begin{array}{c}32.6(14 / 43) \\
46.3(68 / 147)\end{array}$ & $0.56(0.27-1.15)$ & 0.113 \\
\hline Age & $\begin{array}{l}\leq 58 \\
>58\end{array}$ & $\begin{array}{c}50.8(32 / 108) \\
39.4(50 / 82)\end{array}$ & $0.63(0.34-1.16)$ & 0.136 \\
\hline LVEF & $\begin{array}{l}\leq 48 \\
>48\end{array}$ & $\begin{array}{c}46.3(25 / 67) \\
37.3(57 / 123)\end{array}$ & $0.78(0.39-1.56)$ & 0.490 \\
\hline Beta blockers & $\begin{array}{l}\text { Yes } \\
\text { No }\end{array}$ & $\begin{array}{c}43.2(32 / 74) \\
43.1(50 / 116)\end{array}$ & $0.99(0.55-1.79)$ & 0.985 \\
\hline PAI & $\begin{array}{l}\text { Yes } \\
\text { No }\end{array}$ & $\begin{array}{c}44.8(77 / 172) \\
27.8(5 / 18)\end{array}$ & $0.48(0.16-1.39)$ & 0.475 \\
\hline Thrombolysis & $\begin{array}{l}\text { Yes } \\
\text { No }\end{array}$ & $\begin{array}{c}42.0(34 / 81) \\
44.4(48 / 108)\end{array}$ & $1.11(0.62-1.98)$ & 0.735 \\
\hline PTCA & $\begin{array}{l}\text { Yes } \\
\text { No }\end{array}$ & $\begin{array}{c}39.7(27 / 68) \\
45.5(55 / 121)\end{array}$ & $1.27(0.69-2.31)$ & 0.444 \\
\hline Current Smoking & $\begin{array}{l}\text { Yes } \\
\text { No }\end{array}$ & $\begin{array}{c}30.4(7 / 23) \\
44.4(75 / 167)\end{array}$ & $0.54(0.21-1.73)$ & 0.194 \\
\hline Hypercholesterolemia & $\begin{array}{l}\text { Yes } \\
\text { No }\end{array}$ & $\begin{array}{c}42.4(25 / 59) \\
43.5(57 / 131)\end{array}$ & $0.95(0.52-1.78)$ & 0.883 \\
\hline Previous depression & $\begin{array}{l}\text { Yes } \\
\text { No }\end{array}$ & $\begin{array}{c}48.6(18 / 37) \\
41.8(64 / 153)\end{array}$ & $1.32(0.64-2.71)$ & 0.453 \\
\hline Family history of depression & $\begin{array}{l}\text { Yes } \\
\text { No }\end{array}$ & $\begin{array}{l}42.5(40 / 94) \\
43.8(42 / 96)\end{array}$ & $0.95(0.54-1.70)$ & 0.868 \\
\hline Major/minor depression & $\begin{array}{l}\text { Yes } \\
\text { No }\end{array}$ & $\begin{array}{c}51.7(31 / 60) \\
39.2(51 / 130)\end{array}$ & $1.66(0.90-3.07)$ & 0.109 \\
\hline$\geq$ Cut-off BDI & $\begin{array}{l}\text { Yes } \\
\text { No }\end{array}$ & $\begin{array}{c}59.7(43 / 72) \\
33.3(36 / 118)\end{array}$ & $2.68(1.45-4.96)$ & 0.002 \\
\hline
\end{tabular}

$95 \% \mathrm{CI}=95 \%$ confidence interval; $\mathrm{p}$-value $=2$-tailed level of significance; $\mathrm{BDI}$ : Beck Depression Inventory; LVEF: left ventricular ejection fraction; PAI: platelet aggregation inhibitor; PTCA: percutaneous transluminal coronary angioplasty. 


\section{Table 5}

Impact of major and minor depression, corrected for gender and LVEF, on high health care consumption in multivariate logistic regression analysis.

\begin{tabular}{l|c|c}
\hline \multirow{2}{*}{} & \multicolumn{2}{|c}{ Health care Consumption (HCC) } \\
\cline { 2 - 3 } & Exp (95\% CI) & p-value \\
\hline Major/Minor depression & $1.98(1.0-3.93)$ & 0.050 \\
Fernale Gender & $0.53(0.25-1.16)$ & 0.112 \\
Age $>58$ years & $0.79(0.41-1.55)$ & 0.50 \\
LVEF $\leq 48 \%$ & $1.50(0.79-2.83)$ & 0.221 \\
PTCA & $1.29(0.69-2.43)$ & 0.431 \\
Thrombolysis & $1.25(0.67-2.32)$ & 0.487 \\
Current Smoking & $1.62(0.61-4.31)$ & 0.333 \\
\hline$\geq$ cut-off BDI & $3.75(1.86-7.58)$ & $<0.001$ \\
Female gender & $0.334(0.14-0.79)$ & 0.013 \\
Age $>58$ years & $0.82(0.41-1.61)$ & 0.554 \\
LVEF $\leq 48 \%$ & $1.47(0.75-2.89)$ & 0.260 \\
PTCA & $1.10(0.56-2.16)$ & 0.775 \\
Thrombolysis & $1.15(0.59-2.24)$ & 0.679 \\
Current smoking & $1.93(0.69-5.41)$ & 0.210 \\
\hline
\end{tabular}

$95 \% \mathrm{CI}=95 \%$ confidence interval; $\mathrm{P}=2$-tailed level of significance; $\mathrm{LVEF}$; left ventricular ejection fraction; PTCA: percutaneous transluminal coronary angioplasty.

In the models in which the impact of major and minor depression on cardiac prognosis was analysed separately, depression (major or minor) did neither predict major cardiac events nor health care consumption significantly.

\section{Discussion}

In our study, we choose to include only patients following first-MI as these patients were regarded as healthy prior to their MI and normally functioning. In patients with recurrent MI, non-MI-specific factors may play an important role in the relationship between depression and MI. Non-specific depressogenic factors, such as disability or handicap leading to reduced professional and social activities, are related to chronicity of a disease, irrespective of its origin. These non-specific factors have shown strong associations with development of depressive symptoms and post-MI survival. As we aimed to rule out as many non-specific depressogenic factors as possible, to prevent bias occurring with specific factors in the relationship of depression and cardiac prognosis, only patients with first-MI were selected for this study. 
The one-year cumulative incidence rate of major and minor depression in this cohort of first-MI patients was $26.7 \%(n=52)$, with the highest incidence rate of both major and minor depression one month post-MI. Of the included patients, $52.7 \%(\mathrm{n}=109)$ developed depressive symptoms; the cumulative incidence was again the highest in the first month $(25 \%, \mathrm{n}=49)$.

Neither major nor minor depression predicted major cardiac events within the first three years post-MI. However, major and minor depression predicted significantly health care consumption during this period of time. In addition, male gender predict increased health care consumption, whereas there was a trend that female gender predicted major cardiac events.

\section{Depression incidence}

The one-year cumulative incidence rate of major and minor depression of $26.7 \%$ found in this study is similar to numbers found in others studies, screening patients with first and recurrent MI 4,5,7,21-23. The fact that depression incidence was the highest in the first month post-MI is in line with the study by Lesperance et al., who reported that the risk for post-MI depression is the highest in-hospital and during the early post-discharge period ${ }^{10}$.

\section{Impact of depression on cardiac outcome}

Major/minor depression, nor depressive symptoms, had an impact on mortality and recurrent MI in first-MI patients. In contrast, several previous studies found depression to be a risk factor of increased cardiac mortality 5,7,11,21,24. This difference in impact of depression may be due to several factors.

First, in the present study mortality rate was very low. The 6-months mortality was $2.4 \%(n=5)$, compared to the $5.4 \%(n=12)$ of the study by FrasureSmith 5 . Prognosis of patients with MI has strongly improved in the last decade 25. Both in the United States as in the Netherlands 3-year-mortality due to cardiovascular disease and the risk of re-infarction has decreased 26,27. This improvement has been attributed to a better treatment of MI and better secondary prevention.

Second, as only first-MI patients were included in our study, LVEF scores were higher than those in the study by Frasure-Smith (53.3\% versus $43.9 \%$ respectively). The impact of depression on cardiac mortality may be related to baseline cardiac status ${ }^{28}$. Depressive symptoms may be related to CHD risk in older women because of their correlation with impaired physical condition ${ }^{29}$. These factors, first-MI, LVEF and impaired physical condition, may have attenuated the lack of prognostic capability of major depression with regard to mortality ${ }^{30}$.

Third, bias may have occurred as $23 \%$ of the individuals, who were mostly older women, refused to participate. In addition, because of the difficulties of fulfilling DSM-IV duration criterion of two weeks in the immediate period post-MI, patients in the present study were not screened or interviewed earlier than one month post-MI by which time $28 \%$ of the cohort had died. 
The number of clinical and prospective studies failing to find an association between depression and mortality is increasing $8,26,31-31$. In contrast to FrasureSmith et al. who reported an odds ratio of 4.59 for patients with post-MI depression with respect to the risk of cardiac death within 6 months post-MI, more recent studies showed a more differentiated picture with odds ratios between 2.3-3.0 11,36,37. In sum, from more recent studies may be concluded that the first results regarding the relation between depression and post-MI prognosis has to be modified.

In the present study, cardiac dysfunction as measured by LVEF had no relation with occurrence of depression. This is in line with other researcher reporting that severity of cardiac disorder measured by LVEF, Holter registration or angiography is unrelated to development of major depression ${ }^{47}$. All studies using enzyme release as measure for severity of MI also found no relationship with development of depression. The lack of any relation between severity of cardiac disorder and depression runs counter to the intuitive notion that patients with a more severe $\mathrm{MI}$ will develop more severe handicap or are more disabled, a condition which intuitively may trigger depression. As yet we can not explain this absence of correlation.

Although mortality will remain a primary outcome measure, it is also important to focus on other outcome measures like use of health care consumption. In contrast to cardiac mortality, health care consumption was predicted by major/minor depression and depressive symptoms in our study. It has been previously reported that depression may be a stronger risk factor for cardiac morbidity than mortality ${ }^{38}$. Furthermore, in the present study it was found that the risk for increased health care consumption was higher in patients with depressive symptoms $(\mathrm{OR}=3.75)$ than among patients who met DSM-IV criteria for depressive disorder $(\mathrm{OR}=1.98)$. This could mean that not only depressive disorder, but also depressive symptoms are predictors for poor cardiac outcome. Recognition and treatment of major and minor depression and of depressive symptoms is thus warranted. Not only to increase quality of life but also to prevent high health care costs.

A methodological flaw may be the usage of the BDI; this questionnaire has, apart from specific mood items, a high number of items related to physical symptoms which may also be attributed to cardiac disease. It may be that the BDI was acting as a proxy marker of the severity of cardiac symptoms, thus resulting in increased health care utilisation. This notion is counteracted by the fact that correlations between heart function, measured by LVEF, and BDI scores were low (Pearson correlation $=-0.08$ ). Also, similar findings were found with the other questionnaires used in this study, i.e. the SCL-90 and HADS.

In the present study male gender is a predictor of increased health care consumption, whereas there was a trend that female gender was related to major cardiac events. This finding may be explained by gender differences in this cohort for cardiac risk factors. Indeed, we found, that female patients were 
more at risk for developing depressive symptoms $(p=0.04)$, were significantly older than the male patients $(p=0.02)$, and could not stop smoking after MI ( $=0.02$ ).

While the present results agree with previous research, some limitations have to be considered. First, the numbers of major and minor depressed cases were relatively small to evaluate effect of major and minor depression on cardiac prognosis separately. Although this is in line with others, approximately one in three eligible patients refused to participate in the study, with women and elderly being the most likely to refuse ${ }^{5,39}$.

In conclusion, incidence of major and minor depression after first-MI is as high as in multiple MI populations. In a population with merely patients with firstMI, diagnosis of neither major/minor depression nor depressive symptoms had an impact on cardiac mortality or re-infarction up to 3 years post-MI. Impact of depression on cardiac mortality may be smaller than firstly assumed. However, both major/minor depression and depressive symptoms predicted health care consumption in first-MI patients. The impact of minor depression and depressive symptoms on high health care consumption seemed to be as high as that of major depression. Therefore, also for cardiological prognostic purposes, it remains important to recognise and treat depressed MI patients. For a better understanding of the degree of risk that depression plays in mortality following first-MI, larger studies controlling for severity of heart disease and other cardiovascular risk factors are needed and ongoing (MIND-IT ${ }^{40}$ ).

\section{References}

1. Strik JJMH, Honig A, Lousberg R, Denollet J. Sensitivity and specificity of observer and self rating questionnaires in depression following myocardial infarction. Psychosom 2001; 42: 423-8.

2. Strik JJMH, Honig A, Maes M. Depression and myocardial infarction: Relationship between heart and mind. Progr Neuropsychopharm Biol Psychiatry 2001; 25: 87992.

3. Musselman DL, Evans DL, Nemeroff CB. The relationship of depression to cardiovascular disease. Arch Gen Psychiatry 1998; 55: 580-92.

4. Frasure-Smith N, Lespérance F, Talajic M. Depression and 18 months prognosis after myocardial infarction. Circulation 1995; 91: 999-1005.

5. Frasure-Smith N, Lespérance F, Talajic M. Depression following myocardial infarction: impact on 6-months survival. JAMA 1993; 270: 999-1005.

6. Ahern DK, Gorkin L, Anderson JL, Tierney C, Hallstrom A, Ewart C, Capone RJ, Schron E, Kornfeld D, Herd JA. Biobehavioral variables and mortality on cardiac arrest in the Cardiac Arrhythmia pilot study (CAPS). Am J Cardiology 1990; 66: 59 62.

7. Ladwig KH, Kieser M, Konig J, Breithardt G, Borggrefe M. Affective disorders and survival after acute myocardial infarction (results from the post-infarction late potential study). Eur Heart J 1991; 12: 959-64. 
8. Lane D, Carroll D, Ring C, Beevers DG, Lip GY. Mortality and quality of life 12 months after myocardial infarction: effects of depression and anxiety. Psychosom Med 2001; 63: 221-30.

9. Mayou RA, Gill D, Thompson DR, Day A, Hicks N, Volmink J, Neil A. Depression and anxiety as predictors of outcome after myocardial infarction. Psychosom Med 2000; 62: 212-9.

10. Lespérance F, Frasure-Smith N, Talajic M. Major depression before and after myocardial infarction: its nature and consequences. Psychosom Med 1996; 58: 99. 110.

11. Penninx BWJH, Beekman ATF, Honig A, Deeg DJH, Schoevers RA, van Eijk JTM, van Tilburg W. Depression and cardiac mortality: results from a community-based longitudinal study. Arch Gen Psychiatry 2001; 58: 221-7.

12. Ladwig KH. Factors which provoke post-infarction depression. Results from the post-infarction late potential study. J Psychosom Res 1992; 34: 723-9.

13. Pasternak RC, Braunwald E, Sobel RE. In: Heart disease: a textbook of cardiovascular medicine. Braunwald E, ed. Saunders WB Compagny, Philadelphia 1992: 1200-91.

14. First MB, Spitzer RL, Gibbon M, Williams JB. Structured Clinical Interview for DSM-IV Axis I disorders-Patient Edition (SCID-I/P, Version 2.0). New York: Biometrics Research Department, New York State Psychiatric Institute 1995.

15. The American Psychiatric Association. Diagnostic and statistic manual of mental disorders IV. American Psychiatric Association, Washington DC 1994.

16. Beck AT, Ward CH, Mendelson M, Mock J, Erbaugh J. An inventory for measuring depression. Arch Gen Psychiatry 1961; 4: 561-71.

17. Richter P, Werner J, Heerlein A, Kraus A, Sauer H. On the validity of the Beck Depression Inventory. Psychopathology 1998; 31: 160-8.

18. Herrmann C. International experiences with the hospital anxiety and depression rating scale: a review of validation data and clinical results. J Psychosom Res 1997; 1: $17-41$.

19. Derogatis LR, Lipman RS, Covi L. SCL-90: an outpatient psychiatric rating scaleprelimanary report. Psychopharm Bull 1973; 9: 13-27.

20. Arrindell WA, Ettema JHM. Dimensional structure, reliability and validity of the Dutch version of the Symptom Checklist (SCL-90). Ned Tijdschr Psychologie 1981; 43: 381-7.

21. Anda R, Williamson D, Jones D, Macera C, Eaker E, Glassman A, Marks J. Depressed affect, hopelessness, and the risk of ischemic heart disease in a cohort of U.S. adults. Epidemiology 1993; 4: 285-94.

22. Schleifer SJ, Macari-Hinson MM, Coyle DA, Slater WR, Kahn M, Gorlin R, Zucker HD. The nature and course of depression following myocardial infarction. Arch Intern Med 1989; 149: 1785-9.

23. Carney RM, Freedland KE, Jaffe AS. Insomnia and depression prior to myocardial infarction. Psychosom Med 1990; 52: 603-9.

24 Barefoot JC, Schroll M. Symtomps of depression, acute myocardial infarction, and total mortality in a community sample. Circulation 1996; 93: 1976-80.

25. Widdershoven J, Vreede de -Swagemakers J. Acute coronary syndromes in the Maastricht area. University Press Maastricht, Maastricht, The Netherlands 1997.

26. McGovern PG, Jacobs DR, Jr., Shahar E, Arnett DK, Folsom AR, Blackburn H, Luepker RV. Trends in acute coronary heart disease mortality, morbidity, and 
medical care from 1985 through 1997: the Minnesota heart survey. Circulation 2001; 104: 19-24.

27. Chen J, Radford MJ, Wang Y, Marciniak TA, Krumholz HM. Do 'America's best hospitals' perform better for acute myocardial infarction? N Engl J Med 1999; 340: 286-92.

28. Glassman AH, Shapiro PA. Depression and the course of coronary artery disease. Am J Psychiatr 1998; 155: 4-11.

29. Mendes de Leon CF, Krumholz HM, Seeman TS, Vaccarino V, Williams CS, Kasl SV, Berkman LF. Depression and the risk of coronary heart disease in elderly men and women. Arch Int Medicine 1998; 158: 2341-8.

30. Jiang W, Alexander J, Christopher E, Kuchibhatla M, Gaulden LH, Cuffe MS, Blazing MA, Davenport C, Califf RM, Krishnan RR, O'Connor CM. Relationship of depression to increased risk of mortality and rehospitalization in patients with congestive heart failure. Arch Intern Med 2001; 161: 1849-56.

31. Kaufmann MW. Depression, hostility, gender, and myocardial infarction. Abstract from the Annual American Psychiatric Association Meeting, ILLinois 2000.

32. Wulsin LR, Vaillant GE, Wells VE. A systematic review of the mortality of depression. Psychosom Med 1999; 61: 6-17.

33. Lane D, Carroll D, Ring C, Beevers DG, Lip GY. Effects of depression and anxiety on mortality and quality-of-life 4 months after myocardial infarction. I Psychosom Res 2000; 49: 229-38.

34. Lane D, Carroll D, Ring C, Beevers DG, Lip GY. Do depression and anxiety predict recurrent coronary events 12 months after myocardial infarction? QJM 2000; 93: 739-44.

35. Druss BG, Bradford WD, Rosenheck RA, Radford MJ, Krumholz HM. Quality of medical care and excess mortality in older patients with mental disorders. Arch Gen Psychiatry 2001; 58: 565-72.

36. Irvine J, Basinski A, Baker B, Jandciu S, Paquette M, Cairns J, Connolly S, Roberts R, Gent M, Dorian P. Depression and risk of sudden cardiac death after acute myocardial infarction: testing for the confounding effects of fatigue. Psychosom Med 1999; 61: 729-37.

37. Welin C, Lappas G, Wilhelmsen L. Independent importance of psychosocial factors for prognosis after myocardial infarction. J Intern Med 2000; 247: 629-39.

38. Creed $\mathrm{F}$. The importance of depression following myocardial infarction. Heart $1999 ; 82 ; 406-8$.

39. McGee R, Stanton WR. Sources of distress among New Zealand adolescents. J Child Psychol Psychiatry 1992; 33: 999-1010.

40. Van Melle JP, van den Brink RHS, Winter JB, Spijkerman TA, Honig A, Schene AH, Crijns HJGM, Ormel J. Treatment of depression after myocardial infarction and the effects on cardiac prognosis: the Myocardial Infarction and DepressionIntervention Trial (MIND-IT). Abstract from the Spring meeting of the Dutch Association of Cardiology, The Hague, The Netherlands 2000. 


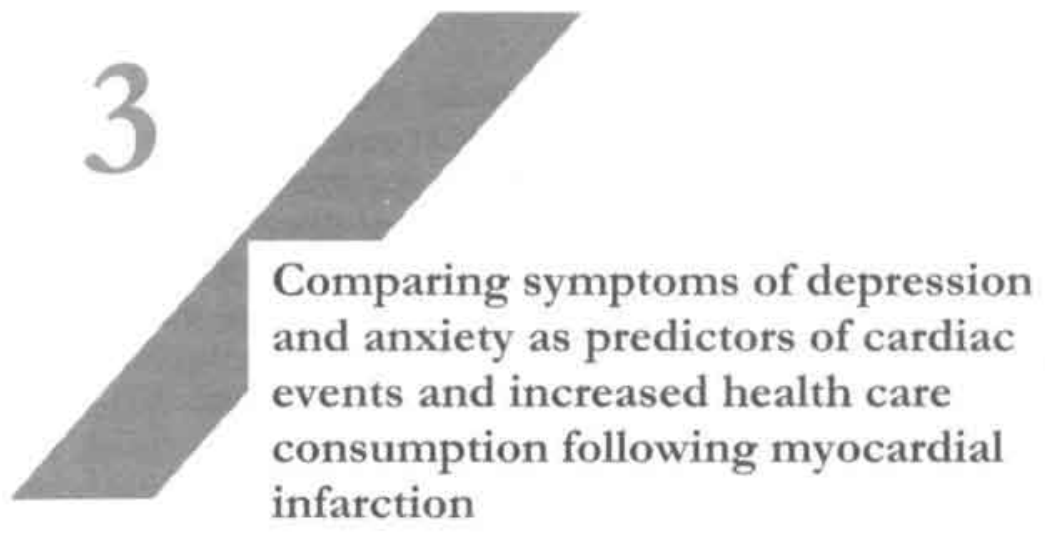




\section{Abstract}

Depressive symptoms have been related to mortality post myocardial infarction (MI) and health care consumption but little is known about the effect of anxiety. We wanted to examine whether depressive symptomatology is a better predictor of prognosis than anxiety, and the effect of emotional distress on health care consumption. Subjects were 318 men (mean age $=58.0$ years) who completed the depression, anxiety and hostility scales from the 90 item Symptom Check List after they survived a first MI. After an average follow-up of 3.4 years, there were 25 cardiac events (fatal or non-fatal MI). Both symptoms of depression $(\mathrm{HR}=2.32 ; 95 \% \mathrm{CI}=1.04-5.18 ; \mathrm{p}=0.039)$ and anxiety $(\mathrm{HR}=3.01 ; 95 \% \mathrm{CI}=1.20-7.60 ; \mathrm{p}=0.019)$ were associated with cardiac events, adjusting for age, LVEF and use of antidepressants. However, a multivariate analysis including all three negative emotions indicated that symptoms of anxiety $(\mathrm{HR}=2.79 ; 95 \% \mathrm{CI}=1.11-7.03 ; \mathrm{p}=0.029)$, explained away the relation between depressive symptoms and cardiac events. Regarding health care consumption, anxiety (OR $=2.00 ; 95 \% \mathrm{CI}=1.24-3.22 ; \mathrm{p}=0.005)$, but not depression/hostility, was a predictor of cardiac re-hospitalizations and frequent visits at the cardiac outpatient clinic. Symptoms of depression and anxiety were associated with cardiac events. Anxiety was an independent predictor of both cardiac events and increased health care consumption, and accounted for the relation between depressive symptoms and prognosis. Symptoms of anxiety need to be considered in the risk stratification and treatment of post-MI patients.

\section{Reference}

Strik JJMH, Denollet J, Lousberg R, Honig A. Comparing symptoms of depression and anxiety as predictors of cardiac events and increased health care consumption following myocardial infarction. JACC 2003 ; In Press. 


\section{Introduction}

Negative emotions, such as depression and anxiety, have been related to coronary artery disease (CAD) ${ }^{1-3}$, and poor prognosis post-myocardial infarction (MI) ${ }^{4}$. Possible mechanisms linking negative emotions to post-MI include increased vulnerability to arrhythmias as a result of increased sympathic tone ${ }^{5}$, and increased platelet aggregation ${ }^{6}$. It is unclear whether treatment of depression may lead to a decrease in post-MI mortality ${ }^{7}$, but the findings of a recent study suggest that reducing emotional stress may improve prognosis 8 .

Depression is frequently studied and considered as a pathogenic factor in postMI patients 9-12. Minor depression and depressive symptoms also have a negative effect on prognosis in cardiac patients ${ }^{13}$. The increased risk of cardiac events may extend to patients with symptoms of negative affect, other than depression 14,15 . In healthy populations, anxiety ${ }^{1-3}$ and anger 16 have been associated with the incidence of cardiac events, but less is known about the role of anxiety and anger in post-MI patients. Some studies found that symptoms of depression and anxiety 17.18 or anxiety alone ${ }^{19}$ did not predict mortality in MI patients, but did predict quality of life among those MI patients who lived to 12 months. Other studies reported that both depression and anxiety independent of each other predicted cardiac events ${ }^{20}$ or CAD ${ }^{21}$.

However, there has been a tendency to focus on only one negative emotion at a time ${ }^{15}$. Hence, the question remains whether symptoms of depression play a specific role in prognosis of post-MI patients, or whether symptoms of other negative emotions such as anxiety and anger have a comparable adverse effect on recovery post-MI. In psychiatric patients, anxiety and depression frequently co-occur, and co-morbid anxiety has been associated with greater severity of depressive disorder and poor response to anti-depressive treatment 22-27. In depressed post-MI patients, evidence suggests that co-morbid anxiety, rather than pure depression, may account for reduced heart rate variability as a cardiotoxic factor ${ }^{28}$. Of note, pharmacological treatment of anxiety may also decrease the risk of major depression ${ }^{27}$.

Most studies investigating the relationship between psychological factors and prognosis post-MI focus on mortality and new cardiac events ${ }^{29-31}$. Negative emotions may also have an adverse effect on other, 'softer' endpoints, such as angina, quality of life and incomplete recovery ${ }^{32}$. The effect of depression on angina and re-hospitalization is even more strongly established than its effect on mortality ${ }^{33}$. This is reason for concern, as adverse outcomes also represent increased health care costs ${ }^{34}$.

The purpose of the present study was twofold. First, we wanted to examine whether depression is a better predictor for incomplete recovery post-MI than anxiety. Second, we wanted to examine the effect of emotional distress not only on major cardiac events, but also on re-hospitalization and increased health care consumption. 


\section{Methods}

\section{Patients}

Between May 1994 and September 1999, a total of 407 eligible male patients were admitted to the First Heart Aid of the Academic Hospital of Maastricht (azM) with an acute MI. Inclusion criteria of the present study were male gender, first MI, clinical picture and electrocardiographic signs typical for an acute MI, and a maximum value of the enzyme aspartate aminotransferase (ASAT $\mathrm{T}_{\max }$ ) of at least $80 \mathrm{U} / \mathrm{L}$ (twice above the upper limit) ${ }^{35}$. Patients were excluded who had a major psychiatric disorder other than affective disorders (e.g. schizophrenia, dementia, or a present psychotic episode). Additionally, patients who were unable to communicate reliably (e.g. because of cognitive dysfunction or not speaking Dutch) or with a co-morbid life-threatening disease were excluded. The local ethics committee approved this study.

Of the 407 eligible patients, $89(21.9 \%)$ refused to participate and 318 patients $(78.1 \%)$ gave written informed consent before inclusion. A refusal rate of $21.9 \%$ is comparable to other studies in which MI patients are screened for depression ${ }^{12,29}$. Of the 318 patients, 14 were treated in a randomised placebocontrolled trial of fluoxetine during 25 weeks ${ }^{36}$. After the trial they were offered further treatment at the mood disorder clinic of the AZM, if necessary. Furthermore, another 11 were rreated with antidepressants by the general practitioner or the mood disorder clinic of the AZM.

\section{Assessment of emotional distress}

The 90-item Symptom Check List (SCL-90), which is a well validated and widely used self-assessment scale 37,38 , was used to measure emotional distress. Each of the items of the SCL-90 ranges from 0 to 4 , with 0 indicating no complaint and 4 maximal complaint. Patients filled out the SCL-90 one month post-MI at home or during the first post-MI visit at the outpatient clinic of the department of cardiology. The scales Depression (16 items), Anxiety (10 items), and Hostility ( 6 items) from the SCL-90 were scored for the purpose of the present study. These scales were conceptualised as markers of emotional distress. In previous research, we evaluated the SCL-90 depression scale in patients with post-MI depression and found it to be a valid instrument with a sensitivity of $81.1 \%$ and specificity of $83.5 \%$. In comparison, the BDI had a sensitivity of $83.8 \%$ and specificity of $71.7 \%{ }^{39}$.

\section{Endpoints}

The endpoints in this study were major cardiac events and health care consumption during an average follow-up period of 3.4 years (range $=1$ to 70 months). Major cardiac events were defined as cardiac death or recurrent MI, as diagnosed by the attending cardiologist. Increased health care consumption was defined as cardiac re-hospitalization and/or frequent visits $>6$ visits during follow-up) at the cardiac outpatient clinic. Patients without cardiac events 
during the follow-up period and with an average number of visits at the cardiac outpatient clinic were considered to be "event free".

\section{Cardiac variables}

Left ventricular ejection fraction (LVEF) was recorded one month after MI as measure of disease severity. Data concerning intervention at the time of MI (thrombolysis, percutaneous transluminal coronary angioplasty, coronary artery bypass surgery), medication (beta blockade, platelet aggregation inhibitors, ACE-inhibitors), and cardiovascular risk factors (smoking, hypertension, hypercholesterolemia, diabetes) were taken from patients' records.

\section{Analyses}

All data were entered into a computerised database and analysed using SPSS standard software ${ }^{40}$. According to the results of the follow-up, patients were classified in one of three groups: patients with a major cardiac event, patients with increased health care consumption, and event free patients. To determine the prognostic power of emotional distress, scores on the depression, hostility and anxiety subscales were dichotomized according to the cut-offs for high risk psychopathology 38: 23 for depression, 12 for anxiety, and 7 for hostility. LVEF was dichotomized at $50 \%$, using standards of a former publication on CAD patients ${ }^{8}$. A median split was used to dichotomize patients on age (median 58.0 years) and on the number of visits at the outpatient cardiology clinic (median of 6 visits). Differences in baseline characteristics between the three groups were tested by independent t-tests in case of continuous variables, and Chi-square test was for all dichotomous variables. Fisher's exact probabilities were calculated when they were expected.

Multivariate Cox regression analysis was used to examine the SCL-90 depression, anxiety and hostility subscales separately as predictors of major cardiac events. To select appropriate co-variates for statistical control, all baseline variables were dichotomized (at predetermined points). Those variables significantly related to major cardiac events in the univariate Cox regression models were entered into the multiple Cox regression analysis, followed by the addition of the SCL-90 depression, anxiety and hostility subscales. Because antidepressive agents can flaw the impact of depression on cardiac prognosis, we also included use of antidepressants as covariate in our model. Finally, a stepwise multivariate Cox regression analysis including all three negative emotions (SCL-90 subscales depression, anxiety and hostility) was used to examine these emotions as independent predictors of major cardiac events.

Regarding analysis of SCL-90 depression, anxiety and hostility subscales as predictors of health care consumption, univariate logistic regressions were first performed. Those baseline variables significantly related to health consumption were entered in a multivariate logistic regression model, followed by the addition of the SCL-90 subscales. Finally, multivariate logistic regression with 
all three negative emotions was used. A two-tailed p-value $\leq 0.05$ was considered to be significant.

\section{Table 1}

Baseline data of demographic data, medication and CAD risk factors and univariate relation with depression, anxiety and hostility.

\begin{tabular}{|c|c|c|c|c|c|c|c|}
\hline \multirow[t]{2}{*}{ Cross tabs } & & \multicolumn{2}{|c|}{ Depression } & \multicolumn{2}{|c|}{ Anxiety } & \multicolumn{2}{|c|}{ Hostility } \\
\hline & & No & p-value & No & p-value & No & p-value \\
\hline Age $>58$ & $\begin{array}{l}\text { Yes } \\
\text { No }\end{array}$ & $\begin{array}{l}64 / 156 \\
83 / 156\end{array}$ & 0.031 & $\begin{array}{r}84 / 155 \\
101 / 156\end{array}$ & 0.058 & $\begin{array}{r}93 / 155 \\
100 / 156\end{array}$ & 0.456 \\
\hline LVEF $\leq 50 \%$ & $\begin{array}{l}\text { Yes } \\
\text { No }\end{array}$ & $\begin{array}{l}67 / 141 \\
80 / 171\end{array}$ & 0.897 & $\begin{array}{r}84 / 141 \\
101 / 170\end{array}$ & 0.977 & $\begin{array}{r}81 / 140 \\
112 / 171\end{array}$ & 0.167 \\
\hline Beta blockers & $\begin{array}{l}\text { Yes } \\
\text { No }\end{array}$ & $\begin{array}{l}87 / 185 \\
60 / 127\end{array}$ & 0.969 & $\begin{array}{r}109 / 184 \\
76 / 127\end{array}$ & 0.915 & $\begin{array}{r}121 / 184 \\
72 / 127\end{array}$ & 0.105 \\
\hline PAI & $\begin{array}{l}\text { Yes } \\
\text { No }\end{array}$ & $\begin{array}{r}133 / 285 \\
7 / 15\end{array}$ & 0.999 & $\begin{array}{r}164 / 284 \\
13 / 15\end{array}$ & 0.026 & $\begin{array}{r}174 / 284 \\
12 / 15\end{array}$ & 0.145 \\
\hline ACE-inhibitors & $\begin{array}{l}\text { Yes } \\
\text { No }\end{array}$ & $\begin{array}{l}46 / 109 \\
94 / 190\end{array}$ & 0.225 & $\begin{array}{r}58 / 109 \\
119 / 189\end{array}$ & 0.099 & $\begin{array}{r}64 / 108 \\
121 / 190\end{array}$ & 0.449 \\
\hline Diuretics & $\begin{array}{l}\text { Yes } \\
\text { No }\end{array}$ & $\begin{array}{r}10 / 26 \\
127 / 269\end{array}$ & 0.393 & $\begin{array}{r}12 / 26 \\
163 / 268\end{array}$ & 0.146 & $\begin{array}{r}14 / 25 \\
168 / 269\end{array}$ & 0.525 \\
\hline Lipid lowering drugs & $\begin{array}{l}\text { Yes } \\
\text { No }\end{array}$ & $\begin{array}{l}62 / 135 \\
75 / 160\end{array}$ & 0.871 & $\begin{array}{l}79 / 135 \\
96 / 159\end{array}$ & 0.746 & $\begin{array}{r}82 / 135 \\
100 / 159\end{array}$ & 0.705 \\
\hline Oral antidiabetics & $\begin{array}{l}\text { Yes } \\
\text { No }\end{array}$ & $\begin{array}{r}10 / 17 \\
126 / 277\end{array}$ & 0.284 & $\begin{array}{r}14 / 17 \\
160 / 276\end{array}$ & 0.047 & $\begin{array}{r}13 / 17 \\
168 / 276\end{array}$ & 0.199 \\
\hline Invasive intervention & $\begin{array}{l}\text { Yes } \\
\text { No }\end{array}$ & $\begin{array}{l}57 / 137 \\
90 / 175\end{array}$ & 0.085 & $\begin{array}{r}82 / 137 \\
103 / 174\end{array}$ & 0.907 & $\begin{array}{r}82 / 137 \\
111 / 174\end{array}$ & 0.477 \\
\hline Smoking & $\begin{array}{l}\text { Yes } \\
\text { No }\end{array}$ & $\begin{array}{l}93 / 170 \\
54 / 142\end{array}$ & 0.003 & $\begin{array}{r}108 / 170 \\
77 / 141\end{array}$ & 0.111 & $\begin{array}{r}115 / 170 \\
78 / 141\end{array}$ & 0.026 \\
\hline Hypercholesterolemia & $\begin{array}{l}\text { Yes } \\
\text { No }\end{array}$ & $\begin{array}{r}33 / 63 \\
114 / 249\end{array}$ & 0.349 & $\begin{array}{r}43 / 63 \\
142 / 248\end{array}$ & 0.112 & $\begin{array}{r}47 / 63 \\
146 / 248\end{array}$ & 0.022 \\
\hline Hypertension & $\begin{array}{l}\text { Yes } \\
\text { No }\end{array}$ & $\begin{array}{r}43 / 89 \\
104 / 223\end{array}$ & 0.789 & $\begin{array}{r}54 / 89 \\
131 / 222\end{array}$ & 0.787 & $\begin{array}{r}58 / 89 \\
135 / 222\end{array}$ & 0.474 \\
\hline Diabetes & $\begin{array}{l}\text { Yes } \\
\text { No }\end{array}$ & $\begin{array}{r}15 / 27 \\
132 / 285\end{array}$ & 0.358 & $\begin{array}{r}21 / 27 \\
164 / 284\end{array}$ & 0.043 & $\begin{array}{r}21 / 27 \\
172 / 284\end{array}$ & 0.078 \\
\hline
\end{tabular}

LVEF: left ventricle ejection fraction; PAI: platelet aggegation inhibitors. 


\section{Results}

\section{Patients}

The average age of the 318 included men was 58.0 years $(\mathrm{SD}=11.0)$ and the mean LVEF and $\mathrm{ASAT}_{\max }$ score were $51 \%(\mathrm{SD}=9.8)$ and $247 \mathrm{U} / \mathrm{L}(\mathrm{SD}=$ $182)$, respectively. There were no differences between the participating and non-participating group with respect to age, ASAT $T_{\max }$ or LVEF. Of the 318 participants, $91.9 \%$ were prescribed platelet aggregation inhibitors (PAI), $58.2 \%$ beta blocking agents, $45.2 \%$ lipid lowering drugs, $36.2 \%$ ACE-inhibiting agents, $9 \%$ diuretics, and $5.7 \%$ oral antidiabetics. Fifty-four percent were smoking preMI, 20.4\% was known with hypercholesterolemia, $8.5 \%$ with diabetes, and $28 \%$ with hypertension. Next, we evaluated whether age and LVEF, but also medication and risk factors for CAD were associated with the distress variables depression, anxiety and hostility (Table 1). Age beneath 58 was associated with patients with depressive symptoms $(p=0.031)$ as was smoking $(p=0.003)$. Diabetes, prescription of oral antidiabetics and PAI were associated with symptoms of anxiety ( $\mathrm{p}=0.043,0.047$ and 0.026 respectively). Hyperlipidemia was associated with symptoms of hostility $(p=0.022)$ as was smoking $(p=$ 0.026). According to the psychological assessment 1 month post-MI, $47.1 \%$ of the patients scored above the cut-off of the SCL-90 depression subscale, $59.5 \%$ above the anxiety subscale and $62.1 \%$ above the hostility subscale.

\section{Cardiac events}

One hundred forty-four patients $(45.2 \%)$ were event free during follow-up, whereas $25(7.9 \%)$ had experienced a major cardiac event. In univariate Cox regression analyses (Table 2), LVEF $\leq 50 \%$ was significantly associated with cardiac death or recurrent MI $(\mathrm{p}=0.031)$. There was also a trend for age $>58$ $(p=0.066)$. The other cardiovascular variables, i.e. beta blockers, invasive intervention, smoking, hypercholesterolemia, hypertension and diabetes were not associated with major cardiac events in the univariate analysis. 


\section{Table 2}

Cardiac events during follow-up as a function of age and cardiovascular variables at baseline.

\begin{tabular}{|c|c|c|c|c|c|}
\hline \multirow{2}{*}{\multicolumn{2}{|c|}{$\begin{array}{l}\text { Univariate Cox } \\
\text { regression analysis }\end{array}$}} & \multicolumn{4}{|c|}{ Major cardiac events } \\
\hline & & $\%(\mathrm{No})$ & Hazard ratio & $95 \% \mathrm{CI}$ & p-value \\
\hline Age $>58$ & $\begin{array}{l}\text { Yes } \\
\text { No }\end{array}$ & $\begin{array}{cc}19 & (18 / 94) \\
9 & (7 / 75)\end{array}$ & 2.27 & $0.95-5.44$ & 0.066 \\
\hline LVEF $\leq 50 \%$ & $\begin{array}{l}\text { Yes } \\
\text { No }\end{array}$ & $\begin{array}{cc}25 & (16 / 72) \\
8 & (9 / 97)\end{array}$ & 2.46 & $1.08-5.57$ & 0.031 \\
\hline Beta blockers & $\begin{array}{l}\text { Yes } \\
\text { No }\end{array}$ & $\begin{array}{lr}16 & (15 / 100) \\
15 & (10 / 69\end{array}$ & 1.33 & $0.58-3.0$ & 0.501 \\
\hline Invasive intervention & $\begin{array}{l}\text { Yes } \\
\text { No }\end{array}$ & $\begin{array}{rr}12 & (8 / 74) \\
18 & (17 / 95)\end{array}$ & 0.57 & $0.25-1.33$ & 0.197 \\
\hline Smoking & $\begin{array}{l}\text { Yes } \\
\text { No }\end{array}$ & $\begin{array}{ll}11 & (10 / 90) \\
20 & (15 / 79)\end{array}$ & 0.59 & $0.26-1.30$ & 0.187 \\
\hline Hypercholesterolemia & $\begin{array}{l}\text { Yes } \\
\text { No }\end{array}$ & $\begin{array}{cr}9 & (3 / 35) \\
17 & (22 / 134)\end{array}$ & 0.62 & $0.19-2.09$ & 0.441 \\
\hline Hypertension & $\begin{array}{l}\text { Yes } \\
\text { No }\end{array}$ & $\begin{array}{cr}21 & (9 / 47) \\
13 & (16 / 122)\end{array}$ & 1.73 & $0.76-3.92$ & 0.193 \\
\hline Diabetes & $\begin{array}{l}\text { Yes } \\
\text { No }\end{array}$ & $\begin{array}{lr}14 & (2 / 14) \\
15 & (23 / 155)\end{array}$ & 0.94 & $0.22-4.0$ & 0.933 \\
\hline
\end{tabular}

$95 \% \mathrm{Cl}=95 \%$ confidence interval; $\mathrm{p}$-value $=2$-tailed level of significance (univariate Cox regression analyses); Invasive intervention: percutaneous transluminal coronary angioplasty or coronary artery bypass surgery; LVEF: left ventricular ejection fraction.

Symptoms of anxiety, but not depression, were associated with cardiac events in univariate analysis (Figure 1). After adjusting for age, LVEF and use of antidepressants, both symptoms of depression and anxiety were associated with cardiac events $(p=0.039$ and $p=0.019$ respectively; Table 4$)$. There was no relation with hostility. 


\section{Figure 1}

Cardiac events during follow-up as a function of emotional distress at baseline.

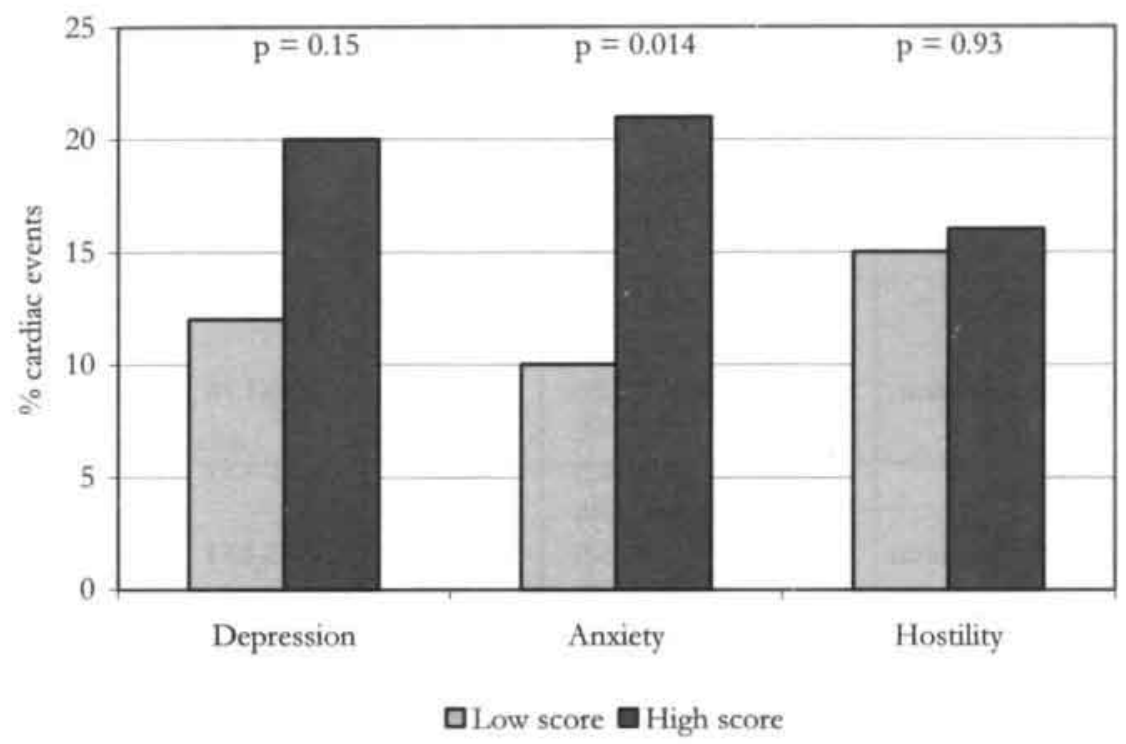

\section{Increased bealth care consumption}

Of the 318 male patients with first MI, $149(46.9 \%)$ had increased health care consumption, i.e. frequent visits at the outpatient cardiac clinic or rehospitalizations due to cardiac events, up to 6 years post-MI. In univariate analyses (Table 3 ), there were no cardiovascular variables related to increased health care consumption, although there was a trend that LVEF $\leq 50 \%$ was related to increased health care consumption $(p=0.069)$. 
Table 3

Increased health care consumption as a function of age, cardiovascular variables, and emotional distress at baseline.

\begin{tabular}{|c|c|c|c|c|c|}
\hline \multirow{2}{*}{$\begin{array}{l}\text { Univariate Logistic } \\
\text { regression analysis }\end{array}$} & & \multicolumn{4}{|c|}{ Increased health care consumption } \\
\hline & & $\%(\mathrm{No})$ & Odds ratio & $95 \%$ CI & p-value \\
\hline Age $>58$ & $\begin{array}{l}\text { Yes } \\
\text { No }\end{array}$ & $\begin{array}{ll}55 & (81 / 148) \\
47 & (68 / 144)\end{array}$ & 0.74 & $0.47-1.17$ & 0.200 \\
\hline LVEF $\leq 50 \%$ & $\begin{array}{l}\text { Yes } \\
\text { No }\end{array}$ & $\begin{array}{ll}57 & (72 / 126) \\
46 & (77 / 166)\end{array}$ & 1.54 & $0.97-2.46$ & 0.069 \\
\hline Beta blockers & $\begin{array}{l}\text { Yes } \\
\text { No }\end{array}$ & $\begin{array}{ll}50 & (85 / 169) \\
52 & (64 / 123)\end{array}$ & 1.07 & $0.67-1.71$ & 0.769 \\
\hline Invasive intervention & $\begin{array}{l}\text { Yes } \\
\text { No }\end{array}$ & $\begin{array}{ll}50 & (64 / 129) \\
52 & (85 / 163)\end{array}$ & 1.11 & $0.70-1.76$ & 0.667 \\
\hline Smoking & $\begin{array}{l}\text { Yes } \\
\text { No }\end{array}$ & $\begin{array}{ll}51 & (82 / 162) \\
52 & (67 / 130)\end{array}$ & 0.96 & $0.61-1.53$ & 0.876 \\
\hline Hypercholesterolemia & $\begin{array}{l}\text { Yes } \\
\text { No }\end{array}$ & $\begin{array}{l}48(30 / 62) \\
52(119 / 230)\end{array}$ & 0.87 & $0.50-1.53$ & 0.640 \\
\hline Hypertension & $\begin{array}{l}\text { Yes } \\
\text { No }\end{array}$ & $\begin{array}{lr}53 & (42 / 79) \\
50 & (107 / 213)\end{array}$ & 1.12 & $0.67-1.89$ & 0.657 \\
\hline Diabetes & $\begin{array}{l}\text { Yes } \\
\text { No }\end{array}$ & $\begin{array}{lr}52 & (13 / 25) \\
51 & (136 / 267)\end{array}$ & 1.04 & $0.46-2.37$ & 0.919 \\
\hline Depression & $\begin{array}{l}\text { Yes } \\
\text { No }\end{array}$ & $\begin{array}{ll}58 & (77 / 133) \\
46 & (71 / 154)\end{array}$ & 1.61 & $1.00-2.57$ & 0.047 \\
\hline Anxicty & $\begin{array}{l}\text { Yes } \\
\text { No }\end{array}$ & $\begin{array}{ll}59 & (98 / 166) \\
42 & (50 / 120)\end{array}$ & 2.02 & $1.25-3.25$ & 0.004 \\
\hline Hostility & $\begin{array}{l}\text { Yes } \\
\text { No }\end{array}$ & $\begin{array}{l}54(96 / 178) \\
47(51 / 108)\end{array}$ & 1.31 & $0.81-2.11$ & 0.271 \\
\hline
\end{tabular}

$95 \% \mathrm{CI}=95 \%$ confidence interval; $\mathrm{p}$-value $=2$-tailed level of significance (univariate Cox regression analyses); Invasive intervention: percutaneous transluminal coronary angioplasty or coronary artery bypass surgery; LVEF: left ventricular ejection fraction.

Regarding emotional distress as a determinant, depressive and anxious symptoms at baseline were associated with increased health care consumption during follow-up ( $\mathrm{P}=0.047$ and 0.004 respectively; Table 3$)$. After adjusting for age, LVEF and use of antidepressants, anxiety was the only negative emotion that was significantly associated with the secondary endpoint $(\mathrm{OR}=2.00$; $95 \% \mathrm{CI}=1.23-3.26 ; \mathrm{p}=0.006$; Table 4 ); i.e., frequent cardiac outpatient visits and re-hospitalizations due to cardiac events. Hostility was not related to increased health care consumption. 


\section{Table 4}

Poor outcome as a function of one negative emotion at a time, adjusting for age, LVEF, and use of antidepressants.

\begin{tabular}{l|c|c|c}
\hline \multirow{2}{*}{ Cox regression model } & \multicolumn{3}{|c}{ Cardiac events } \\
\cline { 2 - 4 } & Hazard ratio & $95 \%$ CI & p-value \\
\hline Depression & 2.32 & $1.04-5.18$ & 0.039 \\
Age $>58 y$ & 2.06 & $0.86-4.96$ & 0.107 \\
LVEF $\leq 50 \%$ & 2.14 & $0.94-4.87$ & 0.070 \\
Use of antidepressants & & & 0.979 \\
\hline Anxiety & 3.01 & $1.20-7.60$ & 0.019 \\
Age $>58 y$ & 2.22 & $0.93-5.36$ & 0.073 \\
LVEF $\leq 50 \%$ & 2.09 & $0.92-4.75$ & 0.078 \\
Use of antidepressants & & & 0.979 \\
\hline Hostility & 1.03 & $0.46-2.30$ & 0.950 \\
Age $>58 y$ & 1.94 & $0.80-4.70$ & 0.142 \\
LVEF $\leq 50 \%$ & 2.18 & $0.96-4.97$ & 0.064 \\
Use of antidepressants & & & 0.978 \\
\hline \hline
\end{tabular}

\begin{tabular}{l|c|c|c}
\hline \hline \multirow{2}{*}{$\begin{array}{l}\text { Logistic regression } \\
\text { model }\end{array}$} & \multicolumn{3}{|c}{ Health care consumption } \\
\cline { 2 - 4 } & Odds ratio & $\mathbf{9 5 \%}$ CI & p-value \\
\hline Depression & 1.55 & $0.96-2.52$ & 0.076 \\
Age $>58 y$ & 0.79 & $0.49-1.28$ & 0.339 \\
LVEF $\leq 50 \%$ & 1.57 & $0.97-2.53$ & 0.065 \\
Use of antidepressants & 1.00 & $0.42-2.35$ & 0.994 \\
\hline Anxiety & 2.00 & $1.23-3.26$ & 0.006 \\
Age $>58 y$ & 0.81 & $0.50-1.31$ & 0.395 \\
LVEF $\leq 50 \%$ & 1.57 & $0.97-2.55$ & 0.067 \\
Use of antidepressants & 1.07 & $0.46-2.51$ & 0.881 \\
\hline Hostility & 1.33 & $0.81-2.16$ & 0.257 \\
Age $>58 y$ & 0.75 & $0.47-1.24$ & 0.245 \\
LVEF $\leq 50 \%$ & 1.60 & $0.99-2.58$ & 0.055 \\
Use of antidepressants & 0.90 & $0.39-2.09$ & 0.804 \\
\hline
\end{tabular}

$95 \% \mathrm{CI}=95 \%$ confidence interval; $\mathrm{p}$-value $=2$-tailed level of significance; $\mathrm{LVEF}$ : left ventricular ejection fraction.

\section{Independent predictors of endpoints}

A multivariate analysis including all three negative emotions indicated that symptoms of anxiety $(\mathrm{HR}=2.79 ; 95 \% \mathrm{CI}=1.11-7.03 ; \mathrm{p}=0.029 ;$ Table 5$)$, explained away the relation between depressive symptoms and cardiac events. This stepwise multivariate Cox regression retained also LVEF $\leq 50 \%(\mathrm{HR}=$ $2.29 ; 95 \% \mathrm{CI}=1.01-5.21 ; \mathrm{p}=0.047)$, and age $>58$ years $(\mathrm{HR}=2.44 ; 95 \% \mathrm{CI}=$ 
1.01-5.88; $\mathrm{p}=0.047$ ) as independent predictors of major cardiac events (Table 5 , top). Neither depression $(p=0.44)$ nor hostility $(p=0.39)$ predicted major cardiac events in this multivariate model. Regarding increased health care consumption, a stepwise logistic regression model retained again anxiety $(\mathrm{OR}=$ $2.00 ; 95 \% \mathrm{CI}=1.24-3.22 ; \mathrm{p}=0.005)$ as an independent predictor of frequent visits at the outpatient cardiac clinic or re-hospitalizations due to cardiac events (Table 5, bottom). Neither depression ( $p=0.65$ ) nor hostility $(p=0.93$ ) predicted increased health care consumption. In other words, a) anxiety accounted for the relation between depression and cardiac events, and b) anxiety was the only significant predictor of increased health care consumption in survivors of an acute MI.

\section{Table 5}

Independent predictors of major cardiac events and health care consumption.

\begin{tabular}{|c|c|c|c|}
\hline \multirow[t]{2}{*}{ Cox regression model } & \multicolumn{3}{|c|}{ Cardiac events } \\
\hline & Hazard ratio & $95 \%$ CI & p-value \\
\hline Anxiety & 2.79 & $1.11-7.03$ & 0.030 \\
\hline Age $>58 y$ & 2.44 & $1.01-5.88$ & 0.047 \\
\hline LVEF $\leq 50 \%$ & 2.29 & $1.01-5.21$ & 0.047 \\
\hline \multicolumn{4}{|c|}{ Variables not in the equation } \\
\hline Depression & & & 0.447 \\
\hline Hostility & & & 0.392 \\
\hline Use of antidepressants & & & 0.137 \\
\hline \multirow[t]{2}{*}{ Logistic regression model } & \multicolumn{3}{|c|}{ Health care consumption } \\
\hline & Odds ratio & $95 \% \mathrm{CI}$ & p-value \\
\hline Anxiety & 2.00 & $1.24-3.22$ & 0.005 \\
\hline \multicolumn{4}{|c|}{ Variables not in the equation } \\
\hline Depression & & & 0.645 \\
\hline Hostility & & & 0.929 \\
\hline Age $>58 y$ & & & 0.494 \\
\hline LVEF $\leq 50 \%$ & & & 0.089 \\
\hline Use of antidepressants & & & 0.937 \\
\hline
\end{tabular}

$95 \% \mathrm{CI}=95 \%$ confidence interval; $\mathrm{p}$-value $=2$-tailed level of significance; LVEF: left ventricular ejection fraction. 


\section{Discussion}

The findings of the present study showed that symptoms of both depression and anxiety were associated with increased risk of adverse cardiac events. However, anxiety was an independent predictor of cardiac events and increased health care consumption, and accounted for the relation between depression and prognosis. These findings support the notion that psychological factors are related to a poor prognosis post-MI ${ }^{1-3}$, and indicate that symptoms of anxiety need to be considered in the risk stratification and treatment of post-MI patients.

The fact that anxiety was a stronger predictor of cardiac outcome in MI patients than depressive symptomatology is a novel finding. A recent review of negative emotions and the onset of CHD in initially healthy individuals also concluded that research should not ignore the risk associated with anxiety ${ }^{41}$. The present study focused on patients with established CHD to examine the relative impact of symptoms of depression and anxiety on prognosis. Whereas most previous research focused on either anxiety ${ }^{1-3}$ or depression ${ }^{4}$ as single risk indicators, these negative emotions were investigated simultaneously in the present study. Although there was a trend that depressive symptoms predicted cardiac outcome in univariate analysis, anxiety explained away this association in multivariate analysis. In fact, anxiety was associated with a more than twofold increased risk $(\mathrm{HR}=2.79 ; 95 \% \mathrm{CI}=1.11-7.03 ; \mathrm{p}=0.029)$ of cardiac death or recurrent MI after controlling for disease severity ( $\mathrm{LVEF} \leq 50 \%, \mathrm{HR}=2.29$; $95 \% \mathrm{C}=1.01-5.21 ; \mathrm{p}=0.047)$, and age $(\mathrm{HR}=2.44 ; 95 \% \mathrm{CI}=1.01-5.88 ; \mathrm{p}=$ 0.047 ). The fact that anxiety, but not depression, was retained as an independent predictor of cardiac outcome is in line with findings of a recent study by Watkins et al. ${ }^{28}$. Herein it was found that high levels of anxiety, measured $6 \pm 3$ days post MI, but not depression, were independently associated with reduced vagal control in patients after MI. Previous research in our own group also indicated that anxiety was a significant predictor of clinical depression in a sample of 206 post-MI patients ${ }^{39}$. Hostility was not associated with cardiac prognosis or increased health care consumption in the present study.

Our findings confirm studies which concluded that depression and anxiety may be predictors of cardiac events post-MI ${ }^{20,21}$. The follow-up period (one year) in studies that could not confirm a relationship between depression/anxiety and cardiac events 17,18 was considerably shorter than the follow-up period in the present study (average of 3.4 years). It may be that cardiac events related with affective dysregulation post-MI tend to occur more in long term periods. Timing of the assessment may also be important. In a study reporting that both depression and anxiety did not predict outcome at 3 years post-MI ${ }^{42}$, the depression and anxiety symptoms were assessed in-hospital. In the present study, these symptoms were assessed at 1 month post-MI. 
Limitations of this study include the relatively small number of cardiac events, the exclusion of female patients and the lack of information on depression treatment during the course of follow-up. However, as yet it is not clear whether treatment of post-MI depression can improve prognosis ${ }^{43}$. Another limitation concerns the use of only one instrument to assess specific symptoms of depression and anxiety. Undoubtedly, measures of depressive symptoms may yield significant prognostic information in post-MI patients ${ }^{41}$. At the present time we do not know what elements of depression predict cardiac mortality. However, the present findings suggest that, in addition to assessing depressive symptomatology, it is equally important to assess other negative emotions, including anxiety.

Apart from cardiac prognosis, the present study also examined the prognostic role of emotional distress on health care consumption. Depression not only precedes cardiac death and recurrent MI, but also may predict morbidity ${ }^{33}$. We found that anxiety was an independent predictor of frequent visits at the outpatient cardiac clinic or re-hospitalizations due to cardiac events. There was a trend that symptoms of depression were also related to increased health care consumption but, once again, anxiety accounted for this association in the multivariate model. Hence, it is also important to detect and treat emotionally distressed patients from an economic point of view, given the fact that increased health care consumption entails a significant increase in health care costs among patients with $\mathrm{CHD}^{\text {i4 }}$.

These findings have implications for clinical research and practice. First, biobehavioral research on CHD has largely focused on depression and depressive symptoms ${ }^{9.12}$; it is timely to also include other psychological factors such as anxiety ${ }^{41}$. Second, the identification of CHD patients who experience anxiety may lead to more accurate risk estimates in clinical practice. Compared to the BDI, total HADS (combination of the anxiety and depression subscale) proved to be more sensitive and specific to depression post-MI than the subscales separately ${ }^{39}$. This appears to be in line with the results of the present study, i.e. the fact that symptoms of anxiety were a predictor of cardiac events, in addition to symptoms of depression. Third, as yet it is not clear whether pharmacological ${ }^{36}$ or behavioral ${ }^{43,4+}$ treatment of depression can influence the prognosis of post-MI patients 7.45 . The present study indicated that besides depression, anxiety is also important in the prediction of cardiac outcome. This finding may help to explain why an intervention that was specifically designed to treat depression ${ }^{37}$ failed to improve the prognosis of post-MI patients ${ }^{45}$. A more comprehensive approach to treatment, including exercise training and individualised treatment of a wide variety of psychological factors, may be more successful in improving cardiac prognosis ${ }^{8}$.

In conclusion, we found that anxiety was an independent predictor of cardiac events and increased health care consumption, after controlling for disease severity and age. Moreover, anxiety accounted for any associations between depressive symptoms and prognosis. These findings support the notion that 
symptoms of emotional distress are related to cardiac prognosis following MI. Yet, they also indicate that, apart from depressive symptoms, other symptoms of emotional distress must be considered to optimise risk stratification and treatment.

\section{References}

1. Rozanski A, Blumenthal JA, Kaplan J. Impact of psychological factors on the pathogenesis of cardiovascular disease and implications for therapy. Circulation 1999;99:2192-217.

2. Hemingway H, Marmot M. Evidence based cardiology: psychosocial factors in the aetiology and prognosis of coronary heart disease. Systematic review of prospective cohort studies. BMJ 1999;318:1460-7.

3. Kubzansky LD, Kawachi I, Spiro A, Weiss ST, Vokonas PS, Sparrow D. Is worrying bad for your heart? A prospective study of worry and coronary heart disease in the Normative Aging Study. Circulation 1997;95:818-24.

4. Barefoot JC, Helms MJ, Mark DB, et al. Depression and long-term mortality risk in patients with coronary heart disease. Am J Cardiology 1996;78:613-7.

5. Carney RM, Blumenthal JA, Stein PK, et al. Depression, heart rate variability, and acute myocardial infarction. Circulation 2001;104:2024-8.

6. Musselman DL, Tomer A, Manatunga AK, et al. Exaggerated platelet reactivity in major depression. Am J Psychiatry 1996;153:1313-7.

7. Carney RM, Freedland KE, Veith RC, Jaffe AS. Can treating depression reduce mortality after an acute myocardial infarction? Psychosom Med 1999;61:666-75.

8. Denollet J, Brutsaert DL. Reducing emotional distress improves prognosis in coronary heart disease: 9-year mortality in a clinical trial of rehabilitation. Circulation 2001;104:2018-23.

9. Lesperance F, Frasure-Smith N, Talajic M. Major depression before and after myocardial infarction: its nature and consequences. Psychosom Med 1996;58:99110.

10. Carney RM, Freedland KE, Jaffe AS. Insomnia and depression prior to myocardial infarction. Psychosom Med 1990;52:603-9.

11. Frasure-Smith N, Lesperance F, Talajic M. Depression and 18 months prognosis after myocardial infarction. Circulation 1995;91:999-1005.

12. Honig A, Lousberg R, Wojchiechowski F, Cheriex EC, Wellens H, Van Praag HM. Depression following a first heart infarct; similarities with and difference from 'ordinary' depression. Ned Tijdschr Geneeskunde 1997;141:196-9.

13. Penninx BWJH, Beekman ATF, Honig A, et al. Depression and cardiac mo ial: results from a community-based longitudinal study. Arch Gen : sychiatry 2001;58:221-7.

14. Carney RM, Freedland KE, Jaffe AS. Depression as a risk factor for coronary heart disease mortality. Arch Gen Psychiatry 2001;58:229-230.

15. Denollet J, Brutsaert DL. Personality, disease severity and the risk of long term cardiac events in patients with a decreased ejection fraction after myocardial infarction. Circulation 1998;97:176-3. 
16. Williams JE, Paton CC, Siegler IC, Eigenbrodt ML, Nieto FJ, Tyroler HA. Anger proneness predicts coronary heart disease risk: prospective analysis from the atherosclerosis risk in communities (ARIC) study. Circulation 2000;101:2034-9.

17. Mayou RA, Gill D, Thompson DR, et al. Depression and anxiety as predictors of outcome after myocardial infarction. Psychosom Med 2000;62:212-9.

18. Lane D, Carroll D, Ring C, Beevers DG, Lip GY. Mortality and quality of life 12 months after myocardial infarction: effects of depression and anxiety. Psychosom Med 2001;63:221-30.

19. Sullivan MD, LaCroix AZ, Spertus JA, Hecht J. Five-year prospective study of the effects of anxiety and depression in patients with coronary artery disease. Am J Cardiology 2000;86:1135-8.

20. Frasure Smith N, Lesperance F, Talajic M. The impact of negative emotions on prognosis following myocardial infarction: is it more than depression? Health Psychol 1995;14:388-98.

21. Kubzansky LD, Kawachi I, Weiss ST, Sparrow D. Anxiety and coronary heart disease: a synthesis of epidemiological, psychological, and experimental evidence. Ann Behav Med 1998;20:47-58.

22. Zimmerman M, McDermut W, Mattia JI. Frequency of anxiety disorders in psychiatric outpatients with major depressive disorder. Am J Psychiatry 2000; 157:1337-40.

23. Wetherell JL, Gatz M, Pedersen NL. A longitudinal analysis of anxiety and depressive symptoms. Psychol Aging 2001; 16:187-95.

24. Goodwin RD. Anxiety disorders and the onset of depression among adults in the community. Psychol Med 2002; 32:1121-4.

25. Zimmerman M, Chelminski I. Generalized anxiety disorder in patients with major depression: Is DSM-IV's hierarchy correct? Am J Psychiatry 2003; 160:504-12.

26. Feske U, Frank E, Mallinger AG, Houck PR, Fagiolini A, Shear MK, Grochocinski V], Kupfer DJ. Anxiety as a correlate of response to the acute treatment of bipolar 1 disorder. Am J Psychiatry 2000; 157:956-62.

27. Goodwin RD, Gorman JM. Psychopharmacologic treatment of generalized anxiety disorder and the risk of major depression. Am J Psychiatry 2002; 159:1935-7.

28. Watkins L.L, Blumenthal JA, Carney RM. Association of anxiety with reduced baroreflex cardiac control in patients after acute myocardial infarction. Am Heart J 2002;143:460-6.

29. Frasure-Smith N, Lesperance F, Talajic M. Depression following myocardial infarction: impact on 6-months survival. JAMA 1993;270;999-1005.

30. Ladwig KH, Kieser M, Konig J, Breithardt G, Borggrefe M. Affective disorders and survival after acute myocardial infarction (results from the post-infarction late potential study). Eur Heart J 1991;12:959-64.

31. Welin C, Lappas G, Wilhelmsen L. Independent importance of psychosocial factors for prognosis after myocardial infarction. J Intern Med 2000;247:629-39.

32. Ladwig KH, Roll G, Breithardt G, Budde T, Borggrefe M. Post infarct depression and incomplete recovery 6 months after acute myocardial infarction. The Lancet 1994;343:20-3.

33. Creed F. The importance of depression following myocardial infarction. Heart 1999;82:406-8.

34. Russel MW, Huse DM, Drowns S, al. e. Direct medical costs of coronary artery disease in the United States. Am J Cardiol 1998;81:1110-5. 
35. Pasternak RC, Braunwald E, Sobel RE. Acute myocardial infarction. In: Braunwald E, ed. Heart disease: a textbook of cardiovascular medicine. 4th edition ed. Philadelphia: W. B. Saunders Compagny, 1992:1200-91.

36. Strik JJMH, Honig A, Lousberg R, et al. Efficacy and safety of fluoxetine in the treatment of patients with major depression following first myocardial infarction: findings from a double-blind placebo-controlled trial. Psychosom Med 2000;62:7839.

37. Derogatis LR, Lipman RS, Covi L. SCL-90: an outpatient psychiatric rating scaleprelimanary report. Psychopharm Bull 1973;9:13-27.

38. Arrindell WA, Ettema JHM. Dimensional structure, reliability and validity of the Dutch version of the Symptom Checklist (SCL-90). Ned Tijdschr Psychologie $1981 ; 43: 381-7$.

39. Strik JJMH, Honig A, Lousberg R, Denollet J. Sensitivity and specificity of observer and self rating questionnaires in depression following myocardial infarction. Psychosomatics 2001;42:423-8.

40. Norusis MJ. SPSS for Windows 6.0. Chicago: SPSS Inc, 1993.

41. Kubzansky LD, Kawachi I. Going to the heart of the matter: do negative emotions cause coronary heart disease? [In Process Citation]. J Psychosom Res 2000;48:32337.

42. Lane D, Carroll D, Ring C, Beevers DG, Lip GY. In-hospital symptoms of depression do not predict mortality 3 years after myocardial infarction. Int J Epidemiology 2002; 31:1179-82.

43. Writing Committee for the ENRICHD Investigators. Effects of treating depression and low perceived social support on clinical events after myocardial infarction: the enhancing recovery in coronary heart disease patients. JAMA 2003; 289: 3106-16.

44. Sheps DS, Freedland KE, Golden RN, McMahon RP. ENRICHD and SADHART: implications for future biobehavioral intervention efforts. Psychosom Med 2003;65:1-2.

45. Louis AA, Manousos IR, Coletta AP, Clark AL, Cleland JGF. Clinical trials update: the heart protection study, IONA, CARISA, ENRICHD, ACUTE, ALIVE, MADIT II and REMATCH. Eur J Heart Fail 2002;4:111-6. 


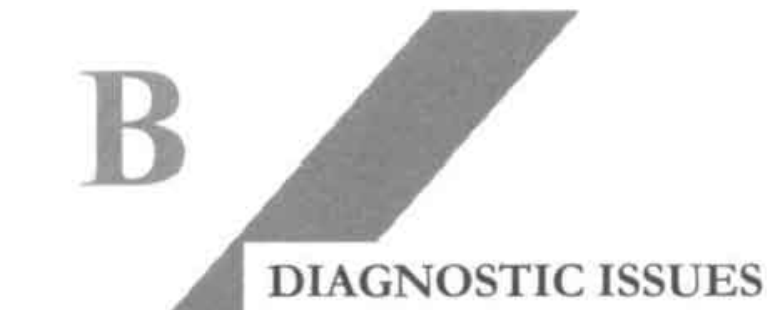





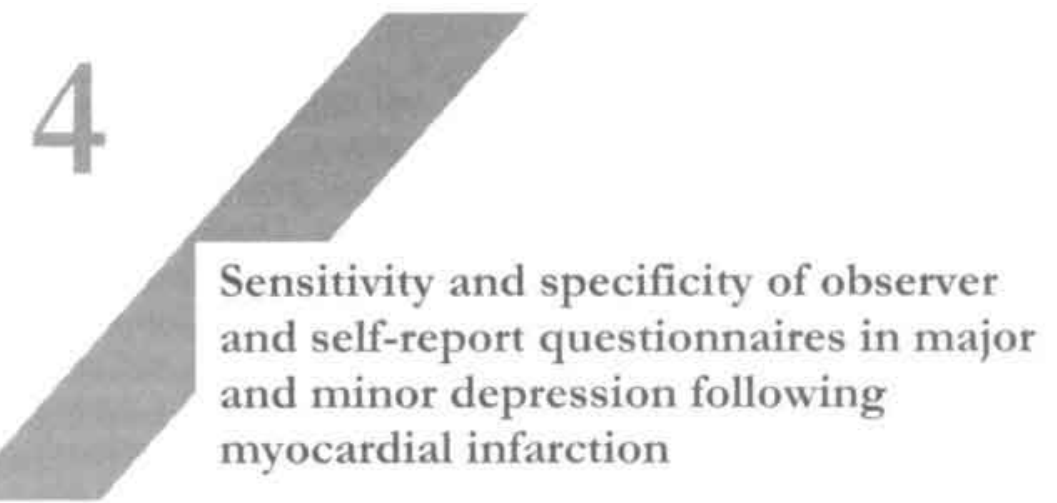




\begin{abstract}
This study evaluated screening abilities of self-report questionnaires for depression in first myocardial infarction (MI) patients. One month post-MI, 206 patients with first MI were screened for major and minor depression using the 90-item Symptom Check List (SCL-90), the Beck Depression Inventory (BDI), the Hospital Anxiety and Depression Scale (HADS), and the 17-item Hamilton Depression Rating Scale (HAMD). The Structured Clinical Interview for DSM-IV criteria was used as the gold standard. Sensitivity and specificity for different cut-off points, using relative operating characteristics curves, were assessed. The internal consistency for all scales was good. When screening for major and minor depression, the optimal cut-off scores are lower than those for screening major depression only. The SCL-90, BDI, HADS and HAMD proved to have acceptable abilities for screening post-MI major and minor depression.
\end{abstract}

\title{
Reference
}

Strik JJMH, Honig A, Lousberg R, Denollet J. Sensitivity and specificity of observer and self-report questionnaires in major and minor depression following myocardial infarction. Psychosomatics 2001: 42:423-8 (second price winner in the Dorfman Journal Paper Award competition 2002 of the Academy of Psychosomatic Medicine). 


\section{Introduction}

Screening for depression in post myocardial infarction (MI) patients is important as depression decreases cardiac prognosis after the MI ${ }^{1-3}$. Patients with MI or coronary artery disease (CAD) are often screened with self-report questionnaires and/or observer rating scales for depression to detect symptoms of depression or even to diagnose depression ${ }^{4-7}$. However, the validity and reliability of most scales as screening instruments for depressive disorder have been established in depressed patients without somatic co-morbidity ${ }^{8-11}$. These questionnaires may have a different sensitivity in identifying patients with depression after an acute MI, because some aspects of MI samples may disturb psychometric abilities of depression rating scales. Symptoms such as loss of energy, insomnia and loss of interest may be a direct consequence of MI rather than related to depression, leading to an overrepresentation of somatic symptoms and to false-positive test results ${ }^{12}$.

The use of self-report questionnaires as screening instruments for depressive disorder or symptoms in patient with MI is only justified in case of a high concurrent validity of these questionnaires in relation to the DSM-IV criteria for major and minor depression. The Beck Depression Inventory (BDI) is an internationally widely used questionnaire and has high internal consistency and high convergent validity with depression rating scales based on data in non-MI patients 13. This explains the popularity of the BDI in research with MI patients. The 90-item Symptom Check List (SCL-90) has been proven to be a useful tool for identifying psychiatric symptoms in a primary care setting and research and is frequently used for case identification ${ }^{14}$. The Hospital Anxiety and Depression Scale (HADS) has been proven to be a reliable and valid instrument for assessing anxiety and depression in medical patients 15 . However, low validity of the HADS for detecting depressive and anxiety symptoms was found in patients with angina pectoris ${ }^{15}$. Although these instruments are frequently used in research, to our knowledge their validity has not been evaluated in MI patients. Cut-off points of these scales are thereby primarily based on data from other than MI-populations.

In this study the concurrent sensitivity and specificity of three self-report questionnaires frequently used in MI or CAD patients, being the SCL-90 $8,16,17$, the BDI 1,9,18-20, the HADS $21-23$ and one observer rating scale, the 17-item Hamilton Depression Rating Scale (HAMD-17) 6,7,11,20-23 were assessed. Validity was achieved in relation to DSM-IV criteria, assessed by the Structured Clinical Interview for DSM-IV (SCID-I-R) ${ }^{24}$, a screenings instrument for major and minor depression, in a consecutive cohort of patients following an acute first MI. In addition, Cronbach's alphas were computed as a measure of internal consistency. 


\section{Methods}

\section{Patients}

Between May 1997 and September 1999, as part of a prospective study on risk factors for post-MI depression, 292 consecutive patients who had had a first acute MI were eligible for this study: $206(71 \%)$ were willing to participate. There were 156 men and 50 women, all Caucasian (Table 1). The average age was 59 years $(S D=10.6$, range 34-84) for men and 62.9 years $(S D=10.7$, range 38-78) for women. This difference in age was statistically significant $(p=0.024)$. The mean maximum value of the enzyme aspartate aminotransferase $\left(\right.$ ASAT $\left._{\max }\right)$ was $239 \mathrm{U} / \mathrm{L}(\mathrm{SD}=167)$ for men and $207 \mathrm{U} / \mathrm{L}(\mathrm{SD}=147)$ for women, which difference was not statistically significant $(p=0.22)$. The participating and non-participating group differed in age and gender; refusers were older $(p=0.03)$ and were more likely to be women $(p=0.03)$. This is comparable to other studies in which MI patients were screened for depression $1,7$.

MI diagnoses were made by a cardiologist according to the following criteria: clinical picture and electrocardiographic signs typical for an acute MI and a $\mathrm{ASAT}_{\max }$ of at least $80 \mathrm{U} / \mathrm{L}$ (twice the upper limit) ${ }^{25}$. Exclusion criteria were recurrent MI or inability to fill out questionnaires.

The local ethics committee approved this study, and all patients gave written informed consent before inclusion.

\section{Assessments}

One month post-MI patients were interviewed by the first author (JS) using the depression section of the SCID-I-R ${ }^{24}$ and the HAMD-17 11. Patients were diagnosed with major depression if they fulfilled at least one core criterion (depressed mood or loss of interest) and at least four additional criteria (total of five) with duration of at least 2 weeks ${ }^{26}$. A diagnosis of minor depression was made in case of one to three in stead of four additional criteria ${ }^{26}$. The outcome on the SCID-I-R interview was considered the gold standard in this study. The HAMD-17 was used to measure severity of the depression.

In addition to the SCID-I-R and HAMD-17, the SCL-90, BDI and HADS were used as self-report questionnaires $8,9,21$. All patients included in this study were asked to fill out these questionnaires at home following the 1-month post-MI interview. If patients did not return the questionnaires within 2 weeks after the interview they received a reminder phone call.

\section{Data analyses}

To assess the optimal cut-off scores, relative operating characteristics (ROC) curves were obtained for all scales ${ }^{27}$. This ROC curve plots the sensitivity versus ' 1 minus specificity' for every possible cut-off score. The optimal cut-off score is determined visually by assessing which score combines maximal sensitivity with optimal specificity. 
The scale with the largest area under the curve (AUC) is better for distinguishing between depressed and non-depressed patients. In addition, positive predictive values (PPV) and negative predictive values (NPV) were measured for different cut-off scores in the central range of the scale scores. All analyses were performed with the STATA software package, release 528 .

\section{Results}

Twenty-three patients met criteria for major depression (M: 13; F: 10), 16 for minor depression $(\mathrm{M}=12 ; \mathrm{F}=4)$, corresponding to a 1 -month post-MI depression prevalence of $18.9 \%$. Of the 206 patients, 11 were diagnosed with a panic disorder ( 8 with depression), 3 with agoraphobia ( 1 with depression), 1 with a single phobia, and 4 with generalised anxiety disorder (in three cases concurrent with depression). The average score on the HAMD-17 was 20.2 $(\mathrm{SD}=4.7$, range 13-30) for the depressed women and $14.5(\mathrm{SD}=6.5$, range 525 ) for the depressed men; the HAMD score for the non-depressed men was $6.8(\mathrm{SD}=4.0$, range $0-18)$ and $9.3(\mathrm{SD}=3.8$, range $3-20)$ for the nondepressed women. One-hundred ninety-nine patients $(96.6 \%)$ returned the questionnaires; 6 patients $(3 \%)$ refused and one patient $(0.5 \%)$ was unable to fill out the questionnaires.

\section{Table 1}

Baseline characteristics of the myocardial infarction patient sample.

\begin{tabular}{l|c|c}
\hline & $\begin{array}{c}\text { Males } \\
\mathbf{n = 1 5 6} \\
\text { Mean (SD) }\end{array}$ & $\begin{array}{c}\text { Females } \\
\mathbf{n}=\mathbf{5 0} \\
\text { Mean (SD) }\end{array}$ \\
\hline Age (years)* $^{*}$ & $59(10.6)$ & $62.9(10.7)$ \\
ASAT $_{\max }(\mathrm{U} / \mathrm{L})$ & $239(167)$ & $207(147)$ \\
Major depression $_{\text {Minor depression }}$ & 13 & 10 \\
HAMD depressed patients & 12 & 4 \\
HAMD non-depressed & $14.5(6.5)$ & $20.2(4.7)$ \\
\hline
\end{tabular}

${ }^{*} \mathrm{p}$-value $=0.02$; values are means $\pm \mathrm{SD}$ where noted. $\mathrm{ASAT}_{\max }=$ maximum value of the enzyme aspartate aminotransferase; HAMD-17 = 17-item Hamilton Depression Rating Scale; MI: myocardial infarction.

The HADS was filled out by 179 patients because this questionnaire was added 2 months after the start of the study. The internal consistency of all self-report questionnaires was good with the Cronbach's alphas ranging from 0.81 (BDI), 0.82 (HADS depression subscale) and 0.83 (HADS anxiety subscale) to 0.86 (SCL-90, depression subscale), and 0.88 (total HADS). 
The optimum cut-off score for detecting major and minor depression post-MI can be obtained visually from the ROC curve (Figure 1 and Table 2). For the SCL-90, depression subscale, this optimal cut-off score was 26/27 (sensitivity = $81.1 \%$; specificity $=83.5 \%$; PPV $=40 \% ; \mathrm{NPV}=93.3 \%)$. For the BDI, the optimal cut-off score was $7 / 8$ (sensitivity $=83.8 \%$; specificity $=71.7 \%$; PPV = $25.3 \%$; NPV $=98.3 \%$ ). For the HADS depression subscale, the optimal cut-off score was $3 / 4$ (sensitivity $=75 \%$; specificity $=77.6 \% ; \mathrm{PPV}=32.1 \% ; \mathrm{NPV}=$ $98.4 \%$ ). For the HADS anxiety subscale, the optimal cut-off score was 5/6 (sensitivity $=96.9 \%$; specificity $=68.7 \%$; PPV $=40 \% ; \mathrm{NPV}=95.8 \%)$. If we add both subscales of the HADS together, the optimal cut-off score was 11/12 $($ sensitivity $=78.1 \%$; specificity $=85 \% ; \mathrm{PPV}=45.2 \% ; \mathrm{NPV}=99.3 \%)$. For the observer rating scale HAMD-17, the optimal cut-off score was 11/12 (sensitivity $=76.3 \%$; specificity $=86.0 \% ; \mathrm{PPV}=40.7 \%$; NPV $=99.3 \%$ ). The AUCs varied from 0.84 (BDI) via 0.85 (HADS depression subscale) and 0.87 (SCL-90) to 0.88 (total HADS) and 0.90 (HADS anxiety subscale). The AUC of the HAMD-17 was 0.89 .

\section{Table 2}

Screening abilities at optimal cut-off values of the SCL-90, depression subscale, BDI, HADS and HAMD for major and minor depression 1 month after first myocardial infarction.

\begin{tabular}{|c|c|c|c|c|c|c|}
\hline & $\begin{array}{c}\text { SCL-90, } \\
\text { dep } \\
n=199\end{array}$ & $\begin{array}{c}\text { BDI } \\
\mathrm{n}=199\end{array}$ & $\begin{array}{c}\text { HADS, } \\
\text { anx } \\
\mathrm{n}=179\end{array}$ & $\begin{array}{c}\text { HADS, } \\
\text { dep } \\
\mathrm{n}=179\end{array}$ & $\begin{array}{c}\text { HADS, } \\
\text { total } \\
\mathrm{n}=179\end{array}$ & $\begin{array}{l}\text { HAMD } \\
\mathrm{n}=206\end{array}$ \\
\hline Optimal cut-off & $\begin{array}{c}\geq 27 \\
M \geq 23 \\
F \geq 27\end{array}$ & $\begin{array}{c}\geq 8 \\
M \geq 8 \\
F \geq 8\end{array}$ & $\begin{array}{c}\geq 6 \\
M \geq 6 \\
F \geq 10\end{array}$ & $\begin{array}{c}\geq 4 \\
M \geq 5 \\
F \geq 3\end{array}$ & $\begin{array}{c}\geq 12 \\
M \geq 10 \\
F \geq 13\end{array}$ & $\begin{array}{l}\geq 12 \\
M \geq 12 \\
F \geq 13\end{array}$ \\
\hline Sensitivity & 81.1 & 83.8 & 96.9 & 75.0 & 78.1 & 76.3 \\
\hline Specificity & 83.5 & 71.7 & 68.7 & 77.6 & 85.0 & 86.0 \\
\hline PPV & 40.0 & 25.3 & 40.0 & 32.1 & 45.2 & 40.7 \\
\hline NPV & 93.3 & 98.3 & 95.8 & 98.4 & 99.3 & 99.3 \\
\hline AUC & 0.87 & 0.84 & 0.90 & 0.85 & 0.88 & 0.89 \\
\hline
\end{tabular}

$\overline{\mathrm{AUC}}=$ area under curve; $\mathrm{BDI}=$ Beck Depression Inventory; $\mathrm{HADS}$ anx $=$ anxiety subscale of the Hospital Anxiety and Depression Scale; HADS dep = depression subscale of the Hospital Anxiety and Depression Scale; HAMD-17 = 17-item Hamilton Depression Rating Scale; NPV =

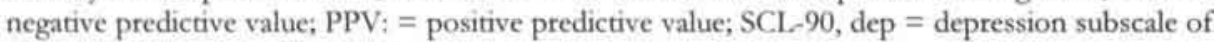
the 90-item Symptom Check List.

For major depression only, the validity and optimum cut-off scores change (Table 3). The optimum cut-off score for the SCL-90 was then $24 / 25$ (sensitivity $=95.5 \%$; specificity $=74 \% ; \mathrm{PPV}=36.8 \% ; \mathrm{NPV}=96.2 \%)$, for the BDI $9 / 10$ (sensitivity $=81.8 \%$; specificity $=78.7 \% ; \mathrm{PPV}=33.3 \% ; \mathrm{NPV}=$ 
$97.9 \%$ ), for the HADS depression subscale $3 / 4$ (sensitivity $=85 \%$; specificity $=$ $74.8 \% ; \mathrm{PPV}=32.1 \%$; NPV $=98.4 \%$ ), and $8 / 9$ for the HADS anxiety subscale (sensitivity $=85 \%$; specificity $=88.1 \%$; PPV $=48.6 \%$; NPV $=97.4 \%)$. For the total HADS, the optimum cut-off score is $12 / 13$ (sensitivity $=90 \%$; specificity $=84.3 \% ; \mathrm{PPV}=45.2 \% ; \mathrm{NPV}=99.3 \%$ ) and for the HAMD $14 / 15$ (sensitivity $=86.4 \%$; specificity $=92.2 \% ; \mathrm{PPV}=58.8 \% ; \mathrm{NPV}=98.2 \%)$.

\section{Table 3}

Screening abilities at optimal cut-off values of the SCL-90, depression subscale, BDI, HADS and HAMD for major depression 1 month after first myocardial infarction.

\begin{tabular}{|c|c|c|c|c|c|c|}
\hline & $\begin{array}{c}\text { SCL-90, } \\
\text { dep } \\
\mathrm{n}=199\end{array}$ & $\begin{array}{c}\text { BDI } \\
\mathbf{n}=199\end{array}$ & $\begin{array}{c}\text { HADS, } \\
\text { anx } \\
\mathrm{n}=179\end{array}$ & $\begin{array}{c}\text { HADS, } \\
\text { dep } \\
\mathrm{n}=179\end{array}$ & $\begin{array}{c}\text { HADS, } \\
\text { total } \\
\mathrm{n}=179\end{array}$ & $\begin{array}{l}\text { HAMD } \\
\mathrm{n}=206\end{array}$ \\
\hline Optimal cut-off & $\geq 25$ & $\geq 10$ & $\geq 9$ & $\geq 4$ & $\geq 13$ & $\geq 15$ \\
\hline Sensitivity & 95.5 & 81.8 & 85.0 & 85.0 & 90.0 & 86.4 \\
\hline Specificity & 74.0 & 78.7 & 88.1 & 74.8 & 84.3 & 92.2 \\
\hline PPV & 36.8 & 33.3 & 48.6 & 32.1 & 45.2 & 58.8 \\
\hline NPV & 96.2 & 97.9 & 97.4 & 98.4 & 99.3 & 98.2 \\
\hline AUC & 0.95 & 0.88 & 0.94 & 0.90 & 0.97 & 0.92 \\
\hline
\end{tabular}

$\overline{\mathrm{AUC}}=$ area under curve; $\mathrm{BDI}=$ Beck Depression Inventory; HADS anx $=$ anxiety subscale of the Hospital Anxiety and Depression Scale; HADS dep = depression subscale of the Hospital Anxiery and Depression Scale; HAMD = 17-item Hamilton Depression Rating Scale; NPV = negative predictive value; PPV: = positive predictive value; SCL-90, dep = depression subscale of the 90-item Symptom Check List.

\section{Discussion}

The goal of this study was to assess sensitivity and specificity of three selfreport questionnaires and one observer rating scale for depression as screening instruments for depression following first MI. The main finding of our study is that all scales have acceptable abilities to be used as screening instruments for post-MI depression. A limitation of this study is that women and older patients in general refused to participate in this study, which decreases generalization of the results.

All optimum cut-off scores for major and minor depression, observed in the ROC curves, were below the general accepted cut-off scores of the SCL-90 depression subscale $(M=22 / 23, F=27 / 28)$, HADS ( $7 / 8$ for both subscales), BDI $(9 / 10)^{7 \cdot 9,11.21}$, and HAMD (17/18) ${ }^{11}$. Relative to our findings, these generally accepted cut-off scores would result in a slight decrease in sensitivity and specificity of SCL-90 (75.3\% and $81.1 \%$, respectively); for the HAMD and HADS depression subscale, it would lead to a higher sensitivity $(98.8 \%$ and 
$95.2 \%$, respectively) but lower specificity ( $55.3 \%$ and $34.3 \%$, respectively). The generally used cut-off scores of $9 / 10$ for the BDI and $7 / 8$ for the HADS anxiety scale 9.21 would result in a slight decrease in sensitivity $(81.1 \%)$ and specificity $(67.6 \%)$ for the BDI and a decreased sensitivity $(86.4 \%)$ but increased specificity (71.9) for the HADS anxiety scale.

In cardiac patients, a lower cut-off score for HADS depression subscale compared with the HADS anxiety subscale has been described ${ }^{21}$. In addition, mean age in our study population (59 years for men and 62.9 years for women) was within the age group that scores highest on HADS anxiety ${ }^{21}$. The validity of the total HADS increases if we add the depression and anxiety subscale together (sensitivity $=78.1 \%$; specificity $=85 \% ; \mathrm{PPV}=45.2 \% ; \mathrm{NPV}=$ $99.3 \%$ ). An explanation for this increase of validity of the total HADS compared with the two subscales could be that depressive affect is typically characterized by a combination of high negative affect and low positive affect ${ }^{29}$. These affective mood states were also identified in coronary patients ${ }^{30}$. Visual inspection of the items of the HADS strongly suggests that the anxiety subscale is closely related to the negative mood dimension, while the depression scale is closely related to anhedonia or the relative absence of positive mood status. Hence, adding the HADS anxiety and depression subscales together may identify those patients who are characterized by depressive affect in twodimensional mood space ${ }^{29,30}$. Because of the increase in specificity and PPV, one might use the total HADS in stead of both subscales, as most studies do ${ }^{21}$. For screening purposes, a high sensitivity and NPV are more important than a high specificity and PPV. In our study, the HADS anxiety subscale had a sensitivity of almost $100 \%(96.9 \%$ and NPV $=95.8 \%)$ at the optimal cut-off $5 / 6$ for screening major and minor depression. Our results show that sensitivity and NPV of the SCL-90, BDI and HAMD can be optimised by choosing lower cut-off scores $(\mathrm{BDI}=3 / 4 ; \mathrm{SCL}-90=17 / 18$; HAMD $=5 / 6)$. However, this induces an unacceptable low specificity in these scales (BDI $=23.1 \%$; SCL-90 $=13.9 \%$; HAMD $=29.9 \%$ ) (see ROC curves), thereby increasing the number of false positives. So, the HADS anxiety subscale is at least comparable to the BDI for screenings purposes in post-first MI depression, having the highest AUC. HAMD as an observer rating scale is equally valid as a screening instrument as the self-report questionnaires for major and minor depression post-MI.

For diagnostic purposes a high specificity and PPV are most important. The PPV of a test depends, in part, on prevalence of the disorder in the population. Due to the relatively low number of depressed patients compared with nondepressed patients in this study, the PPVs are much lower than the NPVs. For example, when using the HADS, one can be quite certain that a patient scoring below the cut-off does not have a depressive disorder. When a patient scores above the cut-off, the chance that this patient has a depressive disorder is equal to the chance of not having a depressive disorder. This would mean that half of the patients who are asked to participate in a lengthy interview do not fulfil 
criteria for depression. Therefore, dichotomizing samples based on the use of self-rating scales for diagnostic purposes remains hazardous.

The optimum cut-off scores for major depression are different and higher than those for both major and minor depression. The general accepted cut-off points for the BDI, HADS anxiety subscale and total HADS are equal to that of the optimum cut-off scores for major depression. Apart from major depression, it is important to screen for minor depression, as minor depression has also an impact on morbidity and mortality post-MI 1,18,31. Therefore lower cut-off scores might be preferable, although they lead to a larger number of false positives.

The possibility that patients may have filled out the questionnaires at home with help of the spouse or someone else may be a limitation of this study, although the high internal consistency (mean Cronbach's $\alpha=0.84$ ) suggests otherwise. Second, generalisation of the outcome to patients with coronary artery disease (CAD) other than first MI should be cautioned. Also predictive values may not reflect the performance of these same instruments when used in non-hospital settings.

In sum, all three self-report questionnaires (SCL-90, BDI and HADS) proved to have acceptable abilities for screening major and minor depression in MI patients, although some optimum cut-off values differ from the general accepted values. Screening abilities of the observer rating scale (HAMD) were comparable to those of the self-report questionnaires. Validity of the HADS is comparable to the BDI because of a high AUC at a cut-off value of $12 / 13$. One has to use different cut-off scores post-MI for screening for major depression only compared with screening for both major and minor depression. 


\section{Chapter 4}

Figure 1

ROC curves with the optimal cut-off values for screening major and minor depression after first myocardial infarction.

A. ROC curve of the SCL-90 depression subscale (AUC $=0.87$ )

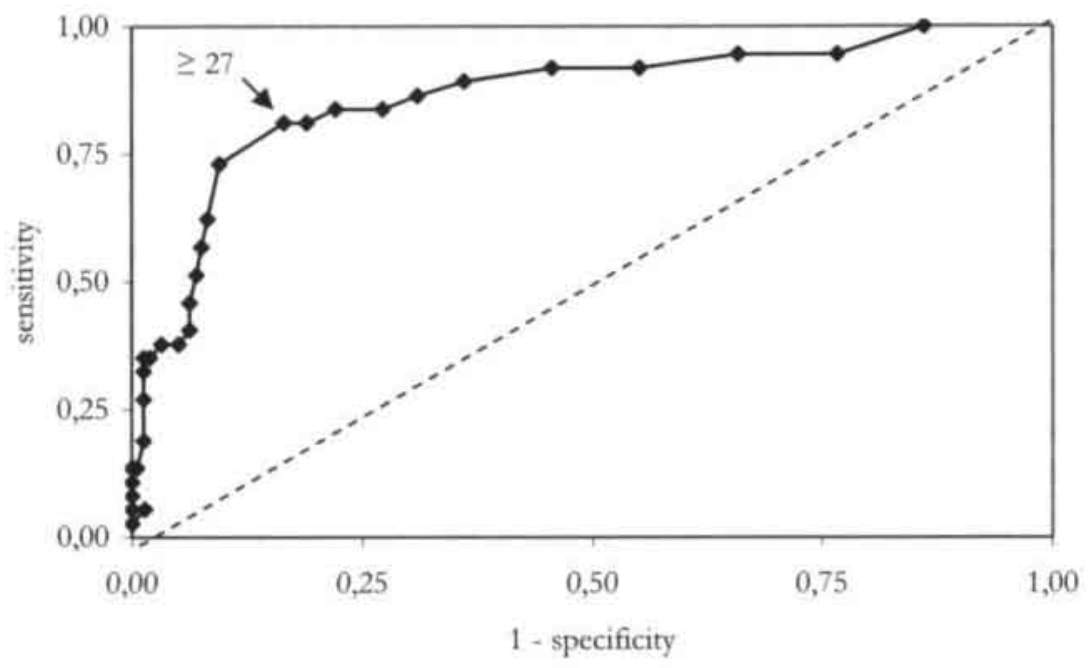

B. ROC curve of the BDI $(\mathrm{AUC}=0.84)$

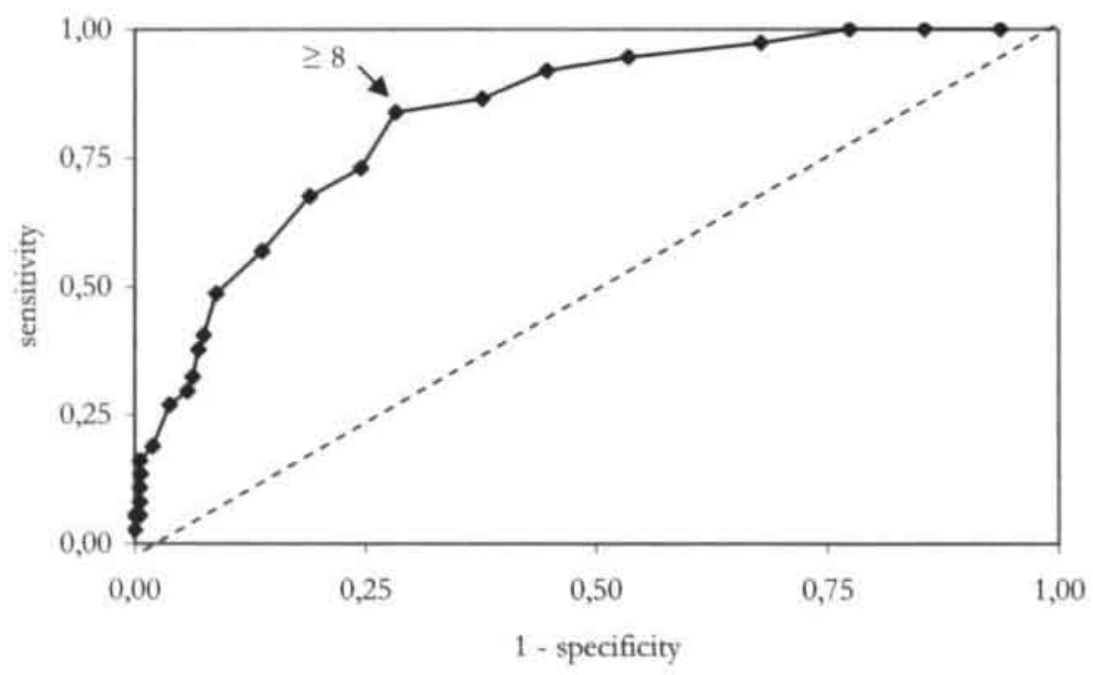


C. ROC curve of the HADS (total) $(\mathrm{AUC}=0.88)$

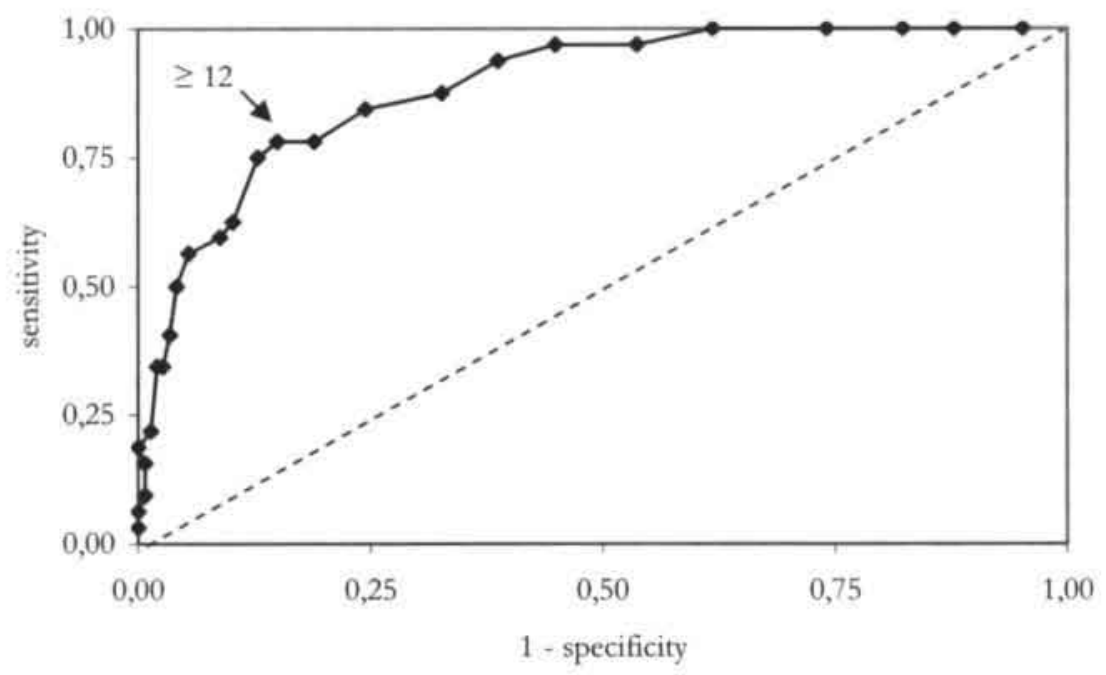

D. ROC curve of the HAMD-17 (AUC $=0.89$ )

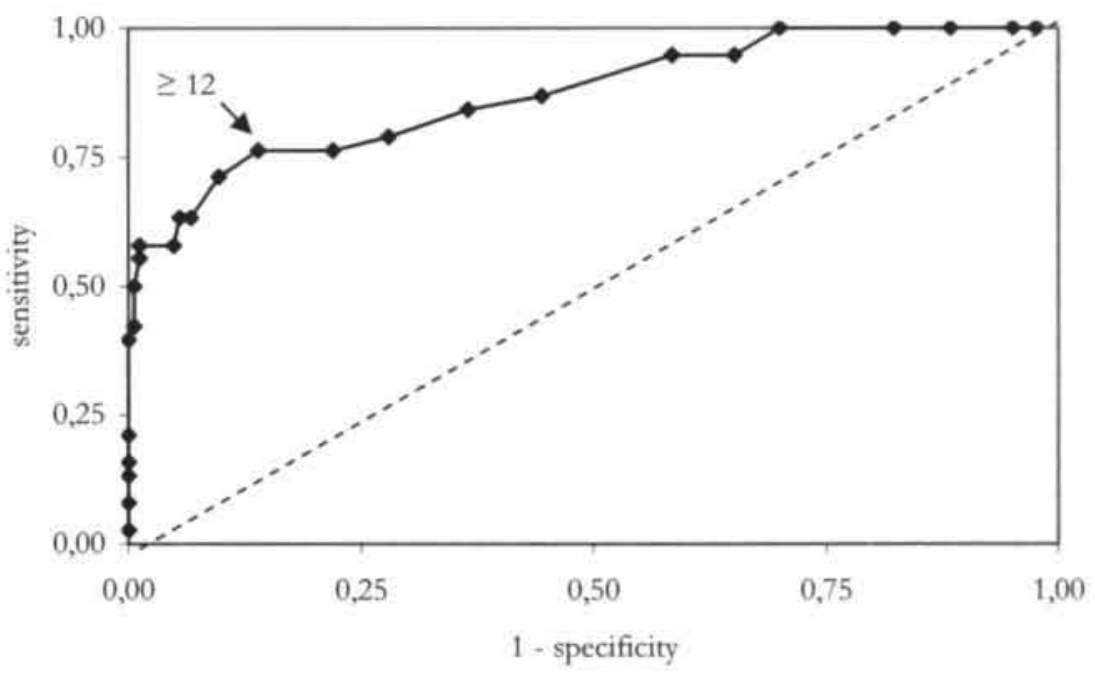

$\mathrm{AUC}=$ area under curve; $\mathrm{BDI}=$ Beck Depression Inventory HADS $=$ Hospital Anxiety and Depression Scale; HAMD $=17$-item Hamilton Depression Rating Scale; $\mathrm{ROC}=$ relative operating characteristics; SCL-90 $=90$-item Symptom Check List. 


\section{References}

1. Frasure-Smith N, Lespérance F, Talajic M. Depression following myocardial infarction: Impact on 6-months survival. JAMA 1993; 270:999-1005.

2. Barefoot JC, Schroll M. Symtomps of depression, acute myocardial infarction, and total mortality in a community sample. Circulation 1996; 93:1976-80.

3. Anda R, Williamson D, Jones D, et al. Depressed affect, hopelessness, and the risk of ischemic heart disease in a cohort of U.S. adults. Epidemiology 1993; 4:285-94.

4. Ahern DK, Gorkin L, Anderson JL, et al. Biobehavioral variables and mortality on cardiac arrest in the Cardiac Arrhythmia pilot study (CAPS). Am J Cardiology 1990; 66:59-62.

5. Fielding R. Depression and acute myocardial infarction: A review and reinterpretation. Soc Sci Med 1991; 32:1017-27.

6. Schleifer SJ, Macari-Hinson MM, Coyle DA, et al. The nature and course of depression following myocardial infarction. Arch Intern Med 1989; 149:1785-9.

7. Honig A, Lousberg R, Wojchiechowski F, et al. Depression following a first heart infarct; similarities with and difference from 'ordinary' depression. Ned Tijdschr Geneeskunde 1997; 141:196-9.

8. Arrindell WA, and Ettema JHM: Dimensional structure, reliability and validity of the Dutch version of the Symptom Checklist (SCL-90). Ned Tijdschr Psycholog 1981;43:381-7.

9. Beck AT, Steer RA. Beck Depression Inventory Manual. San Antonio: HarcourtBrace-Jovanovich; 1987:1-25.

10. Zung WW, Richards CB, Short MJ. A selfrating depression scale. Arch Gen Psychiatry 1965; 12:63-70.

11. Harnilton M. A rating scale for depression. J Neurol Neurosurg Psychiatry 1960; 23:56-62.

12. Freedland KE, Lustman PJ, Carney RM, et. al. Underdiagnosis of depression in parients with coronary artery disease: the role of nonspecific symptoms. Int J Psychiatry Med 1992; 22:221-9.

13. Richter P, Werner J, Heerlein A, et al. On the validity of the Beck Depression Inventory. Psychopathology 1998; 31:160-8.

14. Schmitz N, Kruse J, Heckrath C, et al. Diagnosing mental disorders in primary care: The general health questionnaire (GHQ) and the Symptom Check List (SCL-90-R) as screening instruments. Soc Psychiatry Psychiatr Epidemiol 1999; 34:360-55.

15. Herrmann C, Breuker A, Schmidt T, et al. Angina Pectoris bei Myokardischamie: Bedeuting psychischer Distressfacktoren. Z Kardiol 1993; 82:80.

16. Derogatis LR, Lipman RS, Covi L. SCL-90: an outpatient psychiatric rating scaleprelimanary report. Psychopharm Bull 1973; 9:13-27.

17. Strik JJMH, Honig A, Lousberg R, et al. Efficacy and safety of fluoxetine in the treatment of patients with major depression following first myocardial infarction: findings from a double-blind placebo-controlled trial. Psychosom Med 2000: 62:783-9.

18. Lespérance F, Frasure-Smith N, Talajic M. Major depression before and after myocardial infarction: its nature and consequences. Psychosom Med 1996; 58:99110

19. Carney RM, Rich, Tevelde AJ. Major depressive disorder in coronary heart disease. Am J Card 1987; 60:1273-5. 
20. Forrester AW, Lipsey JR, Teitelbaum ML, et al. Depression following myocardial infarction. Int J Psychiatry Med 1992; 22:33-46.

21. Herrmann C. International experiences with the hospital anxiety and depression rating scale: a review of validation data and clinical results. J Psychosom Res 1997; 1:17-41.

22. Shapiro PA, Lespérance F, Frasure-Smith N, et al. An open-label prelimanary trial of sertraline for treatment of major depression after acute myocardial infarction (the SADHAT trial). Am Heart J 1999; 137:1100-6.

23. Roose SP, Laghrissi-Thode F, Kennedy JS, et al. Comparison of paroxetine and nortriptyline in depressed patients with ischemic heart disease. JAMA 1998; 279:287-91.

24. First MB, Spitzer RL, Gibbon M, Williams JB. Structured clinical interview for DSM-IV axis I disorders: patient edition (SCID-I/P, Version 2.0). New York: Biometrics Research Department, New York State Psychiatric Institute, New York; 1995.

25. Pasternak RC, Braunwald E, Sobel RE. Acute myocardial infarction, in: Braunwald E (ed). Heart disease: a textbook of cardiovascular medicine. Philadelphia,: WB Saunders Compagny, 1992, pp 1200-91.

26. The American Psychiatric Association. Diagnostic and statistic manual of mental disorders IV. Washington DC, American Psychiatric Association, 1994.

27. Murphy JM, Berwick DM, Weinstein MC, et al. Performance of screening and diagnostic tests. Application of receiver operating characteristic analysis. Arch Gen Psychiatry 1987; 44:550-5.

28. Stata Corporation. Stata Statistical Software: Release 5.0. College Station, 1997.

29. Clark LA, Watson D. Tripartite model of anxiety and depression: psychometric evidence and taxonomic implications. J Abn Psychology 1991; 100:316-36.

30. Denollet J. Emotional distress and fatique in coronary heart disease: the Global Mood Scale (GMS). Psychol Med 1993; 23:111-21.

31. Penninx BWJH, Beekman ATF, Honig A, et al. Depression and cardiac mortality: results from a community-based longitudinal study. Arch Gen Psychiatry 2001; $58: 221-7$. 


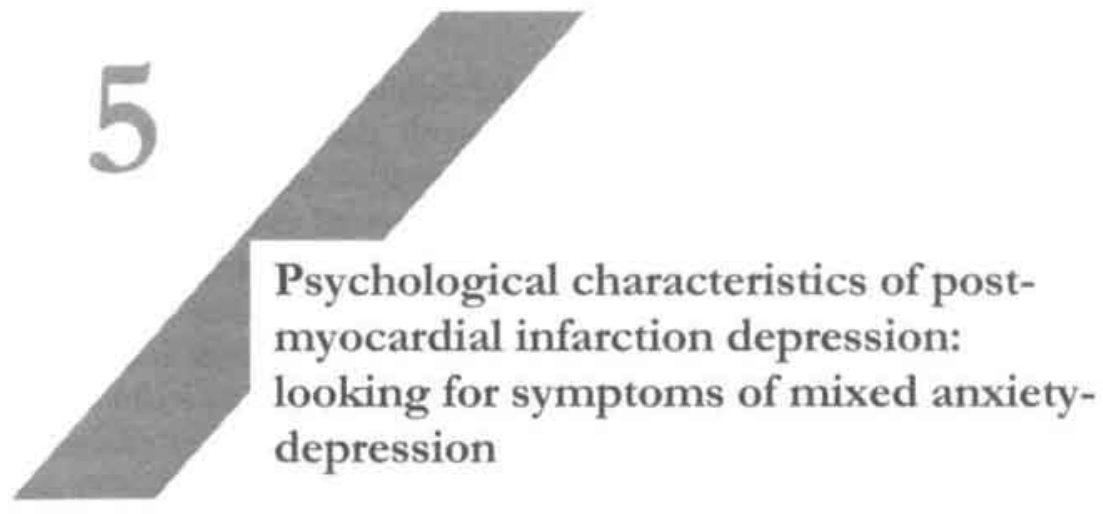




\section{Abstract}

Depression predicts mortality in myocardial infarction (MI) patients but few studies have accounted for the co-occurrence of anxiety. We studied 1) symptoms of anxiety that may go unrecognized in post-MI patients and 2) their association with post-MI depression. One month post-MI, 176 patients filled out six standard scales of depression and anxiety. Using a psychiatric interview, 31 patients $(18 \%)$ were diagnosed with depression. Anxiety and depression scales correlated 0.70 and reflected one mixed anxiety-depression factor, not two symptom dimensions. Four symptoms (tension, restlessness, feeling blue, hopelessness) were selected to comprise a Symptoms of mixed AnxietyDepression (SAD) scale $(\alpha=0.86)$. Mixed anxiety-depression $(\mathrm{SAD} \geq 3$ ) was present in $90 \%$ of depressed MI patients. After adjustment for 'pure' depression symptoms, age, gender, and left ventricular ejection fraction, mixed anxiety-depression was associated with an increased risk of post-MI depression $(\mathrm{OR}=11.2,95 \% \mathrm{CI}=3.0-42.5, \mathrm{p}=0.0001)$. Mixed anxiety-depression was also a predictor of elevated scores on the Beck Depression Inventory that have been related to post-MI mortality $(\mathrm{OR}=5.3 ; 95 \% \mathrm{CI}=2.1-13.3 ; \mathrm{p}<0.0001)$. Anxiety and depression frequently co-occur in post-MI patients. Self-reported symptoms of mixed anxiety-depression are associated with an increased risk of post-MI depression. Clinical trials should include anxiety as a potential focus of intervention.

\section{Reference}

Denollet J, Strik JJMH, Lousberg R, Honig A. Psychological characteristics of post-myocardial infarction depression: looking for symptoms of mixed anxietydepression. Psychomatics 2003; Submitted. 


\section{Introduction}

Depression is a common chronic condition in medical patients 1 . It is the leading cause of chronic disease burden ${ }^{2}$, including decline in physical status and development of ischemic heart disease ${ }^{3}$. Depression is a risk factor for cardiac events after coronary artery bypass surgery ${ }^{4}$, and for poor prognosis following myocardial infarction (MI) ${ }^{5}$. This risk may be caused by noncompliance with treatment ${ }^{6}$ or by direct effects such as increased platelet reactivity ${ }^{7}$ and decreased heart rate variability ${ }^{8}$. Hence, clinical trials have focused on the treatment of depression and distress in these patients ${ }^{9-11}$.

Yet many questions remain unanswered 5,12 It is unclear whether this cardiac risk extends to mild levels of depressive symptoms ${ }^{5}$ and typical symptoms -like sadness- are not always reported by post-MI patients ${ }^{13}$. Few studies have simultaneously accounted for any overlap between depression and anxiety ${ }^{14}$, making it is unclear whether it is 'pure' depression or rather a condition of mixed anxiety-depression ${ }^{15}$ that is associated with cardiac risk. Most studies in post-MI patients are based on the notion that anxiety and depression scales are measuring discriminate negative emotions. In contrast, evidence indicates that anxiety and depression frequently co-occur in psychiatric patients, and that comorbid anxiety is associated with greater impairment ${ }^{16-19}$. We therefore examined the co-occurrence of self-reported symptoms of anxiety and depression in post-MI patients.

The purpose of the present study was (a) to investigate whether symptoms of anxiety are structurally related to depression, (b) to test the hypothesis that symptoms of mixed anxiety-depression may identify patients at high risk for clinical depression post-MI, and (c) to examine the role of clinical depression versus mixed anxiety-depression as a determinant of elevated scores on selfrating depression scales in post-MI patients.

\section{Methods}

\section{Patients}

Subjects were first-MI patients $(134$ men $/ 42$ women; mean age $=60.1 \mathrm{y} \pm 10.7)$ from the Maastricht University Hospital who take part in ongoing research on post-MI depression 20. MI diagnoses were made by a cardiologist according to electrocardiographic signs of MI, maximum value of the enzyme aspartate aminotransferase (ASAT $\max$ ) of at least $80 \mathrm{U} / \mathrm{L}$, and clinical criteria. The present study reports on 176 patients who were administered the entire assessment battery, including the Hospital Anxiety and Depression Scale (HADS) ${ }^{21}$. Exclusion criteria were recurrent MI or inability to fill out scales. Patients who refused to participate in the study $(29 \%)$ were older and more likely to be women, $\mathrm{p}=0.0320$. The local ethics committee approved this study and all patients gave written informed consent before inclusion in the study. 


\section{Symptoms of depression and anxiety}

All patients filled out psychological questionnaires at home following a one month post-MI interview. If patients did not return the questionnaires within two weeks, they received a reminder phone call. The Beck Depression Inventory (BDI), State-Trait Anxiety Inventory (STAI) and 90-item Symptom Check List (SCL-90) are widely used measures of depression and anxiety ${ }^{22}$. The BDI and STAI have also been used in follow-up studies of MI patients (Table 1). In this study, the BDI ${ }^{23}$ and the depression scales from the SCL-90 ${ }^{24}$ and HADS ${ }^{21}$ were used to assess depressive symptoms one month post-MI. Scores of 10 or more on the BDI indicate the presence of at least mild depressive symptoms, and have been associated with a poor prognosis in MI patients ${ }^{25-28}$. BDI scores 4-9 represent minimal depressive symptoms and have also been related to post-MI mortality 29,30 .

Internal validity of mixed anxiety-depression symptoms was examined by including anxiety scales and using factor analysis to examine structural relationships with depression. All patients filled out the state-anxiety scale from the STAI ${ }^{31}$ and the anxiety scales from the SCL-90 ${ }^{24}$ and HADS ${ }^{21}$. The STAI is a popular measure of feelings of tension and worry ${ }^{22}$. Elevated scores on the STAI have been associated with a poor prognosis in MI patients $32-35$. The internal consistency of all measures used in the present study was good, with the Cronbach's $\alpha$ ranging from $\alpha=0.81$ (BDI) to $\alpha=0.88$ (HADS).

\section{Standardized psychiatric interview}

Psychiatric interviews were used as criterion variables to diagnose clinical depression and to rate the severity of depression. DSM-IV criteria for major/minor depression were assessed by the Structured Clinical Interview (SCID-I-R) ${ }^{36}$. All patients were interviewed one month post-MI by the second author (JS) using the SCID-I-R depression section. Patients were diagnosed with major depression if they fulfilled at least one core criterion (depressed mood or loss of interest) and at least 4 out of 5 additional criteria (sleep difficulties, loss of appetite/weight, fatigue, difficulty concentrating, psychomotor agitation/retardation, low self-esteem/guilt, and thoughts of suicide) with duration of at least 2 weeks ${ }^{37}$. Minor depression was considered present if patients fulfilled 1 to 3 instead of 4 additional criteria ${ }^{37}$. The17-item Hamilton Depression Rating Scale (HAMD-17) was used to rate depression severity ${ }^{38}$. This observer-rating scale has been used to study the effect of antidepressants in cardiac patients 9,39 .

\section{Severity of cardiac disorder}

Left ventricular ejection fraction (LVEF) was included to control for cardiac disorder as a determinant of depression. LVEF $\leq 50 \%$ has been associated with increased risk of cardiac events ${ }^{35}$; this cut-off was used to identify MI patients with significant cardiac disorder. 


\section{Table 1}

BDI (Depression) and STAI (Anxiety) as predictors of poor prognosis in patients with CHD

\begin{tabular}{|c|c|c|c|c|c|c|}
\hline $\begin{array}{l}\text { Self-report } \\
\text { scale }\end{array}$ & Pollow-up scudy & Seudy sample & Follow-up & $\begin{array}{l}\text { Significant } \\
\text { end points }\end{array}$ & Risk ratio & p-value \\
\hline \multirow[t]{3}{*}{ BDI } & Ahem et al. 22 & $\begin{array}{l}265 \text { post-MI patients } \\
\text { with arrhythmias }\end{array}$ & 1 year & $\begin{array}{l}\text { deach or } \\
\text { cardiac arrest }\end{array}$ & $1.4(C .1: 1.01-1.9)$ & $<0.05$ \\
\hline & Frasure-Sraith ex al. 21 & 218 post-MI patients & 1.5 year & cardiac death & 7,8 (CI 2.4.25,3) & 0.0002 \\
\hline & Lesperance et al. ${ }^{25}$ & 430 coronary patients & 1 year & $\begin{array}{l}\text { cardiac death or } \\
\text { myocardial infarction }\end{array}$ & 6. $7(K 12.4-18.6)$ & $<0,001$ \\
\hline \multirow[t]{3}{*}{ STAI } & Frasure-Smith et al. ${ }^{42}$ & 218 post-MIl patients & I year & $\begin{array}{l}\text { cardiac events, including } \\
\text { arrhythmic events }\end{array}$ & $2.5(\mathrm{CI}: 2.2 .6)$ & 0.02 \\
\hline & Frasure-Smith et al at & 896 post-MI patients & 1 year & cardiac death in men & $2.6(\mathrm{CI}, 1.1-6.3)$ & 0.04 \\
\hline & Denollet et al. & 322 coronary patients & 5 year & $\begin{array}{l}\text { cardiac events or } \\
\text { CABG/PTCA }\end{array}$ & 1.9 (CI 1.0-3.6) & 0.04 \\
\hline
\end{tabular}

BDI: Beck Depression Inventory to, STAI: State-Trait Anxiety Inventory 32. 


\section{Statistical analyses}

Pearson's correlations and second-order factor analysis (varimax rotation) were used to examine the structural relationship between anxiety and depression. Scree plot criteria were used to decide on the optimum number of factors to retain ${ }^{40}$. Factor loadings on the first unrotated component were used to derive an index of mixed anxiety-depression containing 2 symptoms of anxiety and depression, respectively. Cronbach's $\alpha$, Pearson's correlations and factor analysis were used to examine the characteristics of the mixed anxietydepression scale that emerged from these analyses. Differences in mean scores on standard depression and anxiety scales between MI patients who were high versus low in mixed anxiety-depression were examined. Cross-tabulation was used to examine the association between mixed anxiety-depression and the diagnosis and severity of clinical depression post-MI. Logistic regression analysis was used to test a model of clinical depression, with the BDI, the 4-tem mixed anxiety-depression scale, $\operatorname{LVEF} \leq 50 \%$, gender and age as predictor variables. Criteria for entry and removal were based on the likelihood ratio test with limits set at $p \leq 0.05$ and $p>0.05$. Finally, patients were stratified by BDI scores $\geq 10^{26}$ and 4-9 29 to examine the prevalence of clinical depression and mixed anxiety-depression in patients who fall within these ranges of BDI scores that are associated with increased risk of post-MI mortality.

\section{Results}

Twenty patients met criteria for major and 11 for minor depression. This postMI depression prevalence rate of $31 / 176=18 \%$ is in line with other studies reporting $15-23 \%$ prevalence of post-MI depression ${ }^{41}$. The mean score on the HAMD-17 was $17.0(\mathrm{SD}=6.2)$ for clinically depressed patients and $7.3(\mathrm{SD}=$ 4.5) for non-depressed patients, $\mathrm{p}<0.0001$. Mean scores of self-reported symptoms of depression (BDI $=7.3, \mathrm{HADS}=3.0)$ and anxiety $(\mathrm{STAI}=36.5$, HADS $=5.6$ ) were similar to those reported in other medical populations ${ }^{21}$.

\section{Relationsbip between symptoms of depression and anxiety}

Correlations in the range of $0.57-0.80$ indicated that depression and anxiety scores were closely related (Table 2 , left). The mean correlation between the depression and anxiety scales $(r=0.70)$ was similar to the mean correlation among depression $(r=0.71)$ and anxiety $(r=0.68)$ scales. Factor analysis failed to indicate any structural differences between symptoms of depression and anxiety. The scree plot indicated one dominant dimension of mixed anxietydepression symptoms that accounted for $75 \%$ of the total variance in symptoms (Table 2, right). Succeeding factors were much smaller, explaining a minor proportion of variance. Even the extraction of a second factor, albeit not warranted by scree plot criteria, failed to produce separate 'depression' and 'anxiety' factors (Table 2, right). These findings indicated a significant structural 
relationship between symptoms of depression and anxiety as reported by postMI patients.

\section{Table 2}

Structural relationship between six standard self-report scales of depression and anxiety in post-MI patients $(\mathrm{N}=176)$

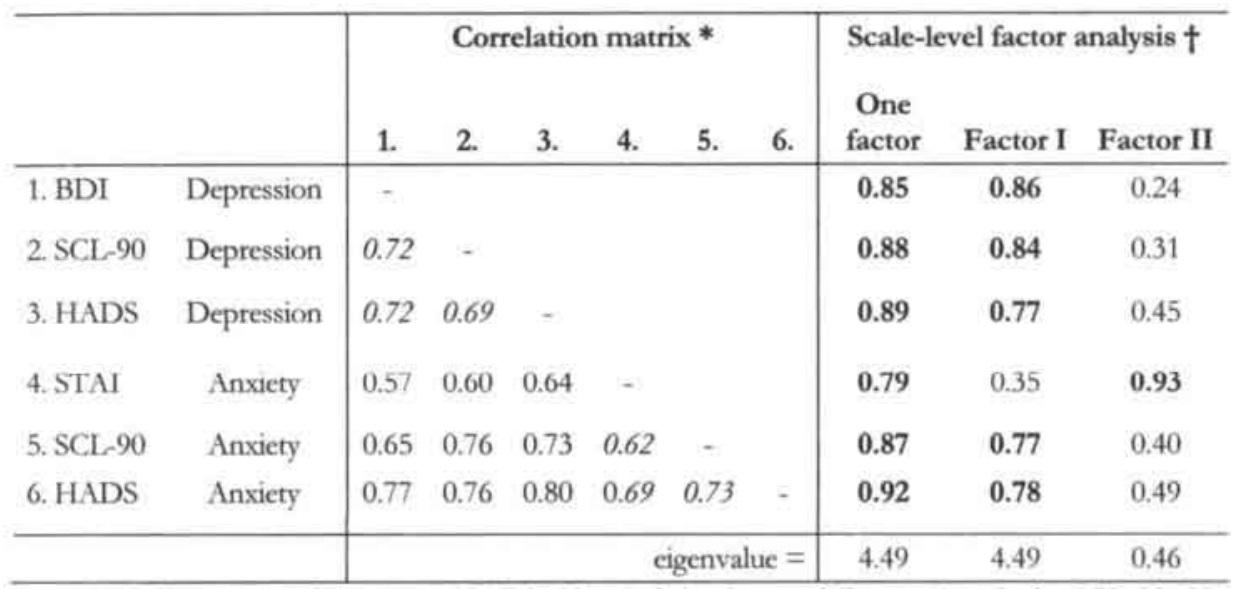

BDI: Beck Depression Inventory; HADS: Hospital Anxiety and Depression Scale; SCL-90: 90item Symptom Check List; STAI: State-Trait Anxiety Inventory.

- intercorrelations among depression scales and among anxiety scales are presented in italics.

$\dagger$ factor loadings $>0.75$ are presented in boldface.

\section{Mixed Anxiety-Depression}

Alternatively, depression and anxiety scales did reflect mixed anxiety-depression 15 as a core of post-MI distress. To test this model, 4 symptoms that correlated highly with the first distress factor (see above) were selected to comprise an index of mixed anxiety-depression containing 2 anxiety (tension, restlessness) and 2 depression (feeling blue, hopelessness) items.

Factor loadings between 0.77 and 0.88 , item-total correlations between 0.61 and 0.76 , and Cronbach's $\alpha=0.86$ indicated the validity of this index (Table 3). Correlations in the range of $0.69-0.87$ indicated that mixed anxiety-depression accounted for $50-75 \%$ of variance in scores on standard depression and anxiety scales (Table 4). Second-order factor analysis of these scales confirmed the mixed anxiety-depression model; i.e., the scree plot indicated that eigenvalues leveled after the first factor (Figure 1). All of the depression and anxiety scales had high loadings on this first factor, with the mixed anxiety-depression index yielding the highest loading $(0.93$, Table 4$)$. 


\section{Figure 1}

Scree plot showing the eigenvalues of the 7 factors representing the SAD, depression and anxiety self-report scales.

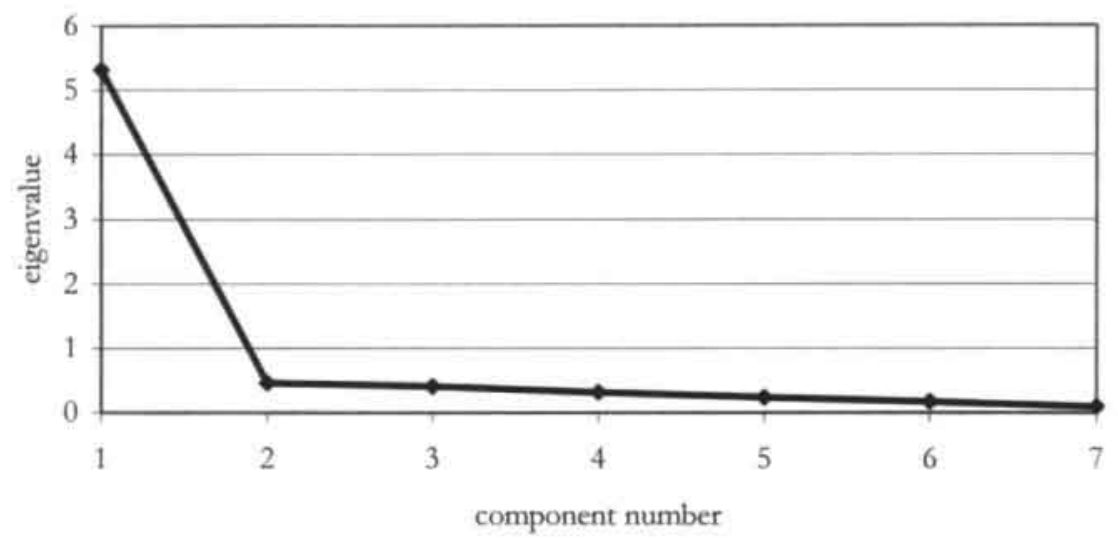

This scree plot indicated a marked 'elbow' that inflected after the first factor; succeeding factors explained only a minor proportion of variance in self-reported symptoms. This analysis yielded one dominant dimension of mixed Anxiety-Depression that is represented well by the 4-item SAD scale.

\section{Table 3}

Internal consistency of the symptoms of mixed Anxiety-Depression (SAD) scale in post-MI patients $(\mathrm{N}=176)$.

\begin{tabular}{|c|c|c|c|c|}
\hline Item & $\begin{array}{l}\text { Source: } \\
\text { Scale }\end{array}$ & (Instrument) & $\begin{array}{l}\text { Factor * } \\
\text { analysis }\end{array}$ & $\begin{array}{l}\text { Corrected } \\
\text { item- Total } \\
\text { correlations t }\end{array}$ \\
\hline 1. I feel blue & Depression & (SCl. 90, itern 30) & 0.86 & 0.73 \\
\hline $\begin{array}{l}\text { 2. I fed hopeless abour the } \\
\text { future }\end{array}$ & Depression & $(\mathrm{SCL}-90$, itcm 54$)$ & 0.84 & 0.70 \\
\hline 3. I feel tense or keyed up & Anxiety & (SCI 90 , item 57$)$ & 0.88 & 0.76 \\
\hline \multirow{2}{*}{$\begin{array}{l}\text { 4. I feel restiess as if } 1 \text { have to } \\
\text { be on the move }\end{array}$} & Anxiety & (HADS, stem 11) & 0.77 & 0.61 \\
\hline & & eigenvalue $=$ & 279 & $x=0.86$ \\
\hline
\end{tabular}

HADS: Hospital Anxiety and Depression Scale, SC1-90: 90-irem Symaptom Check List.

- Factor loadings ate presented in boldface.

† Reliability of scale; $\alpha=$ Cronbach's $\alpha$ estimate of intemal consistency. 
Table 4

Construct validity of the 4-item SAD scale in post-MI patients $(n=176)$.

\begin{tabular}{lc|c|c}
\hline & & $\begin{array}{c}\text { Correlation } \\
\text { SAD }\end{array}$ & $\begin{array}{c}\text { Scale-level } \\
\text { factor analysis }\end{array}$ \\
\hline SAD & Mixed Anxiety-Depression & - & 0.93 \\
BDI & Depression & 0.71 & 0.84 \\
SCL-90 & Depression & 0.87 & 0.89 \\
HADS & Depression & 0.73 & 0.87 \\
STAI & Anxiety & 0.69 & 0.78 \\
SCL-90 & Anxiety & 0.80 & 0.87 \\
HADS & Anxiety & 0.85 & 0.92 \\
\hline & & eigenvalue $=$ & 5.32 \\
\hline
\end{tabular}

BDI: Beck Depression Inventory; HADS: Hospital Anxiety and Depression Scale; SCL-90: 90-item Symptom Check List, STAI: State-Trait Anxiety Inventory.

\section{Table 5}

Mean depression and anxiety scores of post-MI patients who score high on the SAD scale.

\begin{tabular}{lc|c|c|c|c}
\hline & & $\begin{array}{c}\text { Low-SAD } \\
(\mathbf{n}=107)\end{array}$ & $\begin{array}{c}\text { High-SAD } \\
(\mathbf{n}=\mathbf{6 9})\end{array}$ & F* & p-value \\
\hline BDI & Depression & $4.7(3.4)$ & $\mathbf{1 1 . 3}(7.2)$ & $F=65.2$ & 0.0001 \\
SCL-90 & Depression & $\mathbf{3 . 3}(3.0)$ & $\mathbf{1 4 . 4}(8.9)$ & $F=140.5$ & 0.0001 \\
HADS & Depression & $\mathbf{1 . 7}(1.9)$ & $\mathbf{5 . 1}(3.1)$ & $F=84.3$ & 0.0001 \\
STAI & Anxiety & $\mathbf{3 1 . 2}(9.9)$ & $\mathbf{4 4 . 8}(10.2)$ & $F=77.8$ & 0.0001 \\
SCL-90 & Anxiety & $1.7(2.0)$ & $\mathbf{8 . 5}(6.3)$ & $F=107.3$ & 0.0001 \\
HADS & Anxiety & $\mathbf{3 . 5}(2.2)$ & $\mathbf{8 . 9}(3.6)$ & $F=150.9$ & 0.0001 \\
LVEF & Disease severity & $\mathbf{5 3 . 7}(9.9)$ & $\mathbf{5 3 . 5 ( 1 0 . 5 )}$ & $F=0.03$ & 0.876 \\
\hline
\end{tabular}

Standard deviations appear in parentheses.

BDI: Beck Depression Inventory; HADS: Hospital Anxiety and Depression Scale; LVEF: left ventricular ejection fraction;

SAD: symptoms of mixed Anxiety-Depression scale; SCL-90: 90-item Symptom Check List; STAI: State-Trait Anxiety Inventory.

* Degrees of freedom $=1,174$.

\section{Symptoms of mixed Anxiety-Depression (SAD) scale}

Because of this consistent pattern indicating that symptoms of anxiety and depression co-occur in post-MI patients, the 4-item index was labeled the Symptoms of mixed Anxiety-Depression (SAD) scale. Using the upper tertile of scores on the SAD as a cut-off (score $=3$ ), $69 \mathrm{MI}$ patients were classified as being high in mixed anxiety-depression $(\mathrm{SAD} \geq 3)$ and 107 as low in mixed anxiety-depression ( $\mathrm{SAD} \leq 2)$. High $\mathrm{SAD}$ scorers had 2 to 3 -fold increased 
scores on all of the standard depression and anxiety scales as compared to low $\mathrm{SAD}$ scorers, while these subgroups did not differ in cardiac disease severity as measured by LVEF (Table 5).

Next, we examined whether symptoms of mixed anxiety-depression indicate an increased risk of depression not only in psychiatric ${ }^{16-19}$ but also in post-MI patients. This implies that the SAD would predict depression risk above and beyond standard scales such as the BDI. Mixed anxiety-depression ( $\mathrm{SAD} \geq 3$ ) was present in $90 \%(28 / 31)$ of depressed MI patients (Figure 2, left). 'Pure' depressive symptoms $(\mathrm{BDI} \geq 10)$ were present in only $71 \%(22 / 31)$ of these patients. All of the severely depressed patients $(20 / 20)$ were high in mixed anxiety-depression (Figure 2, right).

\section{Figure 2}

Percentage of patients with mixed Anxiety-Depression, stratified by diagnosis (left) and severity (right) of clinical depression.

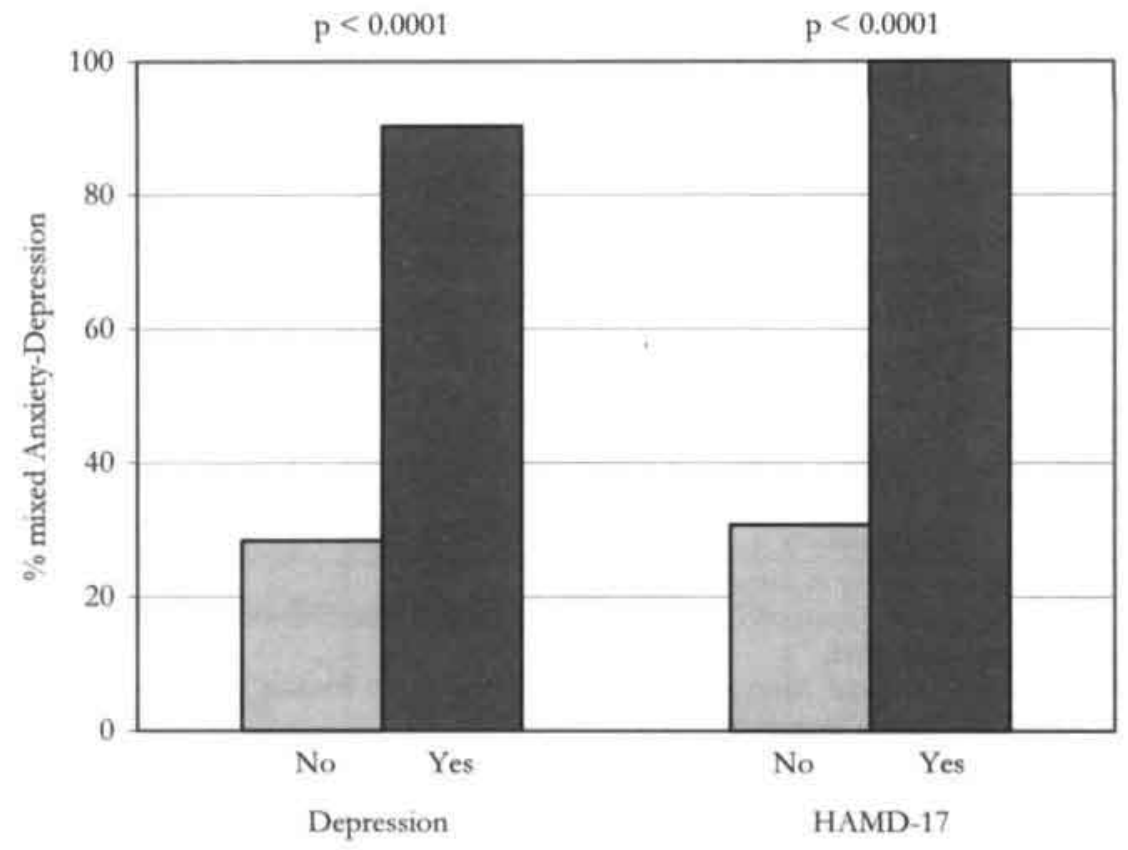

Depression $=$ Major $/$ minor depression following DSM-IV criteria; HAMD-17 = more severe depression with 17-item Hamilton Depression Rating Scale > 17.

Independent predictors of clinical depression post-MI

Multiple logistic regression analysis indicated that mixed anxiety-depression was an independent predictor of post-MI depression $(\mathrm{OR}=11.2, \mathrm{p}<0.0001)$ after 
controlling for scores on the BDI scale (OR $=4.4, \mathrm{p}=004), \mathrm{LVEF}$, age and gender (Table 6). Hence, symptoms of mixed anxiety-depression ( $\mathrm{SAD} \geq 3$ ) did predict the risk of depression above and beyond 'pure' depressive symptoms. This is in line with findings in psychiatric patients ${ }^{16-19}$ indicating that mixed anxiety-depression identifies patients at high risk for clinical depression.

\section{Table 6}

Independent predictors of clinical depression:

\begin{tabular}{|c|c|c|c|c|}
\hline Variable & & Odds ratio & $95 \% \mathrm{CI}$ & p-value \\
\hline \multicolumn{5}{|l|}{ Significant } \\
\hline Mixed Anxiety-Depression & $(\mathrm{S} A D \geq 3)$ & 11.2 & 3.0 to 42.5 & 0.0001 \\
\hline Depressive symptoms & $(\mathrm{BDI} \geq 10)$ & 4.4 & 1.6 to 12.1 & 0.004 \\
\hline \multicolumn{5}{|l|}{ Not significant } \\
\hline LVEF $\leq 50 \%$ & & 1.5 & 0.58 to 4.1 & 0.39 \\
\hline Aget & & 0.96 & 0.92 to 1.0 & 0.08 \\
\hline Female gender & & 1.5 & 0.54 to 4.4 & 0.42 \\
\hline
\end{tabular}

BDI: Beck Depression Inventory; LVEF: left ventricular ejection fraction; SAD: symptoms of mixed Anxiety-Depression scale.

- Major and minor depression coded as 1.

† Estimated per one year increase in age.

\section{BDI post-MI: clinical depression or symptoms of mixed Anxiety-Depression?}

BDI scores $\geq 10^{25-28}$ and BDI scores from 4-9 20,30 have been associated with a poor prognosis in post-MI patients. These scores purportedly reflect mild and minimal severity of 'pure' depressive symptoms, respectively. In this study, only $47 \%$ (22 of 47$)$ MI patients with a BDI score $\geq 10$ were eventually diagnosed with clinical depression. In comparison, $79 \%(37 / 47)$ of these patients reported symptoms of mixed anxiety-depression $(\mathrm{p}<0.0001)$. Only $10 \%(8 / 82)$ of patients with a BDI score $4-9$ were clinically depressed.

Mixed anxiety-depression symptomatology was an independent predictor (OR $=5.3, \mathrm{p}<0.0001$ ) of BDI scores $\geq 10$; clinical depression was only marginally significant $(\mathrm{p}=0.09)$ related to these BDI scores (Table 7 , top). Depression severity, age or gender did not add to the explanatory power of mixed anxietydepression. By analogy, mixed anxiety-depression symptomatology was the only predictor $(\mathrm{OR}=4.58, \mathrm{p}=0.01)$ of $\mathrm{BDI}$ scores from 4 to 9 ; clinical depression was not significantly associated with these BDI scores (Table 7 , bottom). Hence, BDI scores indicating increased cardiac risk ${ }^{25-30}$ only partly reflect clinical depression, but largely reflect mixed anxiety-depression symptoms that may occur in post-MI patients. 


\section{Table 7}

Independent predictors of depressive symptoms that have been associated with poor cardiac prognosis.

\begin{tabular}{|c|c|c|c|}
\hline Variable & Odds ratio & $95 \% \mathrm{CI}$ & p-value \\
\hline & \multicolumn{3}{|c|}{ Mild depressive symptoms (BDI $>9)^{\circ}$} \\
\hline \multicolumn{4}{|l|}{ Significant } \\
\hline Mixed Anxiety-Depression ( $\mathrm{SAD} \geq 3$ ) & 5.30 & 2.11 to 13.3 & 0.0001 \\
\hline \multicolumn{4}{|l|}{ Not siguificant } \\
\hline Clinical depression & 2.92 & 0.84 to 10.1 & 0.091 \\
\hline Severity of depression & 2.53 & 0.55 to 11.6 & 0.23 \\
\hline $\mathrm{LVEF} \leq 50 \%$ & 1.59 & 0.68 to 3.7 & 0.29 \\
\hline Age ${ }^{\prime}$ & 1.00 & 0.96 to 1.0 & 0.90 \\
\hline \multirow[t]{2}{*}{ Female gender } & 1.34 & 0.50 to 3.6 & 0.56 \\
\hline & \multicolumn{3}{|c|}{ Minimal depressive symptoms (BDI 4-9) } \\
\hline \multicolumn{4}{|l|}{ Significamt } \\
\hline Mixed Anxiety-Depression ( $\mathrm{S} A \mathrm{D} \geq 3$ ) & 4.58 & 1.42 to 14.7 & 0.01 \\
\hline \multicolumn{4}{|l|}{ Not significant } \\
\hline Clinical depression & 1.43 & 0.13 to 15.5 & 0.77 \\
\hline $\mathrm{LVEF} \leq 50 \%$ & 1.3 & 0.56 to 3.2 & 0.51 \\
\hline Age $t^{-}$ & 0.99 & 0.96 to 1.0 & 0.80 \\
\hline Female gender & 0.74 & 0.26 to 2.2 & 0.58 \\
\hline
\end{tabular}

BDI: Beck Depression Inventory; LVEF: left ventricular ejection fraction; SAD: symptoms of mixed Anxiety-Depression scale.

- $\mathrm{BDI}>9$ and $\mathrm{BDI} 4$ to 9 coded as 1 , respectively;

† Estimated per one year increase in age.

\section{Discussion}

The present findings indicated the existence of a mixed anxiety-depression factor ${ }^{15}$ as a core of post-MI patients' psychological symptoms. The 4 symptom SAD scale $(\alpha=0.86)$ accounted for $50-75 \%$ of variance in self-rated anxiety and depression and loaded 0.93 on this mixed factor. Mixed anxietydepression symptoms independently predicted clinical depression $(\mathrm{OR}=11.2)$, after controlling for BDI score $\geq 10$, cardiac disease severity, age and gender. Moreover, mixed anxiety-depression, but not clinical depression, was the only independent predictor of mildly $(O R=5.3)$ or minimally $(O R=4.6)$ elevated BDI scores that have been related to post-MI mortality ${ }^{20,30}$. These findings underscore the potential role of mixed anxiety-depression in MI patients.

Depression represents a mixture of sadness, loneliness and guilt, and often occurs in association with some kind of loss; anxiety results from perceptions of threat and inability to control upcoming situations ${ }^{14}$. Typical symptoms of depression, like sadness or guilt, are not frequently reported by post-MI 
patients ${ }^{13}$. Rather, they may complain primarily of atypical symptoms like worries or irritability that may be responsible for a strong association between depression and anxiety scales ${ }^{42}$, an association that we also observed in the present study. While previous research is based on the notion that anxiety and depression scales reflect distinct factors, our findings suggest that these two symptom factors may be difficult to differentiate post-MI. Others have also suggested that depression and anxiety co-occur in MI patients ${ }^{43}$.

This study has a number of limitations. The number of patients who were diagnosed with depression (i.e., 31 ) is relatively small, but the $18 \%$ depression prevalence rate corresponds well with the $15-23 \%$ post-MI depression rate reported by others ${ }^{41}$. The limited number of women (i.e., $42 / 178=24 \%$ ) and the exclusion of patients with a recurrent MI implies that generalization of the present findings should be cautioned. The possibility that patients may have filled out the scales at home with the help of their spouse or someone else may also be a limitation although the high internal consistency (mean Cronbachs' $\alpha$ $=0.84$ ) of the depression and anxiety scales suggests otherwise.

The present findings have implications from both a clinical and conceptual point of view. Clinically, they have implications in terms of screening, treatment and prognosis. First, symptoms of mixed anxiety-depression may signal an increased risk of clinical depression above and beyond the risk associated with standard depression scales. Hence, screening for post-MI depression risk may be enhanced by including symptoms of anxiety. By analogy, anxiety often precedes the onset of depression among adults from the general population ${ }^{17}$. The SAD is a very brief, reliable and valid tool that can be readily used for the detection of symptoms of mixed anxiety-depression among post-MI patients.

Second, co-morbid anxiety has been associated with a poor response to antidepressive treatment in psychiatric patients 18 and with reduced heart rate variability in depressed post-MI patients ${ }^{8}$. Many depressed patients are in need of treatment for anxiety problems, whereas physicians frequently underrecognize anxiety co-morbidity in these patients ${ }^{44}$. Hence, treatment of anxiety should be included in clinical trials of post-MI depression. Findings from the SADHART trial ${ }^{\circ}$ indicated that MI patients may present with a mixture of symptoms -including anxiety- requiring tailored intervention. Such an intervention may improve well-being ${ }^{10}$ and prognosis 11 in coronary patients. Third, in terms of prognosis, early recognition of mixed anxiety-depression would identify post-MI patients at high risk of psychiatric morbidity . morbid anxiety has not only been associated with greater severity of dipression but also with risk of suicidal ideation ${ }^{16}$.

Conceptually, the strikingly co-occurrence of anxiety and depression raises the question whether we should be looking for a common denominator of negative emotions in post-MI patients. Common factors such as personality traits may reflect a vulnerability to develop symptoms that overlap the diagnostic criteria for depression and anxiety. Neuroticism and introversion have been associated with high levels of depressive symptoms in psychiatric patients ${ }^{45}$ and with co- 
morbid anxiety and depression in the general population ${ }^{46}$. Personality traits have also been shown to account for the association between negative emotions and poor prognosis in patients with coronary heart disease ${ }^{3+35}$.

Only $47 \%$ of MI patients with a BDI score $\geq 10$ did cross the threshold for diagnosis of depression, indicating that symptom scales can not be used as a surrogate for a psychiatric diagnosis of depression ${ }^{4}$. Yet, evidence indicates that elevated scores on symptom scales may predict coronary events ${ }^{25-30}$; i.e., the relation between distress and prognosis is not confined to clinical depression alone. Research needs to find out whether symptoms of mixed anxiety-depression may also add to the risk-stratification post-MI.

In sum, this study indicates 1) that anxiety and depression frequently co-occur in MI patients and 2) that there is an urgent need to diagnose and treat symptoms of anxiety in these patients. The 4-symptom SAD scale is a useful tool for the early detection of mixed anxiety-depression and estimating the risk of depression. Finally, research on stress-related cardiac events should include anxiety as a potential harbinger of things to come.

\section{References}

1. Whooley MA, Simon GE. Managing depression in medical outpatients. N Engl J Med 2000; 343: 1942-50.

2. Michaud CM, Murray CJ, Bloom BR. Burden of disease: implications for future research. JAMA 2001; 285:535-9.

3. O'Connor CM, Gurbel PA, Serebruany VL. Depression and ischemic heart disease. Am Heart J 2000; 140:S63-9.

4. Connerney I, Shapiro PA, McLaughlin JS, et al. Relation between depression after coronary artery bypass surgery and 12-month outcome: a prospective study. Lancet 2001; 358:1766-71.

5. Carney RM, Freedland, KE, Jaffe AS. Depression as a risk factor for coronary heart disease mortality. Arch Gen Psychiatry 2001; 58:229-30.

6. Ziegelstein RC, Bush DE, Fauerbach JA. Depression, adherence behavior, and coronary disease outcomes. Arch Intern Med 1998;158:808-9.

7. Kuijpers PM, Hamulyak K, Strik JJ, et al. Beta-thromboglobulin and platelet factor 4 levels in post-myocardial infarction patients with major depression. Psychiatry Res 2002; 109:207-10.

8. Watkins LL, Blumenthal JA, Carney RM. Association of anxiety with reduced baroreflex cardiac control in patients after acute myocardial infarction. Am Heart J 2002;143:460-6.

9. Glassman $\mathrm{AH}$, O'Connor CM, Califf RM, et al. Sertraline treatment of major depression in patients with acute MI or unstable angina. JAMA 2002; 288:701-9.

10. Denollet J, Brutsaert DL. Enhancing emotional well-being by comprehensive rehabilitation in patients with coronary heart disease. Eur Heart J 1995; 16:1070-8.

11. Denollet J, Brutsaert DL. Reducing emotional distress improves prognosis in coronary heart disease: 9-year mortality in a clinical trial of rehabilitation. Circulation 2001; 104:2018-23.

12. Wulsin LR. Does depression kill? Arch Intern Med 2000; 160:1731-2. 
13. Fava M, Abraham M, Pava J, et al. Cardiovascular risk factors in depression: the role of anxiety and anger. Psychosomatics 1996; 37:31-7.

14. Kubzansky L.D, Kawachi I. Going to the heart of the matter: do negative emotions cause coronary heart disease? J Psychosom Res 2000; 48:323-337.

15. Tyrer, P. The case for cothymia: mixed anxiety and depression as a single diagnosis. Br J Psychiatry 2001; 179:191-3.

16. Zimmerman M, Chelminski I. Generalized anxiety disorder in patients with major depression: Is DSM-IV's hierarchy correct? Am J Psychiatry 2003; 160:504-512.

17. Goodwin RD. Anxiety disorders and the onset of depression among adults in the community. Psychol Med 2002; 32:1121-4.

18. Feske U, Frank E, Mallinger AG, et al. Anxiety as a correlate of response to the acute treatment of bipolar I disorder. Am J Psychiatry 2000; 157:956-62.

19. Goodwin RD, Gorman JM. Psychopharmacologic treatment of generalized anxiety disorder and the risk of major depression. Am J Psychiatry 2002; 159:1935-7

20. Strik JJ, Honig A, Lousberg R, et al. Sensitivity and specificity of observer and selfreport questionnaires in major and minor depression following myocardial infarction. Psychosomatics 2001; 42:423-8.

21. Herrmann C. International experiences with the Hospital Anxiety and Depression Scale: a review of validation data and clinical results. J Psychosom Res 1997; 42:1741.

22. Lambert MJ. Use of psychological tests for outcome assessment. In M.E. Maruish (Ed): The use of psychological testing for treatment planning and outcome assessment. Hillsdale,NJ: Lawrence Erlbaum Associates, 1994, pp. 75-97.

23. Beck AT, Ward CH, Mendelson M, et al. An inventory for measuring depression. Arch Gen Psychiatry 1961; 4:561-71.

24. Derogatis LR, Lipman RS, Covi L: SCL-90: an outpatient psychiatric rating scaleprelimanary report. Psychopharm Bull 1973; 9:13-27.

25. Ahern DK, Gorkin L, Anderson JL, et al. Biobehavioral variables and mortality or cardiac arrest in the Cardiac Arrhythmia Pilot Study (CAPS). Am J Cardiol 1990; 66:59-62.

26. Frasure-Smith N, Lesperance F, Talajic M. Depression and 18-month prognosis after myocardial infarction. Circulation 1995; 91:999-1005.

27. Irvine J, Basinski A, Baker B, et al. Depression and risk of sudden cardiac death after acute myocardial infarction: Testing for the confounding effects of fatigue. Psychosom Med 1999; 61:729-37.

28. Lespérance F, Frasure-Smith N, Juneau M, et al. Depression and 1-year prognosis in unstable angina. Arch Intern Med 2000; 160:1354-60.

29. Bush DE, Ziegelstein RC, Tayback M, et al. Even minimal symptoms of depression increase mortality risk after acute myocardial infarction. Am J Cardiol 2001; 88:33741.

30. Lespérance F, Frasure-Smith N, Talajic M, et al. Five-year risk of cardiac mortality in relation to initial severity and one-year changes in depression symptoms after myocardial infarction. Circulation 2002; 105:1049-53.

31. Spielberger CD, Gorsuch RL, Lushene RE. STAI manual for the State-Trait Anxiety Inventory. Palo Alto,CA: Consulting Psychologists Press, 1970.

32. Frasure-Smith N, Lespérance F, Talajic M. The impact of negative emotions on prognosis following myocardial infarction: Is it more than depression? Health Psychol 1995; 14:388-98. 
33. Frasure-Smith N, Lespérance F, Juneau M, et al. Gender, depression, and one-year prognosis after myocardial infarction. Psychosom Med 1999; 61:26-37.

34. Denollet J, Brutsaert DL. Personality, disease severity, and the risk of long-term cardiac events in patients with decreased ejection fraction after myocardial infarction. Circulation 1998;97:167-73.

35. Denollet J, Vaes J, Brutsaert DL. Inadequate response to treatment in coronary heart disease: Adverse effects of Type D personality and younger age on 5-year prognsosis and quality of life. Circulation 2000; 102:630-5.

36. First MB, Spitzer RL, Gibbon M, et al. Structured Clinical Interview for DSM-IV Axis I disorders-Patient Edition (SCID-I/P, Version 2.0). New York: Biometrics Research Department, New York State Psychiatric; 1995.

37. American Psychiatric Association (ed) Diagnostic and statistic manual of mental disorders IV. Washington DC: American Psychiatric Association, 1994.

38. Hamilton M. A rating scale for depression. J Neurol Neurosurg Psychiat. 1960; 23: 56-62.

39. Strik JJ, Honig A, Lousberg R, et al. Efficacy and safety of fluoxetine in the treatment of patients with major depression after first myocardial infarction: findings from a double-blind, placebo-controlled trial. Psychosom Med 2000; 62:783-9.

40. Comrey AL. Factor-analytic methods of scale development in personality and clinical psychology. J Consult Clin Psychol 1988; 56:754-61.

41. Carney RM, Freedland KE, Sheline YI, et al. Depression and coronary heart disease: a review for cardiologists. Clin Cardiol 1997; 20: 196-200.

42. Watson D, Clark LA, Weber K, et al. Testing a tripartite model: II. Exploring the symptom structure of anxiety and depression in student, adult, and patient samples. J Abnorm Psychol 1995; 104:15-25.

43. Lane D, Carroll D, Ring C, et al. The prevalence and persistence of depression and anxiety following myocardial infarction. Br J Health Psychol 2002; 7:11-21.

44. Zimmerman M, Chelminski I. Clinician recognition of anxiety disorders in depressed outpatients. J Psychiat Res 2003; 37:325-33.

45. Enns MW, Larsen DK, Cox BJ. Discrepancies between self and observer ratings of depression. The relationship to demographic, clinical and personality variables. J Affect Disord 2000; 60:33-41.

46. Bienvenu OJ, Brown C, Samuels JF, et al. Normal personality traits and comorbidity among phobic, panic and major depressive disorders. Psychiatry Res 2001; 102:73-85.

47. Kendall PC, Hollon SD, Beck AT, et al. Issues and recommendations regarding use of the Beck Depression Inventory. Cogn Ther Res 1987; 17:313-24. 


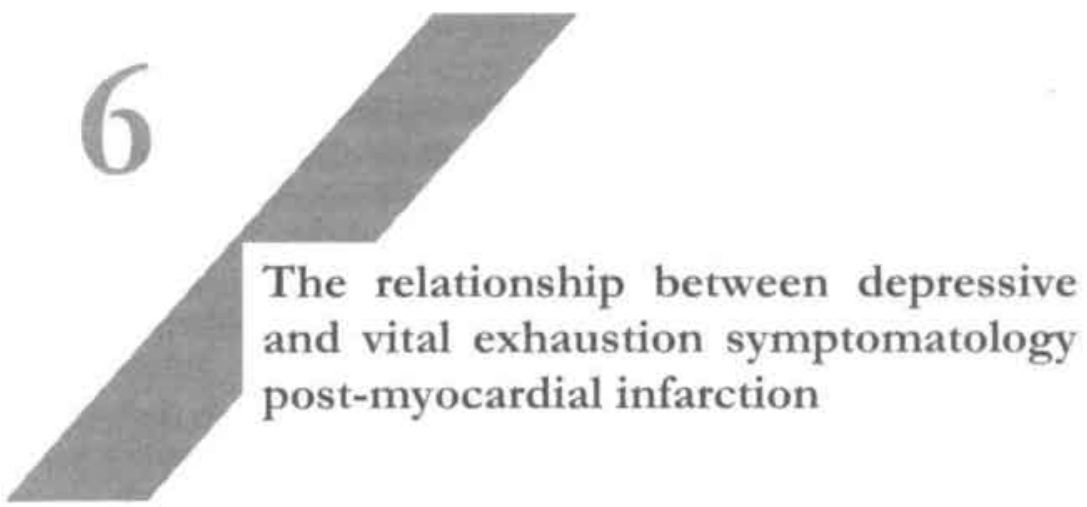




\begin{abstract}
Many peri-myocardial infarction (MI) patients experience decreased well-being, which is either conceptualized as depression or as vital exhaustion. The objective of the present study is to investigate whether or not depression and vital exhaustion are separate entities. It was hypothesized that, if depression and vital exhaustion are separate phenomena, the correlation between two depression questionnaires would be higher than those between either of the two depression questionnaires and a vital exhaustion questionnaire. Subjects were 143 patients who had recently experienced a first acute MI. At 1, 3, 6 and 12 months post-MI, patients completed two self-report depression questionnaires (the Zung-SDS and the depression subscale of the SCL-90), and a vital exhaustion questionnaire (the Maastricht Questionnaire). Correlation coefficients were calculated for the two depression questionnaires and the vital exhaustion questionnaire. Furthermore, an exploratory principal component analysis was performed on the combined items of the three questionnaires. Strong and virtually identical correlations were found between the three measures at all four time-points. A one-factor model was the best fit in the exploratory principal component analysis. The present results do not support the hypothesized separate conceptual identity of depression and vital exhaustion.
\end{abstract}

\title{
Reference
}

Wojciechowski FL, Strik JJMH, Falger P, Lousberg R, Honig A. The relationship between depressive and vital exhaustion symptomatology postmyocardial infarction. Act Scand Psychiatrica 2000; 102:359-65. 


\section{Introduction}

It is well established that, pre- as post-myocardial infarction (MI), many patients experience significantly decreased mental well-being, which in turn is strongly associated with increased mortality 1 . This lack of mental well-being is generally conceptualized as depression ${ }^{1,2}$. Furthermore, depression has been shown to be an independent risk factor for cardiac morbidity that cannot be explained by an association between depression and severity of coronary artery disease $(\mathrm{CAD})^{3}$. 5.

Appels and co-workers conceptualized the decreased level of mental well-being observed peri-MI to be reflecting a state of 'vital exhaustion', a phenomenon claimed to be related to but not identical with depression ${ }^{6,7}$. Excessive fatigue and feelings of general malaise, such as hopelessness, listlessness, loss of libido, increased irritability and problems with sleep are mentioned as symptoms of vital exhaustion; chronic fatigue is reported to be a core symptom ${ }^{7}$. As many patients seen by Appels and colleagues retrospectively attributed this excess fatigue to overwork or longstanding problems that could not be solved, the observed syndrome was termed vital exhaustion ${ }^{8}$. Depression and vital exhaustion have both been shown to be prominent risk factors in CAD independent of clinical indicators of disease severity $6,9,10$.

All too often depression goes undetected in CAD patients, thereby contributing to unnecessarily high mortality levels. This underestimation of depression is attributed to atypical symptoms as well as to the tendency of treating physicians to interpret depressive symptoms as a transient and 'natural' reaction to a lifethreatening event $2,11 \cdot 14$.

Many of the symptoms reported to be associated with vital exhaustion are common also to depression ${ }^{7}$. Moreover, Lespérance ${ }^{15}$ noted that in post MI patients "Fatigue was more than three times more common among patients depressed in the hospital than among the non-depressed", and that fatigue was not related to any measure of CAD severity. Therefore they concluded that feelings of tiredness and lack of energy may be particularly important indicators of post-MI depression, and suggested "that the vital exhaustion concept that has been shown to predict both MI occurrence and cardiac death, may well reflect depression in some parients".

This raises the question whether post-MI vital exhaustion and depression are really different constructs or whether vital exhaustion may be conceptualized as an atypical form of depression. The few empirical studies that have addressed this problem provide some supportive, albeit not conclusive evidence suggesting that the two concepts may not be identical. Van Diest and Appels 7 showed that exhausted but otherwise healthy subjects predominantly suffered from loss of vigor and excess fatigue, while a depressed mood was almost absent. Klein Schiphorst et al. 16 found a significant association between depression (as measured by the Zung Self-rating Depression Scale) and vital exhaustion (as measured by the Vital Exhaustion Interview). However, as the 
highest correlation found $(0.61$, at one month post-MI) did not exceed the level of moderate correlation, they interpreted their findings as "support for the idea that depression and vital exhaustion are different constructs". Finally, in a large-scale epidemiologic study by Kopp et al. ${ }^{17}$, it was found that although "depressive symptoms and vital exhaustion correlated strongly" in a nationwide, stratified sample $(\mathrm{N}=12,600, \mathrm{r}=0.6198)$, there were significant differences in strength of associations between depressive symptoms, vital exhaustion and several behavioral risk factors for CAD.

However, the above mentioned studies cannot provide us with a clear answer to the question of the assumed separate identity of depression and vital exhaustion. The alternative hypothesis, that vital exhaustion and depression refer to the same construct and that vital exhaustion may be an atypical, somatized form of depression, cannot be ruled out on basis of the evidence put forward.

In psychiatric research it is a well-established fact that diagnosing depression and quantifying depressive symptoms is not an easy task, and that concordance rates between self-report depression inventories are far from perfect, varying from 0.56 to $0.80{ }^{18}$. Therefore, finding a correlation coefficient of about 0.60 between a measure of depression and a measure of vital exhaustion cannot be taken as conclusive evidence for the separate conceptual identity of the two constructs.

It was therefore argued that the vital exhaustion construct should prove its conceptual validity by comparison of a vital exhaustion inventory, not with one, but with several depression scales. More specifically, it was hypothesized that if vital exhaustion and depression are really different constructs, then correlations between two separate measures of depression should be significantly higher than those between either of the measures of depression and a measure of vital exhaustion.

\section{Material and methods}

\section{Swbjects}

All patients admitted for acute MI to the Department of Cardiology of the Maastricht University Hospital between May 1, 1994, and January 31, 1996 were asked to participate in the present study, which is part of a research project investigating the incidence and clinical manifestations of depressive psychopathology, and the efficacy of antidepressive pharmacotherapy treatment in post MI patients. The study was approved by the science ethical committee of the Maastricht University Hospital.

Inclusion criteria were: first-time MI, clinical diagnosis established by a cardiologist, ECG changes typical for myocardial infarction, a maximum value of the enzyme aspartate aminotransferase $\left(A_{S A T} T_{\max }\right) \geq 80 \mathrm{U} / \mathrm{L}^{19}$ and age from 18-75 years. Of the 183 eligible patients ( 139 males and 44 females), 143 gave 
their written informed consent, and were included in the present study. Of the 143 participants, 116 were male and 27 were female, mean age was 57.8 years $(\mathrm{SD}=10.3)$, and mean $\mathrm{ASAT}_{\max }$ was $257 \mathrm{U} / \mathrm{L}(\mathrm{SD}=205)$. Eligible nonparticipants were more likely to be female $\left(43 \% ; \chi^{2}=9.55 ; \mathrm{df}=1 ; \mathrm{p}<0.05\right)$, but did not differ significantly from participants on ASATmax (mean $275 \mathrm{U} / \mathrm{L}$; $\mathrm{SD}=168 ; \mathrm{p}=0.61)$, or age $($ mean 59.8 years; $\mathrm{SD}=10.9 ; \mathrm{p}=0.29)$.

\section{Assessment}

Depressive symptomatology was assessed with the Zung Self-rating Depression Scale (Zung-SDS) 20,21 and the depression subscale (DEP) of the 90-item Symptom Check List (SCL-90) 22,23. Vital exhaustion symptomatology was assessed with the Maastricht Questionnaire (MQ) ?.

A previous empirical study investigating the relationship between depressive and vital exhaustion symptoms made use of a lengthy, structured interview for assessing vital exhaustion, and a short self-report form for assessing depression 16. The obvious differences between the two instruments in terms of procedure, duration and mental strain for participants are a clear disadvantage in obtaining valid results. Therefore, in the present study, it was decided to employ assessment instruments with a minimum of variation in these parameters. For practical reasons, self-report measures were chosen. Unlike Kopp et al. ${ }^{17}$, the present study used unabridged versions.

The choice for the Zung-SDS and SCL-90 as self-report measures of depressive symptomatology was made upon the following considerations: The Dutch SCL90 translation has been adequately researched with regard to its psychometrical qualities 21. Furthermore, as the SCL-90 DEP scale, like the Beck Depression Inventory (BDI), is focused on psychological symptoms, it was decided to use a second self-report depression measure that also focuses on somatic symptoms, i.e. the Zung-SDS. In a study of depression in geriatric and adult medical inpatients, the Zung-SDS and DEP scale of the SCL-90 were found to have a correlation of 0.8 (geriatric inpatients, $\mathrm{n}=178$ ) and 0.7 (adult medical inpatients, $\mathrm{n}=201)^{23}$.

\section{Procedures}

At 1, 3, 6, and 12 months following the MI patients were sent a booklet containing three self-report questionnaires. The three questionnaires consisted of the SCL-90, Zung-SDS and the MQ, which were returned in a self-addressed and pre-stamped envelope. Of the 183 patients who received the first booklet, which also included the informed consent form, 35 declined to participate (as evidenced by not returning the booklet, even after a remind telephone call 2 weeks afterwards), and were excluded from further participation in the study. An additional five patients returned the booklets unanswered all four times, and were therefore also considered as dropouts. The remaining 143 patients returned a valid booklet at least once. One hundred and twenty-eight valid 
booklets were returned at 1 month, 113 at 3 months, 106 at 6 months and 90 at 12 months. Seventy-four $(52 \%)$ patients returned all four booklets.

Patients who had a score of $\geq 23$ (males) or $\geq 28$ (females) on the SCL-90 $\operatorname{DEP}(\mathrm{n}=46$ at $\mathrm{t}=1, \mathrm{n}=48$ at $\mathrm{t}=2, \mathrm{n}=37$ at $\mathrm{t}=3$, and $\mathrm{n}=30$ at $\mathrm{t}=4)$ were seen by a psychiatrist for further evaluation of their depressive symptoms (separate cut-off scores for females and males were used, because the Dutch version of the SCL-90 has separate norm groups for males and females, the cutoff score separating an 'above average and a 'high' score on the DEP scale being 23 for males and 28 for females). Eleven patients were diagnosed as clinically depressed according to DSM-III-R criteria at screening 1 , an additional 10 at screening 2,7 at screening 3 , and 2 at screening 4 (cumulative total $\mathrm{n}=30$ ).

As a clinically depressed mood at screening 1 may (at least partially) reflect an adjustment reaction to a potential life-threatening event, i.e. the recent MI, these patients were not yet offered antidepressant pharmacotherapy treatment at that point. However, it was considered unethical to continue withholding antidepressant treatment to patients remaining or becoming clinically depressed after a more prolonged period of time. Therefore all patients being diagnosed as clinically depressed, and having a Hamilton Depression Scale (HAMD-17) score of 18 or above at screening $2(n=14), 3(n=11)$, or $4(n=3)$, were offered antidepressant pharmacotherapy, which was accepted by 16 patients $(n=9$ at screening $2, \mathrm{n}=6$ at screening 3 , and $\mathrm{n}=1$ at screening 4 ). These patients were subsequently withdrawn from the present study and entered a separate trial aimed at evaluating the efficacy of antidepressant pharmacotherapy in post-MI depression. These withdrawals are reflected in the patient numbers given above. A flow-chart of the procedures followed in the present study is given in Figure 1.

\section{Data analyses}

Pearson correlation coefficients were computed between the scores for the Zung-SDS, the SCL-90 DEP, and the MQ at each of the four time points. Descriptive statistics of these variables are given in Table 1 . The valid $\mathrm{N}$ for each time point was large enough to generate meaningful statements about correlational relationships between the three measures. Fisher's procedure would be an adequate instrument to test for differences between correlation coefficients ${ }^{24}$. 
Figure 1

Patient flow chart.

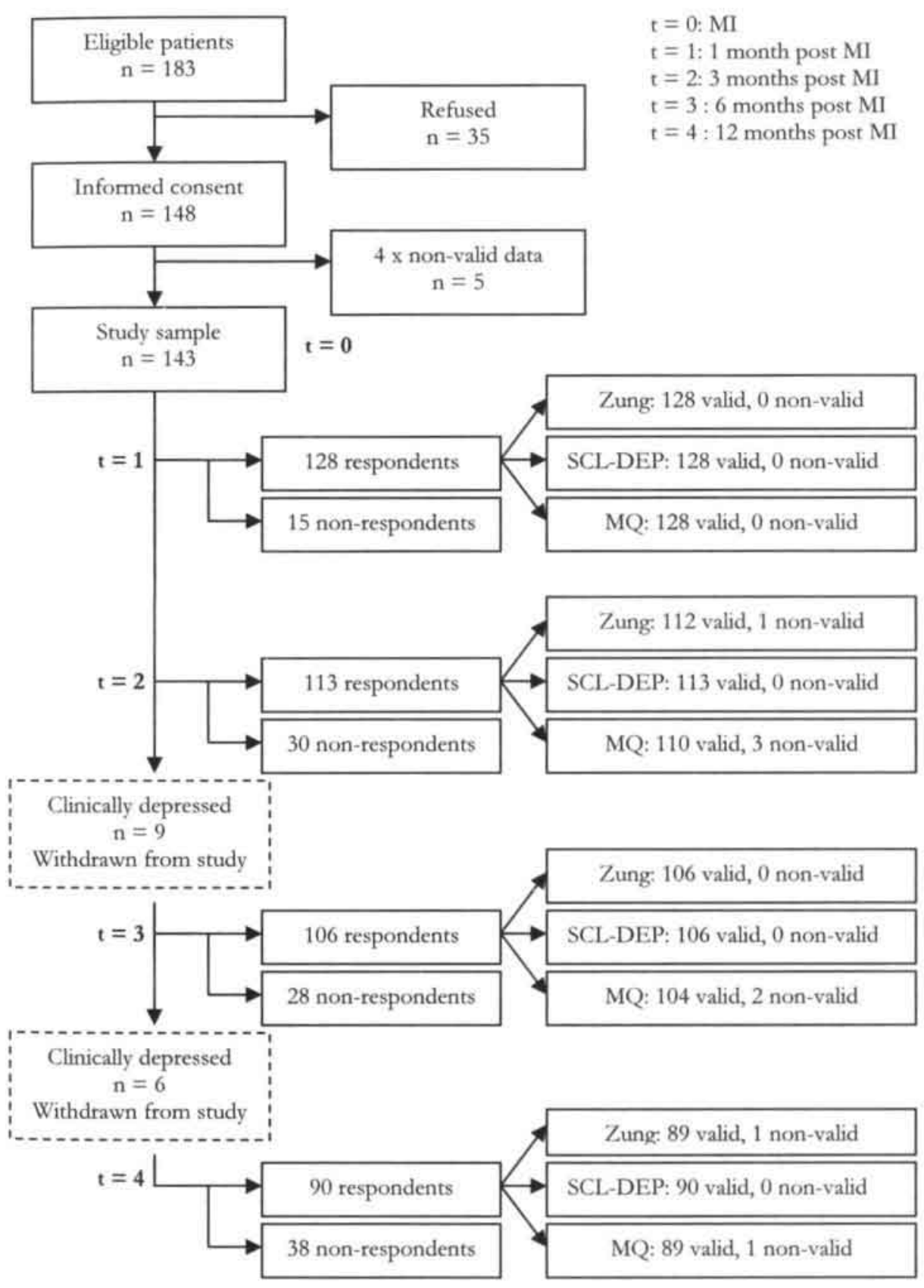




\section{Table 1}

Descriptive statistics for Zung Self rating Depression Scale, depression subscale of the 90-item Symptom Check List, and Maastricht Questionnaire at 1, 3, 6 and 12 months post-MI $(t=1, t=2, t=3, t=4$, respectively).

\begin{tabular}{|c|c|c|c|}
\hline Screening & Zung-SDS & SCL-90 & MQ \\
\hline$t=1$ & $\begin{array}{c}\mathrm{n}=128 \\
\text { mean }=44.49 \\
\mathrm{s.d}=10.35\end{array}$ & $\begin{array}{c}\mathrm{n}=128 \\
\text { mean }=23.98 \\
\mathrm{s.d}=8.15\end{array}$ & $\begin{array}{c}\mathrm{n}=128 \\
\text { mean }=11.96 \\
\mathrm{~s} . \mathrm{d} .=9.45\end{array}$ \\
\hline$t=2$ & $\begin{array}{c}\mathrm{n}=112 \\
\text { mean }=45.06 \\
\text { s.d. }=12.05\end{array}$ & $\begin{array}{c}\mathrm{n}=113 \\
\text { mean }=24.36 \\
\mathrm{~s} . \mathrm{d} .=8.60\end{array}$ & $\begin{array}{c}\mathbf{n}=110 \\
\text { mean }=12.40 \\
\text { s.d. }=9.97\end{array}$ \\
\hline$t=3$ & $\begin{array}{c}\mathrm{n}=106 \\
\text { mean }=44.94 \\
\text { s.d. }=12.81\end{array}$ & $\begin{array}{c}\mathrm{n}=106 \\
\text { mean }=23.53 \\
\text { s.d. }=8.07\end{array}$ & $\begin{array}{c}\mathrm{n}=104 \\
\text { mean }=10.91 \\
\text { s.d. }=9.43\end{array}$ \\
\hline$t=4$ & $\begin{aligned} \mathrm{n} & =89 \\
\text { mean } & =41.95 \\
\text { s.d. } & =9.86\end{aligned}$ & $\begin{array}{c}\mathrm{n}=90 \\
\text { mean }=22.75 \\
\text { s.d. }=7.76\end{array}$ & $\begin{aligned} \mathbf{n} & =90 \\
\text { mean } & =10.08 \\
\text { s.d. } & =9.00\end{aligned}$ \\
\hline
\end{tabular}

\section{Results}

In Table 2 the correlations are shown between the Zung-SDS, the SCL-90 $\mathrm{DEP}$, and the MQ at 1, 3, 6, and 12 months post-MI, respectively.

These data clearly show that the correlations between the two depression measures were either identical or even somewhat lower than those between either of these measures and the vital exhaustion measure. More specifically, at 3 months post-MI the correlation between DEP and Zung-SDS was identical to the correlation between MQ and Zung-SDS. In all other comparisons the correlations between the two depression measures were lower (although only marginally so) than between either of these measures and the vital exhaustion measure.

This means that at the visual inspection level the data do not support the hypothesized higher correlation between the two depression measures, because the trend of the data -if any- was in the opposite direction to that hypothesized. Fisher's procedure to test for differences between correlation coefficients was therefore not used ${ }^{24}$. 


\section{Table 2}

Pearson correlations between Zung Self rating Depression Scale, depression subscale of the 90-item Symptom Check List, and Maastricht Questionnaire scores at $1,3,6$ and 12 months post-MI $(t=1, t=2, t=3, t=4$, respectively).

\begin{tabular}{|c|c|c|c|}
\hline Screening & Zung-SDS & SCL-90 & MQ \\
\hline ZUNG-SDS & $x$ & $\begin{array}{l}\mathrm{t}=1: \mathrm{r}=0.70(\mathrm{n}=128) \\
\mathrm{t}=2: \mathrm{r}=0.76(\mathrm{n}=112) \\
\mathrm{t}=3: \mathrm{r}=0.77(\mathrm{n}=106) \\
\mathrm{t}=4: \mathrm{r}=0.75(\mathrm{n}=89)\end{array}$ & $\begin{array}{l}\mathrm{t}=1: \mathrm{r}=0.79(\mathrm{n}=128) \\
\mathrm{t}=2: \mathrm{r}=0.76(\mathrm{n}=109) \\
\mathrm{t}=3: \mathrm{r}=0.78(\mathrm{n}=104) \\
\mathrm{t}=4: \mathrm{r}=0.81(\mathrm{n}=88)\end{array}$ \\
\hline SCL-90 & $\mathrm{x}$ & $\mathrm{x}$ & $\begin{array}{c}\mathrm{t}=1: \mathrm{r}=0.75(\mathrm{n}=128) \\
\mathrm{t}=2: \mathrm{r}=0.83(\mathrm{n}=110) \\
\mathrm{t}=3: \mathrm{r}=0.76(\mathrm{n}=104) \\
\mathrm{t}=4: \mathrm{r}=0.76(\mathrm{n}=89)\end{array}$ \\
\hline MQ & $x$ & $\mathrm{x}$ & $\mathrm{x}$ \\
\hline
\end{tabular}

In the above analysis, depressive and vital exhaustion symptomatology, as established by the SCL-90 DEP, the Zung-SDS, and the MQ, were measured as continuous variables with a broad range varying from very little to quite high levels of symptomatology. Therefore it can be argued that the results of the analysis may well not apply to clinically depressed patients. Furthermore, at screening points 3 and 4 there is the possible confounding factor of a restricted upper range of the depressive continuum due to the withdrawal of nine clearcut depressives post-screening 2 , and an additional six depressed patients postscreening 3 . Although the above data do not suggest that this confounding effect actually occurred (both the average Zung-SDS and SCL-90 DEP depression scores, the absolute level, and the degree of homogeneity of intercorrelations remained essentially the same between screening 2 and 4 , despite the withdrawal of part of the depressed patients), it was decided to analyze separately the data for the subgroup of depressed patients. The criterion for inclusion in this subgroup was 'time of first occurrence of depression' $(\mathrm{n}=$ 11 at $\mathrm{t}=1, \mathrm{n}=10$ at $\mathrm{t}=2, \mathrm{n}=7$ at $\mathrm{t}=3$, and $\mathrm{n}=2$ at $\mathrm{t}=4$; cumulative $\mathrm{n}=$ 30). Furthermore, a non-depressed control group of equal size (matched on time, age, gender, and $\mathrm{ASAT}_{\max }$ ) was drawn from the same population of postMI patients for comparative purposes.

The correlations for the depressive subgroup were 0.48 between MQ and SCL 90 DEP, 0.56 between MQ and Zung-SDS, and 0.39 between SCL-90 DEP and Zung-SDS. This means that the correlation between the two depressive measures was somewhat lower than those between either of these measures and the MQ measure. Therefore is may also be concluded that in a subgroup of clinically depressed patients no evidence has been found supporting the hypothesized higher correlation between the two depression measures. It is further evident that the absolute levels of intercorrelations in the depressive 
subgroup are significantly decreased, compared to the data of the total sample of post MI patients as reported in Table 2. A comparable decrease in the level of intercorrelations was observed in the equal sized and matched sample of non-depressed post-MI patients (MQ-SCL-90 DEP $=0.51$, MQ-Zung SDS = 0.66, SCL-90 DEP-Zung SDS $=0.59$ ).

A more direct way to address the same research question would be to use factor-analytical methods such as principal component analysis (PCA). Although our database was insufficiently large to perform a conclusive analysis of this type, we performed an exploratory post hoc PCA to see if some recognizable trend emerged. A PCA on all 57 items of the combined MQ, SCL-90 DEP and Zung-SDS was performed on the total sample at T1, being the time-point when our sample was largest (valid cases $n=128$, see Figure 1). Based on the scree-criterion (first eigen-value $=28.38$, with a sharp leveling off at the second eigen-value), and Cronbach's alpha coefficient ( 0.98$)$, the best fit of the data was for a one factor model.

\section{Discussion}

The data from the present study show strong and virtually identical correlations between two measures of depression and a measure of vital exhaustion at several time-points. Moreover, an exploratory PCA on the combined items of the three questionnaires favored the one-factor model clearly. At face value these results therefore suggest that the symptoms reported by post-MI patients, which are variously labeled as depression or vital exhaustion, refer to one underlying syndrome.

However, in both a depressed subgroup and a non-depressed matched control group of equal size, the absolute levels of intercorrelations were significantly decreased compared to both the correlational data of the total sample, and the intercorrelations between depression questionnaires reported in other studies 18,23. This effect was most pronounced in the depressed subgroup. Therefore, it might be argued that the lower levels of intercorrelations (all below 0.6, the lower limit of moderate correlation) indicate that, at least for the subgroup of depressed CAD-patients, depression and vital exhaustion indeed are two separate entities. However, contrary to this hypothesis, the decrease in correlation was most pronounced in the SCL-90 DEP/Zung-SDS comparison in the depressed subgroup. Moreover, this last finding suggests that even two depression measures which have been shown to correlate strongly in an adequate sized sample ${ }^{23}$ fail to reach the level of moderate correlation in a (too) small sample.

It is our hypothesis that the overall decrease of intercorrelations in both subgroups is due to such factors as restricted range (in one subgroup only depressed patients were included, and in the other only non-depressed patients were included), the reduction of sample size ( $n=30$ in both subgroups), and 
the ensuing increased influence of outlying values. Therefore, a replication study with a substantially larger sample of depressed CAD patients is recommended. The study of Magni et al. ${ }^{23}$ suggests that a sample size of 150 to 200 would be adequate to address this issue.

The fact that our results fail to support the hypothesis that depression and vital exhaustion are two separate entities does not automatically mean that vital exhaustion is 'nothing but' a form of depression. This would imply a directionality that correlational techniques inherently do not possess. Theoretically, the reverse relation is equally plausible at this stage. Moreover, the lack of psychometrical distinction between the two concepts has only been demonstrated post-MI, whereas the concept of vital exhaustion was primarily developed on the basis of data derived from $\mathrm{MI}$ patients regarding their pre-MI mental status.

It is therefore suggested that the relationship between depression and vital exhaustion should also be prospectively investigated in pre-MI patients, preferably using both self-report and interviewer-based measures. An additional line of research would be to replicate the present study with clinically depressed, as well as vitally exhausted patients without a history of CAD.

Furthermore, the present results warrant an empirical study with a large enough sample to allow exploratory and confirmatory factor analytical methods such as PCA in order to test the hypothesis that vital exhaustion and depressive symptomatology post-MI reflect one underlying syndrome. In this respect it is to be regretted that the study of Kopp et al. ${ }^{17}$, of which the sample size amply qualified for this purpose $(\mathrm{N}=12,600)$, limited itself to correlational methods and did not perform a PCA on the combined items of the shortened BDI and the shortened MQ.

Finally, in modem psychiatry the depression concept is descriptive and classificatory, and is "neutral with respect to theories of etiology" 25 , whereas the vital exhaustion concept has an explicit etiological focus ${ }^{6,26}$. This means that depression and vital exhaustion address the lack of mental well-being peri-MI at different conceptual levels, and that therefore the two concepts are not automatically competing and mutually exclusive descriptions of the same phenomenon. It could therefore be hypothesized that vital exhaustion is a (somatized) subtype of depression, with exhaustion ('surmenage', 'burnout') being a possible pathway to depression, and that this pathway is particularly relevant in MI patients.

\section{References}

1. Schleifer SJ, Macari-Hinson MM, Coyle DA, et al. The nature and course of depression following myocardial infarction. Arch Intern Med 1989;149:1785-9.

2. Musselman DL, Evans DL, Nemeroff CB. The relationship of depression to cardiovascular disease. Arch Gen Psychiatry 1998;55:580-92. 
3. Barefoot JC, Helms MJ, Mark DB, et al. Depression and long-term mortality risk in patients with coronary heart disease. Am J Cardiology 1996;78:613-7.

4. Carney RM, Rich MW, Freedland KE, et al. Major depressive disorder predicts cardiac events in patients with coronary artery disease. Psychosom Med 1988;50:627-33.

5. Frasure-Smith $\mathrm{N}$, Lespérance $\mathrm{F}$, Talajic $\mathrm{M}$. Depression and 18 months prognosis after myocardial infarction. Circulation 1995;91:999-1005.

6. Appels A. Mental Precursors of myocardial infarction. $\mathrm{Br} J$ Psychiatry 1990;156:465-71.

7. Diest van R, Appels A. Vital exhaustion and depression, a conceptual study. J Psychosom Res 1991;35:535-44.

8. Falger PRJ, Schouten EGW. Exhaustion, psychological stressors in the work environment and acute myocardial infarction in adult men. J Psychosom Res 1992;36:777-86.

9. Appels A, Mulder P. Fatigue and heart disease. The association between 'vital exhaustion' and past, present and future coronary heart disease. J Psychosom Res1989;33:727-38.

10. Kop WJ, Appels A, Mendes de Leon CF, Swart de H, Bar F. Vital exhaustion predicts new cardiac events after successful coronary angioplasty. Psychosom Med 1994:281-7.

11. Freedland KE, Lustman PJ, Carney RM, Hong BA. Underdiagnosis of depression in patients with coronary artery disease: the role of nonspecific symptoms. Int J Psychiatry Med 1992;22:221-9.

12. Carney RM, Rich, Tevelde AJ. Major depressive disorder in coronary heart disease. Am J Cardiology 1987;60:1273-5.

13. Fielding R. Depression and acute myocardial infarction: a review and reinterpretation. Soc Sci Med 1991;32:1017-27.

14. Mayou R, Foster A, Williamson B. Medical care after myocardial infarction. J Psychosom Res 1979;23:23-6.

15. Lespérance F, Frasure-Smith N, Talajic M: Major depression before and after myocardial infarction: its nature and consequences. Psychosom Med 1996;58:99110.

16. Klein Schiphorst A, Stokhof L, Cohen L. Vitale uitputting bij patienten met een recent doorgemaakt hartinfarct. Prevalentie in verband met depressie. Gedrag \& Gezondheid 1994;22:198-204.

17. Kopp MS, Falger PRJ, Appels A, Szedmak S. Depressive symptomatology and vital exhaustion are differentially related to behavioral risk factors for coronary artery disease. Psychosom Med 1998;60:752-8.

18. Shaw BF, Vallis TM, McCabe SB. The assessment of the severity and symptom patterns in depression. In: Beckam EE LW, ed. Handbook of depression: treatment, asessment, and research. Homewood, ILL: The Dorsey Press, 1985:372407.

19. Pasternak RC, Braunwald E, Sobel RE. Acute myocardial infarction. In: Braunwald E, ed. Heart disease: a textbook of cardiovascular medicine. 4th edition ed. Philadelphia: WB Saunders Compagny, 1992:1200-91.

20. Zung WW, Richards CB, Short MJ. A selfrating depression scale. Arch Gen Psychiatry 1965;12:63-70.

21. Evers A, Vliet van-Mulder JC, Ter Laak J. Documentatie van tests en testresearch in Nederland. Assen: Van gorcum \& Comp BV, 1992. 
22. Derogatis LR, Lipman RS, Covi L. SCL-90: an outpatient psychiatric rating scaleprelimanary report. Psychopharm Bull 1973;9:13-27.

23. Magni G, De Leo D, Schifano F. Depression in geriatric and medical inpatients. J Clin Psychology 1985;41:337-44.

24. McNemar Q. Psychological testing. New York: Wiley \& Sons, 1969:157-158.

25. The American Psychiatric Association. Diagnostic and statistic manual of mental disorders IV. Fourth edition (revised). Washington DC: American Psychiatric Association. 1994.

26. Appels A. Depression and coronary heart disease: observations and questions. Psychosom Res 1997;43:443-52. 


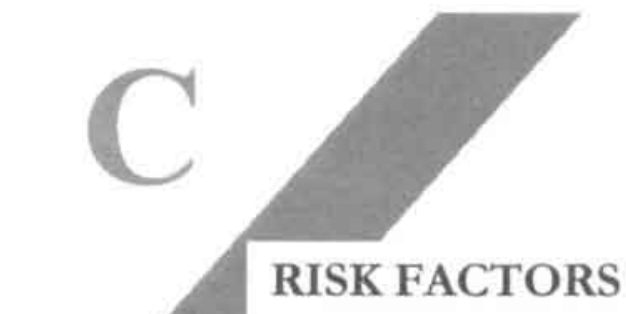





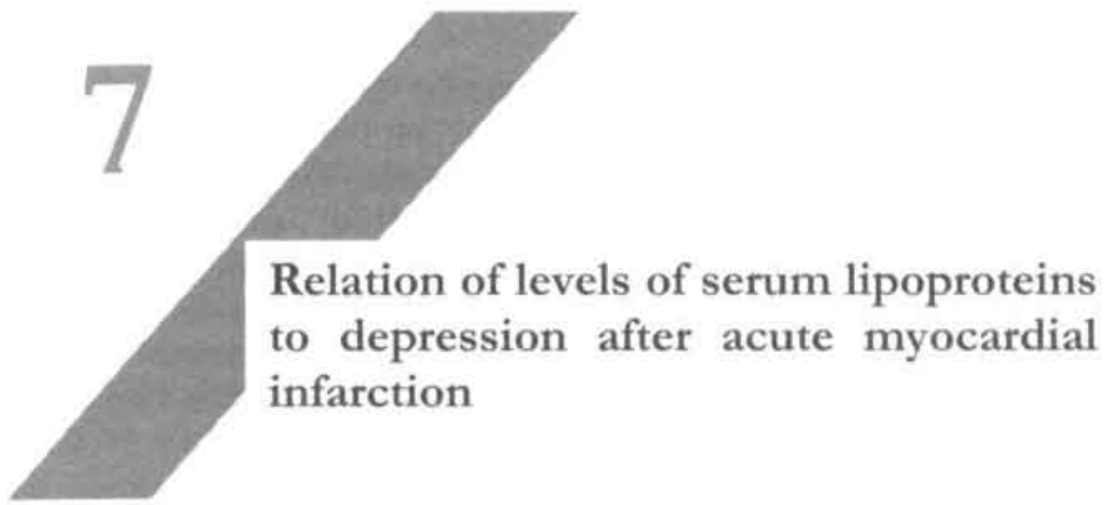




\section{Abstract}

Depression frequently co-occurs with myocardial infarction (MI). Several studies report a possible relationship between low levels of serum total cholesterol and the development of major depression. Herein we study the relationship between serum lipids 1 month post-MI and major/minor depression and depressive symptoms at 3 months post-MI. Serum total cholesterol, High Density Lipoprotein Cholesterol (HDL-C), Low Density Lipoprotein Cholesterol (LDL-C) and Triglycerids (TG) were measured in 140 consecutive patients 1 month post-MI. Also one month post-MI, all patients were interviewed using the Structured Clinical Interview for DSM-IV (SCID-I$\mathrm{R})$. Three months post-MI, patients filled out 3 psychiatric self-rating scales for depression, the Beck Depression Inventory (BDI), the Hospital Anxiety and Depression Scale (HADS), and the 90-item Symptom Check List (SCL-90). Patients, exceeding a previously defined cut-off value on at least one of these scales, were re-interviewed using the SCID-I-R. The BDI was applied to assess depressive symptoms in relation to cardiac outcome as the SCL-90 and HADS showed similar results. It was evaluated whether serum lipids predict depressive disorder and depressive symptoms 3 months post-MI, corrected for major/minor depression and depressive symptoms at 1 month post-MI. In multivariate analyses, LDL-C was significantly inversely related to major/minor depression $(p=0.04)$ and depressive symptoms 3 months post-MI $(p=0.002)$. Total serum cholesterol, HDL-C and TG were not related to the occurrence of major/minor depression nor depressive symptoms. Low LDL-C is related to major/minor depression and depressive symptoms 3 months post-MI. These data, if replicated, may have an impact on clinical regulation of cholesterol in post-MI patients.

\section{Reference}

Strik JJMH, Lousberg R, Crijns HJGM, Maes M, Honig A. Relation of levels of serum lipoproteins to depression after acute myocardial infarction. Am J Cardiology 2002; 90: 1368-70 (published in shortened version as brief report). 


\section{Introduction}

Depression frequently co-occurs with myocardial infarction (MI), increasing morbidity and mortality in the first 18 months post-MI $1-4$. In longitudinal studies serum total cholesterol has been inversely related to the development of depression (Table 1) ${ }^{5-7}$. Also in cross sectional studies, an inverse relationship between serum lipids is reported ${ }^{8-10}$. However, this inverse relationship between cholesterol and depression was not found in all studies. Both in healthy as psychiatric patients no correlation between serum lipids and depression could be found ${ }^{11-13}$.

\section{Table 1}

Prospective studies evaluating the relationship between serum lipids and development of depression.

\begin{tabular}{|c|c|c|c|}
\hline Author & Patients & Follow up & Outcome \\
\hline Morgan, et al., 19935 & $\begin{array}{c}1,020 \text { men, } \\
50 \text { years and } \\
\text { older }\end{array}$ & 13 years & $\begin{array}{l}\text { Among men aged } 70 \text { years and older, } \\
\text { categorically defined depression was } \\
\text { three times more common in the } \\
\text { group with low plasma cholesterol } \\
\text { ( }<4.14 \mathrm{mmol} / \mathrm{L}) \text { than in those with } \\
\text { higher concentrations }\left(5 / 31\left[16^{\circ} \%\right] \text { vs }\right. \\
22 / 363[6 \%] ;=0.033) \text {. }\end{array}$ \\
\hline Steegmans et al., $2000^{6}$ & $\begin{array}{l}200 \text { middle- } \\
\text { aged men }\end{array}$ & 3 years & $\begin{array}{l}\text { Men with a lower cholesterol level } \\
(<4.5 \mathrm{mmol} / \mathrm{L}) \text { have a higher } \\
\text { prevalence of depressive symptoms } \\
\text { than those with a cholesterol level } \\
\text { between } 6 \text { and } 7 \mathrm{mmol} / \text { liter. }\end{array}$ \\
\hline Shibata et al., 1999 ? & $\begin{array}{l}195 \text { men and } \\
309 \text { women, } \\
\text { elderly }\end{array}$ & 4 years & $\begin{array}{l}\text { Total cholesterol, LDL and vLDL at } \\
\text { baseline significantly prevented } \\
\text { progression of depressive status in } \\
\text { men alone, adjusted for age, } \\
\text { education, and the GDS score at } \\
\text { baseline. HDL cholesterol did not } \\
\text { significantly relate to the progression } \\
\text { of depressive status. }\end{array}$ \\
\hline
\end{tabular}

To the best of our knowledge, no longitudinal studies, examining the association between serum cholesterol or lipoproteins and incident depression in MI patients, have been published. This is of critical importance as lowering cholesterol and LDL-C levels in MI patients is part of cardiac routine ${ }^{14,15}$. Low cholesterol and LDL-C, however, have been related to the occurrence of depressive symptoms 7,8 , with depression as a recognized risk factor for increased mortality post-MI 2,3,16,17. 
To answer the question whether cholesterol is a risk factor for the development of depression post-MI, longitudinal studies are warrented. The present study is part of a longitudinal study of risk facors of post-MI depression. Herein we investigate the relationship between the development of depression after a first MI, and baseline serum total cholesterol, LDL-C, HDL or Triglycerid (TG) concentrations.

\section{Methods}

\section{Patients and assessments}

The present study was part of a prospective study on risk factors for post-MI depression in which a cohort of 206 consecutive patients with a first acute MI between May 1997 and September 1999 were included. MI diagnoses were made by a cardiologist according to the following criteria: clinical picture and electrocardiographic signs typical for an acute MI, and a maximum value of the enzyme aspartate aminotransferase ( ASAT $_{\text {max }}$ ) of at least $80 \mathrm{U} / \mathrm{L}$ (twice above the upper limit) 18,19 .

Serum, for the assay of serum fatty acids, was sampled 4 weeks after the MI. Although serum lipid concentrations change during the course of MI, it was reported that four weeks after the MI, serum lipids are reasonable valid estimates of baseline lipid values ${ }^{20}$. It was recorded whether patients were prescribed lipid lowering drugs.

One month following MI, all patients were interviewed using the Structured Clinical Interview for DSM-IV (SCID-I-R) 2!. The SCID-I-R is a structured psychiatric diagnostic interview allowing for a diagnosis of major or minor depression according to DSM-IV. Patients were diagnosed with major depression if fulfilling at least one core criterion (depressed mood or loss of interest) and at least four additional criteria (total of 5) with a duration of at least two weeks. A diagnosis of minor depression was made in case of one to three in stead of four additional criteria (total of 2 to 4 ). A trained physician (JS) administered all interviews. At 3 months following MI, patients were ask to fill out three psychiatric self-rating scales for depression. These were the Beck Depression Inventory (BDI) 22,23 , the Hospital Anxiety and Depression Scale (HADS) ${ }^{24}$, and the 90-item Symptom Check List (SCL-90) 25,26. Patients scoring above the general accepted cut-off values of at least one of these scales, were re-interviewed using the SCID-I-R. Sensitivity of the general accepted cutoffs and predictive validity of the instruments have been reported elsewhere ${ }^{27}$. The BDI was applied to assess depressive symptoms in relation to cardiac outcome, as the BDI is a well accepted instrument to assess depressive symptoms in MI patients and the other two questionnaires, SCL-90 and HADS, showed similar results ${ }^{27}$. 


\section{Data analyses}

All analyses were carried out using SPSS, version $6.0^{28}$. Regression models were applied, in which SCID-I-R diagnosis and BDI scores at 3 months post-MI were considered to be the dependent variables. Serum total cholesterol, HDLC, LDL-C, and TG were used as the predictors in the model. Age, gender, SCID-I-R diagnosis or BDI score at 1 month post-MI, size of infarction measured by left ventricular ejection fraction (LVEF) and body mass index (BMI) were co-variates. Also, use of lipid lowering agents between MI and lipid assessment, and percutaneous transluminal coronary angioplasty (PTCA) as acute intervention following $\mathrm{MI}$ were included as covariates as they may affect lipid levels ${ }^{29}$.

A two-tailed $\mathrm{p}$-value of $\leq 0.05$ was considered to be significant. Stability of the models was checked for influential or outlying cases by Cooks Distance ${ }^{30}$. Data are expressed as means with standard deviation between brackets.

\section{Results}

Of $66(32 \%)$ of the 206 patients eligible for this study no serum lipid data were available 1 month post-MI, for reasons not related to this substudy. These excluded patients were somewhat older $\{63.0$ years $(S D=9.92)$ versus 58.4 $(\mathrm{SD}=10.9)\}$ than the included patients. The excluded patients did not differ in baseline BDI score. Baseline characteristics of 140 included patients are shown in Table 2. One-hundred and seven men and 33 women participated; mean age was 58.4 years $(\mathrm{SD}=10.9)$. Mean $\mathrm{BMI}$ was $25.7(\mathrm{SD}=3.73)$, mean LVEF $53.2 \%(\mathrm{SD}=10.5)$, and mean $\mathrm{ASAT}_{\max } 238 \mathrm{U} / \mathrm{L}(\mathrm{SD}=166)$. Mean total cholesterol was $5.04 \mathrm{mmol} / 1(\mathrm{SD}=1.09)$, mean LDL-C $3.08 \mathrm{mmol} / 1$ (SD = 1.04), mean HDL-C $1.22 \mathrm{mmol} / \mathrm{l}(\mathrm{SD}=0.32)$, and mean TG $1.80 \mathrm{mmol} / \mathrm{l}$ (SD $=1.0)$. Of the 140 patients, $53(37.9 \%)$ underwent PTCA and $107(76.4 \%)$ received lipid lowering agents during the initial admission. At 3 months postMI 15 patients were diagnosed with major and 3 with minor depression. Of these 18 patients diagnosed with depression at 3 months post-MI, 15 were already depressed at 1 month post-MI (13 major, 2 minor depression).

In step-wise regression models with total cholesterol, HDL-C, LDL-C and TG as predictors for major/minor depression and depressive symptoms, without other co-variates, total cholesterol and LDL-C were the strongest predictors (both $\mathrm{p}=0.03$ ). In the models corrected for age, gender, 1-month SCID-I-R diagnosis, 1-month BDI score, LVEF, BMI, use of lipid lowering agents, and PTCA as intervention for the acute MI, LDL-C was of the serum lipids the only independent predictor for diagnosis of major/minor depression $(p=0.04)$ and depressive symptoms $(\mathrm{p}=0.002)$. Total cholesterol, HDL-C and TG were neither significantly related to major/minor depression nor to depressive symptoms. 
Table 2

Baseline characteristics of a consecutive cohort of 141 included first-MI patients.

\begin{tabular}{l|c}
\hline Baseline characteristics & $\begin{array}{c}\text { MI patient sample } \\
\mathbf{M}=\mathbf{1 0 7} / \mathbf{F}=\mathbf{3 3} \\
\text { Mean (SD) }\end{array}$ \\
\hline Age $($ years $)(\mathrm{n}=140)$ & $58.4(10.9)$ \\
BMI $(\mathrm{kg} / \mathrm{m} 2)(\mathrm{n}=140)$ & $25.7(3.73)$ \\
Total cholesterol $(\mathrm{mmol} / \mathrm{I})(\mathrm{n}=135)$ & $5.00(1.09)$ \\
LDL-C $(\mathrm{mmol} / \mathrm{I})(\mathrm{n}=131)$ & $3.01(1.04)$ \\
HDL-C $(\mathrm{mmol} / \mathrm{l})(\mathrm{n}=131)$ & $1.22(0.32)$ \\
TG $(\mathrm{mmol} / \mathrm{l})(\mathrm{n}=133)$ & $1.80(1.01)$ \\
ASAT & $238(166)$ \\
LVEF $(\mathrm{U} / \mathrm{L})(\mathrm{n}=140)(\mathrm{n}=140)$ & $53.2(10.5)$ \\
PTCA $(\%)(\mathrm{n}=140)$ & 37.9 \\
Use of lipid lowering drugs $(\%)(\mathrm{n}=140)$ & 76.4 \\
\hline
\end{tabular}

ASAT $_{\text {max }}$ : maximum value of the enzyme aspartate aminotransferase; BDI: Beck Depression Inventory; BMI: body mass index; HDL-C: high density lipoprotein cholesterol; LDL-C: low density lipoprotein cholesterol; MI: myocardial infarction; PTCA: percutaneous transluminal coronary angioplasty; TG: triglycerids.

\section{Table 3}

Logistic regression model for LDL-C and diagnosis of major/minor depression 3 months post-MI.

\begin{tabular}{l|c|c}
\hline Variable & Coefficient & p-value \\
\hline LDL-C & -0.967 & 0.041 \\
Baseline diagnosis major/minor depression & 2.380 & 0.003 \\
LVEF & -0.012 & 0.820 \\
Age & -0.076 & 0.140 \\
Gender & -0.489 & 0.390 \\
Use of lipid lowering agents & -0.876 & 0.230 \\
BMI & -0.042 & 0.770 \\
PTCA & -0.439 & 0.430 \\
\hline
\end{tabular}

BMI: body mass index; LDL-C: low density lipoprotein-cholesterol; LVEF: left ventricular cjection fraction; MI: myocardial infarction; PTCA: percutaneous transluminal coronary angioplasty. 
Table 4

Lineair regression model for LDL-C and BDI scores 3 months post-MI.

\begin{tabular}{l|c|c}
\hline Variable & Coefficient & p-value \\
\hline LDL-C & -1.601 & 0.002 \\
Baseline BDI & 0.839 & $<0.001$ \\
LVEF & 0.078 & 0.15 \\
Age & -0.008 & 0.88 \\
Gender & -0.695 & 0.58 \\
Use of lipid lowering agents & -0.958 & 0.46 \\
BMI & -0.129 & 0.33 \\
PTCA & -1.072 & 0.26 \\
\hline
\end{tabular}

BDI: Beck depression Inventory; BMI: body mass index; LDL-C: low density lipoproteincholesterol; LVEF: left ventricular ejection fraction; MI: myocardial infarction; PTCA: percutaneous transluminal coronary angioplasty.

If we dichotomize the LDL-C values in a low group, i.e $\leq 2.35 \mathrm{mmol} / 1(25$ percentile), and a high LDL-C group, i.e $>2.35 \mathrm{mmol} / \mathrm{L}$ ( 75 percentile), patients with low LDL-C are more at risk of developping depressive symptoms than those in the high group $(\mathrm{p}=0.02)$. In the model with diagnosis of major/minor depression this relation with dichotomized LDL-C could not be found.

\section{Discussion}

The results of the present study show an inverse relation between LDL-C, measured 1 month post-MI, and diagnosis of major/minor depression, and depressive symptoms 3 months post-MI. Serum total cholesterol, HDL-C and TG, assessed at 1 month post-MI, were not related to major/minor depression nor depressive symptoms at 3 months post-MI.

It has been suggested that low cholesterol levels could precede depression through changes in serotonergic metabolism ${ }^{6,31}$. Decrease in serum cholesterol may influence stability and permeability of cell membranes, which could lead to changes in tryptophan transport over the blood brain barrier or changes in 5HT receptor expression ${ }^{32}$. In non-cardiac compromised patients lower LDL-C levels have been reported to be related to depression ${ }^{7.8}$. This is in line with findings of the present study, in which lower serum LDL $C$ was also associated with higher depression scores, possibly leading also to a lower amount of free cholesterol around the cell.

In the scarce prospective studies evaluating the relation between serum lipids and depressive symptoms, total cholesterol was found to be a predictor for the development of depressive symptoms ${ }^{5-7}$. In the present study, we could not 
found such a relationship between total cholesterol and depressive symptoms in multivariate analyses. In two of these three prospective studies, only total cholesterol was assessed 5,6. We therefore do not know whether LDL-C would also be related to depression in these studies. An inverse relationship between serum cholesterol and depression was only found in men, not in women 6 . In our study the number of women is too small to analyse the effect of LDL-C on depression. Post-hoc evaluation of an interaction between total cholesterol and LDL-C, did not confirm such a relationship.

In the present study baseline status of cholesterol and depression were assessed at 1 month post-MI, and not at the acute phase of MI. This was done as in the acute phase of the MI it may be difficult to identify depressive symptoms as either (a) components of a major depressive episode, (b) sequellae of a sudden catastrophic cardiac life event, or (c) signs of a temporary decreased cardiac functioning ${ }^{33}$. Also, total cholesterol, HDL-C, and LDL-C decreases and TG changes during the days immediately after infarction ${ }^{34-36}$. One month post-MI, serum lipids are reasonable estimates of baseline lipid values ${ }^{20}$. However, generalization of our results to the acute phase of the MI in which the patient is admitted to the hospital, is not possible. At 1 month post-MI many patients $(76.4 \%)$ were prescribed cholesterol lowering drugs, that influence LDL-C and other serum lipids. These drugs might have influenced the relation between HDL-C and depression in this study. We therefore added the prescription of cholesterol lowering drugs as covariat into the model. These drugs were neither related to the diagnosis major/minor depression nor to depressive symptoms at 3 months.

Lowering LDL-C might increase the risk for developing major/minor depression and depressive symptoms, thereby introducing another risk factor for increased cardiac death. These data may indicate the clinician should be careful in lowering LDL-C post-MI beneath the 25 th percentile $(2.35 \mathrm{mmol} / \mathrm{l})$. Further research is needed to clarify the relation between low serum lipids and depression in post-MI patients and the clinical implications for the prescription of lipid lowering agents.

\section{References}

1. Frasure-Smith N, Lespérance F, Talajic M. Depression and 18 months prognosis after myocardial infarction. Circulation 1995;91:999-1005.

2. Frasure-Smith N, Lespérance F, Talajic M. Depression following myocardial infarction: impact on 6-months survival. JAMA 1993;270:999-1005.

3. Ladwig KH, Kieser M, Konig J, Breithardt G, Borggrefe M. Affective disorders and survival after acute myocardial infarction (results from the post-infarction late potential study). Eur Heart J 1991;12:959-64.

4. Penninx BWJH, Beekman ATF, Honig A, et al. Depression and cardiac mortality: results from a community-based longitudinal study. Arch Gen Psychiatry 2001;58:221-7. 
5. Morgan RE, Palinkas LA, Barrett-Connor EL, Wingard DL. Plasma cholesterol and depressive symptoms in older men. Lancet 1993;341:75-9.

6. Steegmans PH, Hoes AW, Bak AA, van der Does E, Grobbee DE. Higher prevalence of depressive symptoms in middle-aged men with low serum cholesterol levels. Psychosom Med 2000;62:205-11.

7. Shibata H, Kumagai S, Watanabe S, Suzuki T. Relationship of serum cholesterols and vitamin $\mathrm{E}$ to depressive status in the elderly. J Epidemiol 1999;9:261-7.

8. Garland M, Hickey D, Corvin A, et al. Total serum cholesterol in relation to psychological correlates in parasuicide. Br J Psychiatry 2000;177:77-83.

9. Lindberg G, Larsson G, Setterlind S, Rastam L. Serum lipids and mood in working men and women in Sweden. J Epidemiol Com Health 1994;48:360-3.

10. Maes M, Smith R, Christophe A, et al. Lower serum high-density lipoprotein cholesterol (HDL-C) in major depression and in depressed men with serious suicidal attempts: relationship with immune-inflammatory markers. Acta Psychiatr Scand 1997;95:212-21.

11. Markovitz JH, Smith D, Raczynski JM, et al. Lack of relations of hostility, negative affect, and high-risk behavior with low plasma lipid levels in the Coronary Artery Risk Development in Young Adults Study. Arch Intern Med 1997;157:1953-9.

12. Brown SL, Salive ME, Harris TB, Simonsick EM, Guralnik JM, Kohout FJ. Low cholesterol concentrations and severe depressive symptoms in elderly people. BM] 1994;308:1328-32.

13. Apter A, Laufer N, Bar-Sever M, Har-Even D, Ofek H, Weizman A. Serum cholesterol, suicidal tendencies, impulsivity, aggression, and depression in adolescent psychiatric inpatients. Biol Psychiatry 1999;46:532-41.

14. Wilhelmsen L. ESC Population Studies Lecture 1996. Cardiovascular monitoring of a city over 30 years. Eur Heart J 1997;18:1220-30.

15. Keil U, Liese AD, Hense HW, et al. Classical risk factors and their impact on incident non-fatal and fatal myocardial infarction and all-cause mortality in southern Germany. Results from the MONICA Augsburg cohort study 1984-1992. Monitoring Trends and Determinants in Cardiovascular Diseases. Eur Heart J 1998;19:1197-1207.

16. Barefoot JC, Helms MJ, Mark DB, et al. Depression and long-term mortality risk in patients with coronary heart disease. Am J Cardiol 1996;78:613-7.

17. Schleifer SJ, Macari-Hinson MM, Coyle DA, et al. The nature and course of depression following myocardial infarction. Arch Intern Med 1989;149:1785-9.

18. De Zwaan C, Willems GM, Vermeer F, et al. Enzyme tests in the evaluation of thrombolysis in acute myocardial infarction. Br Heart J 1988;59:175-83.

19. Stern TA. Psychiatric management of acute myocardial infarction in the coronary care unit. Am J Cardiol 1987;60:59J-67J.

20. Carlsson R, Lindberg G, Westin L, Israelsson B. Serum lipids four weeks after acute myocardial infarction are a valid basis for lipid lowering intervention in patients receiving thrombolysis. Br Heart J 1995;74:18-20.

21. First MB, Spitzer RL, Gibbon M, Williams JB. Structured Clinical Interview for DSM-IV Axis I disorders-Patient Edition (SCID-I/P, Version 2.0). New York: Biometrics Research Department, New York State Psychiatric Institute, 1995.

22. Beck AT, Ward CH, Mendelson M, Mock J, Erbaugh J. An inventory for measuring depression. Arch Gen Psychiatry 1961;4:561-71.

23. Richter P, Werner J, Heerlein A, Kraus A, Sauer H. On the validity of the Beck Depression Inventory. Psychopathology 1998;31:160-8. 


\section{Chapter 7}

24. Herrmann C. International experiences with the hospital anxiety and depression rating scale: a review of validation data and clinical results. J Psychosom Res 1997;1:17-41.

25. Derogatis LR, Lipman RS, Covi L. SCL-90: an outpatient psychiatric rating scaleprelimanary report. Psychopharm Bull 1973;9:13-27.

26. Arrindell WA, Ettema JHM. Dimensional structure, reliability and validity of the Dutch version of the Symptom Checklist (SCL-90). Ned Tijdschr Psychol 1981;43:381-7.

27. Strik JJMH, Honig A, Lousberg R, Denollet J. Sensitivity and specificity of observer and self rating questionnaires in depression following myocardial infarction. Psychosomatics 2001;42:423-8.

28. Norusis MJ. SPSS for Windows 6.0. Chicago: SPSS Inc, 1993.

29. Miida T, Otsuka H, Tsuchiya A, Okada M. Plasma lipoprotein profiles change significantly during cardiac catheterization. Clin Chem 1998;44:517-21.

30. Kleinbaum DG, Kupper LL, Muller KE. Applied regression analysis and other multivariable methods. Boston: PWS-KENT Publishing Company, 1988:718.

31. Steegmans PH, Fekkes D, Hoes AW, Bak AA, van der Does E, Grobbee DE. Low serum cholesterol concentration and serotonin metabolism in men. BMJ $1996 ; 312: 221$.

32. Engelberg H. Low serum cholesterol and suicide. Lancet 1992;339:727-9.

33. Strik JJMH, Honig A, Lousberg R, et al. Efficacy and safety of fluoxetine in the treatment of patients with major depression following first myocardial infarction: findings from a double-blind placebo-controlled trial. Psychosom Med 2000;62:7839.

34. Enger S6, Birlind S. Serum lipopeotein patrem in moocardial infiretion. Aet Med Scamd 1970; $187: 365-9$.

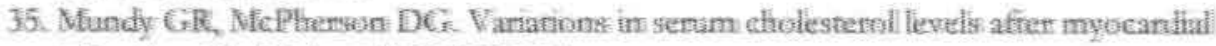
infarctien. Mfed I Aust 1973,1:278-82

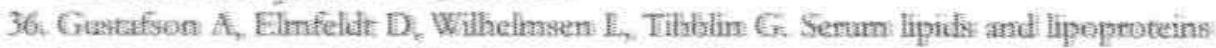
in men after myocardial infarction compared with representatue population samplie. Circularen 1973:46:7109-16: 


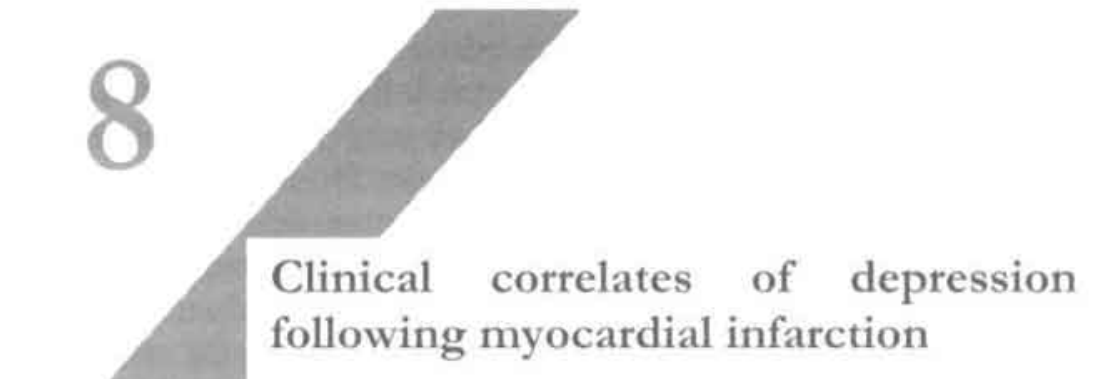




\begin{abstract}
Post myocardial infarction (MI) depression increases mortality, especially in the first 18 months after MI. Identifying patients at risk for post-MI depression is therefore important. In the present study we investigated possible correlates for post-MI depression on an a priori basis. Based on the literature, four clinically easily attainable variables were selected as possible correlates for post-Ml depression. These were prescription of benzodiazepines during the acute hospitalization, cardiac complications during the acute hospitalization, history of depression, and not being able to stop smoking within 6 months after MI. A consecutive cohort of 173 first-MI patients was screened with the SCL-90 depression scale and DSM-III-R criteria for major depression. Of this cohort 35 depressed patients were compared with 35 non-depressed post-MI patients, matched for gender, age, and severity of MI. In univariate analyses, complications during hospitalization $(\mathrm{OR}=2.14 ; \mathrm{CI}=0.89-5.14)$, prescription of benzodiazepines $(\mathrm{OR}=3.67 ; 95 \% \mathrm{CI}=1.11-12.1)$, history of depression $(\mathrm{OR}=3.0 ; 95 \% \mathrm{CI}=0.87-10.4)$ and not being able to stop smoking $(\mathrm{OR}=4.5$; $95 \% \mathrm{CI}=1.11-18.2$ ) were clinical correlates for post-MI depression. Multivariate analyses showed that none of these variables were independent of the others in predicting depression. A number of easily measurable patient characteristics identify those MI-patients at risk of post-MI depression. Further investigations should focus on the predictive value of these factors in relation to post-MI depression.
\end{abstract}

\title{
Reference
}

Strik JJMH, Honig A, Lousberg R, van Os J, van den Berg EJM, van Praag HM. Clinical correlates of depression following myocardial infarction. Int J Psychiatry Med 2002; 31: 271-80. 


\section{Introduction}

Depression often occurs in the peri myocardial infarction (MI) period: a 15$30 \%$ incidence of major depression following MI has been reported 1.2. Depression post-MI not only has clear implications for the patient's quality of life but it also decreases compliance with cardiac therapy, hampers rehabilitation, and worsens cardiac outcome. It has been reported that depression post-MI increases morbidity and mortality, especially in the first 18 months post-MI ${ }^{3}$. Because prognosis is poorer in patients with post-MI depression, it is important to identify such patients in an early stage. The goal of the present study was to detect correlates of post-MI depression, which can be easily obtained by clinicians, i.e. consultant cardiologists and/or consultantliaison psychiatrists.

There have been few studies, which investigated correlates for depression postMI. One study by Ladwig showed that complications during hospitalization increased the risk of depression after MI 4 . Frasure-Smith and co-workers found that patients with a history of depression were more likely to become depressed after MI while they were in the hospital ${ }^{5}$. Not being able to stop smoking and lifetime prescription of benzodiazepines have also been reported to be associated with depression and development of $\mathrm{MI}^{6-9}$.

Methodological flaws of most studies reporting data on markers for post-MI depression compared depressed patients with non-matched controls, included patients who had more than one infarction, or diagnosed depression within 2 weeks of the MI (thereby not excluding adjustment disorder or depressive symptoms possibly directly related to cardiac disfunctioning) ${ }^{49}$. The present study, which is part of a larger intervention trial ${ }^{10}$, investigated on a priori basis clinical correlates for post-MI depression in a homogeneous and matched case control patient sample.

\section{Methods}

\section{Subjects}

Patients were selected from the coronary care unit of the department of cardiology of the Maastricht University Hospital. Inclusion criteria were a first MI, a clinical presentation and electrocardiographic signs typical for an acute MI ", and a maximum value of the enzyme aspartate aminotransferase (ASAT $T_{\max }$ ) of at least $80 \mathrm{U} / \mathrm{L}$ (twice above the normal upper limit ${ }^{12}$ ). When written informed consent was obtained, participants were screened 1,3, and 6 months after MI using a validated Dutch version of the self-rated 90-item Symptom Check List (SCL-90) ${ }^{13}$ and Zung Self-rated Depression Scale (Zung-SDS) ${ }^{14}$. Patients scoring above the cut-off of the SCL-90 depression scale (M: > 22; F > 27 ) or Zung SDS ( $M$ and $F>49$ ) at one or more of the three screening evaluations were invited for an interview with a psychiatrist. The psychiatrist 
then conducted a psychiatric examination in order to establish whether major depression was present using a DSM-III-R check list consisting of section 6, 7, 8 , and 21 of the Schedule for Clinical Assessment in Neuropsychiatry (SCAN) 15. Patients with a score below the cut-off were not invited: they were considered as not having major depression as the SCL-90 depression subscale has a sensitivity and negative predictive value (NPV) of $96 \%$ in a consecutive cohort of 206 first-MI patients ${ }^{16}$.

These patients who did not complete the questionnaires at all three follow-up times or who did not come to the interview were excluded from the analyses. Patients scoring above the cut-off, but without major depression were also excluded. The remaining group was divided into 'cases' and 'controls'. Cases were those patients scoring above the cut-off (on at least of the follow-up times) and who were diagnosed with major depression according the DSM-III$\mathrm{R}$ criteria. Controls were those patients scoring lower than the cut-off on all three follow-up times. Cases were matched with controls for gender, age, and ASAT $_{\text {max. }}$

\section{Correlates}

The four correlates were defined as: prescription of benzodiazepines during acute hospitalization for MI, complications during acute hospitalization, previous depressive episode, and not being able to stop smoking after the MI. Benzodiazepines were defined as alprazolam, oxazepam, temazepam, lorazepam and nitrazepam. Complications during hospitalization were defined as resuscitation, angina pectoris, rhythm disorders, conduction disorders, pericarditis, heart failure, and non-cardiac complications such as shock, pneumonia and allergic reactions. History of depression was defined as the occurrence of at least one major depressive episode in the past (diagnosed using the checklist of section $6,7,8$, and 21 of the SCAN). Not being able to stop smoking was defined as persistence to smoke although during the hospitalization all patients were advised by the cardiologist to stop smoking. Prescription of benzodiazepines and complications during acute hospitalization were collected from the patient files. Data concerning previous depressive episodes of the cases were collected during the SCAN interview. Information of correlates concerning previous depressive episode and smoking habit of the controls was collected during an interview by telephone, because these controls were not invited for the interview due to low scoring on the questionnaires.

\section{Data analyses}

Statistical analyses were carried out using the STATA 5.0 17 and SPSS for Windows software packages ${ }^{18}$. The statistical procedure 'epitab' for matched case control data ${ }^{19}$ was applied for dichotomous variables. Because of the use of matched pairs conditioned logistic regression was used to examine the joint effect of several variables ${ }^{20}$. Both univariate and multivariate analyses were used. Odds ratios $(\mathrm{OR})$ and population attributable fractions (PAF) were 
measured for matched pairs. PAF is a measure indicating the public health importance of a risk factor. PAF is thus the "amount" of disease that could be prevented if the risk factor could be eliminated. This is only the case if the relationship between the disease and the risk factor is a causal one. PAF is a combination of the strength of a risk factor (defined as relative risk, RR) and the prevalence of this risk factor. A very strong risk factor (high RR) that is rare has a lower PAF than a weak risk factor (low RR) with a high prevalence rate. One-tailed tests were carried out (because of the a-priori hypotheses) and a $\mathrm{p}$ value $\leq 0.05$ was considered significant.

\section{Results}

\section{Patients}

Between 1st of May 1994 and 1st of February 1997, 334 consecutive patients were recruited. Of these patients, $32(9.6 \%)$ died within one month, 129 patients $(38.6 \%)$ refused to participate in this study and 173 patients gave their informed consent. Refusers were more likely to be female; age and ASAT $T_{\max }$ did not differ between refusers and non-refusers. The non-refuser group consisted of 35 women $(20.2 \%)$ and 138 men $(79.8 \%)$. Thirty-nine patients were diagnosed to have a major depression; these cases were matched with 39 controls. Three controls had missing data on one of the matching variables and in one case the current MI subsequently proved to be a recurrence. These four patients and their matched counterparts were excluded from further analyses.

The final study sample consisted thus of 35 cases and 35 controls ( 29 men and 6 women in both groups). Cases and controls did not differ in age, and ASAT $_{\max }$. The mean SCL-90 depression score in the depressed patient group was $33.0(\mathrm{SD}=8.0$; range 24-53) for men and $40.0(\mathrm{SD}=11.0$; range 33-62) for women, and in the control group 19.0 ( $\mathrm{SD}=2.0$; range 16-22) for men and 23.0 ( $\mathrm{SD}=3.5$; range 19-26) for women. The mean Zung-SDS score in the depressed patient group was $40(\mathrm{SD}=15$; range 25-65) for men and $49(\mathrm{SD}=$ 19 ; range 25-64) for women, and in the control group $36(\mathrm{SD}=7.1$; range 2653) for men and $43(\mathrm{SD}=5.6$; range 36-49) for women. For the SCL-90, the finding that women score higher on depression rating scales than men is in line with the earlier findings of Arrindel, and is reflected in higher cut-off scores for women than for men ${ }^{13}$.

\section{Correlates}

Of the 70 patients, 34 patients (21 cases and 13 controls) experienced complications during hospitalization. This consisted of resuscitation $(n=4)$, recurrent chest pain $(n=12)$, rhythm disorders $(n=12)$, conduction disorders $(n=11)$, pericarditis $(n=1)$, pump failure $(n=4)$ and pneumonia $(n=1)$. In 18 patients (13 cases and 5 controls) benzodiazepines were prescribed. Benzodiazepines prescribed were oxazepam $10 \mathrm{mg}$ t.d.s. with temazepam $10 \mathrm{mg}$ 
nocte $(\mathrm{n}=1)$, alprazolam $0.5 \mathrm{mg}$ t.d.s with nitrazepam $10 \mathrm{mg}$ with $(\mathrm{n}=1)$, and oxazepam $10 \mathrm{mg}$ t.d.s $(\mathrm{n}=16)$. Of this latter 16 patients, 4 patients were prescribed extra benzodiazepines nocte, i.e. normison $20 \mathrm{mg}(\mathrm{n}=1)$, temazepam $10 \mathrm{mg}(\mathrm{n}=2)$, and lorazepam $1 \mathrm{mg}(\mathrm{n}=1)$. Twelve patients $(9$ cases and 3 controls) had a previous major depressive episode. At the time of the diagnosis of the current depressive episode none of the patients were taking antidepressants. All patients were advised by the cardiologist not to smoke. None of the patients was offered intervention for smoking cessation. Fourtythree patients ( 25 cases and 18 controls) could not stop smoking within 6 months after the MI.

In Table 1, the univariate associations between correlates and post-MI depression are summarised. All four correlates were significantly related to major depression. Of these variables, not being able to stop smoking was the variable most strongly related to post-MI depression: the OR was $4.5(95 \% \mathrm{CI}=$ 1.11-18.2), and the PAF was $74 \%$. Because some of these variables may depend on each other, we performed a multivariate analysis. As can be seen in the table, all ORs were substantial. However, only the p-value for the whole model was statistically significant, but not for the separate variables (all $p>0.05$ ). This means that the four variables were interdependent and individually had a weak relationship with depression.

Table 1

Relationship correlates and post-MI depression

\begin{tabular}{c|cc|cc|ccc}
\hline Correlates & Depressed & $\begin{array}{c}\text { Not } \\
\text { depressed } \\
(\mathrm{n}=35)\end{array}$ & $\mathrm{p}^{5}$ & $\begin{array}{c}\text { OR } \\
\text { (range) } \\
\text { Univar. }\end{array}$ & $\mathrm{p}^{*}$ & $\begin{array}{c}\text { OR } \\
\text { (range) } \\
\text { Multivar. }\end{array}$ & PAF \\
\hline
\end{tabular}

Complications during hospitalization:

\begin{tabular}{l|ll|l|l|lcl} 
Yes & 21 & 13 & & 2.14 & \multicolumn{3}{c}{2.1} \\
No & 14 & 22 & 0.05 & $(0.89-5.14)$ & 0.07 & $(0.77-5.60)$ & $32 \%$ \\
\hline
\end{tabular}

Benzodiazepines during hospitalization:

\begin{tabular}{l|lr|rc|ccc} 
Yes & 13 & 5 & & 3.67 & \multicolumn{3}{c}{2.11} \\
No & 22 & 30 & 0.02 & $(1.11-12.1)$ & 0.15 & $(0.50-9.01)$ & $30 \%$ \\
\hline
\end{tabular}

Previous history of depression:

\begin{tabular}{l|cc|cc|ccc} 
Yes & 9 & 3 & \multicolumn{3}{c}{3.0} & \multicolumn{3}{c}{2.24} \\
No & 26 & 32 & 0.04 & $(0.87-10.4)$ & 0.15 & $(0.50-10.1)$ & $18 \%$ \\
\hline
\end{tabular}

\begin{tabular}{|c|c|c|c|c|c|c|c|}
\hline \multicolumn{8}{|c|}{ Stop smoking: } \\
\hline Yes & 10 & 17 & & 4.5 & & 1.78 & \\
\hline No & 25 & 18 & 0.02 & $(1.11-18.2)$ & 0.13 & $(0.66-4.79)$ & $74 \%$ \\
\hline
\end{tabular}

$\$=$ p-value of univariate analyses, one-tailed; \# = p-value of multivariate model, one-tailed; PAF: population attributable fraction; Univar: univariate model; Multivar: multivariate model. 


\section{Discussion}

This study evaluated correlates of post-MI depression, which can be easily obtained and help the clinician to identify patients at risk for post-MI depression. Univariate results clearly showed that complications during hospitalization, prescription of benzodiazepines during hospitalization, history of depressive episode, and not being able to stop smoking were significantly related to post-MI depression. Not being able to stop smoking was the clinical marker most strongly related to post-MI depression. Post-first MI patients who could not stop smoking were 4.5 times more likely to be or become depressed than patients who could change their smoking habits. The PAF was $74 \%$. This means that if the risk factor of not being able to stop smoking could be eliminated, $74 \%$ of the MI patients would be prevented from being depressed. However, this would only be the case it there is a causal relationship between not being able to stop smoking and development of depression post-MI.

The multivariate analysis showed that the four variables were interdependent $(p$ $=0.03)$, meaning that none of the variables were independent of the others in predicting depression.

This was further shown by the non-significant $\mathrm{p}$-values of each clinical marker separately in the multivariate model. MI patients who are likely to become depressed are those who have all four correlates (complications during hospitalization, prescription of benzodiazepines during hospitalization, previous history of depressive episode and not being able to stop smoking).

Correlates for post-MI depression could be regarded as triggers or as early signs of a depressive episode that already existed before or at the time of the MI. Somatic complications may be the consequence of depression, that existed before or at the time of the MI ${ }^{21}$. For example, arrhythmia, which complicates recovery after MI, has been linked to depression, already present before MI 22 . On the other hand, it could also be a clinical marker for depression developing after $\mathrm{MI}^{4}$.

Prescription of benzodiazepines by the cardiologist during acute hospitalization was found to be an early sign to indicate that patients at risk probably already at an early stage have symptoms of anxiety, sleep disturbances and/or depression 7. In addition, prescription of benzodiazepines may even predict the development of recurrent MI since others have found that women using benzodiazepines are at a greater risk for occurrence of MI ${ }^{23}$. As noted earlier not being able to stop smoking after the MI may also be an early sign of depression. Glassman et al. reported that major depression increased the likelihood that a person smoked and that if that person attempted to stop smoking during a depressive episode there was a greater chance that he or she would fail 6 . History of depression is not only correlated with development of a recurrent episode in non-cardiac compromised patients ${ }^{24}$, but is also a correlate for post-MI depression. This was not only found in the present'study; Frasure- 
Smith and co-workers found that previous depressive episode was associated with development of depression post-MI ${ }^{5}$.

The finding that complications during hospitalization, history of depression and prescription of benzodiazepines during hospitalization are correlates for postMI depression has practical implications, as it can easily alert physicians to patients at risk for depression already in the early phase of hospitalization. Patients at risk can be identified by their inability to stop smoking already during the hospitalization. In case of a recurrent MI, not being able to stop smoking after the first MI may also be a marker for depression. This marker is easily obtainable by the cardiologist. The clinician may find it difficult to screen directly for depression during the acute hospitalization. The clinical correlates evaluated in this study are easily obtainable by the clinician even at an early stage. Identifying these correlates may help the clinician to decide whether or not to perform an initial screening on depressive symptoms, for example using the self rating questionnaire BDI (sensitivity $82 \%$, positive predictive value $33 \%$ 10) and, if present, refer the patient to psychiatry. These risk factors may therefore serve as a first step for lowering the high rate of underdiagnosis.

\section{Limitations}

As we did not study recurrent MI, generalisation of our findings to such a patient group should be cautioned. Another limitation of this study is the small selection of possible correlates. Given the limited number of 35 controls and 35 cases, not more than 4 factors could be included in the model. We investigated only those factors, which would easily and in an objective way be obtained by the clinician. The patient's indication of use of alcohol, for example, does often not reflect actual intake. The small patient sample prevented us from evaluating interactions, and the design from measuring positive predictive values. Finally, we only matched for age, gender and $\mathrm{ASAT}_{\max }$.

\section{Conclusion}

Based on the present results, a clinical marker profile for post-MI patients at risk for depression can be obtained with little specific clinical effort and without stress for the MI-patient, possibly leading to a reduced number of missed diagnoses of depression. Adequate psychiatric treatment at an early stage possibly decreases the number of mortality and morbidity in post-MI depressed patients, in addition to improving their quality of life. 


\section{References}

1. Fielding R. Depression and acute myocardial infarction: a review and reinterpretation. Soc Sci Med 1991;32:1017-27.

2. Honig A, Lousberg R, Wojchiechowski F, Cheriex EC, Wellens H, Van Praag HM. Depression following a first heart infarct; similarities with and difference from 'ordinary' depression. Ned Tijdschr Geneeskunde 1997;141:196-9.

3. Frasure-Smith N, Lespérance F, Talajic M. Depression and 18 months prognosis after myocardial infarction. Circulation 1995;91:999-1005.

4. Ladwig KH. Factors which provoke post-infarction depression. Results from the post-infarction late potential study. J Psychosom Res 1992;34:723-9.

5. Frasure-Smith N, Lespérance F, Talajic M. Depression following myocardial infarction: impact on 6-months survival. JAMA 1993;270:999-1005.

6. Glassman AH, Stetner F, Walsh BT, et al. Heavy smokers, smoking cessation, and clonidine: results of a double-blind, randomised trial. JAMA 1988;259:2863-6.

7. Wiklund I, Oden A, Sanne H, Ulvenstam G, Wilhelmsson C, Wilhelmsen L. Prognostic importance of somatic and psychosocial variables after a first myocardial infarction. Am J Epidemiology 1988;128:786-95.

8. Denollet J, Sys SU, Stroobant N, Rombouts H, Gillebert TC, Brutsaert DL. Personality as independent predictor of long-term mortality in patients with coronary heart disease. Lancet 1996;347:417-21.

9. Denollet J, Vaes J. Adverse effects of type D personality and younger age on 5-year prognosis and quality of life. Circulation 2000;102:630-5.

10. Strik JJMH, Honig A, Lousberg R, et al. Efficacy and safety of fluoxetine in the treatment of patients with major depression following first myocardial infarction: findings from a double-blind placebo-controlled trial. Psychosom Med 2000;62:7839.

11. Pasternak RC, Braunwald E, Sobel RE. Acute myocardial infarction. In: Braunwald E, ed. Heart disease: a textbook of cardiovascular medicine. 4th edition ed. Philadelphia: W. B. Saunders Compagny; 1992:1200-91.

12. Braunwald. Heart disease. 5e ed: Saunders Compagny; 1998.

13. Arrindell WA, Ettema JHM. Dimensional structure, reliability and validity of the Dutch version of the Symptom Checklist (SCL-90). Ned Tijdschr Psychologie 1981;43:381-7.

14. Zung WW, Richards CB, Short MJ. A selfrating depression scale. Arch Gen Psychiatry 1965;12:63-70.

15. Wing JK, Babor $T$, Brugha $T$, et al. Schedules for clinical assessment in neuropsychiatry. Arch Gen Psychiatry 1990; 47:589-93.

16. Strik JJMH, Honig A, Lousberg R, Denollet J. Sensitivity and specificity of observer and self rating questionnaires in depression following myocardial infarction. Psychosomatics 2001;442:23-428.

17. STATA. Stata Statistical Software: Release 5.0. College Station: Stata Corporation; 1997.

18. Norusis MJ. SPSS for Windows 6.0. Chicago: SPSS Inc; 1993.

19. Rothman KJ. Modern epidemiology. Boston: Little, Brown and Company; 1986.

20. Clayton D, Hills M. Conditional logistic regression. In: Clayton D, Hills M (eds). Statistical Models in Epidemiology. Oxford: Oxford Science Publications; 1993:2908. 
21. Carney RM, Rich M, Tevelde A. The relationship between heart rate, heart rate variability and depression in patients with coronary artery disease. J Psychosom Res 1988;32:159-64.

22. Musselman DL, Evans DL, Nemeroff CB. The relationship of depression to cardiovascular disease. Arch Gen Psychiatry 1998;55:580-92.

23. Thorogood M, Cowen P, Mann J. Fatal myocardial infarction and use of psychotrophic drugs in young women. The Lancet 1992;340:1067-68.

24. Keller MB, Lavori PW, Rice J, Coryell W, Hirschfeld RMA. The persistent risk of chronicity in recurrent episodes of nonbipolar depressive disorder: a prospective follow-up. Am J Psychiatry 1989;143:24-8. 


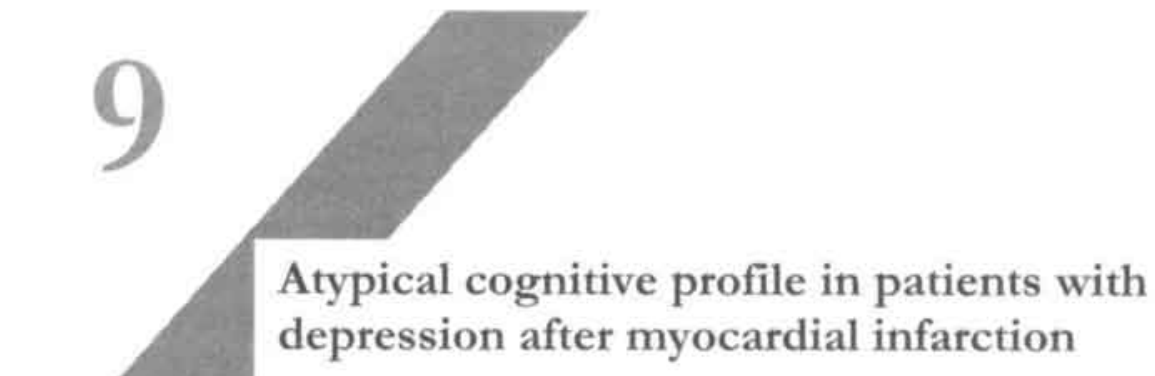




\section{Abstract}

In the present study we evaluated the cognitive profile of 48 patients with major depression following their first myocardial infarction (MI). The cognitive performance of the patients was compared with the performance of 48 nondepressed MI patients and 48 healthy controls. Depressed MI patients performed slower on a simple cognitive speed related measure compared with non-depressed MI patients and healthy controls. Attention and speed related aspects of cognitive functioning were not affected. Surprisingly, (depressed) MI parients showed even better performances with respect to memory function. The cognitive profile of major depression after MI differs from that of noncardiac-related depressive disorder, as described in the literature. This may reflect a different aetiology of post-MI depression from non cardiac-related depression.

\section{Reference}

Dijkstra JB, Strik JJMH, Lousberg R, Prickaerts J, Riedel WJ, Jolles J, van Praag HM, Honig A. Atypical cognitive profile in patients with depression after myocardial infarction. J Aff Dis 2002; 70: 181-90. 


\section{Introduction}

Myocardial infarction (MI) is frequently complicated by a depressive disorder 1 4. Patients with depression after MI are probably doubly at risk for cognitive decline. First, depressive disorder is related to a decline in almost all cognitive domains such as impaired attention ${ }^{5}$, frontal lobe dysfunction ${ }^{6}$, executive deficits ${ }^{7}$ and especially memory impairment ${ }^{8-10}$. Also a slowing of mental processes termed "psychomotor retardation" is often found 7,11,12. Improvement in cognitive function is expected following remission of depressive symptoms.

Secondly, patients with chronic cardiac disease in general perform worse than healthy controls on cognitive tests ${ }^{13,14}$. The cause of this cognitive impairment in cardiovascular disease is not known ${ }^{15}$, but these patients are more likely than healthy controls to have significant stenoses in their cerebrovascular circulation. For this reason, it has been hypothesized that limited oxygenation of the brain may be a risk factor or vulnerability factor for cognitive dysfunction ${ }^{16,17}$. Two studies investigating the effect of a history of MI on cognitive function among elderly subjects ( $>64$ years) found no association ${ }^{18,19}$. However, Breteler et al. ${ }^{20}$ suggested that $\mathrm{MI}$ is associated with white matter lesions in subjects older than 65 years of age, and related these lesions to cognitive dysfunction. Grubb et al. ${ }^{21}$ compared the memory function of patients with acute MI with and without cardiac arrest and only found moderate to severe memory impairment in patients with acute MI and cardiac arrest. It is possible that the patients with acute MI and cardiac arrest suffered from cerebral hypoxia due to cardiac arrest. Hypoxia is known to cause damage to the hippocampus and other medio temporal lobe structures, as well as memory impairment 22.25 .

The present study is the first to investigate cognitive performance in patients with a major depressive episode (according to DSM-IV) after their first MI, in non-depressed first MI patients, and in normal healthy controls. We hypothesized that cognitive performance would be worse in MI patients than in healthy controls and that MI patients with a depressive disorder would show an even worse cognitive performance. This study is part of a larger study investigating the efficacy and side-effects of a placebo-controlled treatment with a SSRI ${ }^{26}$.

\section{Methods}

\section{Inclusion criteria of patients}

Patients were recruited from the in-patient department of cardiology of the Maastricht University Hospital and an affiliated hospital. Inclusion criteria were: age between 18-75 years and a first acute MI, defined as a clinical picture typical for an acute MI, a maximum value of the plasma concentration of the enzyme aspartate aminotransferase (ASAT $T_{\max }$ ) twice higher than the upper limit of the 
normal range ( $80 \mathrm{U} / \mathrm{L})$, and ECG changes specific for MI ${ }^{27}$. Patients were screened for depressive symptomatology using the Dutch version of the 90item Symptom Check List (SCL-90, validated Dutch version ${ }^{28}$ ). Patients with a score above the cut-off on the SCL-90 depression scale $(\geq 23$ for males and $\geq$ 28 for females) were invited for a diagnostic interview by an experienced psychiatrist. Severity of depression was measured by means of the Hamilton Depression Rating Scale, 17-item version (HAMD-17) ${ }^{29}$. All patients diagnosed with a major depressive episode according to DSM-IV criteria with a HAMD17 score higher than 17 entered the depressed group. The non-depressed patients did not show any signs of a depression up to 12 months after MI. These non-depressed patients were matched individually with the depressed patients for age, level of education, gender, and $\mathrm{ASAT}_{\max }$.

Background characteristics of the study population are presented in Table 1.

\section{Table 1}

Background characteristics of the study population.

\begin{tabular}{l|c|c|c|c|c|c}
\hline Group (range, years) & No (\%) & Age & $\begin{array}{c}\text { Education } \\
\text { score }\end{array}$ & $\begin{array}{c}\text { Male/ } \\
\text { female }\end{array}$ & $\begin{array}{c}\text { SCL-90 } \\
\text { depression } \\
\text { score }\end{array}$ & $\begin{array}{c}\text { HAMD-17 } \\
\text { score }\end{array}$ \\
& & \multicolumn{2}{|c|}{ Mean \pm S.D. } & & \multicolumn{2}{|c}{ Mean \pm S.D. } \\
\hline Total group (33-76) & $144(100)$ & $56.6 \pm 10.9$ & $3.0 \pm 2.0$ & $105 / 39$ & $25.8 \pm 11.2$ & n.m. \\
Young (33-56) & $73(51)$ & $47.3 \pm 5.7$ & $3.6 \pm 1.7$ & $67 / 6$ & $24.6 \pm 9.4$ & n.m. \\
Old (57-76) & $71(49)$ & $66.3 \pm 4.9$ & $2.4 \pm 2.1$ & $38 / 33$ & $27.0 \pm 12.8$ & n.m. \\
Healthy control group (37-76) & $48(33)$ & $56.7 \pm 11.1$ & $2.9 \pm 2.0$ & $35 / 13$ & $18.0 \pm 1.8$ & n.m. \\
Young (37-56) & $25(17)$ & $47.4 \pm 5.8$ & $3.6 \pm 1.7$ & $23 / 2$ & $17.8 \pm 1.7$ & n.m. \\
Old (59-76) & $23(16)$ & $66.8 \pm 4.6$ & $2.2 \pm 2.0$ & $12 / 11$ & $18.3 \pm 1.9$ & n.m. \\
MI non-depressed (33-76) & $48(33)$ & $56.5 \pm 10.8$ & $3.1 \pm 1.9$ & $35 / 13$ & $22.4 \pm 5.8$ & $8.0 \pm 4.1$ \\
Young (33-55) & $23(16)$ & $46.9 \pm 5.7$ & $3.5 \pm 5.7$ & $21 / 2$ & $21.5 \pm 5.4$ & $8.4 \pm 4.2$ \\
Old (57-76) & $25(17)$ & $65.4 \pm 5.5$ & $2.8 \pm 2.2$ & $14 / 11$ & $23.1 \pm 6.2$ & $7.6 \pm 4.1$ \\
Ml depressed (37-76) & $48(33)$ & $56.7 \pm 11.0$ & $3.0 \pm 2.1$ & $35 / 13$ & $37.0 \pm 12.0$ & $21.1 \pm 2.3$ \\
Young (37-56) & $25(17)$ & $47.4 \pm 5.8$ & $3.6 \pm 1.9$ & $23 / 2$ & $34.4 \pm 8.8$ & $20.9 \pm 2.4$ \\
Old (58-76) & $23(16)$ & $66.7 \pm 4.6$ & $2.2 \pm 2.0$ & $12 / 11$ & $39.8 \pm 14.4$ & $21.4 \pm 2.2$ \\
\hline
\end{tabular}

n.m. = not measured; HAMD-17: 17-item Hamilton Depression Rating Scale; MI: myocardial infarction; SCL-90; 90-item Symptom Check List.

Exclusion criteria were psychotic symptomatology, the presence of a second psychiatric diagnosis, a previous history of manic symptoms, pregnancy or lactation, a life-threatening physical illness (other than the present MI), concurrent use of psychotropic drugs (except a benzodiazepine in an equivalent of oxazepam to a maximum dose of $50 \mathrm{mg} /$ day), fluoxetine hypersensitivity, 
liver dysfunction, or severe kidney dysfunction (creatinine clearance, 10 $\mathrm{ml} / \mathrm{min}$ ). Patients with an aorta interval (AI) less than 20 and/or a right ventricular systolic pressure higher than 30 were excluded.

Medication for the MI patients was usually prescribed by the cardiologist. For an overview of the medication taken by the patients see Table 2 . The median number of cardiovascular drugs, i.e. all nine drugs mentioned except benzodiazepines/tranquilizers, taken per non-depressed MI patient was four, ranging from one to six. The median number of cardiovascular drugs taken per depressed MI patient was three, ranging from zero to six. In both MI groups no anti-depressive medication was used at the time of the cognitive assessment.

The study was approved by the local ethics committee at the two sites, and all participants gave their written informed consent after the study had been explained to them.

\section{Table 2}

Medication for the depressed and non-depressed MI patients and psychoactive effects

\begin{tabular}{l|c|c|c|c}
\hline Medication & Non-depressed & Depressed & Psychoactive & Effect \\
\hline anti-coagulation agents & $48(100 \%)$ & $42(80 \%)$ & no & \\
Isosorbide nitrate & $30(63 \%)$ & $20(42 \%)$ & no & \\
Beta blockers (lipophilic) & $36(75 \%)$ & $30(63 \%)$ & yes & - \\
Calcium channel blockers & $7(15 \%)$ & $15(32 \%)$ & yes & + \\
Benzodiazepines/tranquilizers & $10(21 \%)$ & $23(48 \%)$ & yes & - \\
Cholesterol-lowering drugs & $38(79 \%)$ & $18(38 \%)$ & yes & + \\
Diuretics & $4(8 \%)$ & $12(25 \%)$ & no & \\
ACE-inhibitors & $11(23 \%)$ & $14(29 \%)$ & yes & + \\
Beta blockers (hydrophilic) & $3(6 \%)$ & $5(10 \%)$ & no & \\
\hline
\end{tabular}

$+=$ positive effect, - = negative effect; MI: myocardial infarction.

\section{Selection criteria of normal volunteers}

The normal volunteers $(\mathrm{n}=48)$ were drawn from 1,450 healthy subjects who were recruited from a patient register of general practices in the region of Maastricht, the Netherlands ${ }^{30}$. This register contains all relevant past and current medical morbidity as documented by the general practitioners. Subjects with previous or actual medical conditions with known impact on cognitive or motor functions were excluded from the selection. Other exclusion criteria were depression (scores higher than the cut-off on the SCL-90 depression scale ( $\geq 23$ for males and $\geq 28$ for females), overt cerebrovascular disease, chronic neural pathology (e.g., dementia, epilepsy, parkinsonism), mental retardation, and psychotropic drug use. The subjects who were eligible for the study filled out a postal questionnaire and participated in an extensive medical and 
neuropsychological investigation. The 48 control subjects were matched individually with the patients for age, level of education and gender.

\section{Procedure and cognitive test battery}

MI patients entered the study not earlier than 4 weeks after the MI, because during the first weeks after a $\mathrm{MI}$ it is not well possible to attribute depressive symptoms to a major depressive episode or to intense distress due to the cardiac event. The MI patients were followed during 12 months to see whether they developed a depressive disorder. Depressive symptoms were assessed at 4 occasions (1, 3, 6 and 12 months) during the 1 st year post-MI. Patient who developed a depressive disorder in this period underwent a neurocognitive investigation. Cognitive data of the non-depressed MI patients, who retrospectively did not develop a depression during the first year following MI, were collected at 1 month post-MI.

Neurocognitive tests were used which have been found to be sensitive to small differences between patient groups and which are in widespread use in largescale studies into cognitive disorders and age-related cognitive decline ${ }^{31-35}$. The tests are part of a cognitive screening battery used in various studies with patients and healthy subjects (for further description and psychometric properties see Jolles et al. ${ }^{30}$ ). The tests exist in parallel versions and can therefore be used in repeated measurements.

\section{Visual Verbal Learning Test (VVLT)}

Visual Verbal Learning Test (VVLT). A visual version 8,36 of the Auditory Verbal Learning Test ${ }^{37}$ was used. The psychometric properties are described in Bouma et al. ${ }^{38}$. In procedure it is quite similar to the California Verbal Learning Test and the Auditory-Verbal Learning Test (AVLT) ${ }^{37}$ except that words are presented visually to control for hearing loss. In this version, a set of 15 frequently used monosyllabic meaningful words is visually presented in a fixed order at a rate of one every two seconds in three consecutive trials. After each trial or presentation the subject is requested to recall as many words as possible with no restriction concerning the order of recall. The dependent variable is the total number of words recalled over the three trials (VVLTTOT). Twenty minutes after the last presentation, the subject is again requested to recall as many words as he or she can remember (delayed recall; VVLTDEL). This test measures memory storage and retrieval of verbal information in episodic memory.

\section{Concept Shifting Test (CST)}

Concept Shifting Test (CST). This test is derived from the Trail Making Test ${ }^{37}$, which is used to measure the ease of shifting between different sets of attention. Compared with the Trail Making Test, the effect of CST on motor function is limited and thereby controls for the influence of simple motor speed on test performance. It consists of four parts. On each test sheet, 16 small 
circles are grouped in a larger circle. In the first part empty circles have to be crossed out as fast as possible (CST0). In the other three parts the circles contain numbers (CSTA), letters (CSTB), or both (CSTC), appearing in a fixed random order. Subjects are requested to cross out the items in the right order. The dependent variable is the time needed for each part ${ }^{30}$.

\section{Stroop Colour-Word Test (SCWT)}

Stroop Colour-Word Test (SCWT). The SCWT is a test of selective attention and interference susceptibility. The test involves three cards displaying 40 stimuli each: colour names (SCWT I), coloured patches (SCWT II), and colour names printed in incongruously coloured ink (SCWT III). For the last card, the colour of the ink has to be named instead of the colour name. This task is particularly sensitive to interference. The variables of interest are the times (seconds) needed to complete each card ${ }^{37,39}$.

\section{Letter-Digit Substitution Test (LDST)}

Letter-Digit Substitution Test (LDST). This test is a modification of the procedurally identical Symbol-Digit-Modalities Test ${ }^{37}$. The subjects are supplied with a code at the top of a page where a digit corresponds to a letter. They then have a short time to fill in blanks which correspond to the correct codes. The test is used to measure the speed of processing of general information, i.e., the test is supposed to draw upon several (cognitive) processes such as visual perception, attention, and memory. The dependent variable is the total number of letters written correctly in one minute (LDSTTOT) ${ }^{30}$.

The cognitive measurements assess the following theoretical underlying cognitive constructs: memory (VVLTTOT, VVLTDEL) and attention-related aspects such as cognitive flexibility (ability to shift between two sequences; CSTC), interference susceptibility (ability to ward off distractions; SCWT III), sensorimotor speed (simple cognitive speed; CST0, CSTA, CSTB, SCWT I and II), and speed of general information processing (LDSTTOT) ${ }^{33}$.

\section{Data analysis}

The number of males and females in each experimental group, that is control non-depressed, MI patients non-depressed and MI patients depressed, were equal. The three groups were matched for age and education. Since all primary efficacy and safety variables were normally distributed and no outlying values more than 3 SD below or above the mean were found, parametric tests were applied. A p-value $\leq 0.05$ was considered significant. Besides group effects the impact of age and gender was also studied. Age was studied as an independent variable to control for possible interactions with group because of the wide age range (33-76 years). Two age groups (middle-aged and elderly) were formed using the split-half method (56 years). Gender was also studied as an independent variable to control for a possible interaction. Thus, the obtained data were subjected to a three-way analysis of variance with group, age and 
gender as independent variables. Group effects between the three experimental groups were evaluated in more detail by a Student-Newman-Keuls test (critical $\mathrm{p}$-value $=0.05)$. Statistical analyses were carried out with the software package SPSS ${ }^{+0}$.

\section{Results}

Patients were enrolled in the study from May 1994 until December 1997: Each experimental group contained 48 subjects which consisted out of 35 males and 13 females. The mean age of the three groups was 56.6 years and the education level of all groups was 2.5 (median) on an 8-point scale ${ }^{41}$.

On all cognitive test variables age effects were found (all Fs $>6.8, \mathrm{p}<0.01$ ). The older subjects showed a worse cognitive performance on all test variables (see also Figure 1). Gender effects were found on the two memory variables (VVLTOT, VVLDEL); females showed a better performance compared to males (Fs $>7.4, \mathrm{p}<0.01)$. No interactions were found between group, age and gender. This indicates that the effect of MI and MI and depression were not different between the age groups and gender.

Group effects of the various tests of cognitive function are summarised in Table 3. With respect to memory performance (VVLT) it was found that for both measures the groups were different between each other (group effect: both Fs $>3.09, \mathrm{p}<0.05$ ). Post hoc analysis of the measure VVLTTOT showed that MI patients performed better than healthy controls. Furthermore, depressed MI patients had an even better performance on this measure than MI patients without a depression (see also Fig. 1A). The latter was also found for the measure VVLTDEL, although separately both MI groups were not different from the control group. 


\section{Table 3}

Differences in cognitive performance of MI patients and controls in various tests of cognitive function. For the CST and SCW'T, a higher score indicates a lower test performance. For VVLT and LDST a higher score indicates a higher test performance.

\begin{tabular}{|c|c|c|c|}
\hline & $\begin{array}{c}\text { Control } \\
\text { non- } \\
\text { depressed } \\
(\mathrm{n}=48)\end{array}$ & $\begin{array}{c}\text { MI patients } \\
\text { non- } \\
\text { depressed } \\
(n=48)\end{array}$ & $\begin{array}{c}\begin{array}{c}\text { MI patients } \\
\text { depressed }\end{array} \\
(n=48)\end{array}$ \\
\hline \multicolumn{4}{|l|}{ Visual Verbal Learning Test (VVLT) } \\
\hline VVLTTOT & $21.3 \pm 5.4^{2}$ & $23.8 \pm 5.0^{b}$ & $26.4 \pm 6.8$ \\
\hline VVLTDEL & $8.4 \pm 3.0 \mathrm{atb}$ & $7.5 \pm 2.6$ & $9.0 \pm 3.1^{\mathrm{b}}$ \\
\hline \multicolumn{4}{|l|}{ Concept shifting Test (CST) } \\
\hline CSTO & $5.3 \pm 1.1$ & $6.0 \pm 1.6^{2}$ & $7.3 \pm 3.1^{\mathrm{b}}$ \\
\hline CSTA & $21.4 \pm 5.6^{4}$ & $24.2 \pm 8.0^{\mathrm{a}}$ & $25.5 \pm 8.3^{\mathrm{a}}$ \\
\hline CSTB & $26.7 \pm 6.9=$ & $29.4 \pm 12.3$ & $31.5 \pm 13.3^{a}$ \\
\hline CSTC & $35.6 \pm 9.8^{a}$ & $38.8 \pm 13.8^{\mathrm{a}}$ & $42.4 \pm 18.2^{4}$ \\
\hline \multicolumn{4}{|l|}{ Stroop Color Word Test (SCWT) } \\
\hline SCWT I & $17.9 \pm 3.5^{\mathrm{a}}$ & $17.3 \pm 3.3^{\mathrm{a}}$ & $19.0 \pm 4.7^{\mathrm{a}}$ \\
\hline SCWT II & $23.6 \pm 4.4^{a}$ & $23.3 \pm 4.3^{n}$ & $23.7 \pm 5.0^{4}$ \\
\hline SCWT III & $37.8 \pm 9.4^{4}$ & $47.0 \pm 15.7 \mathrm{a}$ & $43.7 \pm 22.2^{a}$ \\
\hline \multicolumn{4}{|l|}{ Letter Digit Substitution Test (LDST) } \\
\hline LDST & $29.9 \pm 6.9^{a}$ & $30.8 \pm 6.4^{4}$ & $27.9 \pm 8.6^{4}$ \\
\hline
\end{tabular}

Data represent means \pm SD. Group effects were evaluated in more detail with a Student Newman-Keuls test ( $\mathrm{p}$-value $\leq 0.05$ ) and, subsequently, means which were statistically different were marked with different superscripts.

With respect to the CST it was found that there were differences between the groups for the simple cognitive speed-related measure CST0 only (Group effect: $\mathrm{F}=8.61, \mathrm{p}<0.01)$. There were no differences found for the other three measures, that is CSTA, CSTB and CSTC (Group effect: all Fs $<1.67$, n.s.). Post hoc analysis of the CST0 measure showed that MI on its own had no clear effect on simple cognitive speed when compared to that of the controls. However, depressed MI patients were slower than controls (see Table 3 and Fig. 1B).

On the SCWT and LDST there were no differences between the MI patients and the controls (Group effect: all Fs $<2.89$, n.s.). 


\section{Figure 1}

Differences in cognitive performance between the groups and age effects. A) The results of the VVLTTOT (memory); a higher score indicates a better performance. B) The results of the CST0 (simple speed); a higher score indicates a worse performance.

A. Memory

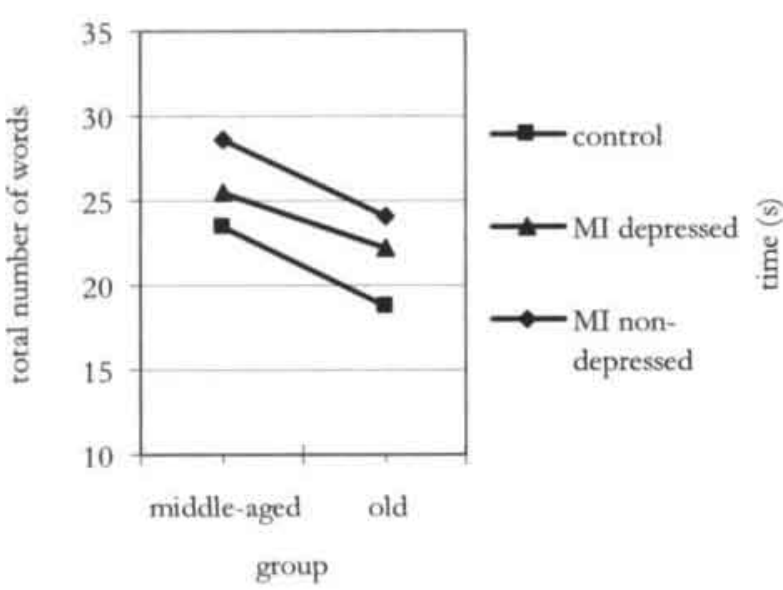

B. Simple speed

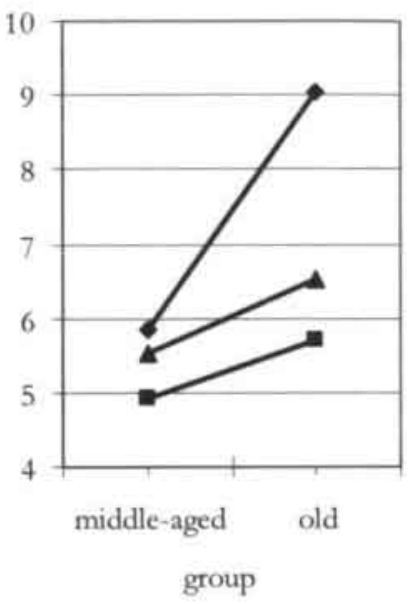

\section{Discussion}

In the present study it was found that depressed MI patients had a better memory performance (VVLT) than MI patients without a depression or controls. In addition, no differences were found between the groups with respect to attention-related aspects (CSTC, SCWT card III), speed of general information processing (LDST) and sensorimotor speed (CSTA, CSTB, CSTC, SCWT Card I and II). However, there was one exception. Depressed MI patients were slower on the most simple cognitive speed related measure, the CST0. The overall performances on the VVLT and CST0 of MI patients without a depression appeared to be equal to the performances of the controls or intermediate between that of the controls and depressed MI patients. Therefore, it can be concluded that the occurrence of a depression in MI patients may result in cognitive symptoms (e.g. VVLTDEL, CST0) on its own which may even further increase cognitive symptoms (e.g. VVLTTOT) already due to a MI. However, MI or MI with a depression has no effect on the other cognitive variables (e.g. CSTA, CSTB, CSTC, SCWT Card, II and III and the LDST) which indicates the selectivity of the cognitive effects. The overall negative effect of age on cognitive performance is in agreement with findings 
of others ${ }^{42}$. There was no interaction with age on the VVLT and CST0 measures, although a closer inspection of the data revealed a tendency of an interaction effect on CST0 $(F=2.4,0.05<\mathrm{p}<0.1)$. This indicates that especially older depressed MI patients are vulnerable to a decline in simple cognitive speed. Finally, women show in general better verbal memory performances than men as has been described by others ${ }^{43}$.

Decreased memory performance is often reported in patients with a depressive disorder ${ }^{8,44,45}$. Riedel et al. ${ }^{8}$, using the same memory test, found that patients with non-cardiac-related depression performed worse on immediate and delayed recall than normal healthy controls. Surprisingly, these findings are clearly in contrast to ours in which depressed MI patients performed better on both memory measures when compared with non-depressed MI patients. With respect to the immediate recall the performance of the depressed MI patients was even better than that of the controls. Unexpectedly, no group differences were found on attention-related aspects, sensorimotor speed and speed of general information processing. In general, (based on the literature) we hypothesized that depressed MI patients would show a worse cognitive performance than healthy controls and that non-depressed MI patients would show an intermediate cognitive performance. The slower performance of depressed MI patients on measures of simple cognitive speed ("psychomotor retardation") is consistent with the findings of others 7,11,12. The trend towards an interaction with age on simple cognitive speed can be explained by a general cognitive slowing with age 42 . Thus the cognitive profile, of depressed MI patients following a first MI appears to differ from that of patients with a noncardiac-related depressive disorder.

A possible explanation for this finding is that the underlying cause of depression post-MI differs from that of non-cardiac-related depression. The symptomatology of MI depression, although it fulfils DSM IV criteria, is atypical in that these patients are more hostile than patients with non-cardiacrelated depression ${ }^{3}$. This hostility is reflected by irritability, resentment about the illness, anger, and frequent disagreement. Increased hostility (and anxiety) might be a 'pacemaker' of a discrete type of depression called anxiety/aggression driven, depression, which has been hypothesized to have a pathogenesis different from that of other subtypes of depression ${ }^{46,47}$. Post-MI depression might belong to this subtype. It is possible that in this subtype no decline in memory function occurs or even a better performance compared to normal healthy controls. The hypothesis of a putative subtype is supported by the finding that the immediate recall was already improved in non-depressed MI patients when compared with controls, which suggests that the memory function in MI patients appears to be a different subtype. Concomitantly, the effects of a depression on memory (or cognitive) function in MI patients may be different from the effects of a depression in healthy controls. However, still other explanations remain possible, which may coincide (see below). 
A second possible explanation is the role of personality factors. Personality and coronary heart disease (CHD) are suggested to be related in MI patients ${ }^{48}$. In a recent study, type-D (the tendency to suppress emotional distress) personality was a significant predictor of long-term mortality in patients with established CHD ${ }^{49}$. The involvement of personality characteristics should be studied in relation to cognitive performance in these groups. Gold and Arbuckle 50 reviewed the interactions between personality and cognition and found that while high neuroticism improves reaction time, other cognitive abilities are detrimentally affected. In line with these findings it may be hypothesized that type $\mathrm{D}$ personality has a positive effect on cognitive performance.

A third explanation concerns the possible psychoactive properties of medication used. The MI patients differed considerably in this respect from the healthy control group in that the latter group was not taking psychoactive medication. Several of the drugs could have influenced cognitive performance. Many patients took several drugs simultaneously. There were no differences between the depressed and non-depressed patient groups in the number of drugs taken (Mann-Whitney U test; overall median 3.5). It remains difficult, if not impossible, to evaluate the influence of each individual substance, let alone their interactions, on cognitive performance. On the basis of current available knowledge on the psychoactive mechanisms of these drugs, five of the nine drugs mentioned can be considered to possess psychoactive properties and hence may have had direct effects on cognitive performance (see Table 2).

In general, antihypertensive drugs may have adverse cognitive effects which, however, tend to be more than offset by the beneficial effect of the lowering of the blood pressure. Benzodiazepines/tranquilizers have a detrimental effect on cognitive performance and can contribute to psychomotor slowness and memory impairment, although the latter effects are in most cases transient ${ }^{51}$. Lipophilic beta-blockers have been shown to slow psychomotor performance in some studies ${ }^{52}$. In contrast, ACE inhibitors, calcium channel antagonists, and cholesterol lowering medication are considered to enhance cognitive performance ${ }^{53}$. For example, ACE inhibitors are thought to have a direct effect on angiotensin receptors in the brain, and via inhibition of angiotensin II, stimulate acetylcholine turnover, enhancing cognition through this mechanism 14,54. Calcium antagonists are thought to enhance cognition by causing dilatation of cerebral blood vessels and an increase in cerebral blood flow ${ }^{55}$. Cholesterollowering agents are thought to act by preventing of cerebral blood flow abnormalities ${ }^{56}$. However, the clinical evidence for the cognition enhancing potential of these drugs in humans is not convincing.

It remains therefore to be established what the effect of psychoactive medication on cognition actually is. There is no strong evidence that the drugs used can explain the difference in cognitive profile between the patients and control group. This also applies to the two MI patients groups. Of the psychoactive drugs mentioned only the medication of two was different between the depressed and non-depressed MI patients (Mantel-Haenszel chi- 
square), viz. benzodiazepines and cholesterol lowering drugs (see also Table 2). Benzodiazepines and cholesterol lowering drugs were given to, respectively, more and less depressed MI patients when compared to those given to the number of non-depressed MI patients. These two findings, however, would suggest an impaired cognitive performance in depressed MI patients, which was not the case. Moreover, even less is known about the possible interactions of these psychoactive substances and their putative effects on cognition. Future studies could address this problem by selecting more homogeneous patient groups, at least in terms of their prescribed psychoactive medications.

In the present study all patients experienced a MI without cardiac arrest. Therefore, it is unlikely that they suffered from cerebral hypoxia, hippocampus damage or damage to other medial temporal lobe structures. Even if these structures were damaged a worse memory performance was expected which is opposite to the present findings.

This is the first study looking at cognitive function in depressed MI patients. An (expected) slower performance on a measure of simple cognitive speed ("psychomotor retardation") was found. However, attention, sensorimotor speed and speed of general information processing were not affected and memory function appeared to be even improved in (depressed) MI patients. In order to find an explanation for this finding, future research should study personality traits and coping mechanisms in relation to cognitive performance in this population.

\section{References}

1. Forrester AW, Lipsey JR, Teitelbaum ML, DePaulo JR, Andrzejeweski PL. Depression following myocardial infarction. Int J Psychiatry Med 1992;22:33-46.

2. Frasure-Smith N, Lespérance F, Talajic M. Depression following myocardial infarction: impact on 6-months survival. JAMA 1993;270:999-1005.

3. Honig A, Lousberg R, Wojchiechowski F, Cheriex EC, Wellens H, Van Praag HM. Depression following a first heart infarct; similarities with and difference from 'ordinary' depression. Ned Tijdschr Geneeskunde 1997;141:196-9.

4. Roose SP, Laghrissi-Thode F, Kennedy JS, et al. Comparison of paroxetine and nortriptyline in depressed patients with ischemic heart disease. JAMA 1998;279:28791.

5. Mialet JP, Pope HG, Yurgelun-Todd D. Impaired attention in depressive states; a non-specific deficit? Psychol Med 1996;26:1009-20.

6. Veiel HOF. A preliminary profile of neuropsychological deficits associated with major depression. J Clin Exp Neuropsychol 1997;19:587-603.

7. Degl'Innocenti A, Agren H, Backman L. Executive deficits in major depression. Act Psychiatrica Scan 1998;97:182-8.

8. Riedel WJ, Klaassen T, Honig A, van Praag HM. 5-HT challenge and cognition in major depression and healthy control subjects. J Psychopharmacol 1998;12:16. 
9. Burt DB, Zembar MJ, Niederehe G. Depression and memory impairment: a metaanalysis of the association, its pattern, and specificity. Psychol Bull 1995;117:285305.

10. Cassens G, Wolfe L, Zola M. The neuropsychology of depression. J Neuropsychiatry Clin Neurosci 1990;2:202-13.

11. Sabbe B, van Hoof J, Hulstijn W, Zitman F. Depressive retardation and treatment with fluoxetine: assessment of the motor component. J Aff Dis 1997;43:53-61.

12. Goodwin GM. Neuropsychological and neuroimaging evidence of the involvement of the frontal lobes in depression. J Psychopharmacol 1997;11:115-22.

13. Townes BD, Bashein G, Hombein RF, et al. Neurobehavioral outcomes in cardiac operations. J Thorac Cardiovasc Surg 1989;98:774-82.

14. O'Brien DJ, Bauer RM, yarrandi H, Knauf DG, Bramlett P, Alexander JA. Patient memory before and after cardiac operation. J Thorac Cardiovasc Surg 1992;104:116-24.

15. Vingerhoets G, Van Nooten G, Jannes C. Neuropsychological impairment in candidates for cardiac surgery. J Int Neuropsychol Soc 1997;3:480-4.

16. Stanton BA. Neurological, cognitive and psychiatric sequelae associated with the surgical management of cardiac disease. In: Tarter RE, Thie DH, Edwards KL (eds.) Medical neuropsychology: the impact of disease on behaviour. New York: Plenum Press, 1988:27-70.

17. Benedict RHB. Cognitive function after open-heart surgery: are postoperative neuropsychological deficits caused by cardiopulmonary bypass? Neuropsychol Rev 1994;4:223-55.

18. Ahto M, Isoaho R, Puolijoko H, Laipalla P, Sulkava R, Kivela SL. Cognitive impairment among elderly coronary heart disease patients. Gerontology 1999;45:8795.

19. Petrovitch $\mathrm{H}$, White L, Masaki $\mathrm{KH}$, et al. Influence of myocardial infarction, coronary artery bypass surgery, and stroke on cognitive impairment in late life. Am J Cardiol 1998;81:1017-21.

20. Breteler MM, van Swieten JC, Bots ML, et al. Cerebral white matter lesions, vascular risk factors, and cognitive function in a population-based study: The Rotterdam Study. Neurology 1994;44:1246-52.

21. Grubb NR, O'Carroll R, Cobbe SM, Sirel J, Fox KA. Chronic memory impairment after cardiac arrest outside hospital. BMJ 1996;313:143-46.

22. Caine D, Watson JD. Neuropsychological and neuropathological sequelae of cerebral anoxia: a critical review. J Int Neuropsychol Soc 2000;6:86-99.

23. Stefanacci L, Buffalo EA, Schmolck H, Squire LR. Profound amnesia after damage to the medial temporal lobe: A neuroanatomical and neuropsychological profile of patient J Neurosci 2000;20:7024-36.

24. Rempel-Clower NL, Zola SM, Squire LR, Amaral DG. Three cases of enduring memory impairment after bilateral damage limited to the hippocampal formation. J Neurosci 1996;16:5233-55.

25. Hopkins RO, Kesner RP, Goldstein M. Memory for novel and familiar spatial and liguistic temporal distance information in hypoxic subjects. J Int Neuropsychol Soc 1995:454-68.

26. Strik JJMH, Honig A, Lousberg $\mathrm{R}$, et al. Efficacy and safety of fluoxetine in the treatment of patients with major depression following first myocardial infarction: findings from a double-blind placebo-controlled trial. Psychosom Med 2000;62:783. 9. 
27. Pasternak RC, Braunwald E, Sobel RE. Acute myocardial infarction. In: Braunwald E (ed). Heart disease: a textbook of cardiovascular medicine. 4th edition. Philadelphia: WB Saunders Compagny, 1992:1200-91.

28. Arrindell WA, Ettema JHM. Dimensional structure, reliability and validity of the Dutch version of the Symptom Checklist (SCL-90). Ned Tijdschr Psychologie 1981;43:381-7.

29. Hamilton M. A rating scale for depression. J Neurol Neurosurg Psychiatry 1960;23:56-62.

30. Jolles J, Houx PJ, Van Boxtel MPJ, Ponds RWMH. The Maastricht Aging Study: determinants of cognitive aging. Maastricht, The Netherlands: Neuropsych Publishers, 1995.

31. de Groot JC, de Leeuw FE, Oudkerk M, et al. Cerebral white matter lesions and cognitive function: the Rotterdam Scan Study. Ann Neurol 2000;47:145-51.

32. Krabbendam L, Derix MM, Honig A, et al. Cognitive performance in relation to MRI temporal lobe volume in schizophrenic patients and healthy control subjects. J Neuropsychiatry Clin Neurosci 2000;12:251-6.

33. Dijkstra JB, Houx PJ, Jolles J. Cognition after major surgery in the elderly: test performance and complaints. Br J Anaesth 1999;82:867-74.

34. Moller JT, Cluitmans P, Rasmussen LS, et al. Long-term postoperative cognitive dysfunction in the elderly ISPOCD1 study. ISPOCD investigators. International Study of Post-Operative Cognitive Dysfunction [published erratum appears in Lancet 1998 Jun 6;351(9117):1742]. Lancet 1998;351:857-61.

35. Van Boxtel MPJ, Buntinx F, Houx PJ, Metsemakers JFM, Knottnerus A, Jolles J. A preliminary profile of neuropsychological deficits associated with major depression. J Clin Exp Neuropsychol 1997;19:587-603.

36. Brand N, Jolles J. Learning and retrieval rate of words presented auditorily and visually. J Gen Psychol 1985;112:201-10.

37. Lezak MD. Neuropsychologiocal Assessment. third ed. New York: Oxford University Press, 1995.

38. Bouma A, Mulder J, Lindeboom J. Neuropsychologische diagnostiek. Lisse, 1998.

39. Klein M, Ponds RWHM, Houx PJ, Jolles J. Effect of test duration on age related differences in Stroop Interference. J Clin Exp Neuropsychol 1997;19:77-82.

40. Norusis MJ. SPSS for Windows 6.0. Chicago: SPSS Inc, 1993.

41. de Bie SE. Standard questions 1987: Proposal for uniformisation of questions regarding background variables and interviews. Second edition. Leiden, the Netherlands: Leiden University Press, 1987.

42. Birren JE, Schaie KW. Handbook of the Psychology of Aging. 3nd edition. San diego: Academic Press, 1990.

43. Herlitz A, Airaksinen E, Nordstroem E. Sex differences in episodic memory: The impact of verbal and visuospatial ability. Neuropsychology 1999;13:590-7.

44. Watts FN, Dalgleish T, Bourke P, Healy D. Memory deficit in clinical depression: processing resources and the structure of materials. Psychol Med 1990;20:345-9.

45. Weingartner H, Cohen RM, Murphy DL, Martello J, Gerdt C. Cognitive processes in depression. Arch Gen Psychiatry 1981;38:42-7.

46. Van Praag HM. 5-HT-related, anxiety-and/or aggression-driven depression. Int Clin Psychopharmacol 1994;9:5-6.

47. van Praag HM. Faulty cortisol/serotonin interplay. Psychopathological and biological characterisation of a new, hypothetical depression subtype (SeCa depression). Psychiatry-Res. 1996;65:143-57. 
48. Dimsdale JE. A perspective on type A behavior and coronary disease. N Engl J Med 1988;318:110-2.

49. Denollet J, Sys SU, Stroobant N, Rombouts H, Gillebert TC, Brutsaert DL. Personality as independent predictor of long-term mortality in patients with coronary heart disease. Lancet 1996;347:417-21.

50. Gold DP, Arbuckle TY. Interactions between personality and cognition and their implications for theories of aging. In: Lovelace EA (ed). Aging and cognition: Mental processes of self awareness and interventions. Amsterdam: Elsevier Science Publisher, 1990:351-77.

51. Riedel WJ, Vermeeren A, van Boxtel MPJ, et al. Mechanismes of drug-induced driving impairment: A dimensional appraoch. Human Psychopharm 1998;13:S49S63.

52. Kalra L, Swift CG, Jackson SH. Psychomotor performance and antihypertensive treatment. Br J Clin Pharmacol 1994;37:165-72.

53. Riedel WJ, Jolles J. Cognition enhancers in age-related cognitive decline. Drugs Aging 1996;8:245-74.

54. Lines CR, Preston GC, Dawson CE. The effects of pretreatment with enalapril maleate on scopolamine-induced cognitive deficits in healthy volunteers. J Psychopharmacol 1991;5:228-33.

55. Fletcher A, Bulpitt C. Quality of life in the treatment of hypertension. The effect of calcium antagonists. Drugs 1992:135-40.

56. Cutler N, Sramek J, Veroff A, Block G, Stauffer L, Lines C. Effects of treatment with simvastatin and pravastatin on cognitive function in patients with hypercholesterolaemia. Br J Clin Pharmacol 1995;39:333-6. 


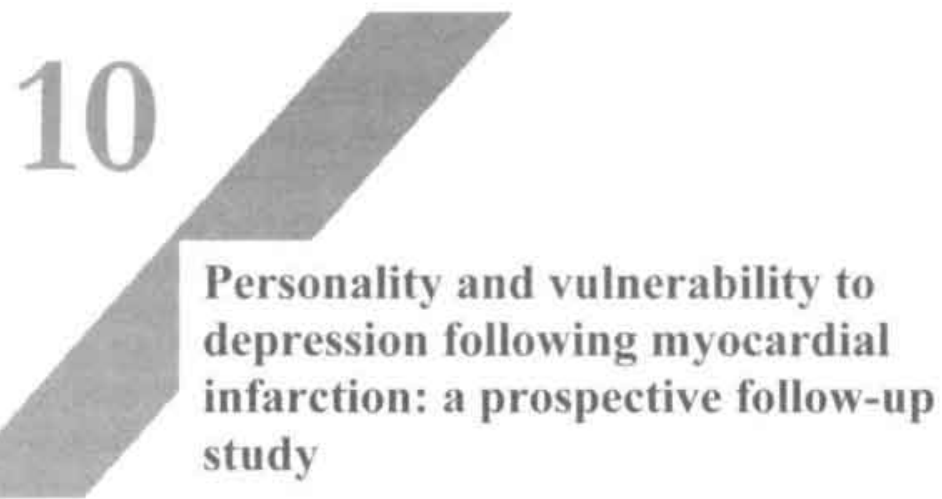




\begin{abstract}
Depression may increase mortality in myocardial infarction (MI) patients, but little is known about its determinants. Although personality has been associated with depression in psychiatric patients, this has been largely ignored in cardiac patients. We therefore examined the Five Factor Model of personality in the prediction of post-MI depression. In this prospective 1-year follow-up study, 206 consecutive patients were interviewed using the Structured Clinical Interview for DSM-IV (SCID-I-R) one month post-MI. They also completed the NEO-Five Factor Inventory to assess personality. Three, 6, 9, and 12 months following MI, patients completed the Beck Depression Inventory, and the depression subscales of the Symptom Checklist-90 and the Hospital Anxiety and Depression Scale. Patients exceeding a previously defined cut-off value on one of these depression scales were re-interviewed using the SCID-IR. Between 1 and 12 months post-MI, 30 patients $(14.6 \%)$ were diagnosed with major depression and $33(16 \%)$ with minor depression. Neuroticism was an independent predictor of both major $(\mathrm{HR}=4.04,95 \% \mathrm{CI}=1.47-11.12, \mathrm{p}=$ $0.007)$ and minor $(\mathrm{HR}=2.81,95 \% \mathrm{CI}=1.35-5.85, \mathrm{p}=0.006)$ depression, controlling for age, gender, and disease severity. Introversion was also an independent predictor of major depression $(\mathrm{HR}=2.52,95 \% \mathrm{CI}=1.08-5.91, \mathrm{p}$ $=0.03$ ) but not of minor depression. Severity of cardiac disorder and younger age were also independent predictors of post-MI depression. Neuroticism and introversion predicted the 1-year depression risk above and beyond age, gender, and disease severity. It is now timely to include personality as a vulnerability factor for depression in the clinical course of post-MI patients.
\end{abstract}

\title{
Reference
}

Strik JJMH, Denollet J, Lousberg R, Honig A. Personality and vulnerability to depression following myocardial infarction: a prospective follow-up study. Am J Psychiatry 2003; Submitted. 


\section{Introduction}

Both major and minor depression are frequent co-morbid conditions post myocardial infarction (MI) and may increase cardiac mortality and morbidity ${ }^{1.5}$. Yet, determinants of depression have been largely ignored in MI patients 6.7. The present paper is based on the notion that personality factors may codetermine the way in which MI patients react to mild to severe consequences for daily-life functioning.

Personality traits have long been suggested to represent vulnerability factors for the development and/or continuation of depressive disorder in non-cardiac patients 8,9 . Most prior studies of relationships between normal personality traits and axis 1 disorders have focussed on major depression and the two traits neuroticism and extraversion ${ }^{8}$. As far as we know, no studies have been published focussing on personality as a determinant of depressive disorder in patients with coronary heart disease (CHD).

Evidence suggests, however, that emotional distress in these patients is largely a function of personality traits ${ }^{10}$. Accordingly, Type D personality has been identified as an independent predictor of morbidity and mortality in patients with CHD 11. This personality profile has been defined as the combination of two broad personality traits, being negative affectivity or neuroticism and social inhibition. Type D has also been associated with the 5-year incidence of depressive affect in CHD patients, suggesting a role for personality factors in the development of post-MI depression ${ }^{12}$.

We therefore investigated personality as a determinant of post-MI depression in this study. In line with the prevailing Five Factor Model (FFM) of personality ${ }^{13}$, the prognostic power of each of these broad personality traits was evaluated with reference to the incidence of clinical depression during the first year following an acute MI.

\section{Method}

\section{Patients}

The present study is part of an ongoing study on the epidemiology and prediction of depression in patients who survived a first MI ${ }^{14}$. Between May 1997 and September 1999, 206 first-MI patients (150 men and 56 women; mean age $=59.0 \pm 10.6$ years) were included in the study. Of these, $18 \%$ had a history of depression and $11.2 \%$ a family history of depression. Depressed patients differed from non-depressed patients with regard to age, gender, and previous depression. After complete description of the study, all participants gave written informed consent. The local medical ethics committee approved the study.

Inclusion criteria were clinical picture and electrocardiographic signs typical for an acute MI, and a maximum value of enzyme aspartate aminotransferase 
$\left(\right.$ ASAT $_{\max }$ ) of at least $80 \mathrm{U} / \mathrm{L}$ (twice above the upper limit) ${ }^{15}$. Exclusion criteria were major psychiatric disorder other than affective disorders (e.g. schizophrenia or dementia), being unable to communicate reliably, or comorbid life-threatening disease. Out of 422 consecutive patients, $96(22.7 \%)$ did not meet study criteria, $99(23.5 \%)$ refused to participate, and $21(5 \%)$ filled out questionnaires but refused to attend the interview. Refusers were older $(65.6 \pm$ 12.2 versus $59.0 \pm 10.6$ years, $\mathrm{p}<0.001$ ); also women refused more frequently than men $(47.4 \%$ versus $21.2 \% ; p<0.001)$. Non-response was $7.5 \%$ at 3 months post-MI increasing to $11.5 \%$ at 12 months post-MI. The reasons for non-response were withdrawn consent $(9.5 \%)$, death within the first 12 months post-MI $(1 \%)$, incidental non-response $(1 \%)$.

\section{Assessment of depression}

All patients were followed-up during one year after MI. One month following MI, all patients were interviewed using the Structured Clinical Interview for DSM-IV (SCID-I-R) ${ }^{16}$. The SCID-I-R is a structured psychiatric diagnostic interview allowing for a diagnosis of major or minor depression according to DSM-IV ${ }^{17}$. Patients were diagnosed with major depression if fulfilling at least one core criterion (depressed mood or loss of interest) and at least four additional criteria (total of 5) with a duration of at least two weeks ${ }^{17}$. A diagnosis of minor depression was made in case of one to three in stead of four additional criteria ${ }^{17}$. A trained physician (first author) assessed all interviews. Three, 6, 9 and 12 months following MI, patients were asked to fill out 3 selfrating scales of depression, i.e. the Beck Depression Inventory (BDI) ${ }^{18,19}$, the Hospital Anxiety and Depression Scale (HADS) ${ }^{20}$, and the 90 -item Symptom Check List (SCL-90) 21,22. Patients exceeding the generally accepted cut-off value of at least one of these scales were re-interviewed using the SCID-I-R. For the BDI, the cut-off value was $9 / 10$, for the HADS $7 / 8$ for both subscales separately, and for the depression subscale of the SCL-90 a threshold of $22 / 23$ was used for men and $27 / 28$ for women. The sensitivity of exceeding the cutoff of at least one of these scales was $85.7 \% 23$.

\section{Assessment of personality}

Personality was assessed one month after MI using the Dutch version of the Neo Five Factor Inventory (NEO-FFI) ${ }^{24}$. This self-report questionnaire consists of 60 statements comprising 5 dimensions of personality. Each statement is related on a 5 point scale ranging from 'strongly disagree' to 'not at all agree', resulting in a total dimension score between 12 and 60 .

The 5 domains are neuroticism, extraversion, openness to new experiences, agreeableness, and conscientiousness. Neuroticism is defined as one's tendency to experience negative emotions and cope poorly, and also as negative affectivity. High neuroticism is broadly related to psychopathology, including anxiety and depression ${ }^{8}$. Low extraversion, or introversion, is defined as one's tendency to be rather unsociable and less active, and has also been associated 
with depression 8,25 . To assess introversion in the present study, the NEO extraversion score was reversed. Openness to experience reflects one's appreciation of experience for his own sake; conscientiousness one's organization, motivation and persistence in achieving goals; and agreeableness, one's orientation and friendly compliance towards others '. Given the potential role of hostility and antagonism in CHD ${ }^{26}$, low agreeableness was defined as antagonism in the present study, reflecting one's tendency to be disagreeable and sceptical ?. To assess antagonism, the NEO agreeableness score was reversed.

\section{Cardiac and demographic data}

Mean left ventricular ejection fraction (LVEF) was $53.3 \%$ (SD = 9.93). A decrease in cardiac function was defined as a LVEF $\leq 50 \%{ }^{12}$, and was used to examine disease severity as a determinant of post-MI depression. Data concerning intervention at the time of the MI (such as thrombolytic therapy or coronary angioplasty), medication, and cardiovascular risk factors were taken from patient's records. Of the 206 patients, $14.4 \%$ smoked after the MI, 30.6\% had hypercholesterolemia, $90.8 \%$ were prescribed platelet aggregation inhibitors, and $39.8 \%$ beta-blockers. Demographic data were collected on interview, as was history of depression, measured using the SCID-I-R.

\section{Analysis}

Cox regression was used to analyse the relative hazards of increasing levels of the five dimensions of personality, measured by the Neo FFI, on the incidence of major and minor post-MI depression. Cox regression is a survival analysis enabling patients with missing values to be left in the analysis. In case of incidental missing values, patients were considered not depressed if the patient was not depressed at the former measurement and the screening thereafter was valid. In all other cases, the patient was excluded from the screening moment of the missing value onwards. Incidence of major and minor depression were the dependent variables and the 5 domains of personality the predictors. To identify patients with a high versus low personality trait score, a median split was used to dichotomise patients on each of the various personality domains; i.e.; neuroticism $\geq 30$, extraversion $\leq 39$ (high introversion), agreeableness $\leq 44$ (high antagonism), openness $\geq 33$, and conscientiousness $\geq 47$.

The bivariate associations of all 5 NEO-FFI personality domains with depression were tested in univariate Cox regression models. Next, these personality domains were included in a stepwise Cox regression model, corrected for age, gender, and LVEF, in order to test for independent predictors of both major and minor depression. For comparisons between descriptive sample characteristics, student t-tests were used in case of continuous, normally distributed, variables. Chi square tests were used for all dichotomised variables. A two-tailed $\mathrm{p}$-value $\leq 0.05$ was considered to be significant. 


\section{Results}

\section{Depression in the first year following MI}

Between 1 and 12 months post-MI, 30 patients (14.6\%) were diagnosed with major depression and $33(16 \%)$ with minor depression. Of the 63 patients with depression, 9 were known with major depression pre-MI and 2 with minor depression. For analyses of the incidence rates, these 11 patients who were already depressed before the MI were additionally excluded. The one-year cumulative incidence of major and minor depression was then $26.7 \%$ (Figure 1). The incidence of both major and minor depression was highest after the first month $(14.4 \%)$. This indicates that depression had an early onset in most cases. Furthermore, the incidence of minor depression was higher from 3 to 12 months than that of major depression.

\section{Figure 1}

Incidence of major and minor depression in the first 12 months post-first-MI.

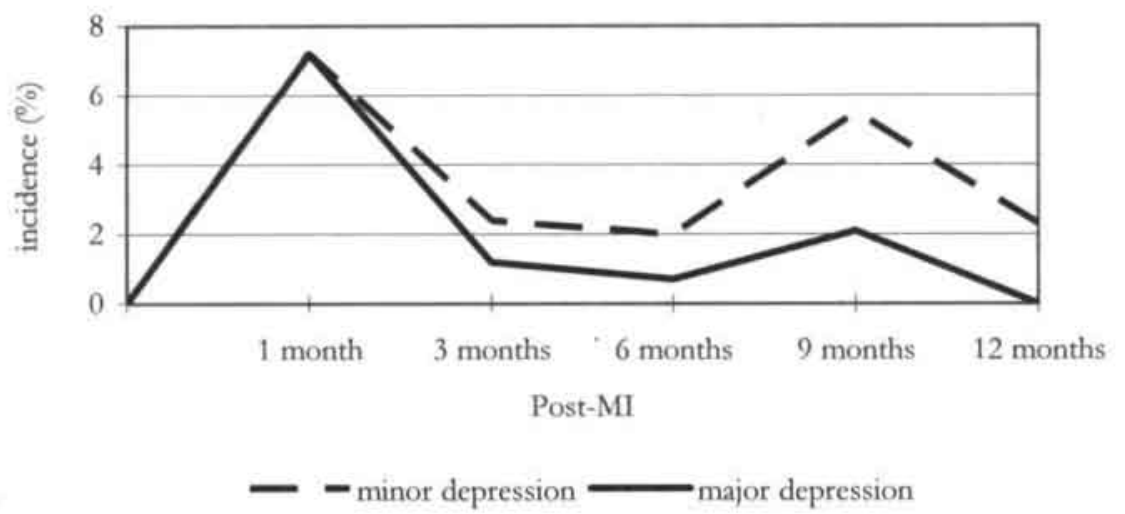

\section{Personality and depression}

Mean personality domain scores are shown in Table 1. Mean neuroticism scores were higher in major $(33.9 \pm 7.5)$ and minor depressed patients $(32.5 \pm 7.7)$ as compared to non-depressed patients $(28.0 \pm 6.8) ; \mathrm{p} \leq 0.001$. Patients with major depression also scored lower on extraversion (38.2 \pm 7.0 versus $41.2 \pm$ $5.7, \mathrm{p}=0.005)$ and agreeableness $(41.7 \pm 5.3$ versus $44.6 \pm 4.7, \mathrm{p}=0.003)$ as compared to non-depressed patients. 


\section{Table 1}

Mean personality domain scores (NEO-FFI) of patients with major or minor depression, and non-depressed patients.

\begin{tabular}{l|c|c|c}
\hline & $\begin{array}{c}\text { Major depression } \\
\text { Mean }( \pm \mathbf{S D}) \\
\mathbf{n}=\mathbf{2 7}\end{array}$ & $\begin{array}{c}\text { Minor depression } \\
\text { Mean }( \pm \mathbf{S D}) \\
\mathbf{n}=\mathbf{3 3}\end{array}$ & $\begin{array}{c}\text { Non-depressed } \\
\text { Mean }( \pm \mathbf{S D}) \\
\mathbf{n}=\mathbf{1 4 3}\end{array}$ \\
\hline Neuroticism & $33.9(7.5)$ & $32.5(7.7)$ & $28.0(6.8)$ \\
Extraversion & $38.2(7.0)$ & $40.6(7.7)$ & $41.2(5.7)$ \\
Agreeableness & $41.7(5.3)$ & $44.2(4.6)$ & $44.6(4.7)$ \\
Openness & $36.1(4.3)$ & $34.2(4.0)$ & $34.8(5.5)$ \\
Conscientiousness & $45.0(4.6)$ & $48.0(5.5)$ & $47.1(5.6)$ \\
\hline
\end{tabular}

Next, the concordant Hazard ratios (HR) were calculated using univariate Cox regression analyses for both major (Table 2 ) and minor (Table 3 ) depression. In these analyses, high neuroticism was associated with a $\mathrm{HR}=5.55$ for major post-MI depression $(\mathrm{p}<0.001)$ and a HR $=2.79$ for minor post-MI depression $(p=0.006)$. In addition, introversion (or low extraversion) was associated with a $\mathrm{HR}=2.77$ and antagonism (or low agreeableness) with a $\mathrm{HR}=2.68$ for major post-MI depression, $\mathrm{p}<0.05$. Hence, in univariate analyses, neuroticism, introversion and antagonism were associated with increased risk of major depression in the first year post-MI, and neuroticism with increased risk of minor depression.

\section{Table 2}

Univariate Cox regression of the 5 NEO-FFI personality domains and demographic variables in relation to major depression.

\begin{tabular}{l|c|c}
\hline Univariate Cox regression analysis & HR $\mathbf{( 9 5} \% \mathbf{C I})$ & p-value \\
\hline Neuroticism & $5.55(2.09-14.7)$ & $<0.001$ \\
Introversion & $2.77(1.23-6.22)$ & 0.014 \\
Antagonism & $2.68(1.08-6.68)$ & 0.034 \\
Openness & $1.17(0.77-1.78)$ & 0.452 \\
Conscientiousness & $0.81(0.55-1.19)$ & 0.277 \\
Age & $0.96(0.93-0.99)$ & 0.011 \\
Female gender & $1.74(1.21-2.51)$ & 0.003 \\
LVEF $\leq 50 \%$ & $1.79(0.86-3.73)$ & 0.118 \\
\hline
\end{tabular}




\section{Table 3}

Univariate Cox regression of the 5 NEO-FFI personality domains and demographic variables in relation to minor depression.

\begin{tabular}{l|c|c}
\hline Univariate Cox regression analysis & HR $(\mathbf{9 5} \% \mathbf{C I})$ & p-value \\
\hline Neuroticism & $2.79(1.34-5.79)$ & 0.006 \\
Introversion & $1.16(0.57-2.34)$ & 0.689 \\
Antagonism & $1.16(0.58-2.33)$ & 0.679 \\
Openness & $0.92(0.64-1.33)$ & 0.668 \\
Conscientiousness & $1.10(0.77-1.57)$ & 0.597 \\
Age & $0.96(0.92-0.99)$ & 0.008 \\
Female gender & $1.21(0.81-1.81)$ & 0.341 \\
LVEF $\leq 50 \%$ & $1.92(0.96-3.85)$ & 0.065 \\
\hline
\end{tabular}

\section{Independent predictors of depression}

After controlling for age, gender, and LVEF, neuroticism $(\mathrm{HR}=4.04, \mathrm{p}=$ $0.007)$ and introversion $(\mathrm{HR}=2.52, \mathrm{p}=0.03$ ) were retained as independent predictors of major depression (Table 4). The univariate association between antagonism and major depression disappeared in multivariate analysis. Neuroticism ( $H R=2.81 ; \mathrm{p}=0.006$ ) was the only independent personality predictor for minor depression in multivariate analysis (Table 5). Other variables independently related to depression in multivariate analysis were LVEF $\leq 50 \%$ (HR $=2.76$ and 2.33 for major and minor depression, respectively) and age ( $\mathrm{HR}=0.94$ and 0.96 for major and minor depression, respectively).

\section{Table 4}

Independent predictors of major depression.

\begin{tabular}{l|c|c|c}
\hline $\begin{array}{l}\text { Major depression } \\
\text { Cox regression model }\end{array}$ & Hazard ratio & $\mathbf{9 5 \%}$ CI & p-value \\
\hline Neuroticism & 4.04 & $1.47-11.12$ & 0.007 \\
Introversion & 2.52 & $1.08-5.91$ & 0.033 \\
Age & 0.94 & $0.91-0.98$ & 0.003 \\
LVEF $\leq 50 \%$ & 2.76 & $1.23-6.24$ & 0.014 \\
\hline \multicolumn{3}{|c|}{ V aniables not in tbe equation } \\
\hline Antagonism & & & 0.287 \\
Openness & & 0.244 \\
Conscientiousness & & 0.696 \\
Gender & & & 0.243 \\
\hline
\end{tabular}


Table 5

Independent predictors of minor depression.

\begin{tabular}{l|c|c|c}
\hline $\begin{array}{l}\text { Major Depression } \\
\text { Cox regression model: }\end{array}$ & Hazard ratio & $\mathbf{9 5 \%}$ CI & p-value \\
\hline Neuroticism & 2.81 & $1.35-5.85$ & 0.006 \\
Age & 0.96 & $0.92-0.99$ & 0.007 \\
LVEF $\leq 50 \%$ & 2.33 & $1.16-4.69$ & 0.017 \\
\hline \multicolumn{3}{|c}{ Variables not in the equation } & 0.974 \\
\hline Introversion & & & 0.365 \\
Antagonism & & 0.526 \\
Openness & & 0.724 \\
Conscientiousness & & 0.544 \\
Gender & & & \\
\hline
\end{tabular}

\section{Discussion}

The present study clearly showed that neuroticism was an independent predictor for both major and minor depression in the first year post-first-MI. High levels of neuroticism were associated with a 4-fold increased risk for major depression, after controlling for age and disease severity. High neuroticism was also associated with an almost 3-fold increased risk for minor depression. Furthermore, introversion was independently associated with a $150 \%$ increase of risk for major depression. Apart from neuroticism and introversion, no other dimension of the FFM of personality showed an independent effect on the development of either major or minor post-MI depression.

It has previously been reported that personality traits predict the development of depression in psychiatric patients 27,28 . To our knowledge, this is first study that showed a clear association between personality and vulnerability for depression among patients who survived an initial MI. More specifically, we found a strong relation between neuroticism and both major and minor depression. In psychiatric patients, neuroticism has been shown to be a vulnerability factor for the development of not only depression, but also anxiety disorders ${ }^{29,30}$. Of note, post-MI depression has a different, more anxious and hostile profile than 'ordinary' depression. That is, post-MI patients typically report more signs of irritation and agitation than listlessness and depressed mood ${ }^{31}$. In addition, the HADS anxiety scale was also more strongly related to the diagnosis of depression than the HADS depression scale in the present sample of post-MI patients ${ }^{23}$. Accordingly, the overlap between depression and anxiety reflects a general distress factor that is shared by both types of disorder. The tendency to experience this form of general distress 
across time and situations has been conceptualised as negative affectivity or neuroticism ${ }^{8}$.

Apart from neuroticism, we found that introversion was an independent predictor of major post-MI depression. Of note, the combination of high neuroticism and low extraversion was described by others to characterize somatic healthy patients who may develop depression ${ }^{27,28}$. In a study by Lyoo et al., this construct distinguished the 'depressive personality disorder'; a form of premorbid vulnerability upon which major depression and other mood disorders may be superimposed ${ }^{32}$. By analogy with these findings, we found that personality traits were also strong determinants of depression in MIpatients. This means that post-MI depression is not solely a consequence of the occurrence of MI, but partly may be a function of person-related characteristics. Evaluation of the full spectrum of determinants of post-MI depression may therefore help identify high-risk patients at risk of post-MI depression.

In the present study, severity of cardiac disorder measured by LVEF $\leq 50 \%$, was related to the diagnosis of major depression, but not of minor depression. In case of serious somatic illness, one would expect size of infarction to be related to occurrence of depression. In post-MI depression, however, no relation between size of infarction and occurrence of depression has ever been found 2,3,33.36. Our finding of cardiac functioning being inversely related to major depression is, however, in contrast with previous research showing no relation between cardiac disorder and depression. With reference to minor depression, we also failed to find an explanation.

A limitation of the present study was the fact that personality was assessed one month post-MI. At that time, a substantial percentage of the MI patients $(46 \%)$ were diagnosed to be depressed. It is unclear whether depression may affect self-rated personality scores; i.e., one study found an association ${ }^{28}$, but this could not be confirmed by others ${ }^{37}$. The stability of the NEO-FFI reported in healthy individuals does seem to provide a strong basis from which personality traits across the course of illness in patient populations can be studied ${ }^{38}$.

We do not know whether there is a causal relationship between personality and post-MI depression, or whether they share the same aetiology 8,38. Anyway, it may be important to screen patients post-MI for a wide variety of negative emotions and personality traits ${ }^{39}$ in addition to screening for a specific diagnosis. The findings from the present study do emphasise the need for further research on personality as a vulnerability factor for clinical depression in patients who survived an initial MI.

\section{References}

1. Frasure-Smith N, Lespérance F, Talajic M. Depression and 18 months prognosis after myocardial infarction. Circulation 1995; 91:999-1005. 
2. Frasure-Smith N, Lespérance F, Talajic M. Depression following myocardial infarction: impact on 6-months survival. JAMA 1993; 270:999-1005.

3. Ladwig KH, Kieser M, Konig J, Breithardt G, Borggrefe M. Affective disorders and survival after acute myocardial infarction (results from the post-infarction late potential study). Eur Heart J 1991; 12:959-64.

4. Barefoot JC, Helms MJ, Mark DB, et al. Depression and long-term mortality risk in patients with coronary artery disease. Am J Cardiol 1996; 78:613-7.

5. Penninx BWJH, Beekman ATF, Honig A, et al. Depression and cardiac mortality: results from a community-based longitudinal study. Arch Gen Psychiatry 2001; 58:221-7.

6. Anda R, Williamson D, Jones D, et al. Depressed affect, hopelessness, and the risk of ischemic heart disease in a cohort of US adults. Epidemiology 1993; 4:285-94.

7. Carney RM, Freedland KE, Jaffe AS. Insomnia and depression prior to myocardial infarction. Psychosom Med 1990; 52:603-9.

8. Clark LA, Watson D. Tripartite model of anxiety and depression: Psychometric evidence and taxonomic implications. J Abnorm Psychology 1991; 100:316-36.

9. Bienvenu OJ, Nestadt G, Samuels JF, et al. Phobic, panic, and major depressive disorders and the five-factor model of personality. J Nerv Ment Dis 2001; 189:1546.

10. Denollet J, De Potter B. Coping subtypes for men with coronary heart disease: relationship to well-being, stress and Type-A behaviour. Psychol Med 1992; 22:667-84.

11. Denollet J, Sys SU, Stroobant N, Rombouts H, Gillebert TC, Brutsaert DL. Personality as independent predictor of long-term mortality in patients with coronary heart disease. Lancet 1996; 347:417-21.

12. Denollet J, Vaes J, Brutsaert DL. Inadequate response to treatment in coronary heart disease : adverse effects of Type D personality and younger age on 5-year prognosis and quality of life. Circulation 2000; 102:630-5.

13. Costa PT Jr, McCrae RR. Manual for the revised NEO Personality Inventory (NEO-PIR) and NEO Five-factor Inventory (NEO-FFI). Odessa, FL: Psychological Assessment Resources, 1992.

14. Strik JJMH, Lousberg R, Cheriex EC, Honig A. One year cumulative incidence of depression after first myocardial infarction and impact on cardiac outcome. J Psychosom Res 2003; In Press.

15. Pasternak RC, Braunwald E, Sobel RE. Acute myocardial infarction. in Heart disease: a textbook of cardiovascular medicine. Ed: Braunwald E. Philadelphia, WB Saunders Compagny, 1992, pp 1200-9.

16. First MB, Spitzer RL, Gibbon M, Williams JB. Structured Clinical Interview for DSM-IV Axis I disorders-Patient Edition (SCID-I/P, Version 2.0). New York, Biometrics Research Department, 1995.

17. American Psychiatric Association. Diagnostic and statistic manual of mental disorders IV. Washington DC, American Psychiatric Association, 1994.

18. Beck AT, Ward $\mathrm{CH}$, Mendelson M, Mock J, Erbaugh J. An inventory for measuring depression. Arch Gen Psychiatry 1961; 4:561-71.

19. Richter P, Werner J, Heerlein A, Kraus A, Sauer H. On the validity of the Beck Depression Inventory. Psychopathology 1998; 31:160-8.

20. Herrmann C. International experiences with the hospital anxiety and depression rating scale: a review of validation data and clinical results. J Psychosom Res 1997; 1:17-41. 
21. Derogatis LR, Lipman RS, Covi L. SCL-90: an outpatient psychiatric rating scaleprelimanary report. Psychopharm Bull 1973; 9:13-27.

22. Arrindell WA, Ettema JHM. Dimensional structure, reliability and validity of the Dutch version of the Symptom Checklist (SCL-90). Ned Tijdschr Psychologie 1981; 43:381-7.

23. Strik JJMH, Honig A, Lousberg R, Denollet J. Sensitivity and specificity of observer and self rating questionnaires in depression following myocardial infarction. Psychosomatics 2001; 42:423-8.

24. Hoekstra HA, Ormel J, De Fruyt F. NEO NEO presonality Questionnaires NEOPI-R. Manual. Lisse (NL): Swets \& Zeitlinger B.V; 1996.

25. Akiskal HS, Hirschfeld RM, Yerevanian BI. The relationship of personality to affective disorders. Arch Gen Psychiatry 1983; 40:801-10.

26. Miller TQ, Smith TW, Turner CW, Guijarro ML, Hallet AJ. A meta-analytic review of research on hostility and physical health. Psychol Bull 1996; 119:322-48.

27. Angst J, Clayton P. Premorbid personality of depressive, bipolar, and schizophrenic patients with special reference to suicidal issues. Compr Psychiatry $1986 ; 27: 511-32$.

28. Hirschfeld RM, Klerman GL, Lavori P, Keller MB, Griffith P, Coryell W. Premorbid personality assessments of first onset of major depression. Arch Gen Psychiatry $1989 ; 46: 345-50$.

29. Clark LA, Watson D, Mineka S. Temperament, personality, and the mood and anxiety disorders. J Abnorm Psychol 1994; 103:103-16.

30. Widiger TA, Trull TJ. Personality and psychopathology: an application of the fivefactor model. J Pers 1992; 60:363-93.

31. Honig A, Lousberg R, Wojchiechowski F, Cheriex EC, Wellens H, Van Praag HM. Depression following a first heart infarct; similarities with and difference from 'ordinary' depression. Ned Tijdschr Geneesk 1997; 141:196-9.

32. Lyoo K, Gunderson JG, Phillips KA. Personality dimensions associated with depressive personality disorder. J Pers Dis 1998; 12:46-55.

33. Ladwig KH, Roll G, Breithardt G, Budde T, Borggrefe M. Post infarct depression and incomplete recovery 6 months after acute myocardial infarction. The Lancet $1994 ; 343: 20-3$.

34. Havik OE, Maeland JG. Patterns of emotional reactions after a myocardial infarction. J Psychosom Res 1990; 34:271-85.

35. Ahern DK, Gorkin L, Anderson JL, et al. Biobehavioral variables and mortality on cardiac arrest in the Cardiac Arrhythmia pilot study (CAPS). Am J Cardiology 1990; 66:59-62.

36. Forrester AW, Lipsey JR, Teitelbaum ML, DePaulo JR, Andrzejeweski PL. Depression following myocardial infarction. Int J Psychiatry Med 1992; 22:33-46.

37. Bagby RM, Rector NA, Bindseil K, Dickens SE, Levitan RD, Kennedy SH. Selfreport ratings and informants' ratings of personalities of depressed outpatients. Am J Psychiatry 1998; 155:437-8.

38. Bagby RM, Russel TJ, Parker JDA, Kalemba V, Harkness KL. Major depression and the five-factor model of personality. J Pers Dis 1995; 9:224-34.

39. Denollet J, Van Heck GL. Psychological risk factors in heart disease: what Type D personality is (not) about. J Psychosom Res 2001; 51:465-8. 


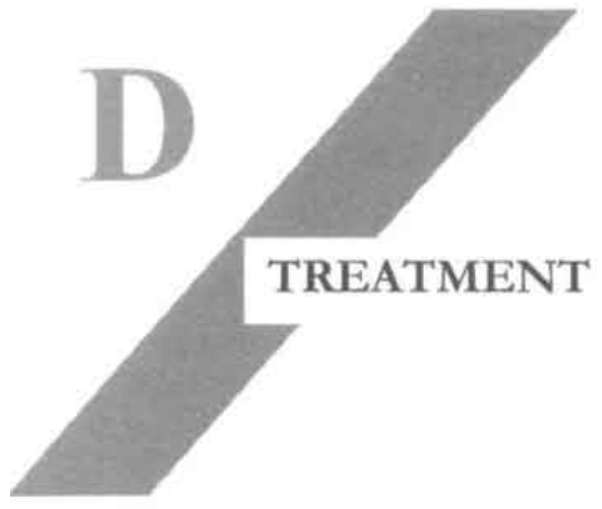





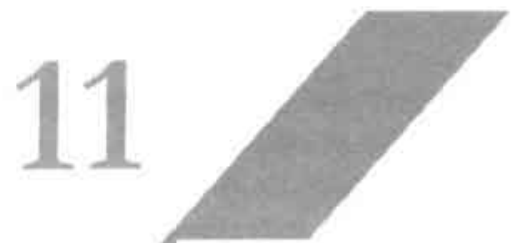

Efficacy and safety of fluoxetine in the treatment of patients with major depression after first myocardial infarction: findings from a double-blind, placebo-controlled trial 


\section{Abstract}

Depression and hostility are significant risk factors for mortality and morbidity after myocardial infarction (MI). Much research is still needed to identify effective ways to reduce emotional distress in patients with cardiovascular disease. This double-blind, placebo-controlled study investigated the efficacy and safety of the antidepressant fluoxetine in patients with depression after their first MI. Fifty-four patients with major depression after MI were randomly assigned to receive a flexible-dose regimen of fluoxetine or placebo for the first 9 weeks of a double-blind, placebo-controlled trial. Patients without serious adverse effects who wished to continue participating in the study were given fluoxetine or placebo for an additional 16 weeks. To evaluate the efficacy of fluoxetine, the 17-item Hamilton Depression Rating Scale (HAMD-17) and the hostility subcale of the 90-item Symptom Check List (SCL-90) were used as primary measures of outcome. To evaluate the safety of fluoxetine, cardiac function was measured before and after treatment with echocardiography and electrocardiography. The a priori difference in antidepressive efficacy (4-point difference in HAMD-17 scores between the fluoxetine and placebo groups) was not met. However, the response rate among patients receiving fluoxetine was significantly greater than that among patients receiving placebo at week 25 (48 versus $26 \%, \mathrm{p}=0.05$ ). Among patients with mild depression (HAMD-17 score $\leq 21$ ), HAMD-17 scores were significantly different $(\mathrm{p} \leq 0.05)$ between the fluoxetine and placebo groups at weeks 9 (by 5.4 points) and 25 (by 5.8 points). Also, hostility scores at week 25 were significantly reduced among patients receiving fluoxetine $(\mathrm{p}=0.02)$. Analysis of electrocardiographic and echocardiographic parameters revealed no decrease in cardiac function as a result of treatment with fluoxetine. Although the overall difference between the fluoxetine and placebo groups was not significant, there was a trend favouring fluoxetine in this relatively small sample. The response rate in the group receiving fluoxetine was comparable with that observed in other studies of patients with cardiovascular disease. In addition, fluoxetine seemed to be particularly effective in patients with mild depression and was associated with a statistically significant reduction in hostility. The results of this study suggest that fluoxetine can be safely used to treat patients with post-MI depression beginning 3 months after the event.

\section{Reference}

Strik JJMH, Honig A, Lousberg R, Lousberg AHP, Cheriex EC, Tuynman-Qua HG, Kuijpers PMJC, Wellens HJJ, Van Praag HM. Efficacy and safety of fluoxetine in the treatment of patients with major depression after first myocardial infarction: findings from a double-blind, placebo-controlled trial. Psychosom Med 2000; 62: 783-9. 


\section{Introduction}

Affective dysregulations are frequent sequelae in patients who have had an MI and increase cardiac morbidity and mortality during the first year after MI 1.3. Of these affective dysregulations, depression and hostility are well documented and operationalized $1,3-5$. The poorer cardiac prognosis in MI patients with affective dysregulation has heightened interest in the treatment of depression after MI and the effect of treatment on subsequent cardiac morbidity and mortality. However, antidepressants may have intrinsic adverse effects on cardiac functioning, although selective serotonergic reuptake inhibitors (SSRIs) have been reported to be safer than tricyclics ${ }^{6}$. Data on the efficacy of SSRIs in patients with post-MI depression are limited. In elderly depressed patients with cardiovascular disease, both paroxetine and nortriptyline have been shown to reduce depression 7 . Fluoxetine was found to be less effective than nortriptyline in older, severely depressed patients with heart disease ${ }^{8}$. Data on the treatment of hostility are even more scarce. Fluoxetine has been found to reduce hostility in patients with personality disorder ", healthy volunteers ${ }^{10}$, and depressed patients ". No data on its effect on increased aggression in depressed post-MI patients are available. Tricyclics are reported to increase heart rate, induce orthostatic hypotension, slow intraventricular cardiac conduction, and suppress ventricular premature depolarization in depressed patients with or without heart disease ${ }^{12-15}$. Although SSRIs are thought to be less cardiotoxic than tricyclics, available data on the safety of SSRIs in patients with ischemic heart disease or MI are limited, and these agents have not been evaluated in a double-blind, placebo-controlled trial (Table 1). SSRIs have been found to have no cardiotoxic effects in healthy volunteers or elderly patients ${ }^{16-18}$. Studies of the adverse cardiovascular effects of SSRIs in patients with somatic disease have been mainly restricted to evaluation of patients with ischemic heart disease. In an open-treatment trial of elderly patients with heart disease, fluoxetine was found to decrease heart rate and increase supine systolic pressure and ejection fraction ${ }^{19}$. In a comparative study with nortriptyline in depressed patients with ischemic heart disease, no adverse cardiovascular effects of paroxetine were reported ?. Fluoxetine and fluvoxamine were not found to have a negative effect on cardiac functioning (measured by echocardiography) of middle- aged and elderly depressed patients ${ }^{20}$. Only one open study focusing on the adverse cardiovascular effects of sertraline in patients with post-MI depression has been published ${ }^{21}$.

In this study, sertraline did not have negative effects on the myocardium in the 26 patients studied ${ }^{21}$. This is the first study to investigate the antidepressant efficacy, antihostility efficacy, and cardiac safety of fluoxetine in patients with post-MI depression using a double-blind, placebo-controlled design. We hypothesized that fluoxetine would be superior to placebo in reducing depression and hostility and would have no significant adverse cardiovascular effects. 


\section{Table 1}

Reported adverse cardiovascular side effects of SSRIs in patients with cardiovascular disease or MI.

\begin{tabular}{l|l|l|l}
\hline Study & Drug & Patients & $\begin{array}{l}\text { Cardiovascular } \\
\text { side effects }\end{array}$ \\
\hline $\begin{array}{l}\text { Open study } \\
\text { Roose, 1998 19 }\end{array}$ & F & $\begin{array}{l}\text { out-patients with heart disease } \\
(\mathrm{n}=27)\end{array}$ & $\begin{array}{l}\text { heart rate } \downarrow, \\
\text { supine systolic pressure } \uparrow, \\
\text { ejection fraction } \uparrow \\
\text { none }\end{array}$ \\
Shapiro, 1999 21 & S & $\begin{array}{l}\text { depressed patients following } \\
\text { MI }(\mathrm{n}=26)\end{array}$ & \\
\hline
\end{tabular}

\section{Double-blind comparative study}

\begin{tabular}{|c|c|c|c|}
\hline Roose et al., $1998^{7}$ & $\mathrm{P}, \mathrm{N}$ & $\begin{array}{l}\text { depressed patients with } \\
\text { ischemic heart disease }(n=41)\end{array}$ & $\begin{array}{l}\text { heart rate } \downarrow \text { in } \mathrm{P} \text {, } \\
\text { heart rate } \uparrow, H R V \downarrow \text { in } \mathrm{N} .\end{array}$ \\
\hline Strik et al., 199820 & $\mathrm{~F}, \mathrm{Fv}$ & $\begin{array}{l}\text { middle-aged and elderly } \\
\text { depressed patients }(n=20)\end{array}$ & $\begin{array}{l}\text { ejection fraction } \uparrow \text { in } \\
\text { patients with heart disease }\end{array}$ \\
\hline
\end{tabular}

$\mathrm{F}=$ Fluoxetine $; \mathrm{Fv}=$ Fluvoxamine $; \mathrm{MI}=$ myocardial infarction; $\mathrm{N}=$ Nortriptyline;

$\mathrm{P}=$ Paroxetine; $\mathrm{S}=$ Sertraline; $\mathrm{HRV}=$ heart rate variability; $\uparrow=$ increase; $\downarrow$ = decrease.

\section{Methods}

\section{Subjects}

The study was conducted at Maastricht University Hospital and an affiliated hospital. Patients with a first MI, which was diagnosed by a cardiologist, were included. Inclusion criteria were 1) age of 18 to 75 years, 2) a clinical picture typical of MI, 3) electrocardiographic changes specific for MI, and 4) a maximum plasma concentration of the enzyme aspartate aminotransferase $\left(\mathrm{ASAT}_{\max }\right)$ of twice the upper normal range $(80 \mathrm{U} / \text { liter })^{22}$. Patients were screened for depression and hostility 1,3,6, and 12 months after their MI using the validated Dutch version of the 90-item Symptom Check List (SCL-90) 23. Patients scoring above the cut-off on the SCL-90 Depression Scale $\geq 23$ for men and $\geq 28$ for women) ${ }^{24}$ at screening were invited for an interview by a psychiatrist or trained physician to determine whether they met DSM-III-R criteria for major depression. During this interview, the severity of depression was measured using the HAMD-17 25. Patients fulfilling DSM-III-R criteria for a major depressive episode, diagnosed by use of a DSM-III-R checklist based on sections 6, 7, 8, and 21 of the Schedules for Clinical Assessment in Neuropsychiatry ${ }^{26}$, and having a HAMD-17 score $>17$, could be enrolled in the trial from month 3 to month 12 after MI. During the first 3 months after MI, it can be difficult to distinguish depressive symptoms as either 1) components of a major depressive episode, 2) sequelae of a sudden 
catastrophic cardiac event, or 3) signs of a temporary decrease in cardiac functioning. In addition, some patients participated in a routine cardiological rehabilitation program, consisting of physical therapy and psychological education that lasted up to 3 months after the MI. Our treatment design did not permit any concurrent psychosocial or therapeutic intervention. Exclusion criteria were psychotic symptomatology, a second psychiatric diagnosis, history of mania, current pregnancy or lactation, life-threatening non-cardiac physical illness, concurrent use of psychotropic drugs (except oxazepam up to 50 $\mathrm{mg} / \mathrm{d}$ ), hypersensitivity to fluoxetine, and liver or severe kidney dysfunction (creatinine clearance $<10 \mathrm{ml} / \mathrm{min}$ ). We included all post-MI patients except those with a right ventricular filling pressure $>30 \mathrm{~mm} \mathrm{Hg}$ and a low systolic volume or an aortic time velocity integral (ATVI) $<20 \mathrm{~cm}$. High filling pressure and low output may result in listlessness and a lack of energy and drive, a condition mimicking depression ${ }^{27}$. Impairment of the left ventricular ejection fraction (LVEF) was not used as an exclusion criterion. The study was approved by the ethics committees at the two sites. The study was completely described to the subjects, who then provided written informed consent. Subjects were recruited from May 1994 to December 1997. The number of eligible patients was 556, of whom $357(64 \%)$ agreed to participate and 199 $(36 \%)$ declined to participate. Of these 357 subjects, 4 died between 1 and 3 months after MI, and 68 met DSM-III-R criteria for major depression (Figure 1). Of the 68 depressed patients, 12 dropped out at a later stage, and 2 were excluded because of an ATVI $<20 \mathrm{~cm}$ and a right ventricular filling pressure $>$ $30 \mathrm{~mm} \mathrm{Hg}$. Non-participants did not differ from participants in age, gender, or $\mathrm{ASAT}_{\max }$. Hence, 54 patients were included in the study, of whom 31 were diagnosed with a major depressive episode at 3 months after MI; 17, at 6 months; and 6 , at 12 months. These 54 patients were randomly assigned to receive fluoxetine $(\mathrm{n}=27)$ or placebo $(\mathrm{n}=27)$.

\section{Intenvention}

Fluoxetine was studied using a randomized, placebo-controlled, double-blind design. The antidepressant was prescribed for a maximum of 25 weeks; the acute treatment period lasted 9 weeks, and the continuation period lasted another 16 weeks. Patients were randomly assigned to receive either fluoxetine $20 \mathrm{mg} / \mathrm{d}$ or placebo. The dose of fluoxetine could be increased to $40 \mathrm{mg} / \mathrm{d}$ in week 3 and to $60 \mathrm{mg} / \mathrm{d}$ in week 6 depending on the clinical response (dose was increased if there was a $<50 \%$ decrease in the HAMD-17 score). Spontaneously reported adverse effects were categorized as gastrointestinal complaints, chest pain, agitation, and other complaints. Patients who were rehospitalized were dropped from the study and offered additional antidepressant treatment. At week 9, patients who wished to continue participating in the trial were allowed to do so and were given the same dose of fluoxetine or placebo for another 16 weeks regardless of their response (even if there was a $<50 \%$ reduction in HAMD-17 score). 


\section{Data Collection}

Depression, hostility, adverse effects and events, and concurrent use of medications were assessed at baseline and weeks 1,3,6, and 9; thereafter these parameters were measured monthly. Serious adverse events were defined as death, re-hospitalization due to cardiac events, and non-cardiac life-threatening disease. Blood pressure, height, and weight were measured at baseline and at weeks 6,9 , and 25 . Blood and urine samples were collected at the same time points for haematological testing, clinical chemistry screening, and measurement of plasma concentrations of fluoxetine and norfluoxetine. Electrocardiography and echocardiography were performed at baseline and weeks 6 and 25. Response and remission were assessed for patients who had at least one assessment after initiation of treatment. Response was defined as a $50 \%$ or greater reduction in the HAMD-17 score. Remission was defined as a HAMD-17 end-point score $\leq 7$. Changes in scores on the SCL-90 Hostility Scale were used to assess the efficacy of fluoxetine as a treatment for hostility. According to Dutch SCL-90 standards, a score of 9 to 11 indicates a high level of hostility; 8 to 9 , moderate; and $<8$, low ${ }^{23}$. Because there is no clear consensus on hostility response or remission, no cut-off was operationalized. The present study focused not only on changes in cardiac conduction and blood pressure but also on changes in cardiac output. Safety measures therefore were electrocardiographic variables, systolic and diastolic blood pressures, and echocardiographic variables. Electrocardiographic variables consisted of heart rate, PR interval, QRS interval, and QTc interval (corrected QT interval). Impaired conduction may lead to an increase in the QRS interval. Enlargement of the QTc interval has been related to arrhythmias. LVEF and ATVI were monitored by echocardiography. ATVI was used as an indirect measure of stroke volume ${ }^{28,29}$, which is related to cardiac output. ATVI multiplied by the aortic valve area (Doppler method) was used to calculate stroke volume. Parameters to assess diastolic function or filling pressures were defined as early or passive/active or late mitral inflow (E/A ratio) ${ }^{30}$.

\section{Statistical analyses}

The required sample size was estimated using the method of Knapp and Miller ${ }^{31}$. If previous outcome data are unavailable for depressed post-MI patients, these guidelines suggest approximating the standard deviation by dividing the range of values for the response variable (HAMD-17 score) by $6^{31}$. A mean of 26 HAMD points was taken as the range ${ }^{32,33}$. An effect size of a 4-point difference in HAMD-17 scores between the fluoxetine and placebo groups and a statistically significant difference in response rate between the fluoxetine and placebo groups was thus expected a priori ${ }^{34}$. If the level of significance $\alpha$ is set at 0.05 , the power $\beta$ is set at 0.95 , and the HAMD- 17 hypothesis is tested using a one-tailed test, the required sample size is 54 (27 per group). Statistical analyses were performed using STATA $5.0^{35}$ and SPSS for Windows 6.0 software ${ }^{36}$. To analyze the efficacy data, $t$ tests were used, given the absence of 
outliers and presence of normality of data tested with skewness/kurtosis test ${ }^{37}$. Efficacy outcome was analyzed on an intention-to-treat basis: All 54 patients were analyzed as they were randomized. For patients not completing the 9 or 25 weeks of treatment, the "last observation carried forward" technique ${ }^{38}$ was used. Increases in HAMD-17 or SCL-90 hostility scores during fluoxetine treatment were unlikely because fluoxetine has established antidepressive 32,33 and antihostility properties 9 . Therefore, tests of the primary efficacy variables (scores on the HAMD-17 and SCL-90 Hostility Scale) were one tailed. All other tests were two tailed. To determine the safety of fluoxetine therapy, regression analyses were applied using cardiologic safety variables as dependent variables and treatment condition and fluoxetine plasma concentration as independent variables. Regression analyses were performed as described by Kleinbaum et al. 39. When there were large Cook distances ( $>3 \mathrm{SDs}$ ), a second regression model was assessed without influential cases. Patients were included in these analyses only if assessment data from baseline and week 6 or baseline and week 25 were available.

\section{Results}

There were no statistically significant differences between the fluoxetine and placebo groups in age, gender, severity of depression, severity of hostility at baseline (using HAMD-17 and SCL-90 hostility scores), or severity of MI (ASAT max $_{\text {ma }}$ (Table 2). During the acute treatment phase of the study (up to week 9), two patients from the fluoxetine group and five from the placebo group dropped out; during the continuation phase (weeks 10 to 25), three patients from the fluoxetine group and four from the placebo group dropped out because of a lack of effect, loss to follow-up, or medical reasons (Figure 1). All patients taking fluoxetine had a plasma level of fluoxetine $0.4 \mathrm{mg} / \mathrm{liter}$ on repeated measurements. Mean plasma levels of fluoxetine and norfluoxetine were $74.8(\mathrm{SD}=55.1)$ and $58.6 \mathrm{mg} /$ liter $(\mathrm{SD}=29.7)$, respectively, at week 3; $131.3(\mathrm{SD}=92.2)$ and $104.2 \mathrm{mg} /$ liter $(\mathrm{SD}=57.0)$, respectively, at week 6; $175.8(\mathrm{SD}=138.0)$ and $129.5 \mathrm{mg} / \mathrm{liter}(\mathrm{SD}=84.8)$ at week 9 ; and $154.3(\mathrm{SD}=$ $144.7)$ and $139.9 \mathrm{mg} /$ liter $(\mathrm{SD}=115.5)$ at week 25 , respectively. The mean fluoxetine dose was $47.3 \mathrm{mg} / \mathrm{d}(\mathrm{SD}=19.1)$. 


\section{Table 2}

Baseline characteristics of the fluoxetine and placebo patient groups a.

\begin{tabular}{l|c|c|c}
\hline Variable & Fluoxetine $(\mathrm{n}=27)$ & Placebo $(\mathrm{n}=27)$ & p-value $^{\mathrm{b}}$ \\
\hline Gender & $\mathrm{M}=21 ; \mathrm{F}=6$ & $\mathrm{M}=17 ; \mathrm{F}=10$ & 0.23 \\
Age (years) & $54.1(\mathrm{SD}=11.3)$ & $58.7(\mathrm{SD}=10.1)$ & 0.11 \\
ASAT $_{\max }(\mathrm{U} / \mathrm{L})$ & $245.5(\mathrm{SD}=155.1)$ & $243.3(\mathrm{SD}=170.1)$ & 0.96 \\
HAMD-17 score & $22.0(\mathrm{SD}=3.5)$ & $21.2(\mathrm{SD}=3.7)$ & 0.46 \\
Hostility score & $10.7(\mathrm{SD}=4.8)$ & $9.5(\mathrm{SD}=4.3)$ & 0.30 \\
LVEF $\%)$ & $51.3(\mathrm{SD}=9.83)$ & $50.7(\mathrm{SD}=10.9)(\mathrm{n}=26)$ & 0.85 \\
TVI $(\mathrm{cm})$ & $25.8(\mathrm{SD}=4.82)(\mathrm{n}=25)$ & $26.8(\mathrm{SD}=7.62)(\mathrm{n}=26)$ & 0.59 \\
E/A ratio & $1.08(\mathrm{SD}=0.34)(\mathrm{n}=21)$ & $1.22(\mathrm{SD}=0.68)(\mathrm{n}=24)$ & 0.42 \\
Heart rate $(\mathrm{b} / \mathrm{min})$ & $67.8(\mathrm{SD}=21.9)(\mathrm{n}=24)$ & $65.8(\mathrm{SD}=24.6)$ & 0.76 \\
PR interval $(\mathrm{msec})$ & $152(\mathrm{SD}=22.0)(\mathrm{n}=23)$ & $153(\mathrm{SD}=24.6)$ & 0.86 \\
QRS interval $(\mathrm{msec})$ & $93.4(\mathrm{SD}=12.0)(\mathrm{n}=25)$ & $93.6(\mathrm{SD}=12.7)$ & 0.94 \\
QTc interval $(\mathrm{msec})$ & $417(\mathrm{SD}=27.8)(\mathrm{n}=25)$ & $414(\mathrm{SD}=17.0)$ & 0.72 \\
DBP (mmHg) & $85.6(\mathrm{SD}=8.81)(\mathrm{n}=21)$ & $81.9(\mathrm{SD}=8.17)(\mathrm{n}=23)$ & 0.44 \\
SBP (mmHg) & $127(\mathrm{SD}=13.6)(\mathrm{n}=21)$ & $130(\mathrm{SD}=16.3)(\mathrm{n}=23)$ & 0.33 \\
\hline
\end{tabular}

$\mathrm{a}=$ Values for all characteristics except gender are mean (SD). DBP = diastolic blood pressure; $\mathrm{SBP}=$ systolic blood pressure; $\mathrm{LVEF}=$ left ventricular ejection fraction, $\mathrm{TVI}=$ aortic time velocity integral, $\mathrm{E} / \mathrm{A}$-ratio = early or passive/active or late mitral inflow.

$\mathrm{b}=$ Differences in baseline characteristics between the fluoxetine and placebo groups were not statistically significant.

\section{Concurrent medications}

Medications used concurrently included aspirin ( $\mathrm{n}=42,77.8 \%$ ), lipophilic betablockers $(\mathrm{n}=33,61.1 \%)$, benzodiazepines $(\mathrm{n}=28,51.9 \%)$, isosorbide nitrate $(\mathrm{n}=23,42.6 \%)$, cholesterol-lowering medication $(\mathrm{n}=22,40.7 \%)$, angiotensinconverting enzyme (ACE)-inhibitors $(n=16,29.6 \%)$, calcium channel blockers $(\mathrm{n}=15,27.8 \%)$, diuretics $(\mathrm{n}=13,24.1 \%)$, anticoagulants $(\mathrm{n}=6,11.1 \%)$, and hydrophilic b-blockers $(\mathrm{n}=5,9.3 \%)$. The median number of cardiovascular drugs taken was 4.9 (range $=1-9$ ) excluding the trial medication. There were no differences in specific drugs between groups (all p-values $>0.10$ ). No patients were taking antidepressant or antipsychotic drugs before the study. 


\section{Figure 1}

Flow chart of depressed post-first-MI patients, eligible for entering the intervention study.

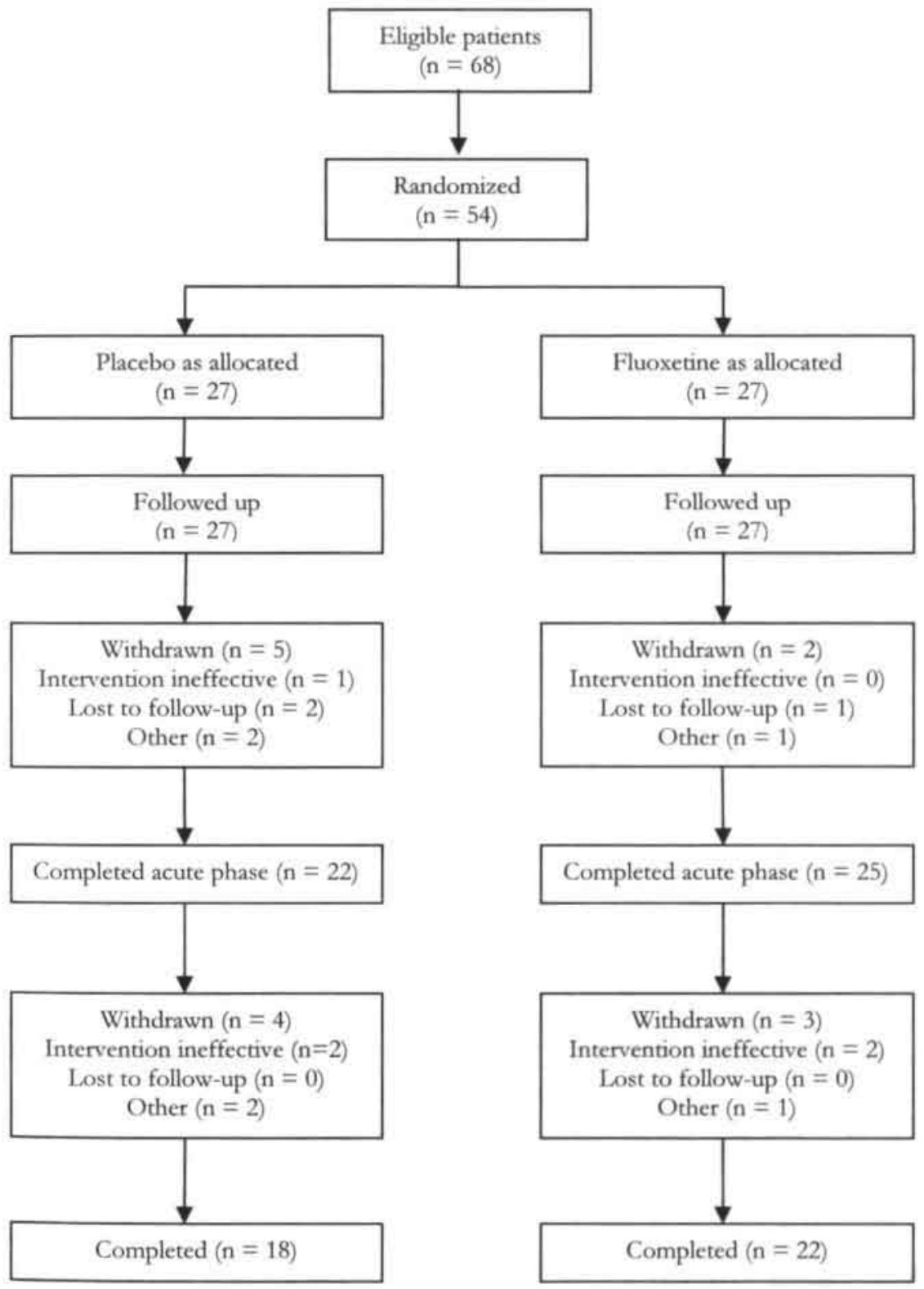




\section{Adverse effects and events}

Patients in both groups reported adverse effects, mainly chest pain, gastrointestinal complaints, and agitation (Table 3), but there were no significant differences between groups in the number of events reported. The only serious adverse event that occurred was re-hospitalization for a cardiac event $(n=7)$; no patients were excluded because of cancer, drug overdose, or death during this study. The mortality rate of MI patients in general in our hospital is highest during acute hospitalization and decreases to 1 to $2 \%$ between 1 and 12 months after MI ${ }^{40}$. Patients were re-hospitalized for one of the following reasons: unstable angina pectoris, anaemia, ventricular fibrillation, decompensatio cordis, and catheterization. The number of re-hospitalizations was higher in the placebo group $(n=6)$ than in the fluoxetine group $(n=1)$, but this difference was not statistically significant $(p=0.13)$.

\section{Tabel 3}

Adverse side effects of fluoxetine and placebo in 54 depressed outpatients following 3 to 12 months after their first MI.

\begin{tabular}{l|c|c|c}
\hline Side effect & $\begin{array}{c}\text { Fluoxetine } \\
(\mathrm{n}=27)\end{array}$ & $\begin{array}{c}\text { Placebo } \\
(\mathrm{n}=27)\end{array}$ & p-value \\
\hline Chest pain & $\mathrm{n}=5$ & $\mathrm{n}=4$ & 1.0 \\
Gastro Intestinal Complaints & $\mathrm{n}=8$ & $\mathrm{n}=6$ & 0.54 \\
Agitation & $\mathrm{n}=6$ & $\mathrm{n}=3$ & 0.47 \\
Other & $\mathrm{n}=17$ & $\mathrm{n}=12$ & 0.17 \\
Re-hospitalization & $\mathrm{n}=1$ & $\mathrm{n}=6$ & 0.13 \\
TVI (cm) & $\downarrow \mathrm{n}=8$ & $\mathrm{n}=0$ & 0.02 \\
QRS interval (msec) & $\downarrow_{\mathrm{n}=15}$ & $\uparrow \mathrm{n}=9$ & 0.03 \\
\hline
\end{tabular}

TVI: aortic time velocity integral. Differences between fluoxetine and placebo of the side effects other than TVI and QRS interval were statistically not significant.

\section{Efficacy during the acute treatment phase}

The mean HAMD-17 score decreased 8.34 points $(S D=5.87)$ in the fluoxetine group and 5.84 points $(S D=5.92)$ in the placebo group (Figure 2, left). The difference of 2.50 HAMD-17 points was not statistically significant at week 9 ( $t$ $=1.56, \mathrm{df}=52, \mathrm{p}=0.06$ ). Nine patients receiving fluoxetine and 8 receiving placebo responded; remission occurred in 3 receiving fluoxetine and 1 receiving placebo. Differences were not significant $(p=0.39$ and $p=0.15$, respectively). The mean SCL-90 hostility score decreased 2.61 points $(\mathrm{SD}=3.06)$ in the fluoxetine group and 1.18 points $(\mathrm{SD}=4.12)$ in the placebo group (Figure 3, left). This difference of 1.44 points was not statistically significant $(\mathrm{p}=0.08)$. Use of benzodiazepine had no influence on the HAMD-17 score, hostility score, response rate, or remission rate. 


\section{Efficacy during the entire treatment phase}

From baseline to week 25, the total HAMD-17 scores decreased 9.65 points $(\mathrm{SD}=7.17)$ in subjects receiving fluoxetine and 6.92 points $(\mathrm{SD}=6.91)$ in subjects receiving placebo (Figure 2, right). This difference was not statistically significant $(p=0.08)$. However, at week 25 there were 13 responders in the fluoxetine group $(48 \%)$ and 7 in the placebo group $(26 \%)\left(\chi^{2}=2.86, \mathrm{df}=1, \mathrm{p}\right.$ $=0.05)$. Remission occurred in 7 responders $(26 \%)$ in the fluoxetine group and in 4 responders $(14.8 \%)$ in the placebo group $(p=0.6)$. The SCL-90 hostility score decreased by 2.44 points $(S D=4.64)$ in patients receiving fluoxetine and by 0.07 points $(\mathrm{SD}=2.57)$ in patients receiving placebo $(\mathrm{t}=2.32, \mathrm{df}=52, \mathrm{p}=$ 0.02) (Figure 3, right). Efficacy outcome was not related to plasma levels of fluoxetine. Benzodiazepines had no influence on efficacy outcome during the entire treatment phase. Post hoc analysis revealed that fluoxetine was more effective in patients with mild depression (HAMD-17 score $\leq 21, \mathrm{n}=32$ ) than in those with severe depression (HAMD-17 score $\geq 21, \mathrm{n}=22$ ); the difference in efficacy (HAMD-17 score) was 5.4 points at week $9(\mathrm{p}=0.01)$ and 5.8 points at week $25(\mathrm{p}=0.04)$.

\section{Figure 2}

Efficacy of fluoxetine versus placebo in depression in post-MI depression.

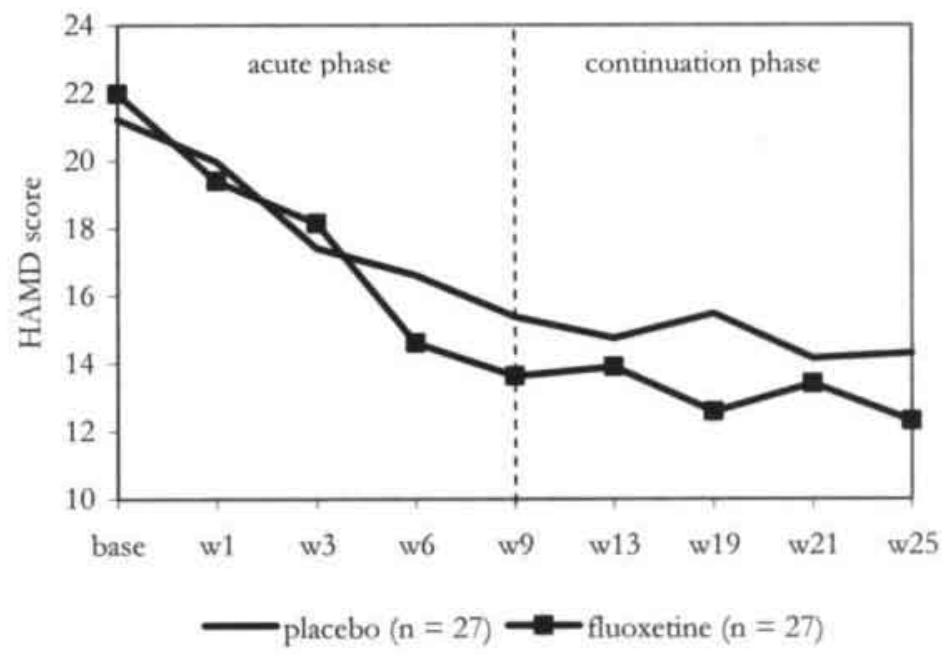




\section{Figure 3}

Efficacy of fluoxetine versus placebo in hostility in post-MI depression.

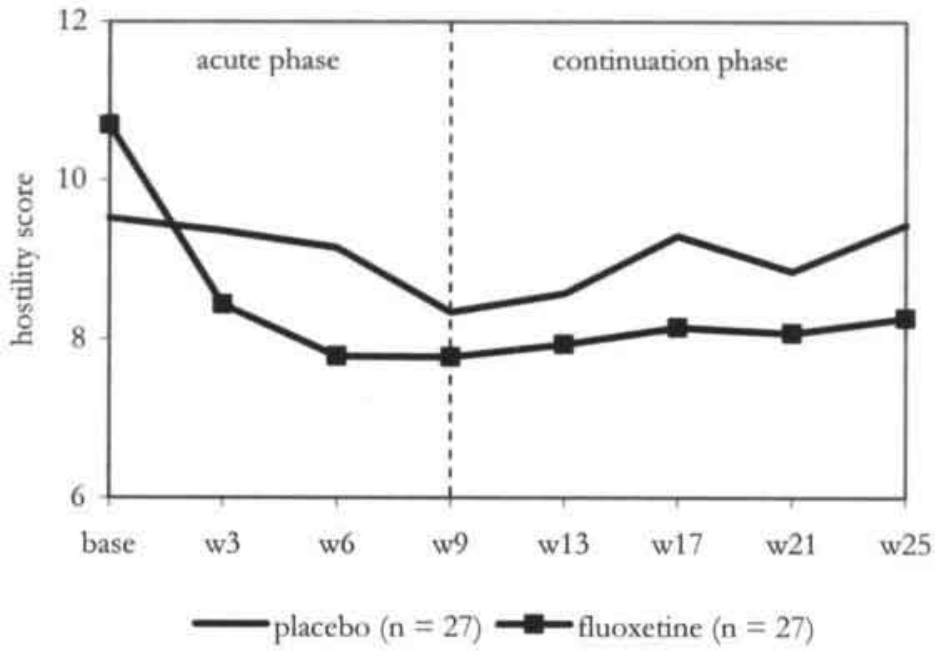

\section{Adverse cardiovascular effects}

The echocardiographic variables LVEF, ATVI, and E/A ratio and the electrocardiographic variables heart rate, PR interval, QRS interval, and QTc interval did not change during the acute treatment phase (Table 3). Between baseline and week 25 , ATVI increased by $3.8 \mathrm{~cm}$ in the placebo group compared with the fluoxetine group $(p=0.02)$. QRS interval decreased by 6.3 $\mathrm{ms}$ in the fluoxetine group compared with the placebo group $(\mathrm{p}=0.03)$. Cardiac safety variables were not related to plasma levels of fluoxetine.

\section{Discussion}

This study was the first to investigate the efficacy and safety of fluoxetine using a double-blind, placebo-controlled design in patients with major depression after their first MI. Overall, the difference in antidepressive efficacy (4-point difference in HAMD-17 scores between the fluoxetine and placebo groups) defined at the beginning of the study was not met. However, there were significantly more responders among the fluoxetine group than among the placebo group at week 25. Furthermore, compared with placebo, fluoxetine was especially effective in reducing the HAMD-17 score of patients with mild depression. In addition, hostility scores were significantly lower in the fluoxetine group after treatment. The difference of $2.5 \mathrm{HAMD}-17$ points between the fluoxetine and placebo groups was lower than our a priori rigorous 
effect size of 4.0 points. However, if we look at response rate, the commonly used efficacy outcome, the antidepressant efficacy was comparable to that reported by Roose et al. ${ }^{7}$ and Shapiro et al. ${ }^{21}$. In the intention-to-treat analysis, $33 \%$ ( 9 of 27) of patients receiving fluoxetine responded at week 9, and $48 \%$ (13 of 27) of these patients responded at week 25 . Of patients included in the end-point analyses, $36 \%$ responded at week 9 and $59 \%$ responded at week 25 . In the placebo group, the response rate was $30 \%$ at week 9 and $26 \%$ and week 25 in the intention-to-treat analysis and 36 and $39 \%$, respectively, in the endpoint analyses. The difference in response rate between the fluoxetine and placebo groups was statistically significant at week $25(p=0.05)$. The response rate in the fluoxetine group in the end-point analysis $(59 \%)$ is comparable with that reported by Shapiro et al. ${ }^{21}$, who observed a response rate of $62.5 \%$ among depressed patients treated with sertraline after an acute MI. Shapiro et al. found this response rate after 16 weeks of treatment, as compared with 25 weeks in our study. The smaller-than-expected difference in HAMD-17 scores between the fluoxetine and placebo groups in our study may be due to the relatively high response to placebo in patients with mild depression. The selflimiting course and higher placebo response may also be related to age ${ }^{41}$ and somatic disease ${ }^{41,42}$. Especially in this population, just seeing a physician in a hospital at regular intervals may be regarded as an intervention in itself, increasing the placebo response. Finally, there are studies suggesting that SSRIs are more efficacious in patients with mild depression than in those with severe depression ${ }^{43-45}$. Hostility levels among patients receiving fluoxetine changed from high to low by the end of the treatment period. Because hostility reportedly increases mortality after MI, a decreased level of hostility might influence a patient's post-MI prognosis ${ }^{3,4}$. There were no significant changes in echocardiographic or electrocardiographic variables or blood pressure during the acute treatment phase. During the entire treatment period of 25 weeks, ATVI decreased in the fluoxetine group as compared with the placebo group. In this same period, QRS interval decreased by $6.3 \mathrm{~ms}$ in the fluoxetine group as compared with the placebo group. Adverse effects (mainly chest pain, gastrointestinal symptoms, and agitation) were reported equally in both groups. Re-hospitalization for cardiac events occurred mainly in the placebo group. QRS interval decreased during the continuation phase among patients receiving fluoxetine, but a change in the QRS complex of $10 \mathrm{~ms}$ in patients with a QRS complex, $110 \mathrm{~ms}$ is not considered clinically relevant, which was the case in patients of this study. Furthermore, the difference in cardiac output or ATVI between the fluoxetine and placebo groups disappeared after correction of ATVI for both heart rate and ASAT $\mathrm{T}_{\max }$. This could be explained by the fact that ATVI is influenced by ASAT max $_{\max }$ or severity of MI, with a larger MI leading to a lower ATVI ${ }^{29}$. Thus, the decrease in ATVI in the fluoxetine group seemed not to be caused by fluoxetine but by cardiac variables. The main limitation of our study was the sample size, which was probably not large enough to reach a 4 point or greater difference in HAMD-17 scores between the fluoxetine and 
placebo groups. Hence, generalizations based on these results must be made carefully. In summary, the results suggest that fluoxetine can be safely used in patients with major depression starting 3 months after MI. Although the overall difference between treatment with fluoxetine and placebo was not statistically significant, there was a clear trend favouring fluoxetine in this relatively small sample. Fluoxetine was especially effective in patients with mild depression (HAMD-17 score $\leq 21$ ), and there was a statistically significant reduction in hostility among these patients. Moreover, the rate of re-hospitalization was lower among patients who received fluoxetine for post-MI depression. By affecting depression and hostility, fluoxetine may reduce the risk of increased morbidity and mortality due to affective dysregulation in post-MI patients. Follow-up studies and placebo-controlled intervention trials must be performed to verify these conclusions.

\section{References}

1. Frasure-Smith N, Lespérance F, Talajic M. Depression following myocardial infarction: impact on 6-month survival. JAMA 1993; 270:1819-25.

2. Frasure-Smith N, Lespérance F, Talajic M. Depression and 18- month prognosis after myocardial infarction. Circulation 1995; 91:999-1005.

3. Denollet J, Sys SU, Stroobant N, Rombouts H, Gillebert TC, Brutsaert DL. Personality as independent predictor of long-term mortality in patients with coronary heart disease. Lancet 1996; 347:417-21.

4. Denollet J, Sys SU, Brutsaert DL. Personality and mortality after myocardial infarction. Psychosom Med 1995;57:582-91.

5. Somervell PD, Kaplan BH, Heiss G, Tyroler G, Kleinbaum DG, Obrist PA. Psychologic distress as a predictor of mortality. Am J Epidemiol 1989;130:1013-23.

6. Menting JEA, Honig A, Verhey FRJ, et al. Selective serotonin reuptake inhibitors (SSRIs) in the treatment of elderly depressed patients: a qualitative analysis of the literature on their efficacy and sideeffects. Int Clin Psychopharmacol 1996;11:16575.

7. Roose SP, Laghrissi-Thode F, Kennedy JS, et al. Comparison of paroxetine and nortriptyline in depressed patients with ischemic heart disease. JAMA 1998;279:28791.

8. Roose SP, Glassman AH, Attia E, Woodring S. Comparative efficacy of selective serotonin reuptake inhibitors and tricyclics in the treatment of melancholia. Am J Psychiatry 1994;151:1735-9.

9. Coccaro EF, Kavoussi RJ. Fluoxetine and impulsive aggressive behavior in personality-disordered subjects. Arch Gen Psychiatry 1997;54:1081-8.

10. Knutson B, Wolkowitz OM, Cole SW, et al. Selective alteration of personality and social behavior by serotonergic intervention. Am J Psychiatry 1998;155:373-9.

11. Fava M, Davidson K, Alpert JE, et al. Hostility changes following antidepressant treatment: relationship to stress and negative thinking. J Psychiatr Res 1996;30:45967.

12. Glassman AH, Roose SP. Risk of antidepressants in the elderly: tricyclic antidepressants and arrhythmia-revising risks. Gerontology 1994;40(Suppl 1):15-20. 
13. Glassman AH, Stage KB. Depressed patients with cardiovascular disease: treatment considerations. CNS Drugs 1994;1:435-40.

14. Roose SP, Glassman AH. Cardiovascular effects of tricyclic antidepressants in depressed patients with and without heart disease. J Clin Psychiatry 1989;50:1-18.

15. Kantor SJ, Glassman AH, Bigger JT, Perel JM, Giardina EV. The cardiac effects of therapeutic plasma concentrations of imipramine. Am J Psychiatry 1978;135:534-8.

16. Feighner JP. Cardiovascular safety in depressed patients: focus on venlafaxine. J Clin Psychiatry 1995;56:574-9.

17. Brymer C, Winograd CH. Fluoxetine in elderly patients: is there a cause for concern? J Am Geriatr Soc 1992;40:902-5. 18. Kellet JM. Fluvoxamine: an antidepressant for the elderly? J Psychiatry Neurosci 1991;42:410-21.

19. Roose SP, Glassman AH, Attia E, Woodring S, Giardina E-GV, Bigger T. Cardiovascular effects of fluoxetine in depressed patients with heart disease. Am J Psychiatry 1998;155:660-5.

20. Strik JJMH, Honig A, Lousberg R, Cheriex EC, Van Praag HM. Cardiac side-effects of two selective serotonin reuptake inhibitors in middle-aged and elderly depressed parients. Int Clin Psychopharmacol 1998;13:263-7.

21. Shapiro PA, Lespérance F, Frasure-Smith N, et al. An open-label preliminary trial of sertraline for treatment of major depression after acute myocardial infarction (the SADHAT trial). Am Heart J 1999;137:1100-6.

22. Pasternak RC, Braunwald E, Sobel RE. Acute myocardial infarction. In: Braunwald E, editor. Heart disease: a textbook of cardiovascular medicine. 4 th ed. Philadelphia: WB Saunders; 1992 . p. 1200-91.

23. Arrindell WA, Ettema JHM. Dimensional structure, reliability and validity of the Dutch version of the Symptom Checklist (SCL-90). Ned Tijdschr Psychol 1981;43:381-7.

24. Honig A, Lousberg R, Wojchiechowski F, Cheriex EC, Wellens H, Van Praag HM. Depression following a first heart infarct: similarives with and differences from 'ordinary' depression. Ned Tijdschr Geneesk 1997;141:196-9.

25. Hamilton M. A rating scale for depression. J Neurol Neurosurg Psychiatry $1960 ; 23 ; 56-62$.

26. Wing JK, Babor $T$, Brugha $T$, et al. Schedules for clinical assessment in neuropsychiatry. Arch Gen Psychiarry 1990;47:589-93.

27. Branwald E, editor. Heart disease: a textbook of cardiovascular disease. 5 th ed. Philadelphia: WB Saunders; 1997.

28. Cheitin MD, Apert JS, Armstrong WF, et al. ACC/AHA guidelines for the clinical application of echocardiography. A report of the American College of Cardiology/ American Heart Association Task Force on Practice Guidelines (Committee on Clinical Application of Echocardiography). Developed in collaboration with the American Society of Echocardiography. Circulation 1997;95:1686-744.

29. Hiceto S, D'Ambrosio G, Marangelli V, Amico A, Biase D, Rizzon P. EchoDoppler evaluation of the effects of heart rate increments on left atrial pump function in normal human subjects. Eur Heart J 1991;12:345-51.

30. Appleton CP, Galloway JM, Gonzales MS, Gaballa M, Basnight MA. Estimation of left ventricular filling pressures using twodimensional and Doppler echocardiography in adult patients with cardiac disease. J Am Coll Cardiol $1993 ; 22: 1972-82$.

31. Knapp RG, Miller MC. Clinical epidemiology and biostatistics. Baltimore: Williams \& Wilkins; 1992. 
32. Lader M. Fluoxetine efficacy vs comparative drugs: an overview. Br J Psychiatry 1988;153(Suppl):51-8.

33. Beasley CM, Sayler ME, Bosomworth JG, Wernicke JF. Highdose fluoxetine: efficacy and activating-sedating effects in agitated and retarded depression. J Clin Psychopharmacol 1991;11:166-74.

34. Montgomery SA. Clinically relevant effect sizes in depression. Eur J Neuropsychopharmacol 1994;4:283-4.

35. STATA statistical software, release 5.0. College Station (TX): Stata Corp; 1997.

36. Norusis M]. SPSS for Windows 6.0. Chicago: SPSS Inc; 1993.

37. D'Agostino RB, Balanger A, D'Agostino RB Jr. A suggestion for using powerful and informative tests of normality. Am Statistician 1990;44:316-21.

38. Little R, Yau L. Intent-to-treat analysis for longitudinal studies with drop-outs. Biometrics 1996;52:1324-33.

39. Kleinbaum DG, Kupper LL, Muller KE. Applied regression analysis and other multivariable methods. 2nd ed. Boston: PWSKent Publishing Co; 1988.

40. Widdershoven J, Vreede de -Swagemakers J. Acute coronary syndromes in the Maastricht area. Maastricht, Netherlands: University Press Maastricht; 1997.

41. Evans M, Hammond M, Wilson K, Lye M, Copeland J. Placebocontrolled treatment trial of depression in elderly physically ill patients. Int J Geriatr Psychiatry $1997 ; 12: 817-24$.

42. Rabkin JG, Wagner GJ, Rabkin R. Fluoxetine treatment for depression in patients with HIV and AIDS: a randomized, placebo controlled trial. Am J Psychiatry 1999;156:101-7.

43. Perry PJ. Pharmacotherapy for major depression with melancholic features: relative efficacy of tricyclic versus selective serotonin reuptake inhibitor antidepressant. J Affect Disord 1996;39:1-6.

44. Anderson IM, Tomenson BM. The efficacy of selective serotonin re-uptake inhibitors in depression: a meta-analysis of studies against tricyclic antidepressants. J Psychopharmacol 1994;8: 238-49.

45. Anderson IM. SSRIs versus tricyclic antidepressants in depressed inpatients: a metaanalysis of efficacy and tolerability. Depress Anxiety 1998;7:11-7. 


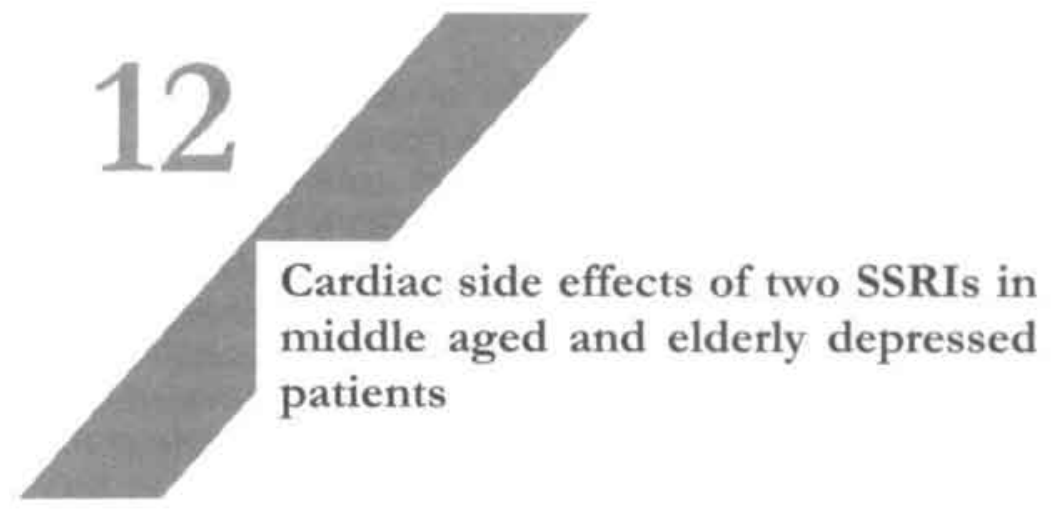




\begin{abstract}
Selective serotonin reuptake inhibitors (SSRI's) are the 'new' drugs of first choice for the treatment of depression in the older patient. Systematic studies on the effects of SSRIs on cardiac function are scarce, despite the high prevalence of cardiac disorders in the older patient. This is a study of cardiac function in middle-aged and elderly depressed patients, who were treated with an SSRI, which systematically assessed cardiac function by echocardiography. In contrast to ECG, echocardiography measures cardiac function directly.

Twenty patients were assigned to receive fluoxetine $20 \mathrm{mg}$ or fluvoxamine 100 $\mathrm{mg} / \mathrm{d}$ for 6 weeks. Cardiac function was assessed by left ventricle ejection fraction (LVEF), aortic flow integral (AI) and early or passive/late or active mitral inflow (E/A ratio), and electrocardiography (ECG).

Neither SSRI significantly affected cardiac function. Compared with patients without a history of myocardial infarction and/or hypertension, patients with such a history showed a significant improvement in the left ventricular ejection fraction.

Despite our small study sample, these data indicate that both fluoxetine and fluvoxamine do not affect cardiac function adversely.
\end{abstract}

\title{
Reference
}

Strik JJMH, Honig A, Lousberg R, Cheriex EC, Van Praag HM. Cardiac side effects of two SSRIs in middle aged and elderly depressed patients. Int Clin Psychopharmacol 1998; 13: 263-7. 


\section{Introduction}

Selective serotonin reuptake inhibitors (SSRIs) are the "new" drugs of first choice for the treatment of depression in the elderly 1,2. Several clinical trials, comparing fluoxetine or fluvoxamine with placebo and/or tricyclic antidepressants (TCAs) have been performed in order to establish efficacy ${ }^{3-5}$. They are as effective as TCAs, at least in outpatient populations, but have a more favourable side effect profile and a lower dropout rate ${ }^{6}$. SSRIs have fewer cardiovascular side effects than TCAs $1,2,7$ although systematic patient studies on cardiovascular side effects of SSRIs are scarce. In case reports bradycardia is the most reported cardiovascular effect of fluoxetine ${ }^{8.11}$. Other reported effects of fluoxetine and fluvoxamine are ECG changes ${ }^{12}$, atrial fibrillation ${ }^{13}$, and decreased heart rate ${ }^{14}$, which may facilitate heart block and bradycardia 0,15,16. The cardiovascular side effects of SSRIs manifested by ECG changes have been investigated in young, healthy volunteers ${ }^{14,17}$. In a double blind parallel group study of fluoxetine and doxepin Baker et al. found in forty patients with major depression but without somatic disease that fluoxetine had no measurable electrocardiographic effects ${ }^{18}$. In addition, Roose et al. investigated the cardiovascular side effects in a double blind trial of paroxetine versus nortriptyline in elderly depressed patients with co-morbid cardiovascular disease 19. They reported that nortriptyline was associated with a significant higher rate of serious adverse events. Furthermore, they found in an open medication trial with 27 patients with cardiac disease that fluoxetine treatment was not associated with cardiovascular side effects ${ }^{20}$. Studies on the effect of SSRIs on the myocardial function of middle-aged and elderly people are important, because this is an age group in which there is a high prevalence of cardiac disorders 21,22 .

This is one of the scarce studies, which investigated in a systematic way cardiac function assessed by electrocardiography (ECG) and echocardiography in middle-aged and elderly depressed patients, being treated with a SSRI. ECG was used to study the effect of SSRI on cardiac conduction properties and echocardiography to obtain information about systolic and diastolic function and to exclude cardiovascular abnormalities before treatment. Like depression, these abnormalities can cause symptoms like fatigue and mood disturbances (e.g., low cardiac output and congestive heart failure). Echo Doppler was used to obtain information about left and right sided function and volumes. Our a priori hypothesis was that SSRIs do not adversely affect cardiac function.

\section{Patients and methods}

\section{Patients}

Patients were recruited from the outpatient mood-disorder clinic of the Maastricht University Hospital. The inclusion criteria were age 45 years or 
older, the presence of a major depressive disorder according to the DSM-III-R criteria, with a score of 18 or more on the Hamilton Depression Rating Scale (HAMD-17) ${ }^{23}$ and written informed consent. Patients were excluded if one of the following criteria were met. A concurrent or recent DSM-III-R diagnosis of alcoholism; drug induced psychosis or dementia; treatment with ECT or MAOI within 2 weeks before inclusion; use of an investigation drug within one month prior to inclusion, or inability to withdraw from any psychoactive drug(s) by the time of the initial visit; treatment with coumarin derivatives, propanolol or any other beta-blocker metabolised by the liver; clinically uncontrolled somatic disease; evidence of hypersensitivity or intolerance to either drug used in this study, previous unsuccessful consecutive treatments with fluvoxamine and fluoxetine or previously being enrolled in the study.

\section{Treatment}

Patients were randomised to receive fluvoxamine $100 \mathrm{mg} / \mathrm{d}$ or fluoxetine $20 \mathrm{mg} / \mathrm{d}$ for a 6 weeks period, during which time they were monitored to determine the efficacy and safety of the SSRIs. After this period, treatment could be continued for another 4 months. For compliance reasons, plasma drug concentrations were measured after six weeks of treatment.

\section{Cardiologic assessments}

ECG and echocardiography were performed before treatment (maximally 2 weeks before the start) and after treatment (maximally 2 weeks after the 6-week treatment period). The measurement consisted out of heart rate, PR and QRS interval. Doppler echocardiography was used to calculate the left ventricular ejection fraction (LVEF) ${ }^{24}$. To exclude influences of SSRI on diastolic function, we recorded the mitral inflow characteristics. The velocity of the early diastolic inflow ( $\mathrm{E}$ wave) and of the atrial inflow ( $\mathrm{A}$-wave) was recorded and is presented as ratio $\mathrm{E}$ versus $\mathrm{A}(\mathrm{E} / \mathrm{A})$.

Aortic flow was measured to evaluate the effect of SSRI on cardiac output more accurately. Stroke volume is usually calculated from the aortic valve area and the aortic velocity integral. Because these parameters are related, we instead measured the aortic flow integral, or stroke distance, using CW Doppler at the apex of the left ventricle. Care was taken to achieve optimal alignment with the aorta.

\section{Statistical methods}

In the analysis summary measures were used for descriptive purposes. Paired Ttests and repeated analysis of covariance (Mancova) were used to analyse the differences before and after treatment. The data were analysed with the statistical software package (SPSS). P-value was measured two-tailed; a p-value $<0.05$ was considered to be significant. 


\section{Results}

Twenty-three consecutive patients ( 15 males and 8 females) with a depressive disorder were included. Eleven patients were assigned to the fluvoxamine and 12 to the fluoxetine group. There was no significant difference between the mean age of both groups. Seven patients had a history of cardiovascular problems: five patients had had a myocardial infarction (MI) and two were suffering from hypertension. Eleven patients had a history of depression. All patients continued the blinded treatment following the trial and 2 patients discontinued after the 6-week period because of lack of efficacy. In the latter 2 patients, both of whom received fluoxetine (which has a half-life of 1-3 days; its metabolite norfluoxetine has a half-life of $7-15$ days 25,26 ), the echocardiography was performed within 3 days after the last drug intake.

In the plasma of three patients, no drug concentration was found: these were excluded in the statistical analyses. In addition, of one patient the LVEF and AI assessments were missing. Thus, the analysis of the E/A-ratio was based on the data of 20 patients and the analysis of the two other echocardiographic variables (AI and LVEF) on the data of 19 patients. Because there were no statistically significant differences between the effects of the two SSRIs on cardiac function, we combined the data for the two patient groups. The mean systolic and diastolic blood pressures were respectively 130.5 (SD $=20.0$, range 110-189) and 82.2 (SD = 11.1, range 70-117) before treatment and 131.5 $(\mathrm{SD}=15.4$, range 110-72) and $79.9(\mathrm{SD}=9.6$, range $-65-108)$ after treatment. The mean heart rate before treatment was 65.4 ( $\mathrm{SD}=12.9$, range 45-95) and after treatment 66.5 ( $\mathrm{SD}=12.4$, range 48-95). The mean PR-interval before treatment was $153.1(\mathrm{SD}=17.8 \mathrm{~ms}$, range $114-180)$ and after treatment 153.6 $(\mathrm{SD}=18.1 \mathrm{~ms}$, range 124-198). The mean QRS-interval before treatment was $92.1(\mathrm{SD}=11.8 \mathrm{~ms}$, range 74-122) and after treatment 91.5 (SD: $12.8 \mathrm{~ms}$, range 72-118). In addition there were no differences in the echocardiographic variables before and after the treatment, as can be seen in Table 1 . The mean LVEF before treatment was $59.84(\mathrm{SD}=8.4)$ versus $60.68(\mathrm{SD}=7.6)$ after treatment; the mean $\mathrm{AI}$ was $26.38(\mathrm{SD}=2.92)$ before and $26.08(\mathrm{SD}=3.86$ ) after treatment and the mean $\mathrm{E} / \mathrm{A}$ ratio was $0.96(\mathrm{SD}=0.29)$ before and 0.88 $(\mathrm{SD}=0.22)$ after treatment. $\mathrm{AI}$ did not change significantly when corrected for heart rate before and after treatment.

The $\mathrm{AI}$ and $\mathrm{E} / \mathrm{A}$ ratio were not significantly different between the patients with a history of cardiovascular events $(n=7)$ and those without a history of cardiovascular events $(n=13)$. This is in contrast with the LVEF that improved significantly in the patients with a history of cardiovascular events comparing with the patients without such a history of cardiovascular events (Table 2). However, it must be considered that the number of patients $(n=7)$ is very low. 


\section{Table 1}

Echocardiographic variables before and after treatment.

\begin{tabular}{l|c|c|c|c}
\hline & $\begin{array}{c}\text { Before treatment } \\
\text { Mean (SD) }\end{array}$ & $\begin{array}{c}\text { After treatment } \\
\text { Mean (SD) }\end{array}$ & t-value & p-value \\
\hline LVEF & $59.84(8.40)$ & $60.68(7.60)$ & 0.82 & 0.42 \\
AI & $26.38(2.92)$ & $26.08(3.86)$ & 0.41 & 0.68 \\
E/A-ratio & $0.96(0.29)$ & $0.88(0.22)$ & 1.32 & 0.20 \\
\hline
\end{tabular}

$\mathrm{AI}$ : aortic flow integtal; E/A ratio: early or passive/late or active mitral inflow; LVEF: left ventricle ejection fraction.

\section{Table 2}

Echocardiographic variables of patients with and without a history of cardiovascular events, before and after treatment with the SSRIs.

\begin{tabular}{|c|c|c|c|c|c|}
\hline & & $\begin{array}{c}\text { Pre- } \\
\text { treatment } \\
\text { Mean (SD) }\end{array}$ & $\begin{array}{c}\text { Post- } \\
\text { treatment } \\
\text { Mean (SD) }\end{array}$ & F-value & p-value \\
\hline \multirow[t]{2}{*}{ LVEF } & Cardiol $+(n=7)$ & $51.83(9.66)$ & $55.67(10.69)$ & 4.73 & 0.04 \\
\hline & Cardiol - $(n=12)$ & $61.53(8.66)$ & $63.0(4.55)$ & & \\
\hline \multirow[t]{2}{*}{ AI } & Cardiol $+(n=7)$ & $27.67(1.41)$ & $25.97(4.61)$ & 1.80 & 0.20 \\
\hline & Cardiol - $(n=12)$ & $25.79(3.27)$ & $26.14(3.67)$ & & \\
\hline \multirow[t]{2}{*}{ E/A-ratio } & Cardiol $+(\mathbf{n}=7)$ & $1.04(0.30)$ & $0.95(0.14)$ & 0.00 & 0.97 \\
\hline & Cardiol - $(\mathrm{n}=13)$ & $0.93(0.29)$ & $0.86(0.25)$ & & \\
\hline
\end{tabular}

Cardiol $+=$ Patients with a history of cardiovascular events.

Cardiol - = Patients without a history of cardiovascular events.

$\mathrm{AI}$ : aortic flow integral: $\mathrm{E} / \mathrm{A}$ ratio: early or passive/late or active mitral inflow; LVEF: left ventricle cjection fraction.

\section{Discussion}

Literature shows that both fluoxetine and fluvoxamine have no cardiovascular side effects, but studies which report cardiac safety in older patients, who are at risk for having depression and/or cardiovascular disease, are scarce, as are studies, which measure cardiac function in a direct way. The present study investigated specific aspects of cardiac function directly in middle-aged and elderly patients being treated with an SSRI for depression. The results confirmed our a priori hypothesis that SSRIs do not have a deleterious effect on cardiac function. There were no differences in blood pressure or ECG assessments or between LVEF, AI and E/A-ratio before and after treatment with SSRIs. AI was not significantly affected, indicating that there was no 
substantial effect on cardiac output in combination with any significant effect of heart rate. Mitral inflow pattern did not show effects on diastolic function. The $\mathrm{E} / \mathrm{A}$ ratio normally gradually decreases with age from more than 2 to 1 in the elderly. If there were substantial changes in E/A ratio, these could indicate that diastolic function is influenced by the SSRI. Because we did not found these decreases, diastolic function was not affected.

Antidepressant efficacy could not be associated with improved cardiac function, because there was no difference in cardiac function between the successfully and less successfully treated patients. In contrast, Fernandez et al. reported that patients in which decreased heart function leads to overlapping somatic symptoms of depression, increasing of the somatic disease leads to decrease of depressive symptoms ${ }^{27}$. What we did find was that patients with a history of cardiovascular diseases had an increase in their LVEF, in contrast to patients without a cardiovascular disease. One has to consider, however, that the patient sample we used was very small as was the number of patients with cardiovascular disease. Further echocardiographic studies of larger numbers of middle-aged and elderly subjects with somatic disease are needed and in progress to further confirm the cardiac safety of SSRIs. But in summary we can say that in our study population of older patients, in whom cardiac function was assessed by direct measurement in stead of only by ECG, both fluoxetine and fluvoxamine are safe antidepressive agents.

\section{References}

1. Glassman AH, Stage KB. Depressed patients with cardiovascular disease: treatment considerations. CNS Drugs 1994;1:435-40.

2. Hale AS. New antidepressants: use in high-risk patients. J Clin Psychiatry 1993;54:61-70.

3. Benfield P, Heel R. Fluoxetine: A review of its pharmacodynamic and pharmacokinetic properties and therapeutic efficacy in depressive illness. Drugs $1986 ; 32: 481-508$.

4. Benficld P, Ward A. Fluvoxamine: A review of its pharmacodynamic and pharmacokinetic properties and therapeutic efficacy in depressive illness. Drugs 1986;32:313-34.

5. Mendlewicz J. Efficacy of fluvoxamine in severe depression. Drugs 1992;43:32-9.

6. Menting JEA, Honig A, Verhey FRJ, et al. Selective serotonin reuptake inhibitors (SSRIs) in the treatment of elderly depressed patients: a qualitative analysis of the literature on their efficacy and side-effects. Int Clin Psychopharm 1996;11:165-75.

7. Roose SP, Glassman AH. Antidepressant choice in the patient with cardiac disease: Lessons from the Cardiac Arrhythmia Suppression Trial (CAST) Studies. J Clin Psychiatry 1994;55:83-9.

8. Hussein S, Kaufman BM. Bradycardia associated with fluoxetine in an elderly patient with sick sinus syndrome. Postgrad Med J 1994;56:819.

9. Ahmed I, Dagincourt PG, Miller LG, Shader RI. Possible interaction between fluoxetine and pimozide causing sinus bradycardia. Can J Psychiatry 1994;38:62-3. 
10. Ellison JM, Milofsky JE, Ely E. Fluoxetine-induced bradycardia and syncope in two patients. J Clin Psychiatry 1990;51:385-6.

11. Feder R. Bradycardia and syncope induced by fluoxetine. J Clin Psychiatry 1991;52:139.

12. Laird LK, Lydiard RB, Morton WA, et al. Cardiovascular effects of imipramine, fluvoxamine and placebo in depressed outpatients. J Clin Psychiatry 1993;54:224-8.

13. Buff DD, Brenner R, Kirtane SS, Gilboa R. Dysrhythmia associated with fluoxetine treatment in an elderly patient with cardiac disease. J Clin Psychiatry 1991;52:174-6.

14. Fisch C. Effect of fluoxetine on the electrocardiogram. J Clin Psychiatry 1985;30:457.

15. Drake WM, Gordon GD. Heart block in a patient on propanolol and fluoxetine. Lancet 1994;343:425-6.

16. Konig F, Hafele M, Loble B, Wossner M, Wolfersdorf M. Bradycardia after beginning therapy with metoprolol and paroxetine. Psychiatr Prax 1996;23:244-5.

17. Upward JW, Edwards JG, Goldie A. Comparetive effects of fluoxetine and amytriptiline on cardiac function. Br J Clin Pharmacol 1988;26:399-402.

18. Baker B, Dorian P, Sandor P, et al. Elektrocardiographic effects of fluoxetine and doxepin in patients with major depressive disorder. J Clin Psychopharmacol 1997;17:15-21.

19. Roose SP, Laghrissi-Thode F, Kennedy JS, et al. Comparison of paroxetine and nortriptyline in depressed patients with ischemic heart disease. JAMA 1998;279:28791.

20. Roose SP, Glassman AH, Attia E, Woodring S, Giardina E-GV, Bigger T. Cardiovascular effects of fluoxetine in depressed patients with heart disease. Am J Psychiatry 1998;155:660-5.

21. Oradell NJ. Physicians desk reference. In: Medical Economics Company 1990: 9058.

22. Feighner JP, Cohn JB. Double blind comparative trials of fluoxetine and dopexin in geriatric patients with major depressive disorder. J Clin Psychiatry 1985;46:20-5.

23. Hamilton M. A rating scale for depression. J Neurol Neurosurg Psychiatry 1960;23:56-62.

24. Schiller NB, Shah PM, Crawford M, et al. Recommendations for quantitation of the left ventricle by two-dimensional echocardiography. J Am Soc Echocardiography 1989;5:358-67.

25. Lemberger L, Bergstrom RF, Wolen RL, Farid NA, Enas GG, Aronoff GR. Fluoxetine: clinical pharmacology and physiologic disposition. J Clin Psychiatry $1985 ; 46: 14-9$.

26. Altamura AC, Moro AR, Percudani. Clinical Pharmacokinetics of fluoxetine. Clin Pharmacokin 1994;26:201-14.

27. Fernandez F. Depression and its treatment in cardiac patients. Tex Heart Inst J 1993;20:188-97. 


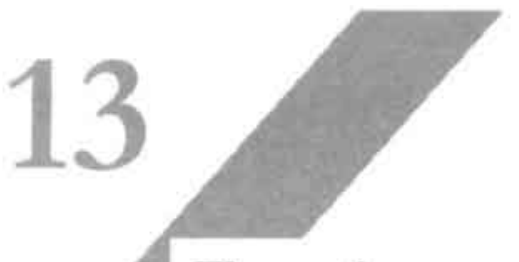

Fluoxetine and effect on cognitive performance in depressed patients post myocardial infarction 


\begin{abstract}
As depression is a considerable risk factor for an unfavourable course of myocardial infarction (MI), treatment of post-MI depression and thereby polypharmacy, related to cardiac disease, has become an important issue. The present study is the first to evaluate cognitive side-effects of fluoxetine as part of a placebo-controlled, double-blind trial. Cognitive performance of 54 depressed patients post-first-MI, treated with fluoxetine $(n=27)$ or placebo ( $n$ $=27$ ), was compared. Duration of treatment was 9 weeks, maximum dose of fluoxetine was $60 \mathrm{mg}$. Cognitive performance was tested before start of treatment and after 9 weeks using the Visual-Verbal-Learning Test, ConceptShifting-Task, Stroop-Colour-Word Test, and Letter-Digit-Substitution Test. There were no differences in cognitive performance between the fluoxetine and placebo group. Fluoxetine has no negative influence on cognitive performance in depression post-MI.
\end{abstract}

\title{
Reference
}

Strik JJMH, Honig A, Klinkenberg E, Dijkstra J, Jolles J. Fluoxetine and effect on cognitive performance in depressed patients post myocardial infarction. Psychosomatics 2003; Submitted. 


\section{Introduction}

Depression is a frequent co-morbid condition of myocardial infarction (MI), increasing morbidity and mortality in the first 18 months post-MI ${ }^{1-4}$, It may be important to treat depressed MI patients, although it is as yet unclear whether treatment of post-MI depression, apart from improving quality of life, increases cardiac prognosis ${ }^{5}$. The selective serotonergic reuptake inhibitors (SSRIs) seem to be first choice of pharmacological antidepressive treatment because of less cardiotoxic side effects compared to tricyclics ${ }^{67}$.

Uptill now cognitive side effects of SSRIs have not been evaluated in depressed MI patients. It is important to evaluate cognitive side effects in depressed MI patients. First, the majority of depressed patients are treated as outpatients and are expected to continue their professional life and normal everyday routine 8 . It thus becomes necessary that antidepressive therapy minimally impair cognitive function. Second, treatment compliance can be endangered if patients experience memory disturbances or psychomotor side effects in a situation where they have to take daily doses of different cardiac medications. Third, cardiac drugs may also be psychoactive and interact with antidepressive therapy. The question of the cognitive effects of administration of antidepressants in combination with other psychoactive drugs has as yet not been addressed ${ }^{8}$.

Most studies evaluating cognitive side effects of SSRIs are performed with a single dose administration in healthy volunteers ${ }^{8}$. In this healthy population, SSRIs such as fluoxetine, fluvoxamine and sertraline had no effect on arousal and reactivity, car driving and sensorimotor performance, and interference susceptibility $9-11$. In a population-based sample of 1,488 adult's tricyclic antidepressants did not cause any measurable cognitive deficits ${ }^{12}$. Very few studies investigated cognitive side effects of SSRIs in depressed patients. A one-month administration of fluvoxamine did not impair memory assessed by a word decision test ${ }^{13}$. In elderly depressed patients fluoxetine $20 \mathrm{mg}$ showed no impairment of cognition compared to $75 \mathrm{mg}$ of amitryptiline in a double-blind trial ${ }^{14}$. In 242 elderly depressed patients treated with paroxetine or fluoxetine no deterioration of cognition was observed ${ }^{15}$.

In the present study we evaluated cognitive side effects of a SSRI, fluoxetine, in depressed first-MI patients, treated with cardiac co-medication, as part of a double-blind, placebo-controlled trial of the efficacy and safety of fluoxetine in post-MI depression 7. Care was taken to use neurocognitive tests with proven sensitivity for use in neuropsychiatric patients 16,17 and in drug-evaluation studies ${ }^{18}$. Thus, memory-related processes were assessed, including attention and speed of information processing. 


\section{Methods}

All consecutive admissions to the first heart aid of the Maastricht University Hospital and an affiliated hospital within a 3 year period were selected. Patients with first time MI, diagnosed by a cardiologist, were included. Inclusion criteria were age between 18-75 years, clinical picture typical of MI, ECG changes specific for $\mathrm{MI}$, and a maximum plasma concentration of aspartate aminotransferase $\left(A_{S A T} T_{\max }\right)$ twice the upper normal range $(80 \mathrm{U} / \mathrm{L}){ }^{19}$. The number of eligible patients was 556; 357 patients agreed to participate and 199 $(35 \%)$ patients refused to participate. Of these 357 patients 4 died between 1 and 3 months post-MI and 68 met the DSM-III-R criteria for major depression within the first 12 months post-MI.

\section{Intervention}

Before inclusion in the study, possible side effects of fluoxetine were explained to the patients and written informed consent was obtained. Fluoxetine was studied according to a randomized, placebo-controlled, double blind design. The antidepressant was prescribed for a treatment period of 9 weeks. Patients were randomly assigned to either fluoxetine $20 \mathrm{mg} / \mathrm{d}$ or placebo. This dose could be increased to $40 \mathrm{mg} / \mathrm{d}$ in week 3 and to $60 \mathrm{mg} / \mathrm{d}$ in week 6 , depending on clinical response $\{<50 \%$ decrease of the score on the 17 -item Hamilton Depression Rating Scale (HAMD-17) ${ }^{20}$.

\section{Data collection}

Age and education were collected at baseline. Cognitive function tests were assessed at baseline and after 9 weeks of treatment.

Visual Verbal Learning Test (VTLT) 21,22: A visual version of the Auditory Verbal Learning Test ${ }^{23}$ was used. In the Netherlands this is the most used memory test and its psychometric properties are quite similar to the California Verbal Learning Test ${ }^{23}$ and the Auditory-Verbal learning Test (AVLT) ${ }^{23,24}$ with the exception that the words are presented visually in order to control for hearing loss. In this Dutch version, a set of 15 frequently used monosyllabic meaningful words is presented in a fixed order at a rate of one every two seconds in three consecutive trials. After each trial the patient is required to recall as many words as possible with no restriction concerning the order of the recalled words. The dependent variable is the total number of words recalled over the three trials (VVLTtot). Twenty minutes after the last presentation the patient is again requested to recall as many words as he or she can remember (VVLTdel). This test measures memory storage and retrieval of verbal information in episodic memory.

Concept Shifting Task (CST) 23,25: This test is derived from the Trail Making Test, which is used to measure the ease of shifting between different sets of attention 
26. The advantage above the Trail Making Test is that the effect of motor function is limited, so that the influence of simple motor speed on test performance is controlled for. It consists of four test sheets, that each contains 16 small circles grouped in a larger circle. On the first test sheet empty circles have to be crossed out as fast as possible (CST0). On the other three test sheets the circles contain numbers (CSTA), letters (CSTB), or both (CSTC), appearing in a fixed random order. Patients are requested to cross out the items in the right order. The dependent variable is the time needed for each part ${ }^{25}$.

Stroop Colour-Word test (SCWT) ${ }^{23}$ : The SCWT tests selective attention and interference susceptibility. The test is made out of three cards displaying 40 stimuli each, i.e. colour names (SCWT1), coloured patches (SCWT2) and colour names printed in incongruously coloured ink (SCWT3). For the last card (SCWT3), the colour of the ink has to be named instead of the colour name. This task is sensitive to interference. The dependent variables are the seconds needed to complete each task.

Letter-Digit Substitution Test (LDST) 23,25: This test is a modification of the Symbol-Digit-Modalities Test. The patients are supplied with a code at the top of the page where a digit corresponds to a letter. Then they have 60 seconds to fill in blanks with corresponds to the corrected codes. This test measures the speed of processing general information obtained by visual perception, attention and memory. The dependent variable is the total number of letters written correctly within the one minute (LDSTtot).

These cognitive tests assess the following theoretical underlying cognitive constructs: memory (VVLTtot, VVLTdel) and attention related aspects such as cognitive flexibility (ability to shift between the two sequences; CSTC), interference susceptibility (ability to ward off distractions, SCWT2), sensorimotor speed (simple cognitive speed; CST0, CSTA, CSTB, SCWT1 and 2 ), and speed of general informating processing (LDSTtot) ${ }^{27}$.

Depression measured by HAMD-17 was assessed at baseline and after 9 weeks of treatment. Blood samples were collected for fluoxetine and norfluoxetine plasma concentrations after 3,6 and 9 weeks of treatment.

\section{Analyses}

Statistical analyses were carried out using SPSS $6.0 \mathrm{~W}$ indows software ${ }^{28}$. Since the study described in our manuscript is part of a double-blind placebocontrolled study of the efficacy of fluoxetine in depressed post-MI patients, the power calculations were a-priori based on depression efficacy measures. The power calculation on the depression outcome is published in Strik et al. ?. For the presence study the required sample size was estimated using the guidelines described by Knapp and Miller ${ }^{29}$. In case of the absence of previous cognitive outcome data in depressed post-MI patients, we used data of normal controls 
25. Effect size of cognitive tests was estimated by choosing one standard deviation of a healthy male and female population, aged between 53 and 62 year, with a medium education level. If, furthermore, the level of significance alpha is set on 0.05 , the power beta is set at 0.95 and the cognition hypothesis is tested one tailed, the required sample size is 46 ( 23 per group).

For the outcome on the cognitive tests, ANCOVA was applied using endpoint scores of the cognitive test battery as the dependent variable and baseline scores of cognition, age, gender, education, and HAMD-17 difference between baseline and week 9 as co-variats. A two-tailed p-value $\leq 0.05$ was considered to be significant. Patients were only included in the analyses if they had assessment data at baseline and week 9 .

\section{Results}

\section{Patients}

Of the 68 patients diagnosed with major depression, 12 refused to participate at a later stage and 2 were excluded due to heart failure. The non-participants did not differ from the included patients with regard to age, gender and ASAT max. Fifty-four patients were included in the study, of whom 31 were diagnosed with major depressive episode at 3 months, 17 at 6 months and 6 at 12 months postMI. Fifty-four patients were randomised to fluoxetine $(n=27)$ or placebo $(n=$ 27). There were 38 males and 16 females. Mean age was 54.1 years $(S D=11.3$ ) in the fluoxetine and 58.7 years $(\mathrm{SD}=10.1)$ in the placebo group; mean education level was $2.8(\mathrm{SD}=2.2)$ on an 8-point scale 30 in the fluoxetine group and $3.0(\mathrm{SD}=2.1)$ in the placebo group; and mean HAMD-17 score was $22(\mathrm{SD}=3.5)$ in the fluoxetine and $21.2(\mathrm{SD}=3.7)$ in the placebo group. There were no statistically significant differences between fluoxetine and placebo groups with regard to age, gender, education or severity of depression (using HAMD-17 scale) (Table 1).

In the acute phase, 2 patients dropped out from the fluoxetine group and 5 from the placebo group due to lack of effect, loss to follow-up, or medical reasons. The HAMD-17 score decreased significantly in both groups: efficacy and cardiac safety of fluoxetine in this patient group is discussed elsewhere ? Overall, the a-priori difference in antidepressive efficacy between fluoxetine and placebo treatment of 4 points on the HAMD-17 score was not met. However, there were significantly more responders during fluoxetine treatment than during placebo treatment at week 25 . Furthermore, compared to placebo, fluoxetine was especially effective with reference to HAMD-17 score of patients diagnosed with mild depression. 


\section{Table 1}

Baseline characteristics of depressed MI patients, treated with fluoxetine or placebo.

\begin{tabular}{l|c|c|c|c|c}
\hline Variable & $\begin{array}{c}\text { Fluoxetine } \\
(\mathbf{n}=27)\end{array}$ & $\begin{array}{c}\text { Placebo } \\
(\mathbf{n}=27)\end{array}$ & Chi & df & p-value \\
\hline Gender & $\mathrm{M}=21 ; \mathrm{F}=6$ & $\mathrm{M}=17 ; \mathrm{F}=10$ & 1.24 & 1 & 0.23 \\
Age (years) & $54.1(\mathrm{SD}=11.3)$ & $58.7(\mathrm{SD}=10.1)$ & 1.76 & 3 & 0.62 \\
Education (8-point scale) & $2.8(\mathrm{SD}=2.2)$ & $3.0(\mathrm{SD}=2.1)$ & 0.68 & 2 & 0.71 \\
HAMD-17 score & $22.6(\mathrm{SD}=3.2)$ & $21.0(\mathrm{SD}=2.2)$ & 2.39 & 3 & 0.50 \\
\hline
\end{tabular}

Data represent means \pm SD. P-value is two-tailed. HAMD-17: Hamilton depression rating scale; MI: myocardial infarction.

\section{Medication}

All patients taking fluoxetine had repeated fluoxetine plasma levels $>4 \mathrm{mg} / \mathrm{L}$. The mean fluoxetine dose was $47.3 \mathrm{mg} / \mathrm{d}(\mathrm{SD}=19.1)$. Co-medication consisted of aspirin $(n=42,77.8 \%)$, lipophilic beta-blockers $(n=33,61.1 \%)$, benzodiazepines ( $\mathrm{n}=28,51.9 \%$ ), isosorbide nitrate $(\mathrm{n}=23,42.6 \%)$, cholesterol lowering medication $(\mathrm{n}=22,40.7 \%)$, ACE inhibitors $(\mathrm{n}=16$, $29.6 \%)$, calcium channel blockers $(\mathrm{n}=15,27.8 \%)$, diuretics $(\mathrm{n}=13,24.1 \%)$, anti-coagulation agents $(n=6,11.1 \%)$ and hydrophilic beta-blockers $(n=5$, 9.3). The median number of cardiovascular drugs taken was 4.9, ranging from 1 to 9, excluding trial medication. There were no significant differences in specific drugs between groups. All patients were antidepressant and antipsychotic drug free prior to starting the study.

\section{Cognitive performance}

In Table 2 the mean scores at baseline of the cognitive tests are summarised for the two groups. Because of missing data, the number of patients is different for each test. There were no differences in mean scores of the different tests of the cognitive battery at baseline and week 9. Also after correction for several confounders, i.e. gender, age, education, difference in HAMD-17 between baseline and week 9, and test performance at baseline, end points of the mean cognitive tests scores, i.e. VVLT (Memory storage and retrieval), CST (ease of shifting between different sets of attention), SWT (selective attention and interference susceptibility) and LDST (speed of processing general information obtained by visual perception, memory and attention) were not statistically significant different (Table 3). 


\section{Table 2}

Mean scores of cognitive performance of 54 patients with post-MI depression treated with fluoxetine or placebo at baseline.

\begin{tabular}{l|c|c|c}
\hline Test & $\begin{array}{c}\text { Placebo } \\
\text { Mean (SD) (n) }\end{array}$ & $\begin{array}{c}\text { Fluoxetine } \\
\text { Mean (SD) (range)(n) }\end{array}$ & p-value \\
\hline VVLTtot (n) & $27.8(1.09)(17-39)(20)$ & $25.6(1.09)(16-43)(20)$ & 0.25 \\
VVLTdel (n) & $9.34(0.34)(3-14)(20)$ & $8.66(0.34)(2-14)(20)$ & 0.92 \\
CST0 (sec) & $6.61(0.26)(3.83-19.0)(16)$ & $7.11(0.24)(3.80-12.1)(17)$ & 0.41 \\
CSTA (sec) & $23.3(0.49)(15.2-46.5)(16)$ & $24.2(0.46)(13.3-43.5)(17)$ & 0.63 \\
CSTB (sec) & $27.1(1.47)(17.2-79.5)(16)$ & $30.0(1.47)(17.9-66)(17)$ & 0.15 \\
CSTC $(\mathrm{sec})$ & $44.4(1.36)(20.2-82.1)(15)$ & $41.7(1.28)(19.6-91.5)(17)$ & 0.73 \\
SCWT1 (sec) & $18.2(0.03)(13.5-37.6)(20)$ & $18.1(0.03)(13.6-24.3)(21)$ & 0.94 \\
SCWT2 (sec) & $23.1(0.07)(15.5-38.0)(20)$ & $23.3(0.07)(16.3-32.5)(21)$ & 0.89 \\
SCWT3 (sec) & $40.8(0.18)(21.8-122)(20)$ & $40.4(0.17)(23.3-134)(21)$ & 0.92 \\
LDSTtot (sec) & $29.3(0.17)(11-44)(18)$ & $29.0(0.16)(17-42)(20)$ & 0.74 \\
\hline
\end{tabular}

Data represent means \pm SD. VVLTtot: total score of the Visual Verbal Learning Test; VVLTdel: delayed recall of the Visual Verbal Learning Test; CST: Concept Shifting Task ; SCWT: Stroop Colour-Word Test; LDST: Letter-Digit Substitution Test; MI: myocardial infarction.

\section{Discussion}

The present study is the first to investigate cognitive side effects of fluoxetine in a double blind, placebo-controlled design in patients with major depression after first MI. We found that there were no differences in cognitive performance between depressed MI patients treated with fluoxetine compared to those treated with placebo.

In literature fluoxetine was already reported to have no negative or sedative side effects ${ }^{8}$. However, cognitive side effects of fluoxetine were mainly tested in young, healthy volunteers in a single dose administration ${ }^{8}$. There is one study in which cognitive effects of fluoxetine were evaluated in elderly depressed patients and compared with paroxetine using the Mini Mental State examination and The Sandoz Clinical Assessment Geriatric scale (SCAG) ${ }^{31}$, which may be less sensitive than the neurocognitive test battery, measuring memory, speed and cognitive flexibility, used in our study 16,18 . 


\section{Table 3}

The effect of treatment with fluoxetine versus placebo.

\begin{tabular}{l|c|c|c}
\hline \multirow{2}{*}{ Measure } & \multicolumn{3}{|c}{ Effect of treatment* } \\
\cline { 2 - 4 } & F & df & p-value \\
\hline VVLTtot (n) & 0.57 & 1 & 0.46 \\
VVLTdel (n) & 0.98 & 1 & 0.33 \\
CST0 (sec) & 1.27 & 1 & 0.27 \\
CSTA (sec) & 0.69 & 1 & 0.41 \\
CSTB (sec) & 1.02 & 1 & 0.32 \\
CSTC (sec) & 1.54 & 1 & 0.23 \\
SCWT1 (sec) & 0.001 & 1 & 0.98 \\
SCWT2 (sec) & 0.01 & 1 & 0.91 \\
SCWT3 (sec) & 0.003 & 1 & 0.96 \\
LDSTtot (sec) & 0.20 & 1 & 0.66 \\
\hline
\end{tabular}

* Baseline measures versus week 9. VVLTtot: total score of the Visual Verbal Learning Test; VVLTdel: delayed recall of the Visual Verbal Learning Test; CST: Concept Shifting Task : SCWT: Stroop Colour-Word Test; LDST: Letter-Digit Substitution Test.

This study found that both fluoxetine and paroxetine improved cognitive function. Another study by Nebes et al., who evaluated toxicity of paroxetine in 29 older depressed patients, found that acute treatment with paroxetine was not associated with any cognitive impairment ${ }^{32}$. Patient's performance improved on several timed tasks, but memory performance remained unchanged, as in our study.

No studies of fluoxetine have been performed in patients with MI, treated for several weeks. Our study was the first to evaluate cognitive side effects of fluoxetine in depressed patients aged $37-75$ years, with $50 \%$ of this patient sample being 55 years and older, with a frequently occurring somatic illness being MI and treated for 9 weeks with placebo or fluoxetine up to $60 \mathrm{mg} /$ day. An additional strength of our study is that we used a neurocognitive test battery, which has been used extensively in neuropsychiatric patients and in drug studies ${ }^{16.18}$. This test battery is very sensitive to subtle cognitive changes, and consists of parallel versions, which enables repeated testing with a great sensitivity. Earlier studies were often hampered by a lack of sensitive tests in parallel versions.

Second, our patient sample was also taking a mean number of 4.9 cardiac drugs per day. One has to consider the role of psychoactive effect of this medication. 
It is very difficult to analyse the separate contribution of each individual substance and their interactions on its influence on cognitive performance. However, there were no statistically significant or clinically relevant differences in the number of cardiac medication in both groups. The only drug that was different was the trial medication fluoxetine/placebo, but this did not lead to difference in cognitive performance (Table 2).

A remarkable finding in our study was that baseline cognition of the depressed MI patients was not different from general baseline cognition in non-depressed MI patients ${ }^{33}$ or healthy controls (matched for gender, age and education) ${ }^{25}$. Hence, it is unlikely that cognitive functioning will further improve during treatment. Data on the interaction between treatment and pre-existing cognitive functioning are inconsistent 32 . One study showed that cognitively intact patients showed an improvement in performance following treatment with nortryptiline ${ }^{34}$, while others did not found an association between treatment outcome and cognitive function at baseline ${ }^{35}$.

One explanation of this surprising finding of cognitive functioning at baseline might be that the underlying cause of depression post-MI differs from that of non-cardiac related depression. The symptomatology of MI depression is atypical ${ }^{3}$. Depressed MI patients are more hostile and anxious than patients with non-cardiac related depression ${ }^{3}$. Increased hostility and anxiety might be a "pacemaker" of a discrete type of depression called anxiety/aggression driven serotonin related depression, which may be hypothesised to have a different pathogenesis to non-cardiac related depression ${ }^{36,37}$. It is possible that in this subtype of depression there is no decline in memory function ${ }^{33}$.

A second explanation might be the role of personality factors. Personality and coronary artery disease (CAD) are suggested to be related in MI patients ${ }^{38}$. More recently, type-D personality (tendency to suppress emotional distress) was a significant predictor of long-term mortality in patients with established CAD ${ }^{39}$. Gold and Arbuckle reviewed also that there might be interactions between personality and cognition as high neuroticism improves reaction time, but decreases other cognitive abilities to. The involvement of personality characteristics was not studied in our sample.

In sum, there were no negative side effects of fluoxetine on cognition in depressed MI patients compared to placebo. Future research should address the effects of subtypes of depression and personality characteristics on cognitive performance.

\section{References}

1. Frasure-Smith N, Lespérance F, Talajic M. Depression following myocardial infarction: impact on 6-months survival. JAMA 1993;270:999-1005.

2. Forrester AW, Lipsey JR, Teitelbaum ML, DePaulo JR, Andrzejeweski PL. Depression following myocardial infarction. Int J Psychiatry Med 1992;22:33-46. 
3. Honig A, Lousberg R, Wojchiechowski F, Cheriex EC, Wellens H, Van Praag HM. Depression following a first heart infarct; similarities with and difference from 'ordinary' depression. Ned Tijdschr Geneeskunde 1997;141:196-9.

4. Roose SP, Dalack GW, Woodring S. Death, Depression and Heart Disease. 1991;52:34-9.

5. Carney RM, Freedland $\mathrm{KE}$, Veith RC, Jaffe AS. Can treating depression reduce mortality after an acute myocardial infarction? Psychosom Med 1999;61;666-75.

6. Menting JEA, Honig A, Verhey FRJ, et al. Selective serotonin reuptake inhibitors (SSRIs) in the treatment of elderly depressed patients: a qualitative analysis of the literature on their efficacy and side-effects. Int Clin Psychopharm 1996;11:165-75.

7. Strik JJMH, Honig A, Lousberg R, et al. Efficacy and safety of fluoxetine in the treatment of patients with major depression following first myocardial infarction: findings from a double-blind placebo-controlled trial. Psychosom Med 2000;62:7839.

8. Amado-Boccara I, Gougoulis N, Poirier Littre MF, Galinowski A, Loo H. Effects of antidepressants on cognitive functions: a review. Neurosci Biobehav Rev 1995;19:479-93.

9. Hindmarch I. A pharmacological profile of fluoxetine and other antidepressants on aspects of skilled performance and car handling ability. $\mathrm{Br}$ J Psychiatry Suppl 1988:99-104.

10. Hindmarch I, Kerr J. behavioural toxicity of antidepressants with particular reference to moclobemide. Psychopharmacology 1992;106:S49-S55.

11. Hindmarch I, Bhatti JZ. Psychopharmacological effects of sertraline in normal, healthy volunteers. Eur J Clin Pharmacol 1988;35:221-3.

12. Podewils LJ, Lyketsos CG. Tricyclic antidepressants and cognitive decline. Psychosom 2002;43:31-5.

13. Lamping DL, Spring B, Gelenberg AJ. Effects of two antidepressants on memory performance in depressed outpatients: a double-blind study. Psychopharmacology 1984;84:254-61.

14. Fairweather DB, Kerr JS, Harisson DA, Moon CA, Hindmarch I. A double-blind comparison of the effects of fluoxitine and amitripyline on cognitive function in elderly depressed patients. Hum Psychopharmacology 1993;8:41-7.

15. Cassano GB, Puca F, Scapicchio PL, Trabucchi M. Paroxetine and fluoxetine effects on mood and cognitive functions in depressed nondemented elderly patients. J Clin Psychiatry 2002;63:396-402.

16. Krabbendam L, Derix MM, Honig A, et al. Cognitive performance in relation to MRI temporal lobe volume in schizophrenic patients and healthy control subjects. J Neuropsychiatry Clin Neurosci 2000;12:251-6.

17. Visser PJ, Verhey FR, Ponds RW, Kester A, Jolles J. Distinction between preclinical Alzheimer's disease and depression. J Am Geriatr Soc 2000;48:479-84.

18. Moller JT, Cluitmans P, Rasmussen LS, et al. Long-term postoperative cognitive dysfunction in the elderly: ISPOCD1 study (International Study of Post-Operative Cognitive Dysfunction) [published erratum appears in Lancet 1998 Jun 6;351(9117):1742]. Lancet 1998;351:857-61.

19. Pasternak RC, Braunwald E, Sobel RE. Acute myocardial infarction. In: Braunwald E, ed. Heart disease: a textbook of cardiovascular medicine. 4th edition ed. Philadelphia: WB Saunders Compagny, 1992:1200-91.

20. Hamilton M. A rating scale for depression. J Neurol Neurosurg Psychiatry $1960 ; 23: 56-62$. 
21. Brand N, Jolles J. Learning and retrieval rate of words presented auditorily and visually. J Gen Psychol 1985;112:201-10.

22. Riedel WJ, Klaassen T, Honig A, van Praag HM. 5-HT challenge and cognition in major depression and healthy control subjects. J Psychopharmacol 1998;12 (3A):16.

23. Lezak MD. Neuropsychologiocal Assessment. third ed. New York: Oxford University Press, 1995.

24. Taylor CB, Miller NH, Smith PM. Prevention of depression and anxiety in patients with cardiovascular disease. I Prev Interv Com 1996;13:53-69.

25. Jolles J, Houx PJ, Van Boxtel MPJ, Ponds RWMH. The Maastricht Aging Study: determinants of cognitive aging. Maastricht, The Netherlands: Neuropsych. Publishers, 1995.

26. Reitan RM. Validity of the Trail Making Test as an indication of organic brain damage. Percept motor skills 1958;8:271-6.

27. Dijkstra JB, Houx PJ, Jolles J. Cognition after major surgery in the elderly: test performance and complaints. Br J Anaesth 1999;82:867-74.

28. Norusis MJ. SPSS for Windows 6.0. Chicago: SPSS Inc, 1993.

29. Knapp RG, Miller MC. Clinical epidemiology and biostatistics. Baltimore: Williams and Wilkins, 1992.

30. De Bie SE. Standard questions 1987: Proposal for uniformisation of questions regarding background variables and interviews. Second ed. Leiden, the Netherlands: Leiden University Press, 1987.

31. Geretsegger C, Bohmer F, Ludwig M. Paroxetine in the elderly depressed patient: randomized comparison with fluoxerine of efficacy, cognitive and behavioural effects. Int Clin Psychopharmacol 1994;9:25-9.

32. Nebes RD, Pollock BG, Mulsant BH, Butters MA, Zmuda MD, Reynolds CF, 3rd. Cognitive effects of paroxetine in older depressed patients. J Clin Psychiatry 1999;60:26-9.

33. Dijkstra JB, Strik JJMH, Honig A; et al. Atypical cognitive profile in patients with depression after myocardial infarction. J Aff Dis 2002;70:181-90.

34. Young RC, Mattis S, Alexopoulos GS, Meyers BS, Shindledecker RD, Dhar AK. Verbal memory and plasma drug concentrations in elderly depressives treated with nortriptyline. Psychopharmacol Bull 1991;27:291-4.

35. Teri L, Reifler BV, Veith RC, et al. Imipramine in the treatment of depressed Alzheimer's patients: impact on cognition. J Gerontol 1991;46:P372-7.

36. Van Praag HM. 5-HT-related, anxiety-and/or aggression-driven depression. Int Clin Psychopharmacol 1994;9:5-6.

37. Van Praag HM. Faulty cortisol/serotonin interplay. Psychopathological and biological characterisation of a new, hypothetical depression subtype (SeCa depression). Psychiatry-Res 1996;65:143-57.

38. Dimsdale JE. A perspective on type A behavior and coronary disease [editorial]. $\mathrm{N}$ Engl J Med 1988;318:110-2.

39. Denollet J, Sys SU, Stroobant N, Rombouts H, Gillebert TC, Brutsaert DL. Personality as independent predictor of long-term mortality in patients with coronary heart disease. Lancet 1996;347:417-21.

40. Gold DP, Arbuckle TY. Interactions between personality and cognition and their implications for theories of aging. In: Lovelace EA, ed. Aging and cognition: Mental processes of self awareness and interventions. Amsterdam: Elsevier Science Publisher, 1990:351-77. 


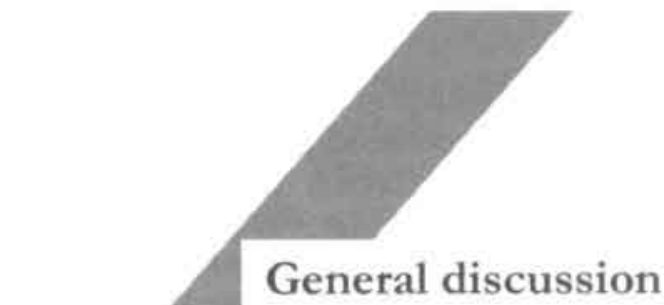




\section{Abstract}

In these studies patients with first myocardial infarction (MI) were selected for studies focusing on epidemiology, aetiology, phenomenology, risk factors and treatment of depression post-MI. Two consecutive cohorts of first MI patients were included. The first cohort was selected between May 1994 and May 1997 $(n=206)$, and the second between May 1997 and September $1999(n=206)$. All patients were screened every 3 months for depression using the 90 -item Symptom Check List (SCL-90) and the Zung Self Depression Rating Scale (cohort 1) or SCL-90, BDI and HADS (cohort 2) until 12 months post-MI. Patients scoring above the cut-off of one of the questionnaires were interviewed using a standardised interview in order to evaluate whether DSMIV criteria for major and minor depression were met; patients of the second cohort were also interviewed 1 month post-MI. Of all patients of the first and second cohort, data concerning major cardiac events and increased health care consumption were assessed during a 1 to 6 years follow-up period. Patients with major depression were offered treatment in the double-blind placebocontrolled trial with fluoxetine $(n=54)$. Depression is a predictor of increased health care consumption but not of major cardiac events such as cardiac death and recurrent infarction in first MI patients up to 6 years post-MI. This finding is in contrast to findings in the literature indicating that in patient populations with mixed first and recurrent MI, depression is a risk factor for cardiac mortality. In contrast to depression, symptoms of anxiety do predict cardiac mortality and recurrent $\mathrm{MI}$ in patients following first MI.

Recognition of risk factors for post-MI depression may help the cardiologist to identify patients at risk for depression. Examples of such risk factors are, according to our studies, complications during admission, such as arrhythmic disorders and recurrent angina pectoris, and prescription of benzodiazepines, Patients at risk can be screened for depression using a 4-item questionnaire, and, if scoring is positive, be referred for psychiatric evaluation.

Although the effectivity of antidepressive treatment in MI patients has as yet not been proven, we found that fluoxetine is a cardiac-safe antidepressive agent, but only in mild depression more effective than placebo. The positive effect of antidepressive treatment on cardiac prognosis has as yet not been shown.

\section{Reference}

Strik JJMH, van Praag HM, Honig A. Depression following myocardial infarction: a prospective study of incidence, prognosis, risk factors and treatment. (Depressie na een eerste hartinfarct: een prospectieve studie naar incidentie, prognose, risicofactoren en behandeling). Ned Tijdschr Geront Geriatr 2003: 34: 104-12 (published in shortened version). 


\section{Introduction}

In the nineties, researchers reported depression to be a major risk factor for increased cardiac mortality in the first eighteen months post myocardial infarction (MI) ${ }^{1-4}$. This impact of depression on mortality was independent of size of infarction or other cardiovascular risk factors as smoking and hypercholesteroleamia. These studies report furthermore that depression is not only a risk factor of increased mortality, but also of increased morbidity, such as recurrent chest pain, not being able to resume working activities and decreased quality of life, post-MI 1,3,5. More recent studies, however, found a less stronger relationship between depression and increased cardiac mortality $4,6,7$, or no relationship at all $8, ?$.

Incidence of depression increases after MI. Incidence rates of 15 to $30 \%$ are reported for major depression (defined as: 1 core criterion en 4 additional criteria of depressive disorder following DSM-IV) and another $20 \%$ for minor depression depression (defined as: 1 core criterion en 1-3 additional criteria of depressive disorder following DSM-IV) and depressive symptoms (defined as depressive symptoms not meeting DSM-IV criteria for depressive disorder) 2,3,10-13. This wide range of incidence rates may be explained by differences in patient samples, first versus recurrent $\mathrm{MI}$, study design and screening instruments ${ }^{14,15}$.

Depression post-MI often remains unrecognised 16. This underestimation of depression post-MI is probably related to several factors. First, depression postMI has an atypical profile 13: depressed MI patients tend to be more hostile than depressed, non-cardiac compromised patients. Second, both patients and clinicians tend to intuitively interpret depression as a normal psychological and common reaction after a life-treathening event ${ }^{15}$.

The identification of depression as a risk factor for increased mortality post-MI stresses the importance to undertake clinical trials, evaluating on the one hand efficacy and safety of antidepressants in ischemic heart disease, and on the other hand the effect of antidepressant treatment on cardiac prognosis ${ }^{17}$.

Within the departments of Psychiatry and Cardiology of the Maastricht University Hospital (azM) and the Institute of Brain \& Behaviour of the Maastricht University (UM) several studies on affective disorders in cardiac compromised patients were started. In these studies only patients following first MI were selected. In chronic patients with CAD and recurrent MI, non-specific factors, next to specific factors, may play an important role in the relationship between depression and MI. As a result from the cumulative burden of chronic disease, non-specific, somatic disorder-related factors often occur. Non-specific depressogenic factors may be defined as mobility-related restrictions and disability or handicap, irrispective of the nature of the chronic disease, leading to reduced professional and social activities. These non-specific factors have shown strong associations with development of depressive symptoms and post- 
MI survival. As we aimed to rule out as many non-specific depressogenic factors as possible, to prevent bias occurring with specific factors in the relationship of depression and cardiac prognosis, only patients with first MI were selected for this thesis. These patients were included in studies focusing on epidemiology, aetiology, phenomenology, risk factors and treatment of depression post-MI.

First, a double-blind, placebo-controlled study of fluoxetine, a selective serotonergic reuptake inhibitor (SSRI), was undertaken in depressed MI patients. Second, a longitudinal study, focussing on the epidemiology and risk factors of depression following first MI, was developed.

Two consecutive cohorts of first MI patients were involved in this thesis. The first cohort on pharmacological intervention was selected between May 1994 and May 1997 ( $\mathrm{n}=206$ ), and the second, on epidemiology and risk factors, between May 1997 and September $1999(n=206)$. The data, presented in the papers in this thesis, are derived either from the first (chapters 6, 8, 11 and 12), the second (chapters 2, 4, 5, 7, and 10) or from both cohorts (chapters 1, 3, 9, and 13 ).

The main conclusions of the studies described in this thesis are presented after a short summary of the study design. The main findings will then be integrated in clinical implications and finally lead to recommendations for future research.

\section{Study design}

Patients with a diagnosis of a first MI were eligible for the present study. The patients were recruited from the First Heart Aid of the University Hospital of Maastricht (table 1). This hospital serves both as a local catchement area as well as a university hospital, as it is the only hospital in the vicinity of Maastricht. It serves approximately 180,000 habitants. Patients were diagnosed with a MI by a cardiologist according to the following criteria: clinical picture and electrocardiographic signs typical for an acute MI, and a maximum value of the enzyme aspartate aminotransferase $\left(\mathrm{ASAT}_{\max }\right.$ ) of at least $80 \mathrm{U} / \mathrm{L}$ (twice above the upper limit) 18,19 . Patients were excluded who had a major psychiatric disorder other than affective disorders (e.g. schizophrenia, dementia, or a present psychotic episode). Additionally, patients who were unable to communicate reliably (e.g. because of cognitive dysfunction or not speaking Dutch) or with a co-morbid life-threatening disease were excluded. 
Table 1

Baseline characteristics of the total sample of 412 first MI patients.

\begin{tabular}{l|c}
\hline & $\begin{array}{c}\text { Total patient population } \\
\mathbf{n}=412\end{array}$ \\
\hline Demografic factors & $318 \mathrm{M} / 94 \mathrm{~V}$ \\
Gender & $59.1(\mathrm{SD}=11.0)$ \\
Age (years) & \\
\hline Biomedical factors & $52.8(\mathrm{SD}=9.8)$ \\
LVEF & $239(\mathrm{SD}=175)$ \\
ASAT $_{\text {max }}$ & $94.5 \%$ \\
Platelet aggregation inhibitors & $36.2 \%$ \\
Ace-inhibitors & $64.1 \%$ \\
Beta-blockers & \\
\hline Cardiovascular factors & $52.2 \%$ \\
Smoking & $22.1 \%$ \\
Hypercholesterolemia & $9.2 \%$ \\
Diabetis mellitus & $30.8 \%$ \\
Hypertension & $42.2 \%$ \\
PTCA & \\
\hline
\end{tabular}

ASAT $T_{\max }$ : aspartate aminotransferase; LVEF: left ventricle ejection fraction; MI: myocardial infarction; PTCA: percutaneous transluminal coronary angioplasty.

Patients of the first cohort were screened for depression using the 90 -item Symptom Check List (SCL-90) ${ }^{20,21}$ and the Zung Self-rating Depression Scale 22 at $1,3,6$ and 12 months post-MI. Patients scoring above the cut-off of one the questionnaires (SCL-90 depression scale: 22/23 for men and 27/28 for women; Zung-SDS: $49 / 50$ for both men and women) were interviewed in order to evaluate whether DSM-IV criteria for major depression were met. The interview was based on the SCAN (Schedules for Clinical assessment in Neuropsychiatry) ${ }^{23}$. Patients with major depression were offered treatment in the double-blind, placebo-controlled trial with fluoxetine; 54 depressed patients were included in this trial.

Patients of the second cohort were also followed-up during the first year after MI. One month following MI, these patients were interviewed using the Structured Clinical Interview for DSM-IV (SCID-I-R) ${ }^{24}$. Data concerning demographics, level of education, living situation, family history of psychiatric disorders, and medication were collected on interview as was personal history of depression, measured using the SCID-I-R. Three, 6, 9 and 9 months following MI, patients were administered three psychiatric self-rating scales for depression, i.e. the Beck Depression Inventory (BDI) ${ }^{25.26}$, the Hospital Anxiety and Depression Scale (HADS) ${ }^{27}$, and the SCL-90. Patients, exceeding the previously defined cut-off value of at least one of these scales, were reinterviewed using the SCID-I-R. For the BDI, the cut-off value was $9 / 10$, for 
the HADS $7 / 8$ for both subscales separately, and for the depression subscale of the SCL- 90 a threshold of $22 / 23$ was used for men and $27 / 28$ for women. For validation purposes, these questionnaires were also administered one month after MI. The predictive validity of these instruments in MI samples have been reported elsewhere ${ }^{28}$. The sensitivity of exceeding the cut-off of at least one of these scales was $85.7 \%$.

Of all patients of the first and second cohort, data concerning major cardiac events, defined as cardiac death and recurrent MI, and increased health care consumption, defined as re-hospitalizations and frequent outpatient visits $(>6$ visits during follow-up) at the department of cardiology, were assessed during a 1 to 6 years follow-up period.

In this general discussion, main findings concerning epidemiology of depression and its effect on cardiac prognosis will be presented, followed by a summary on identified risk factors of depression post-MI and pharmacological treatment. The complex relation between depression and MI, partly based on data of this thesis, will be highlighted using the 'stress-vulnerability-model'. Finally, we will focus on clinical implications and future research.

\section{Main findings}

\section{Clinical presentation}

All too often depression goes undetected in MI patients ${ }^{16}$. This underreporting of depression is attributed to the tendency of physicians and patients to interpret depressive symptoms as a transient and 'natural' reaction to a lifethreatening event ${ }^{15}$. Furthermore, the clinical presentation of post-MI depression is different from non-cardiac related depression. Post-MI depression fulfils DSM-IV criteria of major depression, but with the core symptom being listlesness rather than depressed mood. This can also be defined as "depressio sine depressione". Other important symptoms of post-MI depression are fatigue (not cardiac related), anxiety and hostility. These findings are based upon the following study results:

First, our study found a strong correlation between post-MI depression and vital exhaustion. Vital exhaustion is a phenomenon conceptualised as decreased level of mental well being observed peri-MI ${ }^{29,30}$. Excessive fatigue and feelings of general malaise, such as hopelessness, listlessness, loss of libido, increased irritability and problems with sleep are mentioned as symptoms of vital exhaustion; chronic fatigue is reported to be a core symptom.

Second, findings from our research group indicate that the symptomatology of post-MI depression, although fulfilling DSM-IV criteria, is atypical in that these patients are more hostile than patient with non-cardiac-related depression ${ }^{13}$. This hostility is reflected by irritability, resentment about the illness, anger and frequent disagreement. 
Third, symptoms of anxiety have as high sensitivity and specificity rates in the prediction of major depression following DSM-IV criteria post-MI as symptoms of depression ${ }^{28}$.

The above mentioned findings indicate that next to depressive symptoms, other symptoms of affective dysregulation such as anxiety and hostility, play an important role in post-MI depression. Increased anxiety and hostility may be a 'pacemaker' of a discrete type of depression, called anxiety/aggression driven depression, which has been hypothesised to have a pathogenesis different of that of other subtypes of depression ${ }^{31,32}$. Post-MI depression may belong to this subtype. This means that not the depressed mood, but more symptoms of anxiety and hostility are the cause of affective dysregulation leading to depressive disorder. We found furthermore that a 4-item questionnaire for detection of mixed Anxiety-Depression has a correlation with post-MI depression as strong as the general accepted longer questionnaires for depression ${ }^{33}$. This questionnaire consists of four items, 2 anxiety and 2 depression items. Two items are derived from the SCL-90 depression subscale, one of the SCL-90 anxiety subscale and one of the HADS anxiety subscale. A high score on the 4-item list increases the risk of development of post-MI depression eleven times, even after correction for high BDI scores, decreased heart function, gender and age. Cronbach's $\alpha$ was 0.86 . It may be that this mixed Anxiety-Depression is more representative of affective dysregulation in MI patients than depressive mood per se.

\section{Epidemiology}

In our studies, depression was diagnosed following DSM-IV criteria. MI patients were interviewed not earlier than one month post MI on order to fulfil the DSM-IV duration criterion of depression of two weeks and also to exclude a transient reaction after a life-threatening event. Thus, we found a cumulative prevalence rate of major and minor depression of $31 \%(n=63)$ within the first year post-MI in the second cohort of first MI patients $(n=206)$. Of the depressed patients, 9 were diagnosed with major depression prior to the MI and 2 with minor depression. If we exclude these patients in the incidence analyses, we found a cumulative incidence rate of post-MI depression of $26.7 \%$. Furthermore, our findings indicate that incidence rates of both major and minor depression are the highest at one-month post-MI (Figure 1) ${ }^{34}$, decreasing thereafter.

The incidence rate of major and minor depression, found in our study, is higher than in the general population, but similar with incidence rates of major depression in patient populations with mixed first and recurrent MI. Major depression following DSM-IV criteria has been reported in 15 to $30 \%$ of MI patients, and minor depression and depressive symptoms in another $20 \% 2,3,10$. 13,35. Lespérance et al. also found that occurrence of depression is the highest during the first 5 to 10 days while patients are hospitalized, decreasing thereafter ${ }^{36}$. 


\section{Figure 1}

Cumulative incidence of major and minor depression between 1 and 12 months in the second cohort of 206 patients following first myocardial infarction.

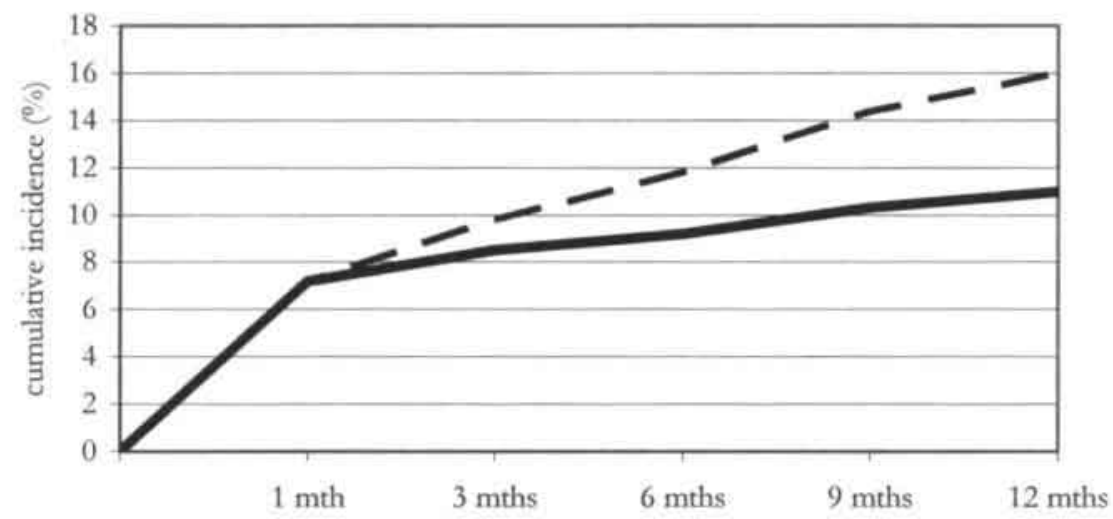

major depression - - minor depression

\section{Diagnostic issues}

As stated above, in contrast to our study, many researchers diagnosed major depression in the immediate post-MI period, using a duration criteria 5 to 10 days 8-10,37. Diagnosis of depression following DSM-IV criteria, however, requires duration of depressive symptoms of at least two weeks ${ }^{38}$. Therefore, diagnosis of a depressive episode post-MI can not be assessed earlier than two weeks post-MI. It is unclear whether symptoms of depression occurring 5-10 days post-MI and thereby not fulfilling the DSM-IV duration criterion of depressive disorder, should be considered as major depression ${ }^{2}$. It may also be possible that some of these patients with depressive symptoms will develop a major depression and others will not. Because of the difficulties of fulfilling DSM-IV duration criterion of two weeks in the immediate period post-MI, patients of both cohorts in our studies were not screened or interviewed for depression earlier than one month post-MI.

\section{Post-MI depression as risk factor}

In our study, the overall mortality rate was $2.4 \%$, measured between 1 and 12 months post-MI within the second cohort of MI patients $(n=206)$. Neither diagnosis of depression nor depressive symptoms were predictors of occurrence of major cardiac events, defined as cardiac death and recurrent MI, up to three years post-MI ${ }^{34}$. In both the first $(\mathrm{n}=206)$ and second cohort $(\mathrm{n}=$ 206) we evaluated the impact of symptoms of depression and anxiety on major cardiac events up to six years post-MI. Again, no association could be found 
between depressive symptoms and major cardiac events. Symptoms of anxiety, however, did predict major cardiac events up to six years post-MI $(\mathrm{HR}=2.79$; $95 \% \mathrm{CI}=1.11-7.03)^{34,39}$.

In contrast to the lack of predictive value of depression on cardiac mortality, we did find a predictive effect of depression on cardiac morbidity 34,39 . Increased health care consumption, defined as frequent visits at the cardiac outpatient clinic and cardiac re-hospitalizations, was predicted by diagnosis of major and minor depression in both cohorts. Apart from diagnosis of depression $(\mathrm{OR}=1.98 ; 95 \% \mathrm{CI}=1.0-3.93)$, also depressive symptoms $(\mathrm{OR}=$ $1.55 ; 95 \% \mathrm{CI}=0.96-2.52)$ and symptoms of anxiety $(\mathrm{OR}=2.0 ; 95 \% \mathrm{CI}=1.24$ 3.22) predicted increased health care consumption. This is furthermore an indication that in first MI patients not diagnosis of depression is important for cardiac prognosis, but a total of depressive and anxiety symptoms.

The finding that depression increases health care consumption, is in line with data in literature 1,3 . The relation between cardiac morbidity and depression may even be stronger than the relation between depression and cardiac mortality ${ }^{5}$. The finding that depression did not predict cardiac mortality post-MI is in contrast to findings in literature. Depression and depressive symptoms increase the risk of death and new cardiac events in mixed patient populations with first and recurrent $\mathrm{MI}^{2}$. Several comments on this difference can be made.

Cardiac mortality rate in our study is lower than that of studies of earlier date 1 ${ }^{3,40}$, possibly due to medical advances in cardiology and inclusion of MI patients not earlier than 1 month post-MI ${ }^{41}$. Other researchers included MI patients already $5-10$ days post-MI. In the first 4 weeks post-MI cardiac mortality rate is the highest ( $29.5 \%$ in our study). Also, opposed to other studies, in our study only first MI patients are included. In such patient sample mortality is reported to be lower than in patient populations with recurrent MI, chronic heart failure or arrhythmia's ${ }^{37}$.

That anxiety next to depression, vital exhaustion and hostility is a predictor is of increased cardiac death has already been described ${ }^{42-46}$. It has also been found that the disability to express adequately negative emotions (Type D personality, characterised by social inhibition combined with negative affectivity) is a risk factor of increased mortality post-MI ${ }^{47}$. It may be that it is not so much the diagnosis of depression that predicts cardiac mortality but a total of negative affectivity (symptoms of depression, anxiety, hostility and vital exhaustion). This might indicate that the categorical diagnosing in psychiatry has a less powerful predictive value than diagnoses using functional psychopathology ${ }^{48}$.

\section{Risk factors of post-MI depression}

Various possible correlates of depression post-MI were investigated in our studies. Correlates of depression can be divided in risk factors and early signs. If correlates occur or are present before the disease and are not a part of the symptom complex of the disease they are defined as risk factors ${ }^{49}$. Correlates that should be regarded as part of the symptom complex of the disease are 
defined as early signs. However, of some of the correlates evaluated, for example use of benzodiazepines during admission, it is not clear whether such a distinction between risk factors and early signs can be made. In our studies we investigated biological, (neuro)psychological and social risk factors and clinical early signs of post-MI depression.

A possible biological risk factor of development of depressive symptoms postMI is low serum concentration of LDL-C (Low Density LipoproteinCholesterol). Low serum LDL-C, measured one month post-MI, was associated with development of depressive symptoms three months post-MI in the second cohort. The risk of depressive symptoms decreased at a LDL-C level above $2.35 \mathrm{mmol} / \mathrm{L}$. This association remained significant after correction for depressive symptoms at baseline (one month post-MI) or use of lipid lowering drugs.

Other more general biological risk factors (which have next to biological also psychological and social aspects) are female gender, younger age and history of depression.

In our studies, cardiac dysfunction as measured by left ventricular function (LVEF) and enzyme release had no relation with occurrence of depression. This is in line with other researcher reporting that severity of cardiac disorder, measured by LVEF, Holter registration or angiography, is unrelated to development of major depression 1.3,35. All studies using enzyme release as measure for severity of MI also found no relationship with development of depression. The lack of relation between severity of cardiac disorder and depression runs counter to the intuitive notion that patients with a more severe MI will develop more severe handicap or are more disabled, and are therefore more at risk for depression. As yet we can not explain this absence of correlation. However, such absence of correlation with severity of illness can also be found in other diseases such as diabetes mellitus, type II.

Psychological factors, which are present one month after MI, are also correlates for development of depression post-MI in the second cohort. Patients reporting symptoms of depression or anxiety after the MI are at risk of developing a depressive episode at a later stage post-MI, compared to patients without emotional complaints ${ }^{50,51}$. We do not know, however, whether these psychological symptoms are risk factors or early signs of the developing depression. In addition, neuropsychological factors, like cognitive functioning, seem not to be related with depression post-MI. Cognitive performance in depressed MI patients of the first cohort is similar to that of non-depressed MI patients and healthy controls ${ }^{52}$.

Not only psychological symptoms, also personality traits may predict major and minor depression up to 12 months post-MI. As psychological symptoms refer to momentary level of distress and are dependent on situational characteristics, personality traits refer to a stable disposition to experience psychological distress across time and situations. Personality was assessed in the second cohort using the NEO-Five Factor Inventory, which measures Neuroticism, 
Extraversion, Agreeableness, Conscientiousness and Openness. Neuroticism was an independent predictor for both major $(\mathrm{HR}=4.04,95 \% \mathrm{CI}=1.47-11.12)$ and minor depression $(\mathrm{HR}=2.81,95 \% \mathrm{CI}=1.35-5.85)$ in the first year postfirst-MI, independent of size of infarction, measured using LVEF, gender and age. Introversion was also an independent predictor of major depression ( $\mathrm{HR}=$ $2.52,95 \% \mathrm{CI}=1.08-5.91)$ but not of minor depression. Apart from extraversion and neuroticism, no other dimension of the five-factor-model of personality showed an independent significant effect on the development of major or minor depression post-MI. As far as to our knowledge, we were the first to find a relationship between personality traits and post-MI depression. However, in literature was already decribed that in somatically healthy patients neuroticism and introversion are determinants of depressive disorder 53,54 .

Social factors, such as living alone and low education, may also be related to development of depression post-MI 55.58. We could, however, not find such a relationship in the first cohort, possibly because of the small numbers ${ }^{51}$. Also in the second cohort no relationship between depression and living alone or education could be found ${ }^{34}$.

Clinical correlates in the first cohort are identified as complications during hospitalization, and not being able to stop smoking. Also hospitalized patients who are prescribed benzodiazepines by the cardiologist are at higher risk for depression compared to patients without prescription of benzodiazepines. Prescription of benzodiazepines can thus be a first sign of symptoms of depression and anxiety that are already developing or will develop in near future 59.

\section{Treatment of depression post-MI}

Various treatment modalities have been described in depressed MI patients. In our studies, we only focussed on pharmacological treatment of depression post$\mathrm{MI}$ and not on psycho-education or cognitive therapy. We therefore will only summarise data of our studies on pharmacological treatment of depression post-MI. There are three issues that are important in the pharmacological treatment of depression post-MI: efficacy, safety and effect on cardiac prognosis.

First, effectivity: our study is the first to investigate efficacy of fluoxetine in a double-blind, placebo-controlled design in patients with major depression after first MI. Overall, the a-priori difference in antidepressive efficacy between fluoxetine and placebo treatment is not met. However, there are significantly more responders during fluoxetine treatment than during placebo treatment at week 25. Furthermore, compared to placebo, fluoxetine is especially effective in patients with HAMD-17 scores equal or lower than 21 (mild depression) ${ }^{60}$. In this same study, we also investigated the effect of fluoxetine on hostility, another indicator of negative affectivity. In our double-blind placebo-controlled trial, fluoxetine was significantly more effective in reducing high levels of hostility than placebo. 
Cardiac safety is the second important issue of the pharmacotherapeutical intervention of depressed MI patients. In our double-blind placebo-controlled intervention study fluoxetine has no negative impact on cardiac functioning in depressed first-MI patients ${ }^{60}$. This is of importance as tricyclics do have proarrhythmic properties in cardiac compromised patients ${ }^{61-64}$. Also in a comparative study in which middle-aged and elderly depressed patients were treated with SSRI (fluvoxamine or fluoxetine), no negative cardiac side effects were reported ${ }^{65}$.

Apart from cardiological side effects, we evaluated cognitive side effects of fluoxetine. It is important to evaluate cognitive side effects of fluoxetine in depressed MI patients. First, the majority of depressed patients are treated as outpatients and are expected to continue their professional life and normal everyday routine ${ }^{66}$. It thus becomes necessary that antidepressive therapy has limited effect on cognitive function. Our study indicates no negative side effects of fluoxetine on cognitive functioning, i.e. attention, concentration and memory, in patients with post-MI depression. Second, cardiac drugs may also be psychoactive or interact with antidepressive therapy ${ }^{67}$. In our study, we did not study idrug interaction although no interaction is reported on the clinical level. The only drug that was different was the trial medication fluoxetine/placebo, but this did not lead to difference in cognitive performance.

Finally, it is important that depression post-MI is effectively treated, not only to improve depressed mood and quality of life, but also to increase patient's cardiac prognosis. Overall, the efficacy of SSRIs in post-MI depression has not been clearly showed as next to our intervention study a second, double-blind placebo-controlled trial also reported a modest effect of a SSRI on post-MI depression ${ }^{68}$. Although there are some scarce data indicating that treatment with SSRIs may decrease the risk of a new MI ${ }^{69}$, it remains as yet unclear whether treatment of post-MI depression can improves cardiac prognosis ${ }^{70,71}$. Our study indicated that fluoxetine tended to reduce re-hospitalizations in postMI depression ${ }^{60}$. Furthermore, in MI patients with mild depression, improvements of depression were associated with better prognosis, whereas in severe depressed patients, reductions in depression symptoms had little improvement in prognosis ${ }^{40}$. This seems of importance as our studies indicate that majority of MI patients (53\%) are diagnosed with mild depression (defined as: 1 core criterion and 1-3 additional criteria of depressive disorder following DSM-IV) or are mildly (defined as HAMD- $17 \leq 21$ ) depressed $(59 \%)$. Also cognitive therapy has been reported as effective in reducing depressive symptoms post-MI, but not in decreasing the risk of cardiac mortality or reinfarction ${ }^{71}$.

It may be possible that, as earlier indicated by our studies, it is not depression per se that predicts decreased cardiac prognosis post MI but negative affectivity. If clinical trials of MI patients, evaluating the effect of SSRIs, would 
use negative affectivity as outcome measure in stead of depression, intervention might be found effective.

\section{Stress-Vulnerability-Model}

Heart and mind have a complex relationship ${ }^{14}$. This has been shown from the facts that the cumulative incidence of post-MI depression is higher than that of depression in general population, and that symptoms of negative affectivity increases risk of incomplete recovery post-MI. As yet, the nature of this relationship remains unclear.

Findings of literature show that several attempts have been made to clarify the relationship between $\mathrm{MI}$ and depression. In recent years the classic medical model' is frequently reported 72 . This type of relationship describes a causal relationship between psychological complaints and somatic illness. Indeed, incidence of depression increases after MI. In prospective studies of both MI and somatically healthy patients, depression has been identified as an independent risk factor of development of cardiovascular events ${ }^{73.76}$. This impact of depression on cardiac prognosis is independent of other cardiovascular risk factors, which may be related to negative mood-driven behaviour, such as smoking and hypercholesteroleamia 1,2,12. Furthermore, one would expect severity of MI to be related to occurrence of depression. In postMI depression, however, no relation between size of infarction and occurrence of depression has been found 1,2,12,335,77,78. These data suggests that the development of depressive disorder in MI patients is not an aspecific reaction to a somatic disease. Also, depression does not always precede or follow MI, but can also occur simultaneously with MI. This could mean that depression and MI have common, pathogenic factors.

We used the 'Stress-Vulnerability-Model' to clarify the relationship between depression and myocardial infarction as found in our studies. In recent literature this Stress-Vulnerability-Model is often used to summarise the multifactorial model of depression ${ }^{79-81}$. In this model the chance of developing a depressive disorder is dependent on vulnerability factors, triggers and protective factors ${ }^{79}$. Depression may develop in already vulnerable individuals who are confronted with stressful life events. In Figure 2 the StressVulnerability-Model is visualised.

First, vulnerability refers to the proneness of individuals to develop depression. In the Stress-Vulnerability-Model, vulnerability factors may be present before both the MI and development of depression. Identified vulnerability factors in our studies are female gender, previous depression, and personality traits as neuroticism and introversion ${ }^{34,82}$.

Next to vulnerability factors, triggers may induce affective or cardiac dysregulation. Triggers of post-MI depression, found in our study, are complications post-MI and prescription of benzodiazepines. In our studies we 
did not focus on possible common pathophysiological mechanisms, shared by both depression and MI (Figure 3). Pathophysiologic mechanisms most frequently reported in literature are 1) immunology, and activation of the HPA (Hypothalamic-Pituitary-Adrenal)-axis and sympathic nervous system ${ }^{83.86}, 2$ ) fatty acids ${ }^{87,88}$, and 3) blood platelets ${ }^{89,90}$. Our Stress-Vulnerability-Model may be expanded by the more pathophysiological mechanisms. Research, focussing on these pathophysiological mechanisms in depressed and non-depressed, in first and recurrent $\mathrm{MI}$ patients, are now ongoing at our institute ${ }^{91}$.

In contrast to vulnerability factors and triggers, protective factors decrease the risk of post-MI depression. In our model, protective factors are male gender and older age.

\section{Figure 2}

Stress-Vulnerability-Model of depression post first myocardial infarction.

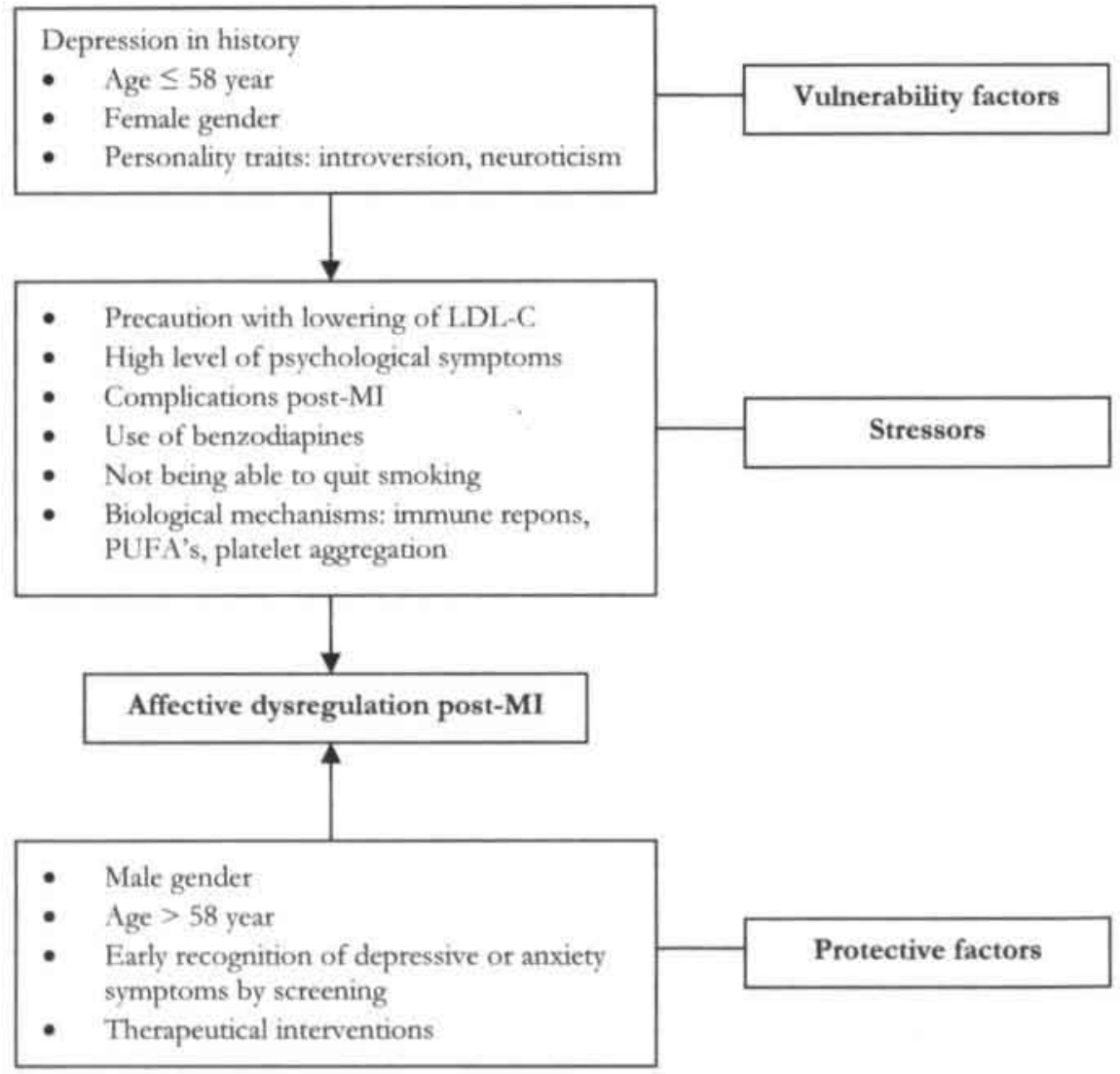




\section{Conclusions}

As stated above, major and minor depression co-occur in about $30 \%$ of the MI patients. As reported earlier, depression post-MI remains, however, often unrecognised 2,16. This lack of recognition may be a consequence of 1) the atypical profile of post-MI depression caused by the fact that depressed MI patients spontaneously report symptoms of anxiety and hostility but not of depression ${ }^{13,52}, 2$ ) the tendency of patients and clinicians to interpret depressive symptoms as a normal psychological and transient reaction following a life threatening event ${ }^{15}$, and 3 ) the scarce knowledge of risk factors of post-MI depression ${ }^{14,56}$.

Second, diagnosis of depression and symptoms of distress must be referred to as predictors of incomplete recovery. It is therefore important to screen MIpatients for depression. One can screen MI patients for depression using the general accepts questionnaires as the SCL-90, BDI or HADS, which we reported to be valid instruments in post-MI patients. Additionaly, one can screen using a simple, short 4-item questionnaire for mixed AnxietyDepression. This questionnaire consists of 4 items derived from the SCL-90 and HADS, but with the same sensitivity as both the SCL-90 and HADS. The cardiologist can thus in easy and simple way screen patients for post-MI depression using this questionnaire. To determine, however, whether DSM-IV criteria for major/minor depression are met, referral to the psychiatrist is of importance.

Third, treatment with SSRI has limited effect on depression, but clear effect on hostility. As stated earlier, there is some evidence that mild depression should be treated ${ }^{40}$. As the majority of MI patients in our study meet criteria of minor $(53 \%)$ or mild $(59 \%)$ depression, it is important to screen and treat MI patients for (minor) depression. It remains however unclear whether treatment of depression leads to a better cardiac prognosis post-MI.

The question remains whether in MI patients we have to hold on to the concept of depression or search for a more complex symptom profile indicator of negative affectivity. In future research, it seems less important to play attention to depressive disorder or depressive symptoms as predictors of worsened cardiac prognosis, and more important to plat attention to affective dysregulation that involves apart from depression also anxiety, hostility and vital exhaustion as core symptoms. Further intervention studies should address all these components of negative affectivity as focus of treatment.

\section{References}

1. Frasure-Smith $\mathrm{N}$, Lespérance $\mathrm{F}$, Talajic $\mathrm{M}$. Depression and 18 months prognosis after myocardial infarction. Circulation. 1995;91:999-1005.

2. Frasure-Smith N, Lespérance $\mathrm{F}$, Talajic M. Depression following myocardial infarction: impact on 6-months survival. JAMA 1993;270:999-1005. 
3. Ladwig $\mathrm{KH}$, Kieser M, Konig J, Breithardt G, Borggrefe M. Affective disorders and survival after acute myocardial infarction (results from the post-infarction late potential study). Br Heart J 1991;12:959-64.

4. Penninx BWJH, Beekman ATF, Honig A, et al. Depression and cardiac mortality: results from a community-based longitudinal study. Arch Gen Psychiatry 2001;58:221-7.

5. Creed $\mathrm{F}$. The importance of depression following myocardial infarction. Heart 1999;82:406-8.

6. Irvine J, Basinski A, Baker B, et al. Depression and risk of sudden cardiac death after acute myocardial infarction: testing for the confounding effects of fatigue. Psychosom Med 1999;61:729-37.

7. Welin C, Lappas G, Wilhelmsen L. Independent importance of psychosocial factors for prognosis after myocardial infarction. J Intern Med 2000;247:629-39.

8. Lane D, Carroll D, Ring C, Beevers DG, Lip GY. Mortality and quality of life 12 months after myocardial infarction: effects of depression and anxiety. Psychosom Med 2001;63:221-30.

9. Mayou RA, Gill D, Thompson DR, et al. Depression and anxiety as predictors of outcome after myocardial infarction. Psychosom Med 2000;62:212-9.

10. Schleifer SJ, Macari-Hinson MM, Coyle DA, et al. The nature and course of depression following myocardial infarction. Arch Intern Med 1989;149:1785-9.

11. Carney RM, Rich MW, Freedland KE, et al. Major depressive disorder predicts cardiac events in patients with coronary artery disease. Psychosom Med 1988;50:627-33.

12. Ladwig KH, Roll G, Breithardt G, Budde T, Borggrefe M. Post infarct depression and incomplete recovery 6 months after acute myocardial infarction. The Lancet 1994;343:20-3.

13. Honig A, Lousberg R, Wojchiechowski F, Cheriex EC, Wellens H, Van Praag HM. Depression following a first heart infarct; similarities with and difference from 'ordinary' depression. Ned Tijdschr Geneeskunde 1997;141:196-9.

14. Strik JJMH, Honig A, Maes M. Depression and myocardial infarction: Relationship between heart and mind. Progr Neuropsychopharmacol Biol Psychiatry 2001;25:879-92.

15. Musselman DL, Evans DL, Nemeroff CB. The relationship of depression to cardiovascular disease. Arch Gen Psychiatry 1998;55:580-92.

16. Freedland KE, Lustman PJ, Carney RM, Hong BA. Underdiagnosis of depression in patients with coronary arterie disease: the role of nonspecific symptoms. Int J Psychiatry Med 1992;22:221-9.

17. Williams RB, Chesney MA. Psychosocial factors and prognosis in established coronary artery disease. The need for research on interventions. JAMA 1993;270:1860-1.

18. De Zwaan C, Willems GM, F. V, et al. Enzyme tests in the evaluation of thrombolysis in acute myocardial infarction. Br Heart J 1988;59:175-83.

19. Pasternak RC, Braunwald E, Sobel RE. Acute myocardial infarction. In: Braunwald E, (ed) Heart disease: a textbook of cardiovascular medicine. 4th edition. Philadelphia: WB Saunders Compagny, 1992:1200-91.

20. Derogatis LR, Lipman RS, Covi L. SCL-90: an outpatient psychiatric rating scaleprelimanary report. Psychopharm Bull 1973;9:13-27. 
21. Arrindell WA, Ettema JHM. Dimensional structure, reliability and validity of the Dutch version of the Symptom Checklist (SCL-90). Ned Tijdschr Psychologie 1981;43:381-7.

22. Zung WW, Richards CB, Short MJ. A selfrating depression scale. Arch Gen Psychiatry 1965;12:63-70.

23. Wing JK, Babor $T$, Brugha $T$, et al. Schedules for clinical assessment in neuropsychiatry. Arch Gen Psychiatry 1990;47:589-93.

24. First MB, Spitzer RL, Gibbon M, Williams JB. Structured Clinical Interview for DSM-IV Axis I disorders-Patient Edition (SCID-I/P, Version 2.0). Biometrics Research Department, New York State Psychiatric, New York 10032, 1995.

25. Beck AT, Ward CH, Mendelson M, Mock J, Erbaugh J. An inventory for measuring depression. Arch Gen Psychiatry 1961;4:561-71.

26. Richter P, Werner J, Heerlein A, Kraus A, Sauer H. On the validity of the Beck Depression Inventory. Psychopathology 1998;31:160-8.

27. Herrmann C. International experiences with the hospital anxiety and depression rating scale: a review of validation data and clinical results. J Psychosom Res 1997;1:17-41.

28. Strik JJMH, Honig A, Lousberg R, Denollet J. Sensitivity and specificity of observer and self -report questionnaires in depression following myocardial infarction. Psychosomatics 2001;42:423-8.

29. Diest van R, Appels A. Vital exhaustion and depression, a conceptual study. J Psychosom Res 1991;35:535-44.

30. Appels A. Mental Precursors of myocardial infarction. Br J Psychiatry 1990;156:65471.

31. Van Praag HM. 5-HT-related, anxiety-and/or aggression-driven depression. Int Clin Psychopharmacol 1994;9:5-6.

32. Van Praag HM. Faulty cortisol/serotonin interplay. Psychopathological and biological characterisation of a new, hypothetical depression subtype (SeCa depression). Psychiatry-Res. 1996;65:143-57.

33. Denollet J, Strik JJMH, Lousberg R, Honig A. Depressive Symptoms Following Myocardial Infarction: Misinterpretation of "Depression" Scales? Br Heart J 2003;Submitted.

34. Strik JJMH, Lousberg R, Cheriex EC, Honig A. One year cumulative incidence of depression after first myocardial infarction and impact on cardiac outcome. J Psychosom Res 2003; In Press.

35. Ahern DK, Gorkin L, Anderson JL, et al. Biobehavioral variables and mortality on cardiac arrest in the Cardiac Arrhythmia pilot study (CAPS). Am J Cardiology 1990;66:59-62.

36. Lespérance F, Frasure-Smith N, Talajic M. Major depression before and after myocardial infarction: its nature and consequences. Psychosom Med 1996;58:99110.

37. Bush DE, Ziegelstein RC, Tayback M, et al. Even minimal symptoms of depression increase mortality risk after acute myocardial infarction. Am J Cardiol 2001;88:33741.

38. The American Psychiatric Association. Diagnostic and statistic manual of mental disorders IV. 4th edition (revised). Washington DC: American Psychiatric Association, 1994. 
39. Strik JJMH, Denollet J, Lousberg R, Honig A. Comparing symptoms of depression and anxiety as predictors of incomplete recovery following myocardial infarction. JACC 2003; In Press.

40. Lespérance F, Frasure-Smith N, Talajic M, Bourassa MG. Five-year risk of cardiac mortality in relation to initial severity and one-year changes in depression symptoms after myocardial infarction. Circulation 2002;105:1049-53.

41. Chen J, Radford MJ, Wang Y, Marciniak TA, Krumholz HM. Do 'America's best hospitals' perform better for acute myocardial infarction? $N$ Engl J Med 1999;340:286-92.

42. Kubzansky LD, Kawachi I. Going to the heart of the matter. do negative emotions cause coronary heart disease? J Psychosom Res 2000;48:323-37.

43. Appels A. Psychological prodromata of myocardial infarction and sudden death. Psychother Psychosom 1987;34:187-95.

44. Appels A, Mulder P. Fatigue and heart disease. The association between 'vital exhaustion' and past, present and future coronary heart disease. J Psychosom Res 1989;33:727-38.

45. Everson SA, Kauhanen J, Kaplan GA, et al. Hostility and increased risk of mortality and acute myocardial infarction: the mediating role of behavioral risk factors. Am J Epidemiol 1997;146:142-52.

46. Barefoot JC, Larsen S, Lieth von der L, Schroll M. Hostility, incidence of acute myocardial infarction, and mortality in a sample of older Danish men and women. Am J Epidemiology 1995;142:477-84.

47. Denollet J, Sys SU, Stroobant N, Rombouts H, Gillebert TC, Brutsaert DL. Personality as independent predictor of long-term mortality in patients with coronary heart disease. Lancet 1996;347:417-21.

48. Van Praag HM. Over the mainstream: diagnostic requirements for biological psychiatric research. Psychiatry Res 1997;72:201-12.

49. Ahlbom A, Norell S. Introduction to modern epidemiology. Stockholm: Epidemiology Resources Inc, 1990:

50. Strik JJMH, Honig A, Lousberg R, Maes M. Relation of levels of serum lipoproteins to depression after acute myocardial infarction. Am J Cardiol 2002;90:1368-70.

51. Strik JJMH, Honig A, Lousberg R, Van Os J, Van den Berg E, Van Praag HM. Clinical correlates of depression following first MI. Int Psychiatry Med 2001;31:27180.

52. Dijkstra JB, Strik JJMH, Honig A, et al. Atypical cognitive profile in patients with depression after myocardial infarction. J Aff Dis 2002;70:181-90.

53. Akiskal HS, Hirschfeld RM, Yerevanian BI. The relationship of personality to affective disorders. Arch Gen Psychiatry 1983;40:801-10.

54. Clark LA, Watson D. Tripartite model of anxiety and depression: Psychometric evidence and taxonomic implications. J Abnormal Psychology 1991;100:316-36.

55. Penninx BW, van Tilburg T, Boeke AJ, Deeg DJ, Kriegsman DM, van Eijk JT. Effects of social support and personal coping resources on depressive symptoms: different for various chronic diseases? Health Psychol 1998;17:551-8.

56. Taylor CB, Miller NH, Smith PM. Prevention of depression and anxiety in patients with cardiovascular disease. J Prev Interv Comm 1996;13:53-69.

57. Frasure-Smith N, Lespérance F, Gravel G, et al. Social support, depression, and mortality during the first year after myocardial infarction. Circulation 2000;101:1919-24. 
58. Coryell W, Endicott 1, Keller M. Major depression in a nonclinical sample. Demographic and clinical risk factors for first onset. Arch Gen Psychiatry 1992;49:117-25.

59. Wiklund I, Oden A, Sanne H, al. e. Prognostic importance of somatic and psychosocial variables after a first myocardial infarction. Am J Epidemiology 1988;128:786-95.

60. Strik JJMH, Honig A, Lousberg R, et al. Efficacy and safety of fluoxetine in the treatment of patients with major depression following first myocardial infarction: findings from a double-blind placebo-controlled trial. Psychosom Med 2000;62:7839.

61. Glassman AH, Roose SP. Risk of antidepressants in the elderly: Trycyclic antidepressants and Arrhythmia-Revising risks. Gerontology 1994;40:15-20.

62. Glassman AH, Stage KB. Depressed patients with cardiovascular disease: treatment considerations. CNS Drugs 1994;1:435-40.

63. Roose SP, Glassman AH. Cardiovascular effects of tricyclic antidepressants in depressed patients with and without heart disease. J Clin Psychiatry 1989;50:1-18.

64. Kantor SJ, Glassman AH, Bigger JT, Perel JM, Giardina EV. The cardiac effects of therapeutic plasma concentrations of imipramine. Am J Psychiatry 1978;135:534-8.

65. Strik JJMH, Honig A, Lousberg R, Cheriex EC, Van Praag HM. Cardiac side-effects of two selective setonine reuptake inhibitors in middle-aged and elderly depressed patients. Int Clin Psychopharm 1998;13:263-7.

66. Amado-Boccara I, Gougoulis N, Poirier Littre MF, Galinowski A, Loo H. Effects of antidepressants on cognitive functions: a review. Neurosci Biobehav Rev 1995;19:479-93.

67. Strik JJMH, Honig A, Klinkenberg E, Dijkstra J, Jolles J. Fluoxetine and effect on cognitive performance in depressed patients post myocardial infarction. Psychosomatics 2003; Submitted.

68. Glassman AH, O'Connor CM, Califf RM, et al. Sertraline treatment of major depression in patients with acute MI or unstable angina. JAMA 2002;288:701-9.

69. Sauer WH, Berlin JA, Kimmel SE. Selective serotonin reuptake inhibitors and myocardial infarction. Circulation 2001;104:1894-8.

70. Carney RM, Freedland KE, Veith RC, Jaffe AS. Can treating depression reduce mortality after an acute myocardial infarction? Psychosom Med 1999;61:666-75.

71. Sheps DS, Freedland KE, Golden RN, McMahon RP. ENRICHD and SADHART: implications for future biobehavioral intervention efforts. Psychosom Med 2003;65:1-2.

72. Siegler M, osmond H. Models of madness, models of medicine. New York: MacMillan, 1974.

73. Aromaa A, Raitasalo R, Reunanen A, et al. Depression and cardiovascular diseases. Act Scand Psychiatrica 1994; 377:77-82.

74. Pratt LA, Ford DE, Crum RM, Armenian HK, Gallo JJ, Eaton WW. Depression, psychotropic medication, and risk of myocardial infarction: prospective data from the Baltimore ECA follow-up. Circulation 1996;94:3123-9.

75. Barefoot JC, Schroll M. Symtomps of depression, acute myocardial infarction, and total mortality in a community sample. Circulation 1996;93:1976-80.

76. Ford DE, Mead LA, Chang PP, Cooper-Patrick L, Wang N-Y, Klag MJ. Depression is a risk factor for coronary artery disease in men. Arch lnt Med 1998;158:1422-6. 
77. Havik OE, Maeland JG. Patterns of emotional reactions after a myocardial infarction. J Psychosom Res 1990;34:271-85.

78. Forrester AW, Lipsey JR, Teitelbaum ML, DePaulo JR, Andrzejeweski PL. Depression following myocardial infarction. Int J Psychiatry Med 1992;22:33-46.

79. Kendler KS, Kessler RC, Neale MC, Heath AC, Eaves LJ. The prediction of major depression in women: toward an integrated etiologic model. Am J Psychiatry 1993;150:1139-48.

80. Kendler KS, Kessler RC, Walters EE, et al. Stressful life events, genetic liability, and onset of an episode of major depression in women. Am J Psychiatry 1995;152:83342.

81. Ormel J, Oldehinkel AJ, Brilman EI. The interplay and etiological continuity of neuroticism, difficulties, and life events in the etiology of major and subsyndromal, first and recurrent depressive episodes in later life. Am J Psychiatry 2001;158:88591.

82. Strik JJMH, Denollet J, Lousberg R, Woijiechowski F, Honig A. Personality and vulnerability to depression following myocardial infarction: A prospective follow-up study, Am J Psychiatry 2003; Submitted.

83. Maes M, Van Bockstaele DR, Gastel A, et al. The effects of psychological stress on leukocyte subset distribution in humans: evidence of immune activation. Neuropsychobiology 1999;39:1-9.

84. Connor TJ, Leonard BE. Depression, stress and immunological activation: the role of cytokines in depressive disorders. Life Sci 1998;62:583-606.

85. Zalcman S, Green-Johnson JM, Murray L, et al. Cytokine-specific central monoamine alterations induced by interleukine-1, -2 , and -6. Brain Res 1994;643:409.

86. McCann SM, Lyson K, Karanth S, et al. Role of cytokinen in the endocrine system. Ann N Y Acad Sci 1994;741:50-63.

87. Maes M, Christophe A, Delanghe J, Altamura C, Neels H, Meltzer HY. Lowered omega3 polyunsaturated fatty acids in serum phospholipids and cholesteryl esters of depressed patients. Psychiatry Res 1999;85:275-91.

88. Albert CM, Hennekens CH, O'Donnel CJ, et al. Fish consumption and risk of cardiac death. JAMA 1998;279:23-8.

89. Willerson JT, Eidt JF, MeNatt J, et al. Role of thromboxane and serotonin as mediators in the development of spontaneous alterations in coronary blood flow and neointimal proliferation in canine models with chronic coronary artery stenoses and endothelial injury. JACC 1991;17:101B-110B.

90. Mendelson SD. The current status of the platelet $5-\mathrm{HT}(2 \mathrm{~A})$ receptor in depression. J Affect Disord 2000;57:13-24.

91. Van Melle JP, Van den Brink RHS, Winter JB, et al. Treatment of depression after myocardial infarction and the effects on cardiac prognosis: the Myocardial Infarction and Depression-Intervention Trial (MIND-IT). Spring meeting of the Dutch Association of Cardiology. The Hague, The Netherlands, 2000. 


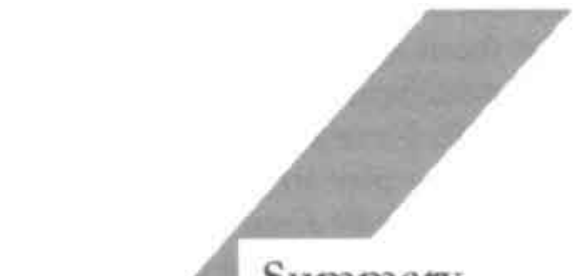

Summary 
There is a strong relationship between depression and myocardial infarction (MI) as the title of this thesis indicates. This thesis focuses on several aspects of this strong although complex specific relationship, i.e. epidemiology, risk factors and treatment of depression following MI. Next to specific factors, in patients with recurrent $\mathrm{MI}$ non-specific factors may play an important role in the relationship between depression and MI. As a result from the cumulative burden of recurrent MI, non-specific, somatic disorder related factors often occur. Non-specific depressogenic factors may be defined as mobility-related restrictions, disabilities or handicap, leading to reduced professional and social activities. These non-specific factors have shown strong associations with development of depressive symptoms and post-MI survival. As we aimed to rule out as many non-specific depressogenic factors as possible to prevent bias occurring with specific factors in the relationship of depression and cardiac prognosis, only patients with first $\mathrm{MI}$ were selected for this thesis.

In the first part of this thesis, an overview of reported data on the epidemiology, risk factors and treatment of mixed patient populations with first and recurrent MI is presented, followed by data on incidence rates of depression post-first-MI. In these papers, the impact of various states of depression on cardiac recovery post-MI is reported. These states are defined as major depression (defined as one core criterion en four additional criteria of depressive disorder following DSM-IV), as minor depression (defined as one core criterion and one to three additional criteria of depressive disorder following DSM-IV), and as depressive symptoms.

The second part of this thesis is focused on diagnostic issues of depression following MI. First, validity of self-rating scales for major and minor depression, frequently used in MI patients, is presented. Second, based on these frequently used questionnaires, a shortened questionnaire as screening instrument for depression is developed with the same psychometric abilities as the earlier mentioned, general accepted, questionnaires. This 4-item questionnaire may be more practical as screening instrument for cardiologists and patients than the general accepted questionnaires, from which this questionnaire has been derived. The last part of diagnostic issues focuses on correlations between two concepts of negative affect related to MI, depression and vital exhaustion. This is investigated using two self-rating questionnaires for depression and one for vital exhaustion.

In the third part of this thesis, possible risk factors and clinical markers for depression post-MI are described.

In the fourth part is focused on pharmacological intervention of depression post-first-MI.

This dissertation is thus divided in 4 parts (chapter 1 to 13), and is preceded by an introduction and closed by a general discussion. 
The introduction explains the importance of studies focussing on depression post-MI.

In the general discussion, the main conclusions of this thesis are summarized and integrated into clinical implications and future research.

Each chapter starts with the background of the research question, followed by study design and results of the study. Finally in the discussion of each chapter, conclusions are drawn.

In chapter 1 an overview is given of possible specific and non-specific factors in the relationship between "Heart \& Mind", i.e. MI and depression. There is strong evidence that a relationship exists between depression and MI. First, in patient populations with mixed first and recurrent MI, depression is associated with increased morbidity and mortality due to recurrent ischemic events and arrhythmia. Second, one would intuitively expect that severity of somatic disease is associated with occurrence of depression. In MI patients this is not the case: depression post-MI is not related to size of infarction.

Depression goes often undetected: of depressed MI patients only $10 \%$ is identified as such and an even smaller percentage is being treated. Two aspects may be related to underdiagnosing post-MI depression. First, post-MI depression has an atypical profile. Apart from listlessness (a core symptom of depressive disorder), MI patients report symptoms of hostility, anxiety and fatigue more readily than symptoms of depression. Second, clinicians tend to interpret these symptoms and complaints as a normal psychological reaction to a life-threatening event rather than symptoms of depressive disorder.

In chapter 2 the cumulative incidence of major and minor depression postfirst-MI is investigated. A 1-year cumulative incidence of $26.7 \%$ of major and minor depression is found. This incidence rate is higher than the $5-10 \%$ in the general population, and similar to incidence rates in patient populations with mixed first and recurrent MI. In addition, up to three years post-MI, depression does not predict major cardiac events defined as death and recurrent MI. This is in contrast to data from literature, in which depression is reported to be a risk factor of mortality and morbidity post-MI. A possible explanation for this difference may be that the overall mortality rate in our study is lower than that of other studies. The lower mortality rate in our studies may be explained by several factors. First, the present study was undertaken several years later than the first report on depression and cardiac prognosis. Medical advances in cardiology at the present time have reduced mortality rates in MI patients substantially. Second, opposed to other studies, our study only includes first MI patients. In such patient sample mortality is lower than in patient populations with recurrent MI, chronic heart failure or arrhythmias. 
In chapter 3 the impact of symptoms of anxiety and depression on recovery post-MI is evaluated. We already reported that up to three years post-MI, neither major/minor depression nor depressive symptoms predicted major cardiac events. Also up to six years post-MI, depression has no clear relationship with major cardiac events. In contrast to depressive symptoms, symptoms of anxiety do predict major cardiac events up to six years post-MI. It remains however unclear why anxiety seems to be a better predictor of cardiac prognosis in first MI patients than depression. As we stated earlier, the lack of effect of depression on cardiac prognosis would be explained by the fact that a part of the depressed patients were treated $(17.5 \%)$. Second, it could be that not only diagnosis of depression is of importance in predicting cardiac recovery, but also a set of emotional complaints, which may be best described as negative affectivity. This notion is supported by data on other states of negative affect, such as vital exhaustion and type-D personality. These states of negative affectivity are also related to incomplete recovery post-MI.

In chapter 4 sensitivity and specificity of four rating scales for depression, frequently used in MI populations, are investigated. These are three self rating scales, i.e. the 90-item Symptom Check List (SCL-90), the Hospital Anxiety and Depression Scale (HADS), the Beck Depression Inventory (BDI), and an observer rating scale, the 17-item Hamilton Depression Rating Scale (HAMD17). All questionnaires are valid screening instruments for depression in this first-MI patient population. The optimal cut-off values (maximum sum of sensitivity and specificity) are lower for minor than for major depression. As minor depression also has an impact on morbidity and mortality post-MI apart from major depression, it is important to screen for minor depression as well. In our study, the anxiety subscale of the HADS is a better predictor of major and minor depression than the depression subscale. The validity of the total HADS increases if we add both the depression and anxiety subscale together. Items of the HADS strongly suggest that the anxiety scale is closely related to the negative mood dimension while the depression scale is closely related to anhedonia or the relative absence of positive mood status. Hence, combining the HADS anxiety and depression scales may identify those patients who are characterized by depressive affect in a two-dimensional mood space. Because of the increase in specificity and positive predictive value, our data indicate that using the total HADS is superior to using both subscales separately.

In chapter 5 symptoms of depression and anxiety in MI patients are evaluated. In literature both depression and anxiety are described as predictors of new cardiac events in healthy patients. As stated earlier in chapter 3 and 4, in our studies with first MI patients, symptoms of anxiety are better predictors of major and minor depression, and recovery post-MI than symptoms of depression. Indeed, when analyzing the self-rating questionnaires SCL-90, HADS, BDI en STAI, depression and anxiety are part of one dimension in 
post-MI depression. Based on four items of the SCL-90 and the HADS, the development of a self-rating questionnaire with a similar validity as the general accepted questionnaires is described. This questionnaire is more accessible and practical for both cardiologists and patients.

In chapter 6 two self -rating questionnaires for depression are compared with one for another negative mood state, i.e. vital exhaustion. Vital exhaustion is a phenomenon claimed to be related to but not identical with depression. Excessive fatigue and feelings of general malaise, such as hopelessness, listlessness, loss of libido, increased irritability and problems with sleep are symptoms of vital exhaustion; chronic fatigue is regarded as a core symptom. Similar to depression, vital exhaustion is related to poorer cardiac prognosis post-MI. The data of this study show strong correlations between two different measures of depression and a measure of vital exhaustion. These results suggest that symptoms reported by post-MI patients, who are variously labelled as depression or vital exhaustion, refer to two aspects of one symptom profile of negative affectivity in MI patients.

In chapter 7 the relationship between the development of major/minor depression and depressive symptoms post-MI, and level of the serum total cholesterol, LDL-C, HDL, and Triglycerid (TG) concentrations is examined. In longitudinal studies, serum total cholesterol has been reported to be inversely related to the development of depression in somatically healthy patients. In our study we examined whether this inverse relationship could also be found in MI patients. Our data indicate that LDL-C is significantly inversely related to major/minor depression and depressive symptoms three months post-MI. Total serum cholesterol, HDL-C and TG are not related to the occurrence of major/minor depression nor depressive symptoms. Lowering of LDL-C concentrations in blood is regarded as an important factor in prevention of recurrent MI. However, our data indicate that more pronounced lowering of LDL-C increases the risk for developing major/minor depression and depressive symptoms, thereby increasing the risk for cardiac death.

The goal of the study presented in chapter $\mathbf{8}$ is to detect correlates of post-MI depression, which can be easily obtained by clinicians. Based on literature, four clinically easily attainable variables were selected as possible correlates for postMI depression. Our data show that complications during hospitalization, prescription of benzodiazepines during hospitalization, history of depressive episode, and not being able to stop smoking are significantly related to development of post-MI depression.

In chapter 9 the cognitive performance of depressed MI patients is compared to that of non-depressed MI patients and healthy individuals. Both depression and ischemic heart disease are related to decline in cognitive performance. 
Therefore, one would expect that depressed MI patients have a double risk of worsened cognitive performance. Our study shows however that there is no difference in cognitive performance between depressed MI patients, nondepressed MI patients, and healthy individuals. As yet we have no explanation for the lack of difference in cognitive performance. It seems that absence of cognitive decline is a specific feature of post-MI depression.

In chapter 10 we investigate personality factors as possible vulnerability factors of post-MI depression. In our study, high levels of neuroticism are strong predictors of major and minor depression. Furthermore, introversion was also an independent predictor of major depression, but not of minor depression. Agreeableness, conscientiousness and openness are not related to post-MI depression in our study.

A combination of high neuroticism and introversion has already been described as a predictor of depression in healthy individuals. In patients with coronary artery disease type-D personality, assembling the combination high neuroticism and introversion is identified as a predictor of not only depressive symptoms but also of poor cardiac prognosis. As in non-somatic compromised patients, in MI patients, personality factors play thus an important role in the prediction of depression.

In chapter 11 we focus on the first double-blind placebo-controlled study of a SSRI (selective serotonergic reuptake inhibitor), i.e. fluoxetine, in the treatment of depressed MI patients. Only in mild depression fluoxetine is superior to placebo. SSRIs are already reported to be especially effective in mild depression. In contrast to depression scores, hostility score decreases from a high to a low level in the fluoxetine group.

As far as cardiac safety of antidepressants is concerned, SSRIs are less cardiotoxic than tricyclics. Data of our study show that fluoxetine has no clinically relevant cardiovascular side effects in depressed MI patients. This means that depressed MI patients can be safely treated with fluoxetine.

In chapter 12 cardiovascular side effects of two SSRIs, i.e. fluoxetine and fluvoxamine, are examined in middle-aged and elderly depressed patients. As stated earlier, tricyclics are reported to induce cardiovascular side effects as rhythm disorders and orthostatic hypotension. SSRIs are reported to be less cardiotoxic in healthy patients. Data of our study showed that also in middle aged and elderly patients both fluoxetine and fluvoxamine have no cardiovascular side effects.

Finally, in chapter 13 the cognitive performance is investigated in the same 54 MI-patients of chapter 11 during fluoxetine treatment. Cognitive performance was assessed using speed, attention and memory tasks. Data of our study show that fluoxetine does not worsen cognitive performance. This is an important 
finding as the majority of depressed patients is treated as outpatients and is expected to continue their professional life and normal everyday routine. 


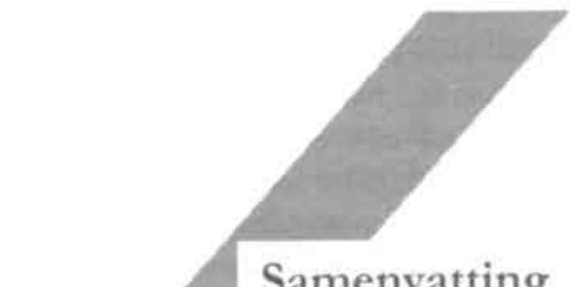

Samenvatting 
Zoals de titel van dit proefschrift aangeeft, bestaat er een sterke relatie tussen depressie en hartinfarct. Dit proefschrift heeft zich gericht op enkele aspecten van deze sterke doch complexe specifieke relatie, namelijk epidemiologie, risicofactoren en behandeling van depressie na een eerste hartinfarct. $\mathrm{Bij}$ patiënten met recidief hartinfarcten spelen naast specifieke factoren in de relatie tussen depressie en hartinfarct mogelijk ook andere, aspecifieke depressogene factoren een rol. Aspecifieke depressogene factoren zijn factoren die voortvloeien uit aspecifieke beperkingen en/of handicaps ten gevolge van een lichamelijke stoornis van welke aard dan ook. Voorbeelden van dergelijke aspecifieke factoren zijn verminderde lichamelijke inspanning, waardoor werk en/of hobby's niet meer kunnen worden uitgeoefend, sociale isolatie en beperkingen in mate van onafhankelijk functioneren. Data in de literatuur geven aan dat dergelijke aspecifieke factoren in het dagelijks leven bij hartinfarctpatiënten gepaard kunnen gaan met depressieve symptomen en slechte cardiale prognose. Wanneer we het vóórkomen van depressie na een hartinfarct en specifieke effecten van de depressie op de cardiale prognose willen onderzoeken, is het noodzakelijk om de invloed van aspecifieke depressogene factoren op het ontwikkelen van een depressie na een hartinfarct zoveel mogelijk te beperken. Daarom is in dit proefschrift gekozen om alleen patiënten met een eerste hartinfarct, en niet met recidief infarcten, te selecteren. Het eerste deel van dit proefschrift geeft een overzicht van de literatuur betreffende de epidemiologie, risicofactoren en behandeling in gemengde patiëntenpopulaties met eerste en recidief infarcten. $\mathrm{Na}$ dit overzichtsartikel volgt de beschrijving van een studie waarin het vóórkomen van depressie na een eerste hartinfarct wordt onderzocht. In dit artikel en het volgende wordt onderzocht of het ontstaan van een depressieve episode (gedefinieerd als 1 kernsymptoom en 4 aanvullende symptomen van depressie volgens DSM-IV criteria), van milde depressie (gedefinieerd als 1 kernsymptoom en 1 tot 3 aanvullende symptomen van depressie volgens DSM-IV criteria), of van symptomen van depressie of angst (onafhankelijk van de diagnose depressie) als depressieve symptomen die niet aan DSM-IV criteria voldoen), invloed heeft op het cardiale beloop.

In het tweede deel van dit proefschrift wordt aandacht geschonken aan diagnostische aspecten van depressie na hartinfarct. Als eerste wordt de validiteit van veelvuldig gebruikte vragenlijsten voor het screenen op depressieve episode en milde depressie beschreven. Vervolgens hebben we onderzocht of er, op basis van deze veelvuldig gebruikte vragenlijsten, een verkorte vragenlijst kon worden ontwikkeld voor het screenen van depressie bij hartinfarctpatiënten, met een zelfde validiteit als de hiervoor genoemde, algemeen geaccepteerde vragenlijsten. Immers, bij een korte vragenlijst wordt de drempel bij de cardioloog en patiënten om hartinfarctpatiënten te screenen mogelijk lager daar de patiënt minder wordt belast. Het laatste onderdeel van het diagnostische gedeelte schenkt aandacht aan de samenhang tussen twee concepten van negatieve affectiviteit die gerelateerd zijn aan een hartinfarct, te 
weten depressie en vitale uitputting. In dit hoofdstuk worden de correlaties onderzocht tussen twee verschillende vragenlijsten voor depressie en één voor vitale uitputting.

In het derde deel van dit proefschrift worden mogelijke risicofactoren en klinische markers voor het ontwikkelen van een depressie na een eerste hartinfarct onderzocht.

Ten slotte wordt er in het vierde en laatste deel aandacht geschonken aan farmacotherapeutische behandeling van depressieve, eerste hartinfarctpatiënten.

Deze dissertatie is daarmee opgebouwd uit hoofdstuk 1 tot en met 13, voorafgegaan door een inleiding en afgesloten door een algemene discussie.

In de inleiding wordt het belang van onderzoek naar depressie na een hartinfarct aangegeven en aan welke facetten van dit onderzoek aandacht besteed zal worden.

In de algemene discussie worden de belangrijkste conclusies van de beschreven artikelen samengevat en de betekenis hiervan voor de klinische praktijk alsook voor toekomstig onderzoek.

Elk artikel begint met een beschrijving van de achtergrond; vervolgens worden de opzet en resultaten van het onderzoek uiteengezet; in de discussie van ieder artikel worden vervolgens een aantal conclusies getrokken.

In hoofdstuk 1 wordt een overzicht gegeven van mogelijke specifieke en aspecifieke factoren in de relatie tussen "Heart \& Mind",te weten tussen hartinfarct en depressie. Data in de literatuur geven aan dat er een relatie bestaat tussen hartinfarct en depressie. Ten eerste zijn depressieve episodes en depressieve symptomen geassocieerd met toegenomen cardiale mortaliteit en morbiditeit, voornamelijk ten gevolge van recidief ischemische events en hartritmestoornissen. Ten tweede lijkt een depressie, ontstaan na een hartinfarct, niet gerelateerd te zijn aan de ernst van het infarct. Dit zou men gevoelsmatig wel verwachten.

Depressieve hartinfarctpatiënten worden vaak niet herkend. Slecht $10 \%$ van de depressieve hartinfarct patiënten wordt als zodanig herkend en een nog lager percentage behandeld. Miskenning van de depressie na een hartinfarct wordt door een tweetal factoren in de hand gewerkt. Ten eerste is de presentatie van een depressie na een hartinfarct atypisch. Naast lusteloosheid (een van de kernsymptomen van een depressieve stoornis) vertonen depressieve hartinfarctpatiënten vaak een hogere mate van hostiliteit, angst en vermoeidheid dan depressieve, niet cardiaal aangedane patiënten. Hostiliteit manifesteert zich in de praktijk onder meer in geïrriteerdheid, wrok over het getroffen lot, woede-uitbarstingen en frequente ruzies. Ten tweede hebben clinici de neiging om deze klachten te interpreteren als normale psychologische 
en voorbijgaande reacties na een hartinfarct, waardoor geen aandacht wordt geschonken aan een mogelijke achterliggende depressie.

In hoofdstuk 2 wordt een cumulatieve incidentie van depressieve episode en milde depressie van $26,7 \%$ in patiënten met eerste hartinfarct beschreven. Deze cumulatieve incidentie is aanmerkelijk hoger dan de $5-10 \%$ in de algemene populatie en gelijkwaardig aan cijfers in patiëntenpopulaties met eerste en recidief infarcten. Voorts blijkt dat tot drie jaar na een eerste infarct de diagnose depressie dan wel de aanwezigheid van depressieve symptomen geen voorspellers van sterfte en recidief infarct zijn. Dit in tegenstelling tot literatuur data die wel een verhoogd overlijdensrisico beschrijven bij patiënten die een depressie ontwikkelen na een hartinfarct. Een mogelijke verklaring voor het ontbreken van een effect van de depressie op cardiale sterfte in onze studie kan zijn dat wij in onze patiëntenpopulatie een laag sterftecijfer van $2,4 \%$ vinden. Sterfte in onze studie is daarbij aanmerkelijk lager vergeleken met andere studies. De lagere mortaliteit in onze studies kan veroorzaakt worden door een aantal factoren. Ten eerste, onze studie is uitgevoerd een aantal jaren na de eerste studie betreffende depressie en cardiale prognose. Verbeterde cardiologische interventies voor het hartinfarct zijn de oorzaak van een lager sterftecijfer in recente jaren. Ten tweede zijn in onze studie alleen patiënten met een eerste hartinfarct geincludeerd. Bij een dergelijke populatie is de kans op sterfte kleiner is dan bij groepen van hartinfarctpatiënten met een recidief hartinfarct, hartritmestoornissen of pompfalen van het hart.

In hoofdstuk 3 wordt gekeken naar het lange termijneffect van depressieve en angst symptomen op cardiale prognose in eerste hartinfarctpatiënten. We hebben al beschreven dat op korte termijn, i.e. tot drie jaar na een eerste hartinfarct, diagnose van depressieve stoornis en milde depressie, dan wel depressieve symptomen geen invloed hebben op cardiale hartdood en recidief infarct. Ook op langere termijn, i.e. tot zes jaar na het eerste infarct, is er geen duidelijke relatie tussen depressieve symptomen en cardiale sterfte dan wel recidief infarct. In tegenstelling tot symptomen van depressie, voorspellen symptomen van angst wel cardiale sterfte en recidief infarct op langere termijn. Het is echter onduidelijk waarom in onze studie met eerste hartinfarctpatiënten, symptomen van angst betere voorspellers zijn voor slecht herstel na een hartinfarct dan symptomen van depressie. Zoals eerder aangegeven zijn in onze studies alleen patiënten met een eerste hartinfarct geïncludeerd en zijn de cardiologische interventies voor hartinfarcten de laatste jaren sterk verbeterd. Een tweede verklaring voor de afwezigheid van verschil in mortaliteit tussen depressieve en niet-depressieve hartinfarctpatiënten in onze studie kan zijn dat een bepaald deel van de depressieve patiënten $(17,5 \%)$ behandeld zijn. Minstens 54 patiënten in onze studie waren gerandomiseerd naar een behandeling met fluoxetine of placebo. Het negatieve effect van depressie op cardiale prognose kan daardoor zijn afgezwakt. 
Ook zou niet zozeer de diagnose depressieve stoornis een belangrijke rol kunnen spelen bij het herstel van hartinfarctpatiënten, als wel verschillende vormen van stemmingsklachten, die omschreven kunnen worden als negatieve affectiviteit. Deze veronderstelling wordt mede ondersteund door de bevindingen dat ook andere vormen van negatieve affectiviteit, zoals vitale uitputting en hostiliteit, een relatie hebben met cardiale prognose na een hartinfarct.

In hoofdstuk 4 worden sensitiviteit en specificiteit onderzocht van subjectieve en objectieve vragenlijsten die vaak gebruikt worden om hartinfarctpatiënten te screenen op depressie. De subjectieve vragenlijsten zijn de 90-item Symptom Check List (SCL-90), de Hospital Anxiety and Depression Scale (HADS), de Beck Depression Inventory (BDI). De objectieve vragenlijst is de 17-item Hamilton Depression Rating Scale (HAMD-17). Alle vragenlijsten blijken valide screeningsinstrumenten te zijn in deze patiëntengroep. De optimale cutoff scores, waarbij de som van de sensitiviteit en specificiteit maximaal zijn, waren voor een depressieve episode hoger dan voor milde depressie. Aangezien ook milde depressie invloed heeft op de gezondheidszorg consumptie van de hartinfarctpatiënten, zou men deze patiënten ook op milde depressie moeten screenen.

Uit onze studie blijkt dat de angstschaal van de HADS een betere voorspeller voor een depressieve episode en milde depressie is dan de depressie schaal. Daarbij blijkt dat de validiteit van de totale HADS groter dan elk van de subschalen apart. De angstschaal is met name gerelateerd aan negatieve stemmingscomponent, terwijl de depressie schaal meer gerelateerd is aan anhedonie en afwezigheid van positief affect. Beide schalen omvatten dimensies van een depressieve stoornis. Het screenen op een depressieve stoornis na een hartinfarct met beide schalen tegelijk zorgt dus voor een hogere specificiteit en verdient aanbeveling.

In hoofdstuk $\mathbf{5}$ wordt dieper ingegaan op de depressieve en angst symptomen bij hartinfarctpatiënten. Gegevens uit de literatuur gaven al aan dat zowel depressie als angst voorspellers zijn voor het optreden van hartziekten in gezonde patiënten. In voorgaande hoofdstukken van deze thesis wordt verder beschreven dat symptomen van angst betere voorspellers van een depressieve stoornis en herstel in hartinfarctpatiënten lijken te zijn dan depressieve symptomen. Inderdaad blijkt bij het analyseren van de zelfvragenlijsten SCL-90, HADS, BDI en STAI dat depressieve en angstsymptomen in hartinfarctpatiënten deel uit maken van één stemmingscomponent. Verder wordt een screeningslijst voor depressie beschreven, gebaseerd op 4 items afkomstig van SCL-90 en HADS maar dezelfde validiteit als de algemeen geaccepteerde vragenlijsten. Deze verkorte vragenlijst zou het screenen op depressie eenvoudiger en praktischer maken voor zowel clinici als patiënten. 
In hoofdstuk 6 worden twee vragenlijsten voor depressie vergeleken met een vragenlijst betreffende een andere negatieve gemoedstoestand, te weten vitale uitputting. Vitale uitputting is een syndroom bij hartinfarctpatiënten waarbij vermoeidheid het hoofdsymptoom vormt. Net als depressie, is vitale uitputting gecorreleerd met een slechte cardiale prognose na het hartinfarct. Onze studie liet zien dat twee vragenlijsten voor depressie even sterk gecorreleerd zijn met de lijst voor vitale uitputting, als met elkaar. Dit suggereert dat beiden tot een domein van stemmingsontregeling behoren. Depressie en vitale uitputting zouden daardoor kunnen worden beschouwd als twee zijden van een munt.

In hoofdstuk 7 wordt onderzocht of serum cholesterol, High-DensityLipoproteine-Cholesterol (HDL-C), Low-Density-Lipoproteine-Cholesterol (LDL-C) en triglyceriden, een relatie hebben met het optreden van depressieve symptomen na een hartinfarct. In de literatuur beschrijven enkele longitudinale studies bij gezonde individuen dat lage cholesterol concentraties in het bloed kunnen leiden tot depressieve symptomen. Wij hebben in onze studie bekeken of we een omgekeerde relatie tussen lipiden in het bloed en depressie ook in hartinfarctpatiënten kunnen aantonen. Een lage concentratie van LDL-C in bloed blijkt gerelateerd aan diagnose van depressie en depressieve symptomen op drie maanden. Er is geen relatie aan te duiden tussen het optreden van depressieve symptomen en serum cholesterol, HDL-C en triglyceriden. Uit onze studie blijkt dat verlagen van LDL-C de kans op depressie kan verhogen en daarmee ook op cardiale sterfte. Voorzichtigheid lijkt dus geboden bij het verlagen van LDL-C.

In hoofdstuk 8 wordt onderzocht hoe de cardioloog op een eenvoudige manier patiënten met een verhoogd risico op het verkrijgen van een depressie, al tijdens opname na het hartinfarct, kan identificeren. Hiertoe zijn een aantal klinische parameters onderzocht. Patiënten met een voorgeschiedenis van depressie, die complicaties na het hartinfarct hebben moeten doorstaan, reeds tijdens opname benzodiazepines kregen voorgeschreven en na het hartinfarct niet hebben kunnen stoppen met roken, hebben allen een hogere kans op het ontwikkelen van een depressieve episode na het hartinfarct.

In hoofdstuk 9 wordt geëvalueerd of het cognitieve functioneren in depressieve hartinfarctpatiënten verschilt van dat van niet depressieve hartinfarctpatiënten en gezonde individuen. Zowel depressieve stoornis als ischemische hartziekten zijn geassocieerd met achteruitgang in cognitief functioneren. Hierdoor zou men verwachten dat depressieve hartinfarctpatiënte een dubbel risico hebben op verminderd cognitief functioneren. Wij hebben echter niet kunnen aantonen dat het cognitieve profiel van depressieve hartinfarctpatiënten verschilt van dat van niet-depressieve hartinfarctpatiënten of gezonde individuen. Wij hebben voor dit gebrek aan cognitieve 
achteruitgang nog geen verklaring. De afwezigheid van cognitieve achteruitgang zou een specifiek kenmerk kunnen zijn van depressie bij hartinfarctpatiënten.

In hoofdstuk 10 wordt onderzocht of persoonlijkheidkenmerken het optreden van een depressie na het hartinfarct kunnen voorspellen. Neuroticisme blijkt een onafhankelijke predictor te zijn voor het optreden van zowel een depressieve episode als een milde depressie na een eerste hartinfarct. Verder blijkt uit onze studie dat introversie ook een onafhankelijke voorspeller is voor een depressieve episode, maar niet voor milde depressie. Er was al eerder beschreven dat de combinatie van neuroticisme en introversie een voorloper is van een depressieve episode in gezonde individuen. In patiënten met cardiovasculaire aandoeningen is vooral type-D persoonlijkheid, vergelijkbaar met het neuroticisme/introversie profiel, van belang. Het voorspelt niet alleen depressieve symptomen, maar ook mortaliteit na een hartinfarct. Net als bij somatisch gezonde patiënten spelen in hartinfarctpatiënten persoonlijkheidskenmerken ook een belangrijke rol in het voorspellen van depressie.

In hoofdstuk 11 staat de eerste dubbelblinde placebogecontroleerde studie van een SSRI (selectieve serotonerge heropname remmers), te weten fluoxetine, in de behandeling van depressieve hartinfarctpatiënten centraal. Alleen bij de milde depressie blijkt fluoxetine een groter antidepressief effect te hebben dan placebo. Van SSRIs is bekend dat ze vooral effectief zijn in milde depressies. De hostiliteitscore daalt significant in de fluoxetine groep ten opzichte van de placebo groep.

Wat cardiale veiligheid betreft blijkt dat SSRIs minder cardiovasculaire bijwerkingen hebben dan tricyclische antidepressiva. Uit onze studie blijkt dat fluoxetine geen klinisch relevante cardiovasculaire bijwerkingen heeft. Depressieve patiënten met een eerste hartinfarct kunnen veilig met fluoxetine behandeld worden.

In hoofdstuk 12 worden cardiovasculaire bijwerkingen van twee SSRIs, te weten fluoxetine en fluvoxamine, in oudere patiënten met ischemische hartziekten, onderzocht. Oudere antidepressiva zoals de tricyclische hebben cardiovasculaire bijwerkingen zoals ritmestoornissen en orthostatische hypotensie. Van SSRIs is bekend dat ze minder cardiovasculaire bijwerkingen vertonen in gezonde individuen, maar het is onduidelijk of dit ook voor ouderen geldt. In onze studie hebben we kunnen aantonen dat er geen cardiovasculaire bijwerkingen optreden bij de behandeling van depressieve ouderen met fluoxetine dan wel fluvoxamine.

Tot slot wordt in hoofdstuk $\mathbf{1 3}$ cognitief functioneren van dezelfde 54 depressieve hartinfarctpatiënten van hoofdstuk 11 onderzocht tijdens behandeling met fluoxetine. Cognitief functioneren wordt gemeten door middel van aandacht, geheugen en snclheidstaken. Onze studie laat zien dat fluoxetine 
geen nadelige effecten op het cognitief functioneren heeft, en dus veilig voorgeschreven kan worden. Dit is een belangrijke bevinding, omdat het gaat om een groep patiënten die, ondanks het hartinfarct en de depressie, nog actief deelneemt aan het arbeidsproces. 


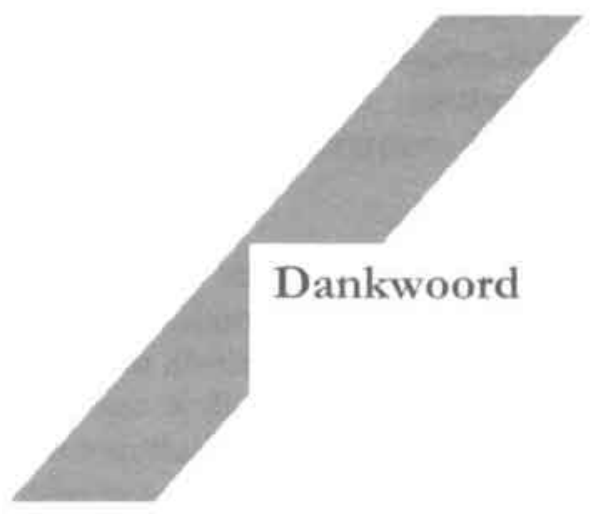

Het schrijven van een proefschrift doe je vaak alleen, het vervaardigen ervan niet. Het hele proces van de voorbereiding, uitvoering en beschrijving, deel je met collegae, net als de gevoelens van blijdschap en frustratie rondom dit proces. Het schrijven van een proefschrift vormt daarnaast niet alleen een onderdeel op je curriculum vitae, het wordt ook een onderdeel van je leven. Het omhelst een periode van een aantal jaren, waarin het denken over, bezig zijn met en schrijven van een belangrijk deel van je leven uitmaakt, dat niet ophoudt buiten kantooruren. Het is daardoor niet alleen een onderdeel van je eigen leven, maar ook van diegenen die dicht bij je staan. Bij het vervaardigen van dit proefschrift waren dan ook heel wat mensen betrokken. En deze wil ik hierbij bedanken.

Als eerste wil ik mijn dagelijkse begeleider en medeoprichter van dit onderzoek, Adriaan Honig, bedanken. Adriaan, iij hebt vanaf mijn eerste sollicitatiegesprek als AGNIO mijn interesse in wetenschappelijk onderzoek aangewakkerd en geïnspireerd om me als wetenschapper te laten opleiden, zodat ik "de krenten uit de pap kon halen". Door jouw begeleiding heb ik als AIO een vliegende start kunnen maken in dit onderzoek, en heb ik uiteindelijk deel uit kunnen maken van een volwaardige en internationaal bekende onderzoekslijn. Jouw enthousiasme nam nooit af, net als jouw motivatie om mij aan te sporen op het rechte "schrijvers"pad te blijven en niet af te dwalen. Jouw geduld en vertrouwen in mijn kunnen, ook als mijn eigen motivatie wel eens daalde, heeft mij mede geholpen dit proefschrift tot een goed einde te brengen. Hiervoor mijn hartelijke dank.

Professor van Praag, als oprichter van het eerste uur van dit onderzoek bent u zeer belangrijk geweest. Uw heldere en analytische blik bij onze besprekingen van de verschillende artikels hebben mij steeds aangespoord kritisch naar het proefschrift te blijven kijken. Ook uw enthousiasme en betrokkenheid bij dit onderzoek was nimmer aflatend. Mijn oprechte dank hiervoor. 
Jim van Os, jij was in eerste instantie betrokken als adviseur bij de STATA analyses, later als medeauteur van een aantal artikels en uiteindelijk zelfs als promotor van dit proefschrift. Jouw enthousiasme en vooral je zeer snel analytisch vermogen heeft mij steeds weer verrast en maakte dat het zeer prettig was en is om met jou samen te werken.

Ivo, met jou deel ik niet alleen het AIO schap, maar ook de geneeskunde opleiding en zelfs de opleiding tot psychiater. In deze ruime periode, waarin we niet alleen onze gedachten over het onderzoek en opleiding deelden, maar ook over de enkele heftige gebeurtenissen in ons beider leven, ben ik je zeer gaan waarderen, niet alleen als collega, maar ook als vriend. Ik zou dan ook niemand anders kunnen bedenken die de rol van paranimf beter zou kunnen vervullen dan jii en ben dan ook zeer verheugd dat je mijn promotie op deze manier met mij wilt delen.

Richel, als er één persoon is geweest die eindeloos veel geduld heeft getoond om mij de basisbeginselen van de statistiek bij te brengen en ervoor te zorgen dat ik uiteindelijk mijn analyses zelf kon uitvoeren, ben jij het wel. Daarnaast heb ook jii je steeds voor $100 \%$ ingezet voor dit onderzoek en een belangrijke bijdrage geleverd bij het vervaardigen van dit proefschrift. Onze gezamenlijke gesprekken over de diepere betekenis van het onderzoek, maar ook het leven, hebben een diepe indruk bij mij achter gelaten. Mijn dank en waardering hiervoor.

Petra, als cardioloog en mede-AIO stond jij altijd klaar om mij te helpen met de cardiologische aspecten van het onderzoek; jouw kennis hieromtrent is van grote waarde geweest. Ik wil je hiervoor bedanken, net als voor de gezellige tijd die we samen op een kamer deelde,

Ik wil alle onderzoeksassistenten bedanken die geholpen hebben de vele onderzoeksgegevens mee te verzamelen en overzicht te blijven behouden in de niet altijd waterdichte administratie. Met name Aimée, Femke, Kirsten, Patricia en Sandra, bedankt! Allard-Dirk, Anna, Jitske, Marlies en Miriam, bedankt voor jullie inzet bij het invoeren van de data en bijwerken van de vaak grote achterstand in het databestand. Dank aan het secretariaat voor hun ondersteuning. Philomeen, dank voor je steun bij het verwerken van de "officiële"stukken. Beste Kitty, mijn oprechte dank voor al je snelle en accurate hulp, ook als ik op het laatste nippertije weer eens iets naar je toe mailde. Ook dank aan de dames van de poli psychiatrie van het azM, die steeds de onderzoekspatiënten aan de balie hebben opgevangen. Dank aan alle andere mede-AIO's van Psychiatrie en Neuropsychologie voor hun gezelligheid op de gang, bij barbecues en St. Klaasavonden, maar ook voor de actieve wijze waarop aan de AIO-vergaderingen vorm werd gegeven. Mijn dank voor de goede samenwerking met de arts-assistenten, voor hun bijdrage en 
belangstelling voor de vordering van het proefschrift. Dank aan de vakgroep en verpleegafdeling Cardiologie van het azM die mij de ruimte hebben gegeven "hun" patiënten te benaderen. Dank aan alle patiënten van de afdeling Cardiologie die belangeloos hebben meegewerkt aan de studies binnen dit proefschrift.

Ik wil graag alle vrienden, op afstand en dichtbij, bedanken voor hun nimmer aflatende interesse in mijn "onderzoekswerkzaamheden" en met name het afronden ervan!

Marcel, "big brother", ik wil jou bedanken voor alle steun die je in mijn leven hebt gegeven en nog steeds geeft. Wij hebben samen veel meegemaakt en overpeinsd. Jij hebt mij steeds gesteund bij het volgen van mijn levensweg en de keuzes die ik daar in maakte. Ook bij het vervaardigen van dit proefschrift heb je vanaf het eerste uur laten weten dat ik op je kon rekenen: ik ben er dan ook trots op dat iij als paranimf naast mij staat bij mijn promotie. Dit boekje is voor jou!

Lieve mamma, ik denk niet dat ik je ooit genoeg kan bedanken voor je onvoorwaardelijke steun en liefde. Jij hebt mij samen met Manfred steeds de veiligheid geboden van een "thuis", ook toen je er alleen voor kwam te staan. Jouw nooit aflatende positivisme en vertrouwen in mijn kunnen hebben er mede voor gezorgd dat ik daar ben waar ik nu sta. Ook voor jou is dit boekje.

Mijn lief, dank voor je onuitputtelijke inzet bij de echte laatste loodjes van dit proefschrift. Dank dat je in mijn leven bent. 


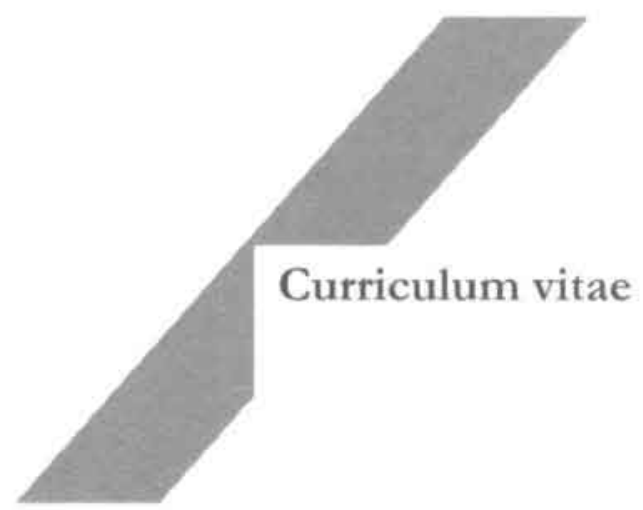

Jacqueline Julienne Marie Huberthe Strik werd geboren op 6 december 1970 te Maastricht. Na het gymnasium aan het Jeanne d'Arc College te Maastricht ging ze in 1989 geneeskunde studeren aan de Rijksuniversiteit Limburg (nu Universiteit Maastricht), alwaar zij in 1996 haar artsexamen behaalde. Direct aansluitend begon ze als AGNIO bij de vakgroep Psychiatrie \& Neuropsychologie van het Academisch Ziekenhuis Maastricht, waar zij onder andere participeerde in de onderzoekstrial "depressie na hartinfarct". In 1997 werd zij als AIO aangesteld bij dezelfde vakgroep en werd "depressie na hartinfarct" het onderwerp van haar dissertatie. Vanaf 2001 is zij in opleiding tot psychiater, die zij in 2005 hoopt af te ronden. 


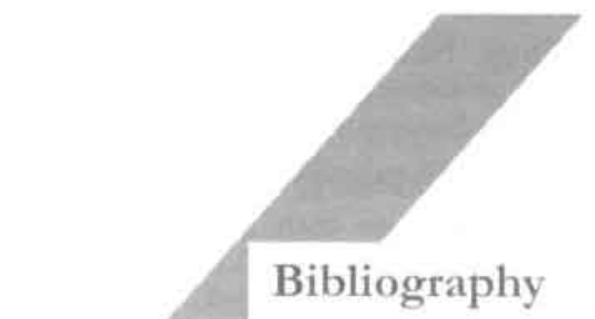

\section{Papers}

\section{Published}

Strik JJMH and Honig A. Depression nach Myocardinfarkt. Psycho 1998; $24: 235-8$.

Strik JJMH, Honig A, Lousberg R, EC Cheriex, HM van Praag. Cardiac side effects of two selective serotonin reuptake inhibitors in middle-aged and elderly depressed patients. Int Clin Psychopharmacology 1998; 13:263-7.

Wojciechowski F, Strik JJMH, Falger P, Lousberg R, Honig A. Depression and vital exhaustion post-myocardial infarction: Two labels for one phenomenon? Act Psych Scand, 2000; 102:359-5.

Strik JJMH, Honig A, Lousberg R, Lousberg A, Cherix EC, Tuynman-Qua H, Kuijpers PMJC, Wellens HJJ, van Praag HM. Efficacy and safety of fluoxetine in the treatment of patients with major depression following first myocardial infarction: findings from a double-blind placebo-controlled trial. Psychosom Med 2000; 62:783-9.

Strik JJMH, Honig A, Lousberg R, van den Berg EJM, Van Praag HM. Clinical correlates of depression following myocardial infarction. Int J Psych Med 2001; 31:271-80.

Strik JJMH, Lousberg R, Denollet J, Honig, A. Sensitivity and specificity of observer and self rating questionnaires in major and minor depression following myocardial infarction. Psychosomatics 2001; 42: 423-8 (second price winner in the 2002 Dorfman Journal Paper Award competition of the Academy of Psychosomatic Medicine). 
Strik JJMH, Honig A, Maes M. Depression and myocardial infarction: Relationship between heart and mind. Progr Neuropsychopharmacol Biol Psychiatry 2001; 25: 879-92.

Dijkstra, J, Strik JJMH, Honig A, Lousberg R, Prickaerts J, Riedel W, Jolles J, van Praag HM. Atypical cognitive profile in patients with depression after myocardial infarction. J Aff Dis 2002; 70:181-90.

Strik JJMH, Honig A, Lousberg R, Crijns H, Maes M. Low-Density-Cholesterol as a risk factor for depressive symptoms post-myocardial infarction. Am J Cardiology 2002; 90:1368-70.

Strik JJMH, Lousberg R, Cheriex EC, Honig A. One year cumulative incidence of depression after myocardial infarction and impact on cardiac outcome. J Psychosom Res 2002 (in press).

Kuijpers PMJC, Hamulyak K, Strik JJMH, Wellens HJ, Honig A. Betathromboglobulin and platelet factor 4 levels in post-myocardial infarction patients with major depression. Psychiatry Res $2002 ; 109: 207-10$.

Strik JJMH, Denollet J, Lousberg R, Honig A. Comparing symptoms of depression and anxiety as predictors of incomplete recovery following myocardial infarction. JACC 2003 (in press).

Aben I, Verhey F, Strik JJMH, Lousberg R, Lodder J, Honig A. A comparative study into the one year cumulative incidence of depression after stroke and myocardial infarction. 2003 J Neurol Neurosurg Psychiatry 2003; 74:581-5.

\section{Submitted}

Strik JJMH, Honig A, Klinkenberg E, Dijkstra J, Jolles J. Fluoxetine and effect on cognitive performance in depressed patients post myocardial infarction. Psychosomatics (submitted).

Strik JJMH, Denollet J, Lousberg R, Honig A. Personality and vulnerability to depression following myocardial infarction: A prospective follow-up study. Am J Psychiatry (submitted).

Denollet J, Strik JJMH, Lousberg R, Honig A. Depressive Symptoms Following Myocardial Infarction: Misinterpretation of "Depression" Scales? Br Heart J (submitted). 


\section{Abstracts/posters}

Strik JJMH, Honig A, Lousberg R, Cheriex EC, van Praag HM. Cardiac side effects of two selective reuptake inhibitors in middle-aged and elderly depressed patients. Voorjaarscongres NVVP 1997; XXIst CINP Glasgow 1998.

Strik, JJMH, Lousberg R, van Os J, Wellens HJJ, van Praag HM, Honig A. Depression following myocardial infarction: a prospective assessment of myocardial infarction and depression incidence. Voorjaarscongres NVVP 1997; XXIst CINP Glasgow 1998; Werkgroep Cardiologische Centra NL. Dec. 1999.

Strik JJMH, Honig A, Lousberg R, Lousberg A, Cherix EC, Tuynman-Qua H, Kuijpers PMJC, Wellens HJJ, van Praag HM. Fluoxetine in the treatment of depression and hostility in patients with major depression following first myocardial infarction: a double-blind placebo-controlled trial. Voorjaarscongres NVVP 1997; APA Washington 1999, Annual meeting, Birmingham, 1999; Werkgroep Cardiologische Centra NL. Dec. 1999;

Strik JJMH, Ballieux M, Lousberg R, Honig A, Kuijpers P, Wellens HJJ, van Praag HM. Depression following myocardial infarction: a primary investigation of some risk factors. Voorjaarscongres NVVP 1997; XXIst CINP Glasgow 1998; Werkgroep Cardiologische Centra NL. Dec. 1999.

Kuijpers PMJC, Strik JJMH, Lousberg R, Honig A, van de Veen FH, van Praag HM, Wellens HJJ. Depression after a first myocardial infarction has no influence on mortality. ENCP 1998 Manchester, Annual meeting, Birmingham, 1999.

Wojciechowski F, Strik JJMH, Falger P, Lousberg R, Honig A. Depression and vital exhaustion post-myocardial infarction: Two labels for one phenomenon? Annual meeting, Birmingham, 1999.

Kuijpers PMJC, Strik JJMH, Lousberg R, Honig A, van de Veen FH, van Praag $\mathrm{HM}$, Wellens HJJ. Size of myocardial infarction has an inverse relationship with depression after first MI in the first three months post-MI. Voorjaarsvergadering Ned. Vv Cardiologie, Amsterdam april 2000, 4th Euron day, Maastricht sept. 2000.

Strik JJMH, Honig A, Lousberg R, Lousberg A, Cheriex EC, Tuynman-Qua H, Kuijpers PMJC, Wellens HJJ, van Praag HM. Safety of fluoxetine in depressed patients with a first myocardial infarction: findings from placebo-controlled trial. Voorjaarscongres NVVP 2000; 
Strik JJMH, Honig A, Lousberg R, van Os J, Wellens HJJ, van Praag HM. Clinical markers of depression following first myocardial infarction. 4th Euron day, Maastricht sept. 2000.

Strik JJMH, Honig A, Lousberg R, Lousberg A, Cheriex EC, Tuynman-Qua H, Kuijpers PMJC, Wellens HJJ, van Praag HM. Efficacy and safety of fluoxetine in major depression following a first myocardial infarction: findings from a double-blind placebo-controlled trial. 4th Euron day, Maastricht sept. 2000.

Strik JJMH, Honig A, Lousberg R, Denollet J. Sensitivity and specificity of depression rating scales in depression following myocardial infarction. Voorjaarscongres NVvP 2001, Rotterdam.

Strik JJMH, Honig A, Klinkenberg E, Dijkstra J, Jolles J. Cognitive side effects of fluoxetine in depression post myocardial infarction. Voorjaarscongres NVvP 2001, Rotterdam.

\section{Oral presentations/abstracts}

Strik JJMH, Aben I, Honig A, Verhey F. Research designs in vascular compromised patients with affective disorders. 5th Tryptich workshop, Houthem St. Gerlach 1997

Strik JJMH. Preliminary data of risk factors of depression post myocardial infarction. Euron PhD-student day, Sept.1997

Strik JJMH. Depressie na myocard infarct. Psychiatrisch genootschap, Maastricht 1998.

Strik JJMH. Depression following myocardial infarction: incidence, profile and risk factors. BCN Summerschool, Groningen, 1998.

Strik JJMH: A double-blind placebo-controlled study of efficacy and safety of fluoxetine in patients with major depression following a first myocardial infarction. 2nd Euron PhD-student day, azM Maastricht, April 1998:

Strik IJMH. Depression and vital exhaustion post-myocardial infarction: Two labels for one phenomenon? The second Dutch conference on psychology and health, Houthem St. Gerlach, 1998.

Strik JJMH. Depression following myocardial infarction: prospective assessment of myocardial infarction and depression incidence. XXIst; APA, 
Washington 1999, Royal College of Psychiatrists, Annual Meering, Birmingham 1999; Voorjaarscongres NVvP 1999.

Strik JJMH. Depression following myocardial infarction: incidence relationship with size of infarction and mortality. Voorjaarscongres NVvP, Noordwijkerhout 1999.

Strik JJMH. Affective disorders post-myocardial infarction. 3rd Euron PhDstudent day, azM Maasstricht, Sept. 1999

Strik JJMH. Profile of depression post myocardial infarction. Voorjaarscongres NVvP april 2000.

Strik JJMH. Sensitivity and specificity of observer and self rating questionnaires in major and minor depression following myocardial infarction. "Wetenschapsmiddag" azM, 2-11-2000.

Strik JJMH. Cardiopsychiatry: relationship between heart and mind. Day of the Institute Brain \& Behaviour, Rolduc Kerkrade, 19-01-2001.

Strik JJMH, Honig A, Lousberg R, Maes M. Cholesterol as risk factor for depression post myocardial infarction. Voorjaarscongres NVvP 2001, Rotterdam.

Strik JJMH, Denollet J, Lousberg R, Honig A. A 4-item screening list for depression post myocardial infarction. Voorjaarscongres NVvP 2001, Rotterdam.

Strik JJMH. Depression, myocardial infarction and cognition. Day of the Institute Brain \& Behaviour, University of Maastricht, 18-01-2002.

Strik JJMH. MIND THE HEART: depression following first myocardial infarction. (Nominated for the Pélerin Research price). Pélerin "Wetenschapdag", University Hospital Maastricht, Maastricht, 13-06-2002. 


\section{MIND THE HEART}

Epdidemiology, risk factors and treatment of depression following first myocardial infarction

Is there a relationship between depression and first myocardial infarcrion (MI)? What are risk factors of post-MI depression? How can postMI depression be treated? This thesis has tried to give an answer to these questions. One in three patients develops major or minor depression after a first MI. Diagnosis of depression and symptoms of distress must be referred to as predictors of incomplete recovery; It is therefore important to screen MI-patients for depression. Risk factors of post-MI depression do not differ from those of "ordinary" depression. SSRIs are the first choice of treatment although it is not clear whether treatment of post-MI depression can improve cardiac prognosis. The question remains whether in MI patients we have to hold on to the concept of depression. In future research, it seems less important to play atrention to depressive disorder or depressive symptoms as predictors of worsened cardiac prognosis, and more important to plat attention to affective dysregulation that involves apart from depression also anxiety, hostility and vital exhaustion as core symptoms.

ISBN 90-9017384-6 